\title{
Built to order
}

Citation for published version (APA):

Hertroijs, D. F. L. (2019). Built to order: patient profiling to tailor type 2 diabetes care. [Doctoral Thesis, Maastricht University]. Ridderprint. https://doi.org/10.26481/dis.20190529dh

Document status and date:

Published: 01/01/2019

DOI:

$10.26481 /$ dis.20190529dh

Document Version:

Publisher's PDF, also known as Version of record

\section{Please check the document version of this publication:}

- A submitted manuscript is the version of the article upon submission and before peer-review. There can be important differences between the submitted version and the official published version of record.

People interested in the research are advised to contact the author for the final version of the publication, or visit the DOI to the publisher's website.

- The final author version and the galley proof are versions of the publication after peer review.

- The final published version features the final layout of the paper including the volume, issue and page numbers.

Link to publication

\footnotetext{
General rights rights.

- You may freely distribute the URL identifying the publication in the public portal. please follow below link for the End User Agreement:

www.umlib.nl/taverne-license

Take down policy

If you believe that this document breaches copyright please contact us at:

repository@maastrichtuniversity.nl

providing details and we will investigate your claim.
}

Copyright and moral rights for the publications made accessible in the public portal are retained by the authors and/or other copyright owners and it is a condition of accessing publications that users recognise and abide by the legal requirements associated with these

- Users may download and print one copy of any publication from the public portal for the purpose of private study or research.

- You may not further distribute the material or use it for any profit-making activity or commercial gain

If the publication is distributed under the terms of Article $25 \mathrm{fa}$ of the Dutch Copyright Act, indicated by the "Taverne" license above, 


\section{Built to order}

Patient profiling to tailor type 2 diabetes care

Dorijn Francisca Louise Hertroijs 


\section{Colofon}

The research presented in this dissertation was conducted at the Care and Public Health Research Institute (CAPHRI), department of Health Services Research, Maastricht University. CAPHRI is part of the Netherlands School of Primary Care (CaRe), which has been acknowledged by the Royal Netherlands Academy of Science (KNAW). This research was funded by Novo Nordisk B.V.

(C) Dorijn Hertroijs, Maastricht 2019

Cover design: Mattt Baaij \& Dorijn Hertroijs

Cover Illustration: Mattt Baaij | www.illumatie.nl

Lay-out: Dorijn Hertroijs

Printing: Ridderprint BV | www.ridderprint.nl

ISBN: 978-94-6375-382-1

All rights reserved. No parts of this thesis may be reproduced or transmitted, in any form or by any means, electronic or mechanical, including photocopying, recording or otherwise, without prior written permission of the holder of the copyright. 


\title{
Built to order
}

\section{Patient profiling to tailor type 2 diabetes care}

\author{
PROEFSCHRIFT
}

Ter verkrijging van de graad van doctor aan de Universiteit Maastricht, op gezag van de Rector Magnificus, prof. dr. Rianne M. Letschert, volgens het besluit van het college van Decanen, in het openbaar te verdedigen op woensdag 29 mei 2019 om 12.00 uur

$$
\text { door }
$$

Dorijn Francisca Louise Hertroijs 


\section{Promotor}

Prof. dr. D. Ruwaard

\section{Copromotoren}

Dr. A.M.J. Elissen

Dr. M.C.G.J. Brouwers

\section{Beoordelingscommissie}

Prof. dr. J.F.M. Metsemakers (Voorzitter)

Dr. J.F.B.M. Fiolet

Prof. dr. M. Minkman (Tilburg University and TIAS Business School)

Dr. P.M. Rijken (NIVEL)

Prof. dr. S.P.J. Kremers 


\section{Voor pap en mam}





\section{CONTENTS}

Chapter 1 General introduction

Chapter 2 Profiling patients' healthcare needs to support integrated, person-centered models for long-term disease management (Profile): research design

Chapter 3 Relevant patient characteristics for guiding tailored integrated diabetes primary care: a systematic review

Chapter 4 Differences in biopsychosocial profile of diabetes patients by level of glycaemic control and health-related quality of life: a cross-sectional study

Chapter 5 A risk score of BMI, glycated haemoglobin and triglycerides 105 predicts future glycaemic control in type 2 diabetes

Chapter 6 Relevant patient characteristics for estimating healthcare needs according to healthcare providers and people with type 2 diabetes: a Delphi survey

Chapter 7 Preferences of people with type 2 diabetes for diabetes care: a discrete choice experiment

Chapter 8 Tailored health care: two perspectives on the development and 179 use of patient profiles

Chapter 9 General discussion

Addenda Summary

Samenvatting

Valorisatie

Dankwoord

About the author

Publications 



\section{CHAPTER 1}

General introduction 


\section{The rise in chronic diseases}

On a cold December night in 1799, George Washington, the first president of the United States, died at the age of 67 of an acute infectious disease believed to have been bacterial epiglottitis [1]. At that time, infectious diseases were the most common cause of death and a major healthcare challenge around the world [2]. No one alive then could have imagined the major advances in understanding and controlling infectious diseases that have since then been made [2, 3].

Although outbreaks of infectious diseases, such as Ebola and Zika virus, still exist, chronic diseases, such as type 2 diabetes mellitus, chronic obstructive pulmonary disease (COPD), and cardiovascular disease (CVD), have taken on a more prominent role $[4,5]$. These diseases, characterized by a long development period and a prolonged course of illness [6,7], are now the leading cause of death worldwide [8]. The increase in the prevalence of chronic diseases is mainly due to an increase in tobacco use and caloric intake, a diet rich in saturated fat, sugars and sodium, inadequate physical activity, and the ageing of the population [9-12]. The consequences of chronic diseases are not mild and include lower quality of life, functional impairment, and other health complications $[6,13]$. Had George Washington lived in the current century, he would have most likely lived a longer, but not necessarily healthier life. For societies, chronic diseases are also very expensive. In the US alone, the five most prevalent chronic conditions caused an economic burden of 1.5 trillion dollars between 2008 and 2010 [14].

As the world experienced the epidemiological transition from infectious to chronic diseases, healthcare systems did not undergo major adjustments $[4,15,16]$. These systems were originally designed to deliver reactive and episodic care by diagnosing and treating, rather than preventing, acute illnesses. However, the treatment of chronic diseases requires proactive, continuous, and often multidisciplinary care [17]. Care that optimally supports patients in making important lifestyle changes and takes into account patients' interpersonal variation in disease development, management and impact $[11,18]$. The best approach for providing such optimal care for people with chronic disease is, however, unclear. Therefore, the Dutch PROFILe project, which stands for PROFiling people's healthcare needs to support Integrated, person-centered models for Long-term disease management, started in 2014. The aim of this project was to develop and validate so-called 'patient profiles' as an instrument for tailoring chronic care management to the needs, preferences and abilities of patients. Type 2 diabetes mellitus was chosen as the starting point for profile development, because, due to its complications, it is a priority health problem in the Netherlands and a good model for other chronic diseases [19-21]. This dissertation describes the development and validation of the patient profiles. This first chapter introduces the topic of this dissertation, the aims and its outline. 


\section{Type 2 diabetes mellitus}

\section{Symptoms}

Type 2 diabetes mellitus (from now on referred to as type 2 diabetes) is a complex and heterogeneous disorder that is characterized by an excess of glucose in the bloodstream [22]. This excess of glucose is caused by a resistance of the body to the effect of insulin and/or insufficient production of insulin, a hormone that is produced in the pancreatic islets and regulates the movement of glucose into body cells [23,24]. Patients are diagnosed with type 2 diabetes when their fasting blood glucose values exceed $7.0 \mathrm{mmol} / \mathrm{l}$ on two different days or when their non-fasting blood glucose value exceeds $11.1 \mathrm{mmol} / \mathrm{l}$ in combination with symptoms related to hyperglycemia [25]. Type 2 diabetes often develops slowly. At diagnosis, patients who have type 2 diabetes may show little or no symptoms. Those patients who do have symptoms, typically experience polyuria, thirst, hunger, extreme fatigue, weight loss and a blurry vision due to elevated blood glucose levels [25].

\section{Epidemiology and consequences of type 2 diabetes}

According to the latest estimates, type 2 diabetes affects 451 million patients worldwide [26]. If no effective preventable measures are undertaken, the number of patients with type 2 diabetes is likely to increase to 693 million by 2045 . Once "a disease of affluence", it is now not only a common disease in high-income countries, but also in low- and middle income countries [27]. Asia is the epi-center of the epidemic, due to its large population, rapid economic development, and adoption of western lifestyle patterns $[27,28]$. In the Netherlands, approximately one million patients live with type 2 diabetes, which is almost $6 \%$ of the total population [29,30]. Type 2 diabetes disproportionally affects socially and materially disadvantaged people [31]. It is a major cause of morbidity and the $14^{\text {th }}$ leading cause of disability-adjusted life years [32]. It is important for patients with type 2 diabetes to keep their blood glucose levels under control, as inadequate glycaemic control can lead to long-term complications [33]. The most common complication is CVD, which affects approximately $34 \%$ of patients with type 2 diabetes [34]. The hazard ratio for CVD is approximately twice as high for patients with type 2 diabetes compared with those without [35]. CVD accounts for as much as 75\% of all mortality in type 2 diabetes. Other diabetesrelated complications include chronic kidney failure, vision loss and lower-extremity amputations [19, 20, 36]. Furthermore, type 2 diabetes has been related to depression, lower quality of life and impaired physical fitness [37-39]. Treatment with glucose-lowering drugs, especially insulin, can have considerable side effects such as hypoglycemia, which is a very unpleasant experience for many patients further increasing the burden of disease [40].

\section{Economic and societal burden}

Type 2 diabetes does not only have a considerable impact on people's health, but also places a heavy financial burden on society, health systems, individuals and employers. In high-income countries, the financial burden of type 2 diabetes mostly affects government or (public) health 
insurance budgets, whereas in poorer countries, with limited health insurance coverage, much of the burden falls on the person with type 2 diabetes [41]. In the Netherlands, the total estimated economic burden of type 2 diabetes in 2016 was $€ 5.9$ billion [22]. Of course, many of these costs are directly related to medical care, such as primary and secondary care costs. However, more than half of the total costs of diabetes are indirect costs, such as income losses, lost work hours due to illness, welfare payment costs, and indirect costs due to complications.

\section{Management of type 2 diabetes}

\section{Setting}

As noted above, type 2 diabetes is a chronic disease that cannot be cured. However, with the right management, patients with type 2 diabetes can live a long and healthy life; this implies that patients need continuous care. In the Netherlands, more than $80-90 \%$ of people with type 2 diabetes are treated in primary care [42]. The majority (85\%) of these patients has at least one diabetes consultation at a primary care practice per year, where they are treated by a team consisting of a general practitioner (GP) and a practice nurse (PN) or specially trained diabetes nurse $[25,42]$. On average, these patients have 5.6 primary care consultations for type 2 diabetes per year [42]. Patients who are unable to reach individual treatment targets in primary care and/or have severe complications and/or comorbidities, need more complex diabetes management. These patients are treated in secondary care by a diabetes team, most often led by an endocrinologist/diabetologist [43].

In an attempt to change from reactive, episodic care for patients with chronic diseases to proactive, continuous care, a new funding system for chronic care based on bundled payments was formally introduced in the Netherlands in 2010 [44, 45]. Under this system, health insurers annually pay a single fee for the full 'bundle' of diabetes care per insured client to a new organizational construct in primary care: the care group (in Dutch: 'zorggroep'). A care group consists of care providers, such as GPs, PNs, dieticians, and - in some cases endocrinologists, who are responsible for the delivery of chronic care to a specific patient population under a bundled payment contract [44]. The fee received per patient, which they freely negotiate with health insurers, covers a full range of care services for a fixed period, usually one year [44]. These services are codified in the Dutch Diabetes Federation Health Care Standard for type 2 diabetes [46], which focusses on the content, organization, and process of care. They are also in accordance with strict diabetes guidelines from the Dutch college of General Practitioners on type 2 diabetes, which guide healthcare providers in making adequate treatment decisions [25]. For example, a care group might receive $€ 300$ per year for a patient with type 2 diabetes. Within this budget, the patient receives four primary care consultations, a number of screenings and laboratory tests, and weight loss treatment from a dietitian. Care groups receive a higher budget for patients who, for example, need additional consultations or guidance in smoking cessation. There are approximately 130 care groups in 
the Netherlands, which take care of the treatment of the majority of patients (85-90\%) with type 2 diabetes $[45,47]$.

\section{Treatment}

Because an unhealthy lifestyle is an important risk factor of complications and insufficient glycaemic control, lifestyle improvement is usually the first advice from healthcare providers to patients with type 2 diabetes[25]. Previous studies have shown that weight loss and increased physical activity can lead to a marked decrease in hemoglobin A1c (HbA1c), which provides an estimate of the blood glucose level over the prior 2 to 3 months [48, 49]. Moreover, these lifestyle interventions have a beneficial effect on other CVD risk factors. When target values of $\mathrm{HbA} 1 \mathrm{c}$ are not reached, oral glucose lowering drugs are prescribed. In the Netherlands, approximately $70 \%$ of the patients with type 2 diabetes use these drugs [29]. Insulin is used by approximately $25 \%$ of people with type 2 diabetes and is prescribed when oral glucose lowering drugs fail to decrease a patient's $\mathrm{HbA1c}$ below the target value $[29,50]$.

\section{Self-management (support)}

A large proportion of diabetes care is based on self-management, which is defined as the active participation of patients in their treatment [51]. Self-management activities for type 2 diabetes include day-to-day blood glucose monitoring for patients on insulin therapy, medication intake, consuming a healthy diet, being physically active, preventing hypoglycemia, coping with emotions, and dealing with the side effects of medication [52]. Healthcare providers should educate and support patients in obtaining and sustaining the knowledge, skills and confidence to self-manage their disease $[25,53]$. In the guideline of the Dutch College of General Practitioners on type 2 diabetes, self-management support is a key element [25]. Providing high-quality self-management support is important, because it can improve patients' health-related behaviors [54] and self-efficacy, i.e. the belief in their ability to accomplish specific goals [55]. Subsequently this can lead to improved health- and/or functional status [54]. However, in reality, there is a limited degree of self-management support and patient involvement in practice in the Netherlands, as well as in many other countries in Europe $[56,57]$. Healthcare providers often lack the time, skills and resources necessary to provide adequate self-management support- and education. Moreover, they are primarily trained to react to acute episodes of illness, and not to educate and support patients in maintaining their health and quality of life [56].

\section{Quality of type 2 diabetes care}

In the Euro Diabetes Index, most recently published in 2014, the Netherlands ranks second after Sweden in terms of quality of diabetes care [58]. This high rating is mainly due to an excellent multidisciplinary collaboration and coordination among healthcare providers [59]. Although Dutch diabetes care is considered to be of very high quality, it also has its drawbacks. One of the major drawbacks is that the care recommended in the care protocols is highly 
standardized, based on the average patient with type 2 diabetes $[25,46]$. Yet, the average patient does not exist. Patients with type 2 diabetes differ in glycaemic control, cardiovascular risk and socio-demographic characteristics, amongst many other factors. Yet, barring some exceptions for older patients, they all receive very similar diabetes care [25]. Not all patients seem to benefit from the current 'one-size-fits-all' approach, leading to differential treatment effects. Studies have for example shown that approximately 20 to $30 \%$ of patients with type 2 diabetes have insufficient glycaemic control [60-64]. This suggests that these patients might benefit from more intensive disease management, such as frequent and longer consultation visits. Vice versa, patients with adequate glucose levels might maintain these levels with less frequent consultation visits. These hypotheses were tested in two previous Dutch studies. In the first study, patients with type 2 diabetes treated in a hospital did not only receive usual care (e.g. three-monthly consultations with an endocrinologist and diabetes team), but also a diabetes passport, which included the results of medical examinations. The aim of the passport was to promote shared decision making, which is a method to establish mutually accepted treatment goals between a patient and healthcare providers [65]. Patients also attended educational meetings. After one year, the intervention seemed cost-effective for patients who had insufficient glycaemic control at the start of the study, but was not costeffective for patients who had adequate glycaemic control. In the second study, the effectiveness of six-monthly consultations compared to three-monthly consultations, as stipulated in the care standard, was assessed in patients with adequately controlled type 2 diabetes and without a strong preference for their monitoring frequency [66]. After 18 months of follow-up, patients were equivalent to the three-monthly consultation group in terms of cardio metabolic control. Furthermore, 9 out of 10 patients were satisfied with the lower frequency of care. These findings suggest a shift towards more personalization of care.

\section{Personalization of care}

\section{History}

The personalization of care, defined as the tailoring of medical treatment based on individual patient characteristics, needs, and preferences $[67,68]$, is a concept that has received much attention over the past two decades, but is certainly not new. It was first described more than 2000 years ago as 'Ayurvedic medicine' in sacred texts from India [69]. Ayurveda, meaning 'science of life', is a traditional healing system that classifies people at birth into three subgroups based on their physical, physiological, and psychological characteristics. Individuals belonging to different subgroups, but displaying the same symptoms, may be treated differently. Thus, Ayurvedic medicine emphasizes the individual rather than the disease. Not much later, Hippocrates, a Greek physician, wrote: "it is far more important to know what person has the disease, than what disease the person has" [70]. He included patients' age and physique in the decision making process to prescribe drugs [71].

Even though, at the time, there was some emphasizes on the personalization of care, patients were used to, and perhaps also expected to, adopt the 'sick role' [72, 73]. In this role, first 
described by Parsons in 1951, patients had very little autonomy and complied with the orders of healthcare providers in order to get well [74]. Healthcare providers acted to what they thought to be in the best interest of patients and were solely responsible for making all treatment decisions [75]. Until about 1960, this relationship between patients and healthcare providers was very common [73]. However, in the past several decades, the population has become increasingly educated and the emergence of the internet has made information about medical problems and treatment accessible for patients $[72,73]$. Furthermore, the number of people with a chronic disease has increased: as part of their treatment, these patients have to make important behavioral and lifestyle changes (i.e. self-management) $[8,11]$. Many patients are experts when it comes to embedding these changes in their daily lives [76]. This forces healthcare providers to discuss available treatment options with them and, as such, has increased the empowerment of patients $[72,73]$. It has also made healthcare providers understand that patients have different care preferences, needs and abilities [72]. By incorporating shared decision-making, patient and healthcare providers are beginning to find a healthier balance of power [73], which has led to the growing popularity of care personalization.

The digitalization of health care is another reason for the increased popularity of the personalization of care. Since the mid-1980s, the capacity to produce, store and communicate digital data has exploded [77]. In health care, data from electronic health records, clinical trials and genomics, amongst others, have been compiled and analyzed to identify associations that would otherwise go unnoticed [78]. This so called 'big data' has the potential to improve clinical practice and patient care. It can detect genomic regions associated with a given trait in which disease-related genes are located, identify high-risk patients, and more precisely target treatment to their needs $[61,78,79]$. This type of personalization of care is often referred to as 'personalized care' or 'precision medicine' [80]. The use of the term precision medicine increased when the former president of the United States, Barack Obama, launched the Precision Medicine Initiative in 2015 [81]. The aim of this initiative is to predict the process of disease and to create personalized care by gaining more knowledge on the genetic variation in disease. For type 2 diabetes, efforts have been undertaken to unravel its genetic background by studying not only common gene variants, but also infrequent and rare variants [82]. To date, however, only $10-15 \%$ of the disease's heritability has been unveiled [23, 83].

\section{Patient profiles}

Since precision medicine based on a genotyping approach seems far away for the treatment of type 2 diabetes, shifting towards a phenotyping approach could be a more promising alternative. In this approach, patients' biomedical characteristics, such as blood pressure and BMI levels, as well as psychosocial characteristics, such as quality of life and social support, are identified and used to stratify patients into clinically relevant subgroups with similar care preferences, needs and abilities. In this dissertation, these subgroups are called 'patient profiles'. Stratifying patients into patient profiles can be used to develop optimal combinations of provider-led care and self-management support for each profile. For 
example, for patients with increased care needs, the consultation frequency could be increased in combination with receiving group-based diabetes education and emotional support from a psychologist. This can help healthcare providers to translate concepts such as shared decision making and self-management into concrete care activities. There is increasing consensus that this approach could improve patients' health outcomes [67, 84-86]. Figure 1 shows the steps that need to be taken to stratify patients into patient profiles and adjust care accordingly.

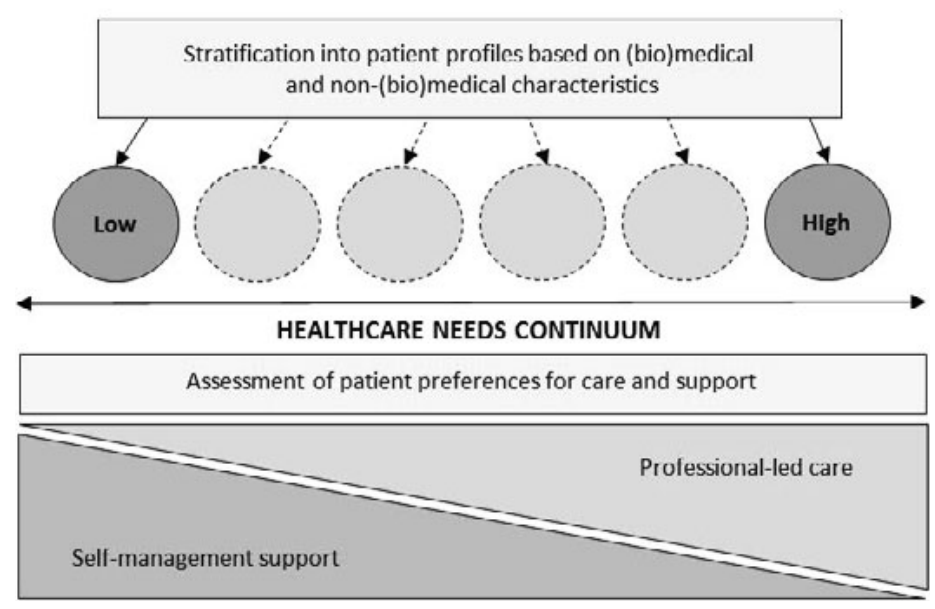

Figure 1. Framework for tailored chronic care management based on patient profiles

Patient profiling is related to the concept of 'mass customization', where goods and services are delivered with enough variety and customization that nearly everyone finds exactly what they want at costs close to those of mass production $[87,88]$. Take Starbucks for example, which offers only a few products, but you can order them in many different ways. Mass customization has recently moved from products to healthcare services, with the goal to make care more cost-effective [89]. It constitutes a promising approach for achieving the so-called 'Triple Aim', which is a framework developed to optimize health system performance [90]. The first aim of the Triple Aim, improving patient experience, can be achieved by including patients' care preferences in treatment decisions. The second aim, improving the health of populations, can be achieved by including patients' care needs and abilities in treatment decisions. Reducing the per capita costs of health care, which is the final aim, can be achieved by providing the right care, to the right person, at the right time. Patient profiling aims to make care more personalized by identifying subgroups of patients who are more homogeneous than the population as a whole. 


\section{Aim and outline of the dissertation}

At the initiation of the PROFILe project described in this dissertation, a tailored care approach for the treatment of type 2 diabetes was not structurally implemented in Dutch diabetes care, or even developed, due to two reasons. First, it was unclear which patient characteristics can be used to stratify patients into patient profiles. Second, it was unclear how type 2 diabetes care can be tailored to meet the care preferences, needs and abilities of the patients in each patient profile. Within this context, the overall aim of this dissertation was to develop and validate patient profiles as a tool to establish tailored care for patients with type 2 diabetes. Three objectives have been formulated:

1. To determine which health-, person-, and context-related patient characteristics are relevant for guiding tailored chronic care management

2. To determine how these characteristics can be combined into a scientifically robust and practicably feasible set of patient profiles

3. To assess the preferences and their determinants of patients with type 2 diabetes towards type 2 diabetes care

Chapter 2 provides a detailed description of the patient profiling approach. Chapter 3 provides the results of a systematic literature review on patient-related effect modifiers that influence the outcomes of integrated care programs for type 2 diabetes in primary care. Chapter $\mathbf{4}$ is a cross-sectional cohort study which gives insights into the relationship between patient characteristics and glycaemic control in patients with type 2 diabetes. In Chapter 5 real world data from a Dutch diabetes care network are used to identify glycaemic control trajectories and build a model to predict these trajectories using patient characteristics. In the same chapter the findings of the prediction model are validated using real world data from another Dutch diabetes care network. In Chapter 6 the opinions of HCPs and patients about relevant patient characteristics for estimating healthcare needs of patients with type 2 diabetes are assessed and compared. Chapter 7 provides the results of a discrete choice experiment (DCE) on the preferences of patients with type 2 diabetes towards type 2 diabetes care. In Chapter $\mathbf{8}$, two different patient profiling approaches are discussed and compared. The final chapter discusses the main findings of the studies in this dissertation, provides a reflection on these findings, as well as methodological and theoretical considerations. Lastly, recommendations for clinical practice, future research and policy are presented. 


\section{References}

1. Morens DM. Death of a president. N Engl J Med 1999; 341:1845-1849.

2. Fauci AS, Morens DM. The perpetual challenge of infectious diseases. N Engl J Med 2012; 366:454-461.

3. Fenner F. Smallpox: emergence, global spread, and eradication. Hist Philos Life Sci 1993; 15:397-420.

4. Omran AR. The epidemiologic transition. A theory of the epidemiology of population change. Milbank Mem Fund Q 1971; 49:509-538.

5. Zimmet P. Globalization, coca-colonization and the chronic disease epidemic: can the Doomsday scenario be averted? J Intern Med 2000; 247:301-310.

6. Australian Institute of Health and Welfare. Chronic Diseases. 2016.

7. Bernell S, Howard SW. Use Your Words Carefully: What Is a Chronic Disease? Front Public Health 2016; 4:159.

8. Global Health Estimates 2016: Deaths by Cause, Age, Sex, by Country and by Region, 2000-2016. Geneva: World Health Organization 2018.

9. Christensen K, Doblhammer G, Rau R, Vaupel JW. Ageing populations: the challenges ahead. Lancet 2009; 374:1196-1208.

10. Cutler DMD, A. S. Lleras-Muney, A. The determinants of mortality. Journal of Econcomic Perspectives 2006; 20:97-120

11. Dans A, Ng N, Varghese C, Tai ES, Firestone R, Bonita R. The rise of chronic noncommunicable diseases in southeast Asia: time for action. Lancet 2011; 377:680-689.

12. McGinnis JM, Foege WH. Actual causes of death in the United States. JAMA 1993; 270:2207-2212.

13. Megari K. Quality of Life in Chronic Disease Patients. Health Psychol Res 2013; 1:e27.

14. Chatterjee A, Kubendran S, King J, Devol R. Checkup time: chronic disease and wellness in America. In: Silver E, ed.: The Milken Institute 2014.

15. Glasgow RE, Orleans T, Wagner EH, Curry SJ, Solberg L I. Does the chronic care model serve also as a template for improving prevention In: Quarterly TM, ed. Oxford, UK 2001.

16. Yang G, Kong L, Zhao W, Wan X, Zhai Y, Chen LC, et al. Emergence of chronic noncommunicable diseases in China. Lancet 2008; 372:1697-1705.

17. Nolte E, Mckee M. Caring for people with chronic conditions. A health system perspective. European Observatory on Health Systems and Policies Series. Berkshire, England World Health Organization 2008.

18. Garrod AE. The inborn factors if disease: an essay. Oxford, UK: Oxford University Press; 1931.

19. 19. Bailey RA, Wang Y, Zhu V, Rupnow MF. Chronic kidney disease in US adults with type 2 diabetes: an updated national estimate of prevalence based on Kidney Disease: Improving Global Outcomes (KDIGO) staging. BMC Res Notes 2014; 7:415.

20. Gregg EW, Sorlie P, Paulose-Ram R, Gu Q, Eberhardt MS, Wolz M, et al. Prevalence of lower-extremity disease in the US adult population $>=40$ years of age with and without diabetes: 1999-2000 national health and nutrition examination survey. Diabetes Care 2004; 27:1591-1597.

21. Nathan DM, Meigs J, Singer DE. The epidemiology of cardiovascular disease in type 2 diabetes mellitus: how sweet it is ... or is it? Lancet 1997; 350 Suppl 1:SI4-9.

22. Peters ML, Huisman EL, Schoonen M, Wolffenbuttel BHR. The current total economic burden of diabetes mellitus in the Netherlands. Neth J Med 2017; 75:281-297. 
23. Polonsky KS. The past 200 years in diabetes. N Engl J Med 2012; 367:1332-1340.

24. Taylor R. Insulin resistance and type 2 diabetes. Diabetes 2012; 61:778-779.

25. Nederlands huisartsen genootschap. NHG-standaard Diabetes mellitus type 2 (vierde (partitiële) herziening). 2018.

26. International Diabetes Federation. IDF Diabetes Atlas, 8th edition Brussels, Belgium International Diabetes Federation 2017.

27. Hu FB. Globalization of diabetes: the role of diet, lifestyle, and genes. Diabetes Care 2011; 34:1249-1257.

28. Forouhi NG, Wareham NJ. Epidemiology of diabetes. Medicine (Abingdon) 2014; 42:698702.

29. Vektis. Factsheet Diabetes. 2013.

30. Kleefstra N, Landman GW, Van Hateren KJ, Meulepas M, Romeijnders A, Rutten GE, et al. Dutch diabetes prevalence estimates (DUDE-1). J Diabetes 2016; 8:863-865.

31. Hill J, Nielsen M, Fox MH. Understanding the social factors that contribute to diabetes: a means to informing health care and social policies for the chronically ill. Perm J 2013; 17:67-72.

32. Murray CJ, Lopez AD. Measuring the global burden of disease. N Engl J Med 2013; 369:448-457.

33. Gaede P, Vedel P, Larsen N, Jensen GV, Parving HH, Pedersen O. Multifactorial intervention and cardiovascular disease in patients with type 2 diabetes. N Engl J Med 2003; 348:383-393.

34. Norhammar A, Bodegard J, Nystrom T, Thuresson M, Eriksson JW, Nathanson D. Incidence, prevalence and mortality of type 2 diabetes requiring glucose-lowering treatment, and associated risks of cardiovascular complications: a nationwide study in Sweden, 2006-2013. Diabetologia 2016; 59:1692-1701.

35. Emerging Risk Factors C, Sarwar N, Gao P, Seshasai SR, Gobin R, Kaptoge S, et al. Diabetes mellitus, fasting blood glucose concentration, and risk of vascular disease: a collaborative meta-analysis of 102 prospective studies. Lancet 2010; 375:2215-2222.

36. Lee R, Wong TY, Sabanayagam C. Epidemiology of diabetic retinopathy, diabetic macular edema and related vision loss. Eye Vis (Lond) 2015; 2:17.

37. Huang ES, Brown SE, Ewigman BG, Foley EC, Meltzer DO. Patient perceptions of quality of life with diabetes-related complications and treatments. Diabetes Care 2007; 30:24782483.

38. Mezuk B, Eaton WW, Albrecht S, Golden SH. Depression and type 2 diabetes over the lifespan: a meta-analysis. Diabetes Care 2008; 31:2383-2390.

39. Sayer AA, Dennison EM, Syddall HE, Gilbody HJ, Phillips DI, Cooper C. Type 2 diabetes, muscle strength, and impaired physical function: the tip of the iceberg? Diabetes Care 2005; 28:2541-2542.

40. Group UKHS. Risk of hypoglycaemia in types 1 and 2 diabetes: effects of treatment modalities and their duration. Diabetologia 2007; 50:1140-1147.

41. Seuring T, Archangelidi O, Suhrcke M. The Economic Costs of Type 2 Diabetes: A Global Systematic Review. Pharmacoeconomics 2015; 33:811-831.

42. Hek K, Ursum J, Tol J, Verheij RA. Eerstelijnszorggebruik voor diabetes: een overzicht. NIVEL Zorgregistraties eerste lijn 2016.

43. Sluiter AC, Van Wijland JJ, Arntzenius AB, Bots AFE, Dijkhorst-Oei LT, Van der Does FEE, et al. Landelijke transmurale afspraak diabetes mellitus type 2 diabetes [Dutch transmural agreement on diabetes mellitus type 2]. Huisarts Wet 2012; 55:1-12. 
44. Struijs JN, Baan CA. Integrating care through bundled payments--lessons from The Netherlands. N Engl J Med 2011; 364:990-991.

45. Campmans-Kuijpers MJ, Baan CA, Lemmens LC, Rutten GE. Change in quality management in diabetes care groups and outpatient clinics after feedback and tailored support. Diabetes Care 2015; 38:285-292.

46. Netherlands Diabetes Federation. NDF Care Standard. Transparancy and quality of diabetes care for people with diabetes type 2 [NDF Zorgstandaard. Transparantie en kwaliteit van diabeteszorg voor mensen met type 2 diabetes] Amersfoort: Netherlands Diabetes Federation 2015.

47. Klomp M, Romeijnders A, de Braal E, Rutten GE, Meulepas M. Transparante ketenzorg rapportage 2017 zorggroepen diabetes mellitus, VRM, COPD en astma. Op weg naar genuanceerde rapportage van zorg. Utrecht, the Netherlands: Ineen 2018.

48. Turner R, Cull C, Holman R. United Kingdom Prospective Diabetes Study 17: a 9-year update of a randomized, controlled trial on the effect of improved metabolic control on complications in non-insulin-dependent diabetes mellitus. Ann Intern Med 1996; 124:136-145.

49. Umpierre D, Ribeiro PA, Kramer CK, Leitao CB, Zucatti AT, Azevedo MJ, et al. Physical activity advice only or structured exercise training and association with $\mathrm{HbA1c}$ levels in type 2 diabetes: a systematic review and meta-analysis. JAMA 2011; 305:1790-1799.

50. Elissen AMJ, Hertroijs DFL, Schaper NC, Bosma H, Dagnelie PC, Henry RM, et al. Differences in biopsychosocial profiles of diabetes patients by level of glycaemic control and health-related quality of life: The Maastricht Study. PLoS One 2017; 12:e0182053.

51. Koch T, Jenkin P, Kralik D. Chronic illness self-management: locating the 'self'. Journal of advanced nursing 2004; 48:484-492.

52. Coyle ME, Francis K, Chapman Y. Self-management activities in diabetes care: a systematic review. Aust Health Rev 2013; 37:513-522.

53. Beck J, Greenwood DA, Blanton L, Bollinger ST, Butcher MK, Condon JE, et al. 2017 National Standards for Diabetes Self-Management Education and Support. Diabetes Care 2017; 40:1409-1419.

54. Norris SL, Engelgau MM, Narayan KM. Effectiveness of self-management training in type 2 diabetes: a systematic review of randomized controlled trials. Diabetes Care 2001; 24:561-587.

55. Coleman MT, Newton KS. Supporting self-management in patients with chronic illness. Am Fam Physician 2005; 72:1503-1510.

56. Elissen A, Nolte E, Knai C, Brunn M, Chevreul K, Conklin A, et al. Is Europe putting theory into practice? A qualitative study of the level of self-management support in chronic care management approaches. BMC Health Serv Res 2013; 13:117.

57. Stiggelbout AM, Van der Weijden T, De Wit MP, Frosch D, Legare F, Montori VM, et al. Shared decision making: really putting patients at the centre of healthcare. BMJ 2012; 344:e256.

58. Cebolla Garrofé B, Björnberg A, Yung Phang A. Euro Diabetes Index 2014. Health Consumer Powerhouse Ltd. 2014.

59. de Bakker DH, Struijs JN, Baan CB, Raams J, de Wildt JE, Vrijhoef HJ, et al. Early results from adoption of bundled payment for diabetes care in the Netherlands show improvement in care coordination. Health affairs 2012; 31:426-433. 
60. Elissen AM, Duimel-Peeters IG, Spreeuwenberg C, Spreeuwenberg M, Vrijhoef HJ. Toward tailored disease management for type 2 diabetes. Am J Manag Care 2012; 18:619-630.

61. Hertroijs DFL, Elissen AMJ, Brouwers M, Schaper NC, Kohler S, Popa MC, et al. A risk score including body mass index, glycated haemoglobin and triglycerides predicts future glycaemic control in people with type 2 diabetes. Diabetes Obes Metab 2018; 20:681688.

62. Pimouguet C, Le Goff M, Thiebaut R, Dartigues JF, Helmer C. Effectiveness of diseasemanagement programs for improving diabetes care: a meta-analysis. CMAJ 2011; 183:E115-127.

63. Rothe U, Muller G, Schwarz PE, Seifert M, Kunath H, Koch R, et al. Evaluation of a diabetes management system based on practice guidelines, integrated care, and continuous quality management in a Federal State of Germany: a population-based approach to health care research. Diabetes Care 2008; 31:863-868.

64. Walraven I, Mast MR, Hoekstra T, Jansen AP, van der Heijden AA, Rauh SP, et al. Distinct HbA1c trajectories in a type 2 diabetes cohort. Acta Diabetol 2015; 52:267-275.

65. Marrero DG, Ard J, Delamater AM, Peragallo-Dittko V, Mayer-Davis EJ, Nwankwo R, et al. Twenty-first century behavioral medicine: a context for empowering clinicians and patients with diabetes: a consensus report. Diabetes Care 2013; 36:463-470.

66. Wermeling PR, Gorter KJ, Stellato RK, de Wit GA, Beulens JW, Rutten GE. Effectiveness and cost-effectiveness of 3-monthly versus 6-monthly monitoring of well-controlled type 2 diabetes patients: a pragmatic randomised controlled patient-preference equivalence trial in primary care (EFFIMODI study). Diabetes Obes Metab 2014; 16:841-849.

67. Inzucchi SE, Bergenstal RM, Buse JB, Diamant M, Ferrannini E, Nauck M, et al. Management of hyperglycemia in type 2 diabetes: a patient-centered approach: position statement of the American Diabetes Association (ADA) and the European Association for the Study of Diabetes (EASD). Diabetes Care 2012; 35:1364-1379.

68. Jameson JL, Longo DL. Precision medicine--personalized, problematic, and promising. $N$ Engl J Med 2015; 372:2229-2234.

69. Joshi K, Ghodke Y, Shintre P. Traditional medicine and genomics. J Ayurveda Integr Med 2010; 1:26-32.

70. Murugan R. Movement towards personalised medicine in the ICU. Lancet Respir Med 2015; 3:10-12.

71. Sykiotis GP, Kalliolias GD, Papavassiliou AG. Pharmacogenetic principles in the Hippocratic writings. J Clin Pharmacol 2005; 45:1218-1220.

72. Frosch DL, Kaplan RM. Shared decision making in clinical medicine: past research and future directions. Am J Prev Med 1999; 17:285-294.

73. Truog RD. Patients and doctors--evolution of a relationship. N Engl J Med 2012; 366:581585.

74. Parsons T. The Social System. Glencoe, IL: Free Press; 1951.

75. Brody DS. The patient's role in clinical decision-making. Ann Intern Med 1980; 93:718722.

76. Tattersall RL. The expert patient: a new approach to chronic disease management for the twenty-first century. Clin Med (Lond) 2002; 2:227-229.

77. Austin C, Kusumoto F. The application of Big Data in medicine: current implications and future directions. J Interv Card Electrophysiol 2016; 47:51-59. 
78. Auffray C, Balling R, Barroso I, Bencze L, Benson M, Bergeron J, et al. Making sense of big data in health research: Towards an EU action plan. Genome Med 2016; 8:71.

79. Mohammadi D. Turning big data into personalised diabetes care. Lancet Diabetes Endocrinol 2015; 3:935-936.

80. Pearson ER. Personalized medicine in diabetes: the role of 'omics' and biomarkers. Diabetic medicine : a journal of the British Diabetic Association 2016; 33:712-717.

81. Collins FS, Varmus H. A new initiative on precision medicine. N Engl J Med 2015; 372:793795.

82. Fuchsberger C, Flannick J, Teslovich TM, Mahajan A, Agarwala V, Gaulton KJ, et al. The genetic architecture of type 2 diabetes. Nature 2016; 536:41-47.

83. Rich SS. Diabetes: Still a geneticist's nightmare. Nature 2016; 536:37-38.

84. Abbasi J. For Patients With Type 2 Diabetes, What's the Best Target Hemoglobin A1C? JAMA 2018; 319:2367-2369.

85. 85. Cao MM, Tong NW. Stratifying and tailoring $\mathrm{HbA1c}$ control targets for adults with Type 2 diabetes: interpretation of the consensus proposed by the Chinese Society of Endocrinology. J Diabetes 2011; 3:201-207.

86. Lauritzen T, Sandbaek A, Skriver MV, Borch-Johnsen K. HbA1c and cardiovascular risk score identify people who may benefit from preventive interventions: a 7 year follow-up of a high-risk screening programme for diabetes in primary care (ADDITION), Denmark. Diabetologia 2011; 54:1318-1326.

87. Tseng MM, Hu SJ. Mass Customization. Manufacturing Technology 2014; 836-843.

88. Pine II BJ, Victor B, Boynton AD. Making mass customization work. Harvard Business Review 1993:108-116.

89. Kimberley JR, Minvielle E. Can health care be "build to order"? Making the shift toward customized care. NEJM Catalyst 2017.

90. Berwick DM, Nolan TW, Whittington J. The triple aim: care, health, and cost. Health affairs 2008; 27:759-769. 


\section{Profiling patients' healthcare needs to support integrated, person-centered models for long-term disease management \\ (Profile): research design}

\section{Published as:}

A.M.J. Elissen, D.F.L. Hertroijs, N.C. Schaper, H.J.M. Vrijhoef, D. Ruwaard. Profiling patients' healthcare needs to support integrated, person-centered models for long-term disease management (Profile): Research design. International Journal of Integrated Care. 


\section{Abstract}

Background: This article presents the design of PROFILe, a study investigating which (bio)medical and non-(bio)medical patient characteristics should guide more tailored chronic care. Based on this insight, the project aims to develop and validate 'patient profiles' that can be used in practice to determine optimal treatment strategies for subgroups of chronically ill with similar healthcare needs and preferences.

Methods/Design: PROFILe is a practice-based research comprising four phases. The project focuses on patients with type 2 diabetes. During the first study phase, patient profiles are drafted based on a systematic literature research, latent class growth modeling, and expert collaboration. In phase 2 , the profiles are validated from a clinical, patient-related and statistical perspective. Phase 3 involves a discrete choice experiment to gain insight into the patient preferences that exist per profile. In phase 4, the results from all analyses are integrated and recommendations formulated on which patient characteristics should guide tailored chronic care.

Discussion: PROFILe is an innovative study which uses a uniquely holistic approach to assess the healthcare needs and preferences of chronically ill. The patient profiles resulting from this project must be tested in practice to investigate the effects of tailored management on patient experience, population health and costs. 


\section{Background}

One of the greatest challenges for health systems and economic and social development in Europe is the rising burden of chronic disease [1]. Around 32 percent of Europeans is now chronically ill, with many - especially elderly - people suffering from multiple conditions at the same time [2]. Without action, the chronic disease epidemic in the region will continue to develop rapidly: diabetes prevalence, for example, is expected to increase by 12.6 million cases over the next 15 years [3]. Chronic conditions cause serious disability, lower quality of life and early mortality, and already consume 70 to 80 percent of healthcare budgets across Europe [1].

When it comes to managing chronic disease, thus far the trend in most countries is to treat conditions separately through multidisciplinary care teams using disease-specific guidelines [4]. While such one-dimensional disease management can lead to improved care quality and outcomes [5-8], its value is quickly decreasing in proportion to rising multimorbidity. For the growing group of patients living with a complex of (interrelated) chronic conditions - such as diabetes, cardiovascular disease, asthma and dementia - disease management means having several care teams working according to different guidelines [10]. This may lead to fragmented care, loss of responsibility among providers, and confusion or even harm for patients [9]. Recent studies of chronic care in Europe also point to overstandardised service provision, limited preventive action, and a lack of support for patients' self-management $[4,10,11]$. Overall, the return on investment in chronic disease management seems relatively poor: real improvements in population health are not always achieved and many patients remain dissatisfied about their care, while costs reach unprecedented levels $[1,12]$.

In recent years, there is increasing consensus that better management of chronic conditions requires an approach centered on patients instead of on their primary diagnosed disease [10]. It has become clear that active participation and commitment of patients is critical for achieving any kind of chronic disease control. Hence, their personal healthcare needs and preferences must be taken into account in clinical decision-making. Such individualisation of care, while important for all chronically ill, is particularly relevant for people with type 2 diabetes [13]. Besides generally being considered the 'quintessential self-managed disease', type 2 diabetes is a highly heterogeneous condition both in pathogenesis and clinical manifestation [10]. This means that the 'typical' diabetes patient does not exist and standardised management is likely to yield differential treatment effects. Indeed, recent research in Germany and the Netherlands shows that unstable, high-risk diabetes patients benefit significantly more from disease management than patients with better disease control for whom such intensive treatment may have little added value $[14,15]$. Similarly, various large-scale international studies suggest that not all diabetes patients profit from intensive glucose- or blood pressure-lowering therapy, pointing towards characteristics like age, disease duration, comorbidities, and patient attitude as possible effect modifiers $[10,13]$.

Taking into account patient characteristics - with the potential to modify treatment outcomes in chronically ill - in clinical decision-making is important to enable the right care to be 
provided to the right person at the right time, with a focus on increased patient engagement, self-management and, ultimately, cost containment. However, thus far, it remains unclear which patient features should guide a more tailored approach to chronic care management and how these can be translated into a feasible tool to support professionals and patients in daily practice. This paper describes the design of a three-year, multiple-phase research project entitled 'PROFiling patients' healthcare needs to support Integrated, person-centered models for Long-term disease management (PROFILe)', which seeks to fill this significant gap in knowledge and, in so doing, support more patient-centered, sustainable chronic care management in practice.

\section{Research aims and questions}

The PROFILe project aims to develop and validate a novel, practical instrument - in the form of patient profiles - that supports more tailored chronic care management in practice. Unique about the profiles to be developed is that they will combine (bio)medical and non-(bio)medical patient characteristics relevant for determining an optimal treatment strategy for subgroups of patients with similar care needs and preferences. The objective here is not to create a complex network of detailed patient features, but rather to identify a limited number of key characteristics that, when combined into profiles, can serve as an instrument to help tailor the general stipulations of chronic care standards and guidelines in a patient-driven manner. More specifically, the PROFILe project will answer the following research questions:

1. Which (bio)medical and non-(bio)medical patient characteristics are (clinically) relevant for guiding tailored chronic care management?

2. How can those characteristics be combined into a scientifically robust and practicably feasible set of patient profiles?

3. What are patients' preferences for specific configurations of professional-led care and selfmanagement support per developed patient profile?

Although the objective of PROFILe is explicitly not to develop another disease-specific approach to chronic care management, type 2 diabetes (as primary diagnosis) is used as a starting point for profile development.

\section{Methods/Design}

\section{Study design}

PROFILe is designed as a practice-based, mixed-methods research comprising four phases, which are completed sequentially over a total period of 36 months. The project started in December 2014. Study design and phasing are shown in Figure 1. The research is conducted at Maastricht University in the Netherlands, in close collaboration with various stakeholders, and funded by Novo Nordisk. No ethical approval is needed for the research: as the data used are already available and patients are not physically involved in the research, the study is not subject to the Dutch Medical Research (Human Subjects) Act (WMO). PROFILe draws in considerable part on the 10-year, epidemiological Maastricht Study [16], which has previously 
been approved by the medical ethical committee of Maastricht University Medical Centre (MUMC+) (NL31329.068.10) and the Netherlands Health Council under the Dutch Population Screening Act (Permit 131088-105234-PG).

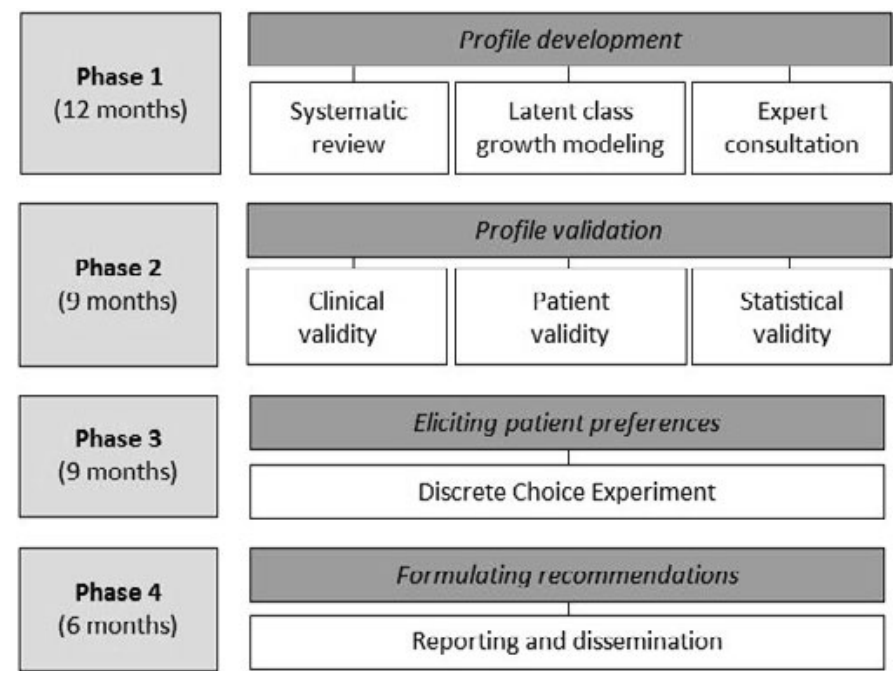

Figure 1. Study design and phasing

\section{Setting}

Over the past decade, diabetes has become a public health priority for the Dutch Ministry of Health [17]. Considerable resources have been and still are invested in reforming the content, organization and funding of diabetes management with the aim of improving care quality and outcomes for patients. According to Wensing et al. [18], the Dutch Ministry of Health regards diabetes as 'an ideal case for general policies for chronic illness care'. Indeed, some of the most important changes of late in Dutch chronic care management have started with pilots in diabetes care and were consequently rolled out to, for example, COPD care and vascular risk management [19]. Internationally, the Netherlands is regarded as a pioneer of high-quality diabetes care, ranking second after Sweden on the 2014 Euro Diabetes Index which compared diabetes management in 30 European countries [20].

In the Netherlands, the vast majority (85-90\%) of patients with type 2 diabetes are managed by GPs in primary care [21]. Patients who need more complex management are treated in secondary care by a diabetes team led by an endocrinologist. According to the National Transmural Agreement (NTA) for type 2 diabetes [22], complex management concerns patients 'who are unable to reach individual treatment targets in primary care (and for whom there are valid grounds for expecting improvement in secondary care) and/or whose management is problematic due to severe complications or therapy resistant cardiovascular risk factors'. When patients are referred to secondary care, the endocrinologist assumes responsibility for their diabetes care, either indefinitely or until they can transition back to 
general practice. The NTA specifies the formal criteria for referrals between primary and secondary care [22].

Because primary care is widely considered to be the most suitable medical home for chronically ill [23], and most Dutch type 2 diabetes patients are treated there, PROFILe will develop patient profiles specifically for the primary care setting. In recent years, Dutch primary care has undergone a considerable transformation as most GPs have gathered in so-called 'care groups'. These provider networks are similar to Accountable Care Organizations in the United States and Clinical Commissioning Groups in the United Kingdom [24,25]. Care groups first emerged in Dutch primary care in 2007 with the experimental introduction of a bundled payment system for integrated type 2 diabetes care. Quickly growing in number, there are now around 100 groups covering near to all Dutch regions and 85 to 90 percent of type 2 diabetes patients [26]. Annually, care groups negotiate a bundled payment contract with health insurers to organise, coordinate and provide the whole package of non-complex type 2 diabetes care for patients in their region. The care group is responsible for all patients covered by its bundled payment contract; GPs (and affiliated personnel, such as practice nurses) deliver care themselves and/or subcontract services from other providers, such as physical therapists, dieticians, laboratories, and, to a limited extent, medical specialists. The content of the care package is prescribed by a national standard for diabetes care developed by the Dutch Diabetes Federation, which stipulates, amongst others, that patients are seen in general practice at least four times annually, receive a specific number of tests and screening, and are offered education about their disease and self-management [24].

Although diabetes care in the Netherlands is viewed internationally as 'best practice', recent evaluations suggest there is room for further improvement. Most notably, the role that patients have in their care remains limited, with support interventions for self-management still largely in their infancy [11,19]. Another limitation is the high level of service standardisation based on the Dutch diabetes care standard, which - according to the Euro Diabetes Index - is followed 'so strictly that new ideas not accepted in the standard are shunned' [20].

\section{Conceptual framework}

Aim of the PROFILe project is to develop and validate a robust and feasible set of patient profiles that can be used in daily practice to support more patient-centered, tailored chronic care management. Although in essence, the patient profiles to be developed constitute a tool for case-mix classification - for which many other methods exist that have been studied extensively over the past years $[28,29]$ - they will be unique in combining both (bio)medical patient features, such as disease duration and severity, and non-(bio)medical patient characteristics, like age, sex and educational level. Using non-(bio)medical characteristics for stratification purposes is assumed to provide better insight into patients' abilities for selfmanagement of their chronic condition(s) and, in so doing, enables the intensity of professional-led care to be matched optimally to patients' actual care needs. 
Figure 2 shows the conceptual framework underlying PROFILe, which draws upon the Population Health Conceptual Framework of the Care Continuum Alliance [30]. The figure illustrates that the ultimate goal of profiling is to enable patient subgroups to be aligned with interventions across the continuum of self-management support and professional-led care that match their established level of healthcare needs as well as their preferences for specific services. Thus, patients with a low level of healthcare needs - based on their (bio)medical and non-(bio)medical characteristics - might prefer support by a community nurse and/or incidental email contact with a primary care provider to manage their health. On the other end of the spectrum, those with a high-needs profile could favour regular monitoring in general practice combined with individual, nurse-led education. However, rather than assuming patients' likings for specific configurations of care and support, the PROFILe project will utilise a research method called 'discrete choice experimentation' to gain insight into the actual preferences of chronically ill patients for various attributes of chronic care management, such as the frequency of professional monitoring, central care giver, and methods and tools for self-management support. Moreover, as patients' perception of their illness is known to often differ from health professionals' assessment, the validity of the profiles will be tested against patients' own perceptions of their level of healthcare needs.

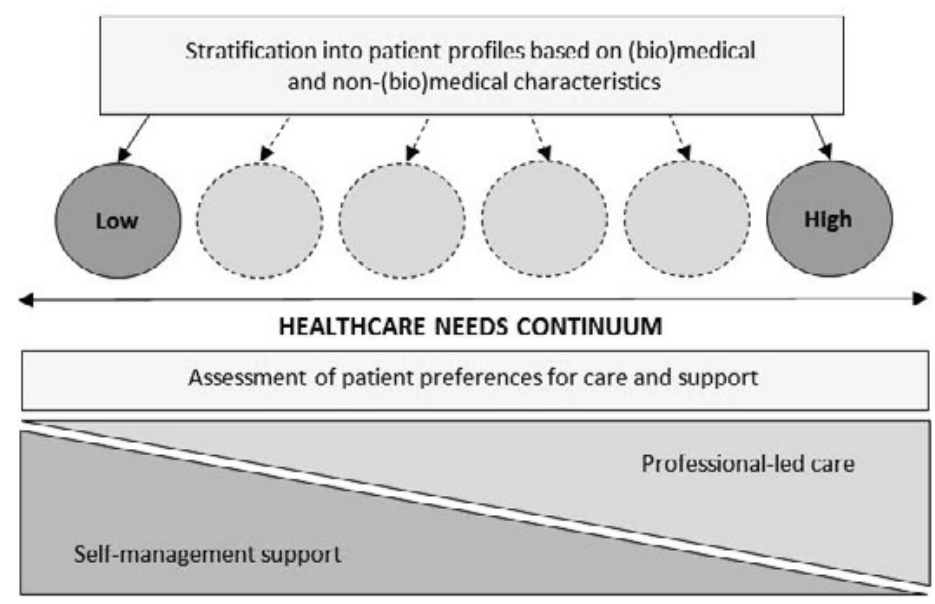

Figure 2. Framework for tailored chronic care management based on patient profiles

\section{Data collection and analyses}

The PROFILe project will combine a mixture of quantitative and qualitative data and analytic methods across four research phases.

\section{Phase 1: Profile development}

During the first research phase (12 months), the objective is to draft a robust and feasible set of patient profiles for tailoring type 2 diabetes management. Three research methods will be used to identify key patient characteristics influencing diabetes control and subsequently 
combine those factors into real-valued prediction models: (a) systematic literature review; (b) latent class growth modeling; and (c) expert collaboration.

\section{Systematic literature review}

The systematic literature review is intended to gain insight into which bio(medical) and non(bio)medical variables are potentially relevant for assessing the healthcare needs of type 2 diabetes patients. For this purpose, we will synthesise existing evidence about characteristics of patients that cause heterogeneity in the utilization and clinical outcomes of disease management strategies. In line with previous research [5-8], 'disease management' is operationalised as interventions targeting at least two of the four practice-level elements of the Chronic Care Model, that is, self-management support, delivery system design, decision support and clinical information [31].

Searches for English language empirical studies published between 1998 and 2015 will be conducted in PubMed, EMBASE and CINAHL using multiple groups of search terms related to type 2 diabetes, disease management, the Chronic Care Model, patient characteristics and relevant outcomes. The latter will include various measures of diabetes control and resource utilization. Included articles will be analysed descriptively; in addition, the two to three most consistently reported outcome variables across included articles will be meta-analysed to explain heterogeneity in disease management outcomes based on variation in patient characteristics.

\section{Latent class growth modelling}

In the second part of the profile development phase, quantitative data analyses will be conducted using a technique called latent class growth modelling (LCGM). LCGM is a type of cluster analysis that is increasingly employed in clinical research to capture heterogeneity between individuals in, for instance, treatment responses or disease patterns [32]. Using LCGM, subgroups of patients with distinct clinical trajectories over time can be identified and their characteristics determined [33].

Within PROFILe, LCGM will be applied to identify classes of type 2 diabetes patients with unique trajectories over the course of time in three measures of diabetes control, that is, $\mathrm{HbA1c}$, LDL cholesterol and systolic blood pressure, as well as in a composite of these three measures. Longitudinal data on these and other relevant measures are collected from the Diabetes Patient Registry of the regional care group in Maastricht, which has been providing integrated type 2 diabetes care based on bundled payment contracts since 2007. Based on its achievements, the group was recently designated one of nine 'pioneer sites' in population (health) management in the Netherlands by the Minister of Health [34].

The Diabetes Patient Registry contains individual patient data registered during primary care visits from 2007 onward concerning a wide range of variables related to patient demographics, clinical status, and type and frequency of care provision. The study population will include all patients who entered the Diabetes Patient Registry at some point in time between January 2009 and December $2014(N=\sim 9,000)$. Based on the Diabetes Patient Registry data, models 
with increasing numbers of classes will be run. Model fit and parsimony are assessed using the Bayesian Information Criterion and Lo-Mendell-Rubin Likelihood Ratio Test [32]. A standardised entropy score is calculated to determine the amount of ambiguity in class allocation [35]. Potential associations between various patient characteristics on the one hand and membership of a given class on the other will be explored using multinomial logistic backward regression analyses. All available determinants in the Diabetes Patient Registry will be analysed separately; correlations are assessed to test for co-linearity. Those determinants achieving a $p$-value $<0.10$ will be included simultaneously through a backward elimination method, resulting in a model that includes only significant $(p<0.05)$ determinants.

In addition, multinomial logistic backward regression analyses will be conducted for a subsample of Diabetes Patient Registry patients, that is, those patients participating in the Maastricht Study [16]. This detailed epidemiological study, which started in 2010, focuses on the etiology and pathophysiology of type 2 diabetes, its classic complications (i.e. cardiovascular disease, nephropathy, neuropathy and retinopathy), and its emerging comorbidities, including cognitive decline, depression, and gastrointestinal, respiratory and musculoskeletal diseases [16]. During three to four 4-hour visits per participant, state-of-theart imaging techniques and extensive biobanking are used to determine health status in a population-based cohort of 10,000 individuals enriched with type 2 diabetes patients. The latter are recruited from the Diabetes Patient Registry of the regional care group in Maastricht. An in-depth description of the design of the Maastricht Study can be found elsewhere [16]. Included in the multinomial logistic regression analyses are Maastricht Study participants with at least 24 months of registered data in the Diabetes Patient Registry prior to their inclusion in the Maastricht Study $(\mathrm{N}=\sim 1,000)$, enabling combination of cross-sectional (Maastricht Study) data and longitudinal (Diabetes Patient Registry) data on the individual patient level. Compared to the Diabetes Patient Registry, the Maastricht Study adds extensive phenotype data as well as information on quality of life, lifestyle, socioeconomic and psychological features. These data will be used to place the latent classes developed based on the Diabetes Patient Registry data in a larger system of variables that may include hypothesised predictors not available in the Diabetes Patient Registry (e.g. education level) as well as potential longterm outcomes of latent class membership (e.g. quality of life) [36].

\section{Expert and stakeholder consultation}

Based on the combined findings from the literature review and LCGM analyses, a preliminary set of patient profiles is drafted by the research team in close collaboration with various stakeholders and scientific experts. These are represented in the project's Stakeholder Group, which includes representatives from patient organisations, provider associations, health insurers and policymakers, and the Scientific Advisory Board gathering (inter)nationally renowned experts in type 2 diabetes, disease management, case-mix classification and risk stratification. A priori, we assume phase 1 to result in three to eight draft patient profiles which, based on a limited number of pertinent (bio)medical and non-(bio)medical variables, describe relatively homogeneous classes of chronically ill in terms of their healthcare needs. 


\section{Phase 2: Profile validation}

During phase 2 of the research ( 9 months), the aim is to validate the draft patient profiles focusing specifically on clinical validity, patient validity and statistical validity.

\section{Clinical validity}

To assess clinical (i.e. face) validity, that is, the extent to which health professionals consider the draft profiles as valid for assessing patients' healthcare needs, an electronic Delphi panel will be conducted with representatives of provider associations involved in type 2 diabetes management in the Netherlands. Relevant associations are the Dutch General Diabetes General Practitioners Advice Group (DiHAG), Diabetes and Nutrition Organization (DNO), Professional Organisation for Diabetes Care Providers (EADV), Diabetes Education Study Group (DESG), Royal Dutch Pharmacists Association (KNMP), Royal Dutch Society for Physical Therapy (KNGF) and the Dutch Internists' Association (NIV). The aim is to include two representatives from each Dutch association involved in structured diabetes management, so as to compose a balanced Delphi panel with sufficient professional expertise and mixed backgrounds.

The RAND/UCLA appropriateness method [37] will be used to design multiple Delphi rounds, including: (a) an online survey to assess experts preliminary scores of the profiles in terms of validity; (b) a face-to-face expert meeting to discuss individual scores and, where necessary and possible, increase group consensus; and (c) individual reassessment on a paper-based survey to produce final scores. Additional rounds may be added if insufficient consensus is reached after the face-to-face meeting. The focus of the Delphi study will be on the validity according to healthcare professionals - of each separate patient characteristic identified as relevant during the first research phase, as well as on the validity of different combinations of these characteristics into patient profiles.

\section{Patient validity}

Given that patient profiles are intended to support more patient-centered management of type 2 diabetes, validation of the profiles by patients is also considered crucial. We will use a mixed-methods approach to test the validity of the draft profiles against patients' own views of their level of healthcare needs. The latter will be measured using the validated Problem Areas in Diabetes (PAID) questionnaire, which is a widely used, 20-item measure of emotional adjustment to life with diabetes [38]. A purposive sample of five to ten type 2 diabetes patients per draft patient profile will be selected from GP practices in Maastricht to participate in the profile validation.

The results of the PAID questionnaire form the input for an individual, in-depth follow-up interview, which aims to: (1) elaborate on patients' PAID scores by providing them the opportunity to tell their illness narratives; and (2) compare patients' own view of their level of healthcare needs with the profile chosen by the researchers. As the primary focus of patient validation is on the subjective experience of healthcare needs by the person who is chronically ill, a descriptive phenomenological approach is used for the interviews and analysis. 
Phenomenology requires researchers to look at things in a new way without predispositions and prejudices, thus enabling fresh, rich and new understandings of existing phenomena [39]. A semi-structured interview guide will be used during the interviews to steer the conversation; the number and nature of questions can vary depending on the respondent's illness narrative. All interviews are audio-recorded. Data analysis will be conducted conform the descriptive phenomenological method using Hycner's 15-step framework [40], which starts with individual interview transcription and ultimately results in a composite summary of all interviews capturing the essence of the phenomenon under study as experienced by respondents.

\section{Statistical validity}

Finally, the statistical validity of the draft patient profiles - in particular, their generalisability to other settings - will be tested using quantitative data collected retrospectively from a different, larger cohort of patients than the one used for developing the profiles. This cohort will comprise a comprehensive selection of type 2 diabetes patients from the three remaining primary care groups in the Dutch province of Limburg (besides the one in Maastricht). Limburg is chosen as validation site because of its relatively poor population health compared to other provinces in the Netherlands, especially in terms of chronic disease prevalence [41].

Together, the three selected care groups cover an estimated population of approximately 65,000 to 70,000 individuals with type 2 diabetes. The groups' Diabetes Patient Registries will be used as source of retrospective data collection. Relevant parameters are identical to those used in research phase 1 , that is, all routinely registered measures of patient demographics, clinical status, and type and frequency of care provision. Included in the validation sample are all adult ( $\geq 18$ years) type 2 diabetes patients with at least 24 months of Diabetes Patient Registry data.

The generalisability of the draft profiles will be determined by assessing to which extent: (a) they cover the entire type 2 diabetes patient population in Limburg; (b) routine Diabetes Patient Registry data are sufficient to enable stratification into profiles and/or which additional data collection is necessary; and (c) identified trajectories and associations between patient characteristics and class membership are comparable. Based on the results of this research phase, the patient profiles will be adapted where necessary and finalised.

\section{Phase 3: Eliciting patient preferences}

The objective of the third PROFILe phase (9 months) is to provide insight into the patient preferences that exist per profile for specific configurations of diabetes care and support. For this purpose, a discrete choice experiment (DCE) will be conducted. Discrete choice experimentation is a validated, systematic approach for eliciting preferences, which has a strong theoretical basis in economic science and is increasingly used in international health systems to involve patients in health policymaking [42]. The technique is based on two assumptions: (a) that healthcare services can be described by their attributes; and (b) that an individual's valuation depends on the levels of these attributes. When determining an optimal 
way to provide a service, such as tailored type 2 diabetes management, a DCE can be used to show how people are willing to trade between attributes.

The DCE to be conducted in this study will consist of five steps (see Table 1). First, five focus group discussions are held with purposive samples of four to eight type 2 diabetes patients per session. In selecting participants, we will ensure that each draft profile is represented by at least one person during each focus group discussion. Goal of the sessions is to select healthcare service attributes for inclusion in the DCE. Nominal group technique (NTG) will be used to prioritise attributes based on patients' preferences [43], with preliminary identification of potentially relevant attributes based on two sources: (1) the Dutch Diabetes Federation's care standard for type 2 diabetes [27]; and (2) the Dutch version of the Patient Assessment of Care for Chronic Conditions (PACIC) survey [44,45]. Examples of relevant attributes may include the frequency of professional monitoring, setting of care, involved providers, different methods and tools for self-management support, use of electronic applications, and so on.

Table 1. Steps of the discrete choice experiment (DCE) process and methods and sample size per step

\begin{tabular}{lll}
\hline DCE step & Method & Sample size \\
\hline 1. Attribute identification and & Focus group discussions (N=5) using & $4-8$ respondents per \\
selection & the nurninal group lechnique & focus gruup \\
2. Assigning levels to the & Based on existing evidence (e.g. & - \\
attributes & guidelines, protocols) & - \\
3. Developing scenarios & Based on chosen attributes and & \\
& levels & 50 respondents per \\
4. Establishing preterences & Patient survey & profile \\
& & 50 respondents per \\
5. Data analysis & Regression analyses & profile
\end{tabular}

Second, levels are assigned to each of the identified attributes: the attribute 'frequency of monitoring', for instance, might have four levels (e.g. two, four, six or eight times per year). Third, scenarios are drawn up describing all possible service (or outcome) configurations given the attributes and levels chosen. For example, we could ask respondents to choose between these two scenarios: (a) to have four annual check-ups, with the nurse as central care giver; or (b) to have two annual check-ups, with the GP as central care giver. The number of scenarios to be developed will depend on the number of attributes and levels chosen.

Fourth, a patient survey is conducted to elicit patients' preferences for the developed scenarios. Although there is limited guidance on sample size calculations for DCE patient surveys, Pearmain et al. [46] suggest that sample sizes over 100 are a proficient basis for modeling preference data. Within this study, we aim for a larger sample size and will include 
at least 50 respondents per draft profile. Thus, if the analyses in phases 1 and 2 result in a final set of six profiles, 300 patients will be needed to participate in the survey. Fifth, regression techniques are used to analyse patients' survey responses in general as well as focusing specifically on the level of heterogeneity in results between profiles.

The discrete choice experiment will be designed, conducted and analysed following published guidelines $[42,47]$. Respondents for the focus group sessions and survey will be selected from the Diabetes Patient Registry of the regional care group in Maastricht. Based on the findings from this research phase, recommendations will be formulated on how to tailor type 2 diabetes management to the developed and validated patient profiles. Moreover, the survey itself constitutes a project deliverable that can be used internationally to elicit patients' preferences for chronic care management.

\section{Phase 4: Formulating recommendations}

Aim of the final PROFILe phase (6 months) is to integrate the results of the three previous phases and derive evidence-based recommendations on which (bio)medical and non(bio)medical patient characteristics should guide tailored chronic care management and how these can be combined into a robust and feasible profiling instrument for everyday practice. Explorations of the generalisability of findings to other conditions than type 2 diabetes will be an important focus in this phase. Findings are reported back to key stakeholders and disseminated to broader audiences in a variety of ways, including through scientific publications and conference contributions.

\section{Discussion}

This paper describes the design of the PROFILe project (2014-2017), a practice-based, mixedmethods research aiming to develop and validate a robust and feasible set of patient profiles for tailored chronic care management. It builds upon findings from the European collaborative DISMEVAL project, which was conducted between 2009 and 2012, and showed, amongst others, that current chronic disease management approaches in Europe tend to be highly standardised, insufficiently patient-centered, and result in differential - and often less than optimal - treatment effects across populations of chronically ill $[48,49]$.

There is increasing consensus that better chronic care management requires a more patientcentered, tailored approach [10], which combines the advantages of maintaining a certain level of standardisation with the benefits of increased individualisation and patient participation. In business terms, this might be referred to as mass customisation, which is a service delivery trend adopted by major international companies, such as Levi's, Starbucks and Burger King. Mass customisation combines the flexibility and personalisation of custom-made service delivery with the low unit costs of mass production. In practical terms, the strategy is not about promising customers anything, anytime, anywhere and anyhow, but rather about differentiating services within a predetermined 'envelope of variety' ascertained from the client perspective [50]. 
PROFILe aims to support exactly such differentiation in chronic care management: patient profiles are intended as an instrument to segment the chronically ill population into subgroups with similar healthcare needs for whom - based on insight into their preferences - a range of matching care and support options can be developed. In the long run, tailored management based on patient profiles offers considerable potential for achieving Berwick's Triple Aim [51] of health system performance: (1) to improve patients' experience of care, by stimulating explicit inclusion of their healthcare needs and preferences in treatment decisions; (2) to improve population health and quality of life, by aligning patients with appropriate levels of treatment and self-management support; and (3) to reduce the per capita cost of care, by minimizing the over-, under- and misuse of healthcare resources that results, amongst others, from overly standardised service provision and a lack of patient self-management. In this respect, the PROFILe project fits within a broader health policy trend seen in many European countries, in which governments are rearranging healthcare services based on population health needs, and non-complex healthcare tasks and responsibilities are increasingly transferred back to patients and their families, not in the least for cost containment purposes [52].

An important strength of the PROFILe project is its use of a mixed-methods approach, combining quantitative and qualitative data and study techniques within and across research phases. In particular when investigating complex, multicomponent interventions, a mixedmethods design is increasingly viewed as superior to more classic methodological approaches such as the randomised controlled trial [53]. Another strong point of the study is the involvement of patients in multiple study phases and the use of innovative methods, such as discrete choice experimentation, in order to produce robust and meaningful findings that emphasise the patient perspective. Although more research has been and is being conducted internationally concerning individualisation of type 2 diabetes management [54,55], PROFILe is unique in its use of variables of non-(bio)medical nature for tailoring purposes. Given the strong impact that patients' personal circumstances have on their ability to self-manage and their level of treatment adherence [56], broadening the scope of individualisation beyond (bio)medical factors to also include demographic, socioeconomic and psychological aspects is a key forte of the PROFILe project.

There are also some limitations. Most notably, the disease-specific nature of the profiles to be developed - intended for patients with a primary diagnosis of type 2 diabetes - limits the generalisability of results and hampers development of a generic instrument for tailored chronic care management. However, there are two important arguments in favour of focusing on diabetes. First, because it is a priority health problem in the Netherlands, focusing on diabetes enables us to capitalise on the full potential that so-called 'big data' in electronic diabetes registries offer for personalising care [17]. Second, type 2 diabetes is widely considered to be a good model for chronic disease in general, in particular given its strong association with comorbidities [9,16], and is used as such in many countries' health policymaking efforts in chronic care, including in the Netherlands [18,57]. Another limitation concerns the setting of the study in primary care, which leads to exclusion of the 10 to $15 \%$ 
most complex cases of type 2 diabetes - i.e. patients who are treated in secondary care in the Netherlands [21] - from our profiling efforts. Although the Dutch NTA for type 2 diabetes [22] seeks to ensure care continuity and safety during transitions between primary and secondary care, patients with complex type 2 diabetes might still benefit from a more tailored approach based on patient profiles. Hence, it is important to broaden the scope of future research efforts beyond primary care to include all patients with type 2 diabetes. A final limitation of the study is the lack of prospective evaluation of the effects of tailoring diabetes management based on patient profiles, for example in a randomised controlled trial, which is beyond the scope of this development and validation project. Following PROFILe, further research is necessary to gain detailed insight into the impact of tailored diabetes management on a range of measures related to the Triple Aim, including patient experience, population health and costs. 


\section{References}

1. Economist Intelligence Unit: The future of healthcare in Europe. [cited 2015 Mar 18]. Available from: http://www.janssen.pt/sites/default/files/The-Future-Of-Healthcare-InEurope.pdf (2011).

2. European Commission: DG Health \& Consumers. European Core Health Indicators (ECHI). Self-reported chronic morbidity. Proportion of people aged 65+ reporting any longstanding chronic illness or longstanding health problem, 2013. [cited 2015 Mar 18]. Available from: http://ec.europa.eu/health/indicators/echi/list/ (2015).

3. International Diabetes Federation: IDF Diabetes Atlas, $6^{\text {th }}$ edn. Brussels: International Diabetes Federation; 2013.

4. Nolte E, Knai C, Saltman RB (eds): Assessing chronic disease management in European Health Systems: concepts and approaches. Brussels: European Observatory on Health Systems and Policies; 2015.

5. Drewes HW, Steuten LMG, Lemmens LC, Baan CA, Boshuizen H, Elissen AMJ, et al: The effectiveness of chronic care management for heart failure: a systematic review and metaregression analysis to explain the heterogeneity in outcomes. Health Services Research 2012;47(5):1926-59.

6. Meeuwissen JAC, Lemmens LC, Drewes HW, Lemmens KMM, Steuten LMG, Elissen AMJ, et al: Meta-analysis and meta-regression analyses explaining heterogeneity in outcomes of chronic care management for depression. International Journal of Person Centered Medicine 2012;2(4):716-58.

7. Elissen AMJ, Steuten LMG, Lemmens LC, Drewes HW, Lemmens KMM, Meeuwissen JAC, et al: Meta-analysis of the effectiveness of chronic care management for diabetes: investigating heterogeneity in outcomes. Journal of Evaluation in Clinical Practice 2013;19(5):753-62.

8. Lemmens KMM, Lemmens LC, Boom JHC, Drewes HW, Meeuwissen JAC, Steuten LMG: Chronic care management for patients with COPD: A critical review of available evidence. Journal of Evaluation in Clinical Practice 2013;19(5):734-52.

9. Van Bussel B, Pijpers E, Ferreira I, Castermans P, Nieuwenhuijzen Kruseman A: Polymorbidity in diabetes in older people: consequences for care and vocational training. Postgraduate Medical Journal 2007;83:763-67.

10. Inzucchi SE, Bergenstal RM, Buse JB, Diamant M, Ferrannini E, Nauck M, et al: Management of hyperglycemia in type 2 diabetes: a patient-centered approach. Diabetes Care 2012;35:1364-79.

11. Elissen A, Nolte E, Knai C, Brunn M, Chevreul K, Conklin A, et al: Is Europe putting theory into practice? A qualitative study of the level of self-management support in chronic care management approaches. BMC Health Services Research 2013;13:117.

12. European Union Health Policy Forum: Answer to DG SANCO consultation on chronic diseases. [cited 2015 Mar 19]. Available from:

http://ec.europa.eu/health/interest_groups/docs/euhpf_answer_consultation_jan2012_ en.pdf (2012).

13. Riddle MC, Karl DM: Individualizing targets and tactics for high-risk patients with type 2 diabetes. Practical lessons from ACCORD and other cardiovascular trials. Diabetes Care 2012;35:2100-07.

14. Rothe U, Müller G, Schwarz PEH, Seifert M, Kunath H, Koch R, et al: Evaluation of a diabetes management system based on practice guidelines, integrated care, and 
continuous quality management in a Federal State of Germany. A population-based approach to health care research. Diabetes Care 2008;31(5):863-868.

15. Elissen AMJ, Duimel-Peeters IGP, Spreeuwenberg C, Spreeuwenberg M, Vrijhoef HJM: Toward tailored disease management for type 2 diabetes. American Journal of Managed Care 2012;18(10):619-30.

16. Schram MT, Sep SJ, Van der Kallen CJ, Dagnelie PC, Koster A, Schaper N, et al: The Maastricht Study: an extensive phenotyping study on determinants of type 2 diabetes, its complications and its comorbidities. European Journal of Epidemiology 2014;29:439-51.

17. Ministry of Health, Welfare and Sports: Opting for a healthy life. Public health policy in the Netherlands, 2007-2010. The Hague: Ministry of Health, Welfare and Sports; 2006.

18. Wensing M, Koetsenruijter J, Rogers A, Portillo MC, Van Lieshout J: Emerging trends in diabetes care practice and policy in the Netherlands: a key informants study. BMC Research Notes 2014;7:693.

19. Struijs JN, De Jong-Van Til JT, Lemmens LC, Drewes HW, De Bruin SR, Baan CA: Three years of bundled payment for diabetes care in the Netherlands. Bilthoven: National Institute for Public Health and the Environment (RIVM); 2012.

20. Cebolla Garrofé B, Björnberg A, Yung Phang A: Euro Diabetes Index 2014. Täby: Health Consumer Powerhouse Ltd; 2014.

21. Campmans-Kuijpers MJ, Baan CA, Lemmens LC, Rutten GE. Diabetes quality management in Dutch care groups and outpatient clinics: a cross-sectional study. BMC Research Notes 2014;7:497.

22. Sluiter AC, Van Wijland JJ, Arntzenius AB, Bots AFE, Dijkhorst-Oei LT, Van der Does FEE, Palmen JVH, van Loon BJ P, Schaper NC, Van Balen JAM. Landelijke transmurale afspraak diabetes mellitus type 2[Dutch transmural agreement on Diabetes mellitus type 2]. Huisarts Wet 2012;55:1-12. [In Dutch].

23. Ham C. The ten characteristics of the high-performing chronic care system. Health Economics, Policy and Law 2010, 5:71-90.

24. McClellan M, McKethan AN, Lewis JL, Roski J, Fisher ES: A national strategy to put accountable care into practice. Health Aff (Millwood) 2010;29(5):982-90.

25. Naylor C, Curry N, Holder H, Ross S, Marshall L, Tait E: Clinical commissioning groups. Supporting improvement in general practice? London: The King's Fund and Nuffield Trust; 2013.

26. De Jong-Van Til JT, Lemmens LC, Baan CA, Struijs JN: The organisation of care groups in 2011. Current state and recent developments. Bilthoven: National Institute for Public Health and the Environment (RIVM); 2012.

27. Netherlands Diabetes Federation: NDF Care Standard. Transparency and quality of diabetes care for people with type 2 diabetes. Amersfoort: Netherlands Diabetes Federation; 2007.

28. Liu C, Sales AE, Sharp ND, Fishman P, Sloan KL, Todd-Stenberg J, et al: Case-mix adjusting performance measures in a veteran population: pharmacy- and diagnosis-based approaches. Health Services Research 2003;38(5):1319-38.

29. Huntley AL, Johnson R, Purdy S, Valderas JM, Salisbury C: Measures of multimorbidity and morbidity burden for use in primary care and community settings: a systematic review and guide. The Annals of Family Medicine 2012;10(2):134-41.

30. Care Continuum Alliance: Implementation and Evaluation: A Population Health Guide for Primary Care Models. Washington, DC: Care Continuum Alliance; 2012. 
31. Wagner EH, Austin BT, Davis C, Hindmarsh M, Schaefer J, Bonomi A: Improving chronic illness care: translating evidence into action. Health Affairs (Millwood) 2001;20(6):64-78.

32. Nagin DS, Odgers CL: Group-based trajectory modeling in clinical research. Annual Review of Clinical Psychology 2010;6:109-38.

33. Muthén B, Muthén LK: Integrating person-centered and variable-centered analyses: growth mixture modeling with latent trajectory classes. Alcohol: Clinical and Experimental Research 2000;24(6):882-91.

34. Drewes HW, Heijink R, Struijs JN, Baan CA: National monitor population management. Part 1: Description pioneer sites. Bilthoven: National Institute for Public Health and the Environment; 2014.

35. Köhler S, Hamel R, Sistermans N, Koene T, Pijnenburg Y, Van der Flier WM, et al: Progression to dementia in memory clinic patients without dementia. A latent profile analysis. Neurology 2013;81:1342-49.

36. Masyn KE: Latent class analysis and finite mixture modeling. In: Little TD (ed). The Oxford Handbook of Quantitative Methods in Psychology. Volume 2: Statistical Analysis. New York, NY: Oxford University Press; 2013:551-611.

37. Fitch K, Bernstein S, Aguilar MD, Burnand B, LaCalle JR, Lazaro P, et al: The RAND/UCLA Appropriateness Method User's Manual. Santa Monica, CA: RAND; 2001.

38. Polonsky WH, Anderson BA, Lohrer PA, Welch GW, Jacobson AM: Assessment of diabetes-related emotional distress. Diabetes Care 1995;18:754-60.

39. Cocozza Martins D: Experiences of homeless people in the health care delivery system: a descriptive phenomenological study. Public Health Nursing 2008;25(5):420-30.

40. Hycner RH: Some guidelines for the phenomenological analysis of interview data. Human Studies 1985;8:279-303.

41. Department of Public Health Status and Forecasting: Dutch National Atlas of Public Health. Bilthoven: National Institute for Public Health and the Environment; 2014.

42. Lancsar $\mathrm{E}$, Louviere J: Conducting discrete choice experiments to inform healthcare decision making: a user's guide. Pharmacoeconomics 2008;26(8):661-77.

43. Hiligsmann M, Van Durme C, Geusens P, Dellaert BGC, Dirksen CD, Van der Weijden T, et al: Nominal group technique to select attributes for discrete choice experiments: an example for drug treatment choice in osteoporosis. Journal of Patient Preference and Adherence 2013;7:133-39.

44. Glasgow RE, Wagner EH, Schaefer J, Mahoney LD, Reid RJ, Greene SM: Development and validation of the patient assessment of Chronic Illness Care (PACIC). Medical Care 2005;43(5):436-44.

45. Vrijhoef HJM, Berbee R, Wagner EH, Steuten LMG: Quality of integrated chronic care measured by patient survey: identification, selection and application of most appropriate instruments. Health Expectations 2009;12:417-29.

46. Pearmain D, Swanson J, Kroes E, Bradley M: Stated preference techniques: a guide to practice. The Hague: Steer Davis Gleave and Hague Consulting Group; 1991.

47. Bridges JF, Hauber AB, Marshall D, Lloyd A, Prosser LA, Regier DA, et al: Conjoint analysis applications in health - a checklist: a report of the ISPOR Good Research Practices for Conjoint Analysis Task Force. Value Health 2011;14(4):403-13.

48. Nolte E, Hinrichs S (eds): DISMEVAL. Developing and validating disease management evaluation methods for European healthcare systems. Cambridge, UK: RAND Europe; 2012. 
49. Elissen AMJ, Duimel-Peeters IGP, Spreeuwenberg C, Vrijhoef HJM: Evaluation of disease management in the Netherlands. In: Nolte E, Hinrichs S (eds): DISMEVAL. Developing and validating disease management evaluation methods for European healthcare systems. Cambridge, UK: RAND Europe; 2012, pp. 99-112.

50. Hart WL: Mass customization: conceptual underpinnings, opportunities and limits. International Journal of Service Industry Management1995;6(2):36-45.

51. Berwick DM, Nolan TW, Whittington J: The triple aim: care, health and cost. Health Affairs (Millwood) 2008;27(3):759-69.

52. Elissen AMJ, Struijs JN, Baan CA, Ruwaard D: Estimating community health needs against a Triple Aim background: what can we learn from current predictive risk models? Health Policy 2014, http://dx.doi.org/10.1016/j.healthpol.2014.12.007.

53. Berwick DM: The science of improvement. Journal of the American Medical Association 2008;299(10):1182-4.

54. Ceriello A, Gallo M, Armentano V, Perriello G, Gentile S, De Micheli A, et al: Personalizing treatment in type 2 diabetes: a self-monitoring of blood glucose inclusive innovative approach. Diabetes Technology and Therapeutics 2012;14(4):373-8.

55. Walraven I, Mast MR, Hoekstra T, Janssen APD, Van der Heijden AA, Rauh SP, et al: Distinct HbA1c trajectories in a type 2 diabetes cohort. Acta Diabetologica 2014, DOI 10.1007/s00592-014-0633.

56. World Health Organization: Adherence to long-term therapies. Evidence for action. Geneva: World Health Organization; 2003.

57. Nolte E, Knai C, Hofmarcher M, Conklin A, Erler A, Elissen A, et al: Overcoming fragmentation in health care: chronic care in Austria, Germany and the Netherlands. Health Economics Policy and Law 2010;7:125-46. 

CHAPTER 3

\section{Relevant patient characteristics for guiding tailored integrated diabetes primary care: a systematic review}

\section{Published as}

D.F.L. Hertroijs, A.M.J. Elissen, M.C.G.J. Brouwers, N.C. Schaper \& D. Ruwaard. Relevant patient characteristics for guiding tailored integrated diabetes primary care: a systematic review. Primary Health Care Research and Development. 2018;19(5):1-24. 


\section{Abstract}

Aim: To identify which patient-related effect modifiers influence the outcomes of integrated care programs for type 2 diabetes in primary care.

Background: Integrated care is a widespread management strategy for the treatment of type 2 diabetes. However, most integrated care programs are not tailored to patients' needs, preferences and abilities. There is increasing consensus that such a patient-centered approach could improve the management of type 2 diabetes. Thus far, it remains unclear which patientrelated effect modifiers should guide such an approach.

Methods: PubMed, CINAHL and EMBASE were searched for empirical studies published after 1998. A systematic literature review was conducted according to the PRISMA guidelines.

Findings: In total, 27 of 1,015 studies were included. Twenty-one studies measured the effects of integrated diabetes care programs on HbA1c and 3 on LDL-cholesterol, systolic blood pressure and health care utilization. Forty-nine patient characteristics were assessed as potential effect modifiers with $\mathrm{HbA} 1 \mathrm{c}$ as an outcome, of which 46 were person or healthrelated and only 3 were context-related. Younger age, insulin therapy and longer disease duration were associated with higher $\mathrm{HbA} 1 \mathrm{c}$ levels in cross-sectional and longitudinal studies. Higher baseline $\mathrm{HbA1c}$ was associated with higher $\mathrm{HbA1c}$ at follow-up in longitudinal studies. Information on context- and person-related characteristics was limited, but is necessary to help identify the care needs of individual patients and implement an effective integrated type 2 diabetes tailored care program. 


\section{Introduction}

Diabetes is one of the most prevalent chronic conditions worldwide and a public health priority in many countries [1, 2]. In Europe, an estimated 9.8 million people suffer from diabetes; type 2 diabetes is responsible for $90 \%$ of cases. People with type 2 diabetes are at high risk for developing complications, such as cardiovascular disease and kidney failure, which in turn lead to increased healthcare costs[1, 2]. To prevent diabetes-related comorbidities and complications, and lower medical care expenditure for patients with type 2 diabetes, it is important to implement effective and efficient management strategies. An example of such a strategy is the implementation of integrated care. It aims to improve patient care and experience through improved coordination [3].

The implementation of integrated care programs is widespread in North America, Europe, and other parts of the world $[3,4]$. However, most integrated care programs are not tailored to patients' needs and preferences, but rather highly standardized according to evidencebased guidelines for specific diseases, such as diabetes. Findings from recent studies suggest that not all patients benefit equally from such a standardized approach [5-7]. These studies report that patients with poorly controlled diabetes benefit mostly from intensive, providerdriven disease management, whereas patients with adequate glucose levels might maintain these levels independent of the type of care they receive.

In 2012, the European Association for the Study of Diabetes (EASD) and the American Diabetes Association (ADA) recommended a more patient-centered approach for the management of type 2 diabetes [8]. In a patient-centered approach, care is tailored according to individual patient needs and preferences [8-11]. It draws on the concept of 'mass customization', where goods and services are delivered with enough variety and customization that nearly everyone finds exactly what they want [12]. Dividing the population based on healthcare needs creates groups that are more homogenous than the population as a whole. Hence, care offered to these groups will be more tailored to the patients' needs, while acknowledging that a certain amount of heterogeneity within the subgroups will remain.

There is increasing consensus that a patient-centered approach could improve the management of type 2 diabetes [8]. However, to date, it is unclear what the best method is for establishing patient-centered care [13]. Since intensive, provider-driven disease management is not beneficial to every type 2 diabetes patient, several studies have pointed towards patient characteristics - for example, number of co-morbidities, disease duration or attitude - as possible effect modifiers of treatment [8,14-16]. These effect modifiers could be used to identify patients with different care needs and preferences, and subsequently serve as input to tailor treatment $[17,18]$. However, it is unclear which effect modifiers should guide a more patient-centered approach. Therefore, the aim of this systematic review was to identify which patient effect modifiers influence the outcomes of integrated care programs for type 2 diabetes in primary care. These effect modifiers can help to segment the chronicallyill population into subgroups with similar healthcare needs for whom, based on insight into their needs and preferences, a range of matching care and support options can be developed. 
This review is the first part of the research project entitled "PROFiling patients' healthcare needs to support Integrated, person centered models for Long-term disease management' (PROFIle)" [19]. The aim of this 4-year Dutch project is explicitly not to develop another disease-specific approach, but we use type 2 diabetes as starting point to develop, validate and test so-called 'patient profiles' as an instrument to support more patient-centered chronic care management in practice.

\section{Methods}

\section{Data sources and searches}

A systematic literature search according to PRISMA guidelines [20] was performed on PubMed, CINAHL and EMBASE databases in January 2015. Included were English- or Dutchlanguage randomized controlled trials (RCT), prospective and retrospective cohort- and crosssectional studies which: [1] focused on integrated care (defined below) ; [2] included adult patients ( $\geq 18$ years) with type 2 diabetes; [3] were set in primary care; [4] measured effects on 1 or more measures of diabetes management (HbA1c, LDL-cholesterol (LDL-c) and systolic blood pressure (SBP)) and/or health care utilization as outcome variables; and [5] included sub analyses with patient characteristics as independent variables. In line with previous research, integrated care was defined as interventions combining 2 or more components of the wellknown Chronic Care Model (CCM) [21]. The CCM stresses the need for a more proactive healthcare system by focusing on 4 components: self-management support (e.g. patient education), decision support (e.g. evidence-based guidelines), delivery system design (e.g. care process) and clinical information systems (e.g. electronic registries) [22, 23]. Since the CCM was developed in 1998, only studies published in or after 1998 were included [24]. The search strategy included targeted terms related to diabetes, integrated care, CCM components, care outcomes and subgroup analyses based on patient characteristics. The complete search terms and search string can be found in Table 1. The snowball method was used to search for other relevant studies.

\section{Study selection}

Potentially relevant studies were retrieved from the electronic databases based on the inclusion criteria in 3 screening rounds. First, titles and abstracts were screened. The first 50 titles and abstracts were screened independently by 2 reviewers ( $\mathrm{DH}$ and $\mathrm{AE}$ ). More than $90 \%$ agreement was reached. Therefore, the remainder of the titles and abstracts were screened by 1 reviewer $(\mathrm{DH})$. Second, the first 20 full texts were screened independently by 2 reviewers ( $\mathrm{DH}$ and $\mathrm{AE}$ ). Again, more than $90 \%$ agreement was reached and therefore, each reviewer independently screened half of the full texts. Third, the reference lists of the included studies were screened to obtain additional studies. Steps 1 and 2 of the study selection process were then repeated. 


\section{Data extraction and quality assessment}

Descriptive data on studies were extracted by 1 reviewer $(\mathrm{DH})$ between August and October 2015. Studies were coded for author names, year of publication, country, study design, length of follow up, population size, age, percentage of males and CCM components. In case of uncertainties, a group discussion was held with two other authors ( $A E$ and $M B$ ).

The Effective Public Health Practice Project Quality Assessment Tool (EPHPP) was used to assess the quality of the included studies [25]. This tool was chosen because it allows the assessment of different study designs. The studies were rated based on 6 domains: [1] selection bias; [2] study design; [3] confounders; [4] blinding; [5] data collection and [6] withdrawals and dropouts. Each domain was rated as 'strong', 'moderate' or 'weak'. A global rating was given based on the number of weak components.

Two reviewers ( $\mathrm{DH}$ and $\mathrm{MB}$ ) independently performed the quality assessment for each study. Disagreements were resolved via discussion conform EPHPP guidelines.

\section{Data synthesis and analysis}

The included studies were categorized according to: [1] the reported outcome(s) of interest (HbA1c, LDL-c, SBP and/or health care utilization); and [2] the type of patient characteristic(s) investigated in subgroup analyses. Characteristics were classified as person-related (predisposing)-, context-related (enabling)-, or health-related (illness level) characteristics according to Andersen and Newman's Behavioral Model of Health Service Use [26]. The model provides a theoretical framework for viewing health services utilization, taking into account both societal and individual characteristics. The model was chosen, because the individual characteristics can inform tailored care by, for example, helping determine the best intensity of care for the individual patient. Relationships between outcomes and characteristics were depicted as ' + ' for significant positive relationships, as '-'for significant negative relationships and as 'o' for non-significant relationships.

\section{Results}

\section{Search results}

In total, 1,374 studies were identified through electronic databases and by checking the references of the included studies. Figure 1 shows the flow diagram of the study selection. Most studies were excluded because none relevant outcomes were reported $(n=453)$, and/or type of care was not integrated $(n=257)$. After the title, abstract and full text screening, 27 studies were included [5, 27-52]. 
Table 1. Search terms and search string

\begin{tabular}{|c|c|c|}
\hline$\#$ & Category & Search terms \\
\hline 1 & Diabetes & $\begin{array}{l}\text { Diabetes OR diabetes mellitus OR diabetic patient OR type } 2 \text { diabetes OR type } 2 \\
\text { diabetes mellitus OR T2DM OR NIDDM }\end{array}$ \\
\hline 2 & Integrated care & $\begin{array}{l}\text { Integrated care OR disease management OR disease state management OR } \\
\text { comprehensive healthcare OR comprehensive health care OR shared care OR } \\
\text { coordinated care OR case management OR chronic care model OR primary care OR } \\
\text { primary health care OR outpatient clinic OR outpatient services OR primary health } \\
\text { care OR primary healthcare OR primary health clinics OR general practice OR } \\
\text { family practice OR community care }\end{array}$ \\
\hline 3 & $\begin{array}{l}\mathrm{CCM} \text { - self-management } \\
\text { support }\end{array}$ & $\begin{array}{l}\text { Self-management OR self-management support OR self-care OR patient- } \\
\text { centeredness OR patient-centered care OR behavioral support OR motivational } \\
\text { support OR self-management education OR patient education }\end{array}$ \\
\hline 4 & $\begin{array}{l}\mathrm{CCM}-\text { delivery system } \\
\text { design }\end{array}$ & $\begin{array}{l}\text { Delivery system design OR care pathway OR critical pathway OR individualized } \\
\text { care OR clinical case management OR medicines management OR medication } \\
\text { management OR comorbidities management OR health literacy OR cultural } \\
\text { sensitivity OR practice nurse OR care team OR health care team Or healthcare } \\
\text { team OR patient care team OR personalized care OR personalized management OR } \\
\text { individualized management OR multidisciplinary care team OR tailored care OR } \\
\text { tailored support OR multidisciplinary care }\end{array}$ \\
\hline 5 & CCM - decision support & $\begin{array}{l}\text { Decision support, clinical reminders, clinician reminders, patient reminders, } \\
\text { provider education, reminder systems, individualized care plans, individual care } \\
\text { plans }\end{array}$ \\
\hline 6 & $\begin{array}{l}\mathrm{CCM}-\text { clinical } \\
\text { information system }\end{array}$ & $\begin{array}{l}\text { Clinical information system, clinical information systems, clinical registry, health } \\
\text { information system, health information systems, health information technology, } \\
\text { electronic registry, clinical reminders, clinician reminders, patients reminders, } \\
\text { provider feedback, performance monitoring, ICT device, patient portal, patient } \\
\text { registry, diabetes registry, telemonitoring, telehealth, teleassistance, } \\
\text { telehomecare, videoconferencing, mobile phone }\end{array}$ \\
\hline 7 & Outcome measures & $\begin{array}{l}\text { Glycemic control, glycaemic control, diabetic control, diabetes control, diabetes } \\
\text { status, Charlson Comborbidity Index, resource use, health care use, health care } \\
\text { utitlity, service use, resource utility, service utility }\end{array}$ \\
\hline 8 & Sub group analysis & $\begin{array}{l}\text { Factor, predictor, predictive factor, determinant, patient characteristic, patient } \\
\text { characteristics, patient feature, patient features, patient dynamics, subgroup, } \\
\text { subgroups, segment, strata, classes }\end{array}$ \\
\hline 9 & Complete search string & $\begin{array}{l}\# 1 \text { AND (\#2 OR (\#3 AND \#4) OR (\#3 AND \#5) OR (\#3 AND \#6) OR (\#4 AND \#5) OR } \\
\text { (\#4 AND \#6) OR (\#5 AND \#6)) AND \#7 AND \#8 }\end{array}$ \\
\hline
\end{tabular}

CCM: Chronic Care Model

\section{Quality assessment}

The methodological quality of the included studies can be found in supplementary Table S1. The domains with the most 'weak' ratings were confounders ( $n=10)$, blinding $(n=9)$, and selection bias $(n=9)$. Almost all studies $(n=25)$ scored high on the domain data collection. The overall study quality was strong for 4 studies, moderate for 11 studies and low for 12 studies. Most studies with low quality had a cross-sectional study design and did not report on or adjust for possible confounders. 


\section{Study- and sample characteristics}

Of the included studies, 9 (33.3\%) were retrospective cohort studies, 7 (25.9\%) cross-sectional studies, 7 (25.9\%) (randomized) controlled studies, and 4 (14.8\%) prospective cohort studies. Table 2 shows that the median follow-up duration for retrospective cohort-, prospective cohort-, and randomized controlled studies $(n=20)$ was 15 months (range 6 to 112). The median sample size consisted of 376 individuals (range 80 to 105,056) with an average age of 60.0 years (range 50.5 to 70.9); the percentage of male subjects ranged from 31.3 to 68.0.

Table 2 also provides an overview of the CCM components implemented in each study. Eight studies included all 4 components of the CCM model. The CCM component delivery system design was included in most studies $(n=25)$, followed by self-management support $(n=20)$. Of the studies that included the components delivery system design, most introduced a care team ( $n=13)$, followed by regular follow-up visits $(n=8)$. Self-management support was mostly realized through individual educational sessions on diabetes, health and nutrition $(n=14)$.

\section{Outcome variables}

\section{HbA1c}

Eighteen uncontrolled studies - including prospective-, retrospective-, and cross-sectional cohort designs - measured the effects of integrated care programs on $\mathrm{HbA1c}$. In addition, 7 studies compared the influence of patient characteristics on the effectiveness of integrated diabetes care programs between intervention- and control groups. In total, 51 patient characteristics were assessed as potential effect modifiers of the relationship between integrated care and HbA1c. The results will be presented according to study design. For RCTs all characteristics assessed by this study design will be discussed. Due to the high number of characteristics assessed by the cross-sectional-, retrospective-, and prospective cohort studies, only characteristics assessed by 3 or more studies will be presented.

(Randomized) controlled trials. Five RCTs and 2 CTs compared the influence of patient characteristics on the effectiveness of integrated diabetes care programs on the HbA1c level between intervention- and control groups (Table 3). In total 8 patient characteristics were evaluated as potential modifiers.

Sex and age were the person-related characteristics evaluated as potential effect modifiers. Three studies assessed sex as a potential modifier, of which two found that women in the intervention group had statistically significant lower $\mathrm{HbA} 1 \mathrm{c}$ values at follow-up compared to women in the control group $[40,51]$. For men, no statistically significant difference was found. The third study did not find a statistically significant relationship [39]. Age was assessed by 2 studies. Both found that younger patients receiving integrated diabetes care had statistically significantly lower HbA1c values at follow-up compared to patients receiving usual care [39, 43]. 


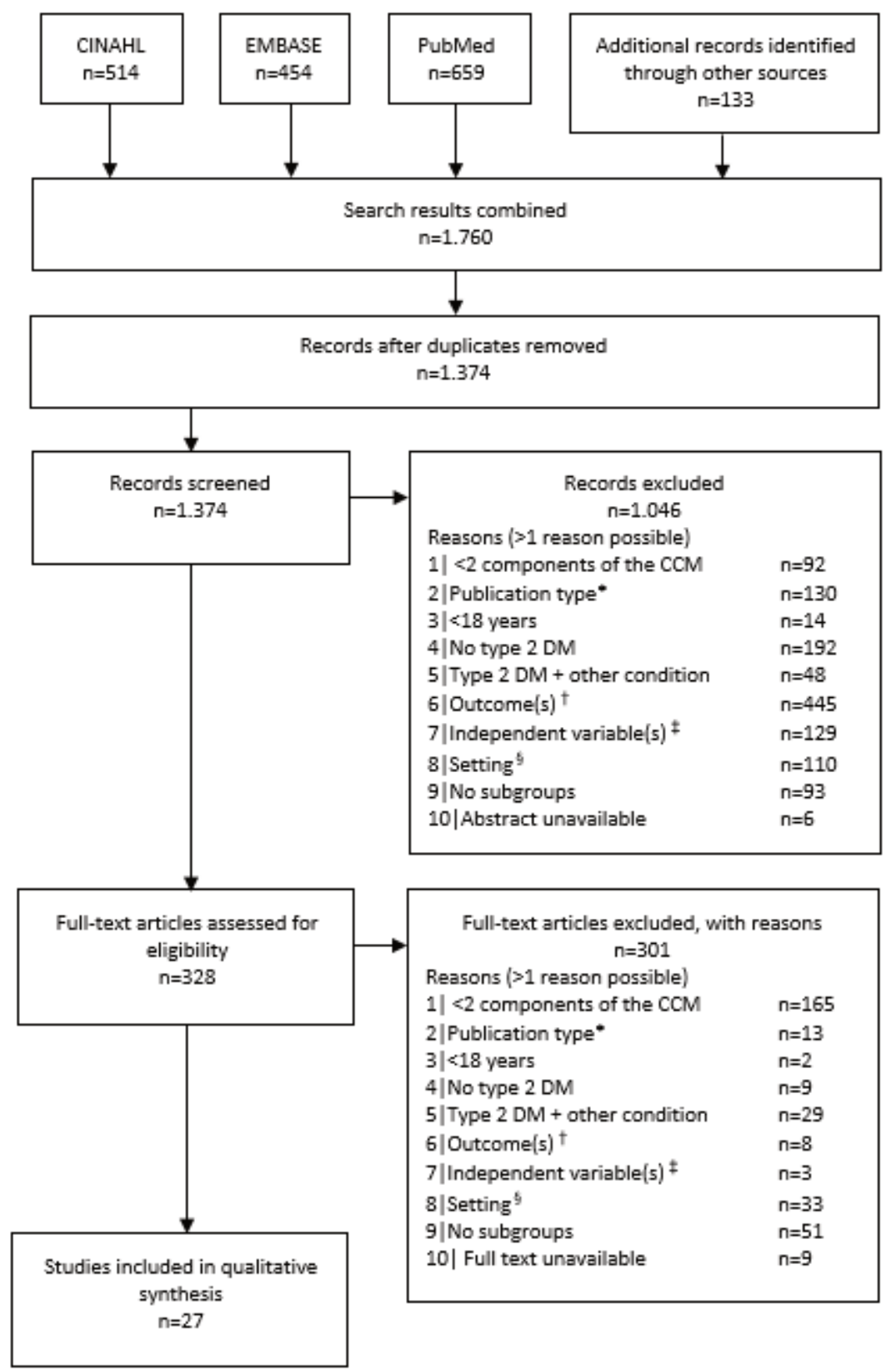

Figure 1. Flow diagram of the study selection

*qualitative-, or mixed-method studies; ${ }^{+}$any outcome other than HbA1c, LDL-cholesterol, blood pressure or health care utilization; ${ }^{\prime}$ Independent variable is not a person-, context-, or health-related patient characteristic (e.g. healthcare provider characteristics); ${ }^{\S}$ setting is not a primary care setting (e.g. hospital). 


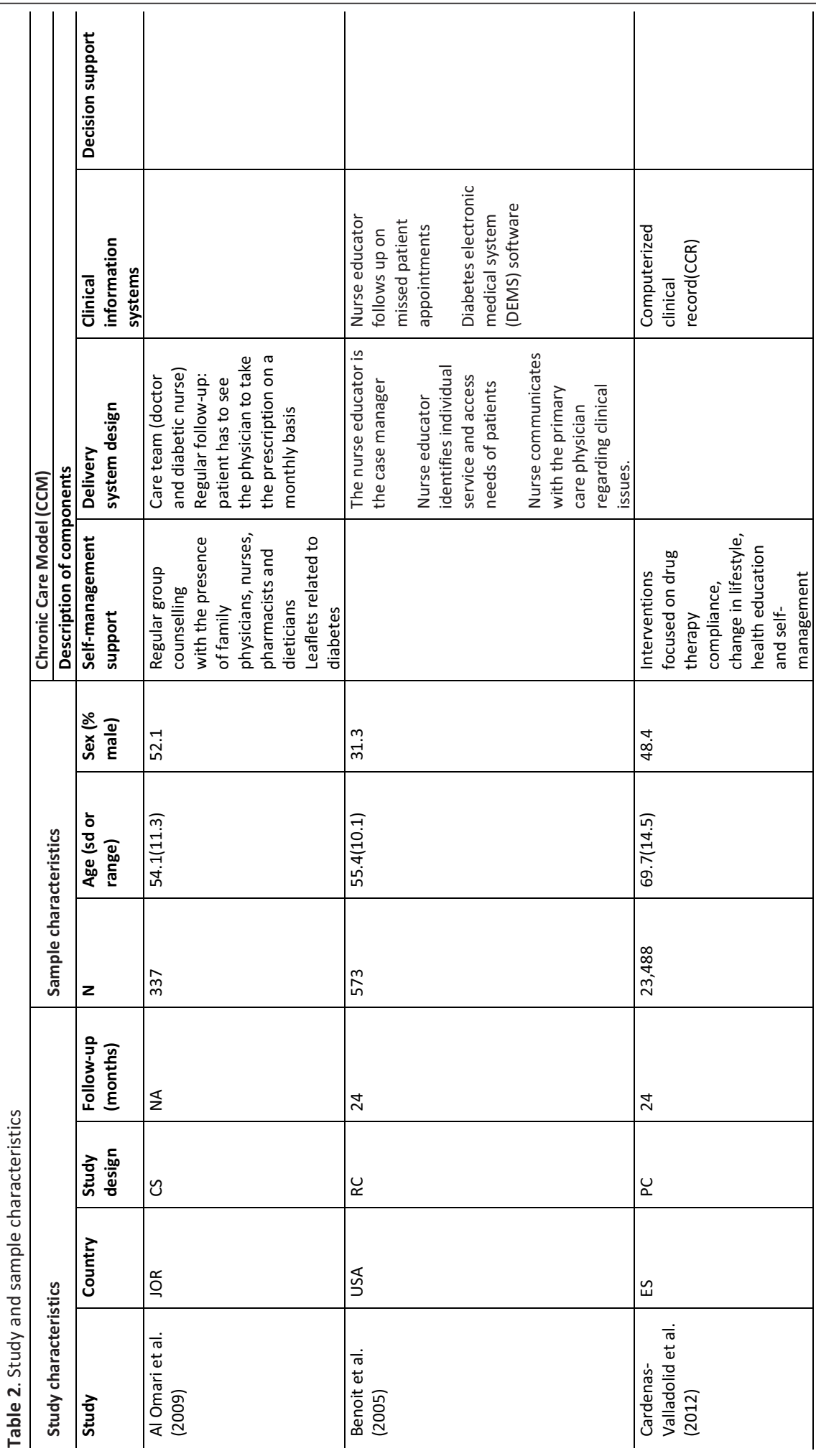




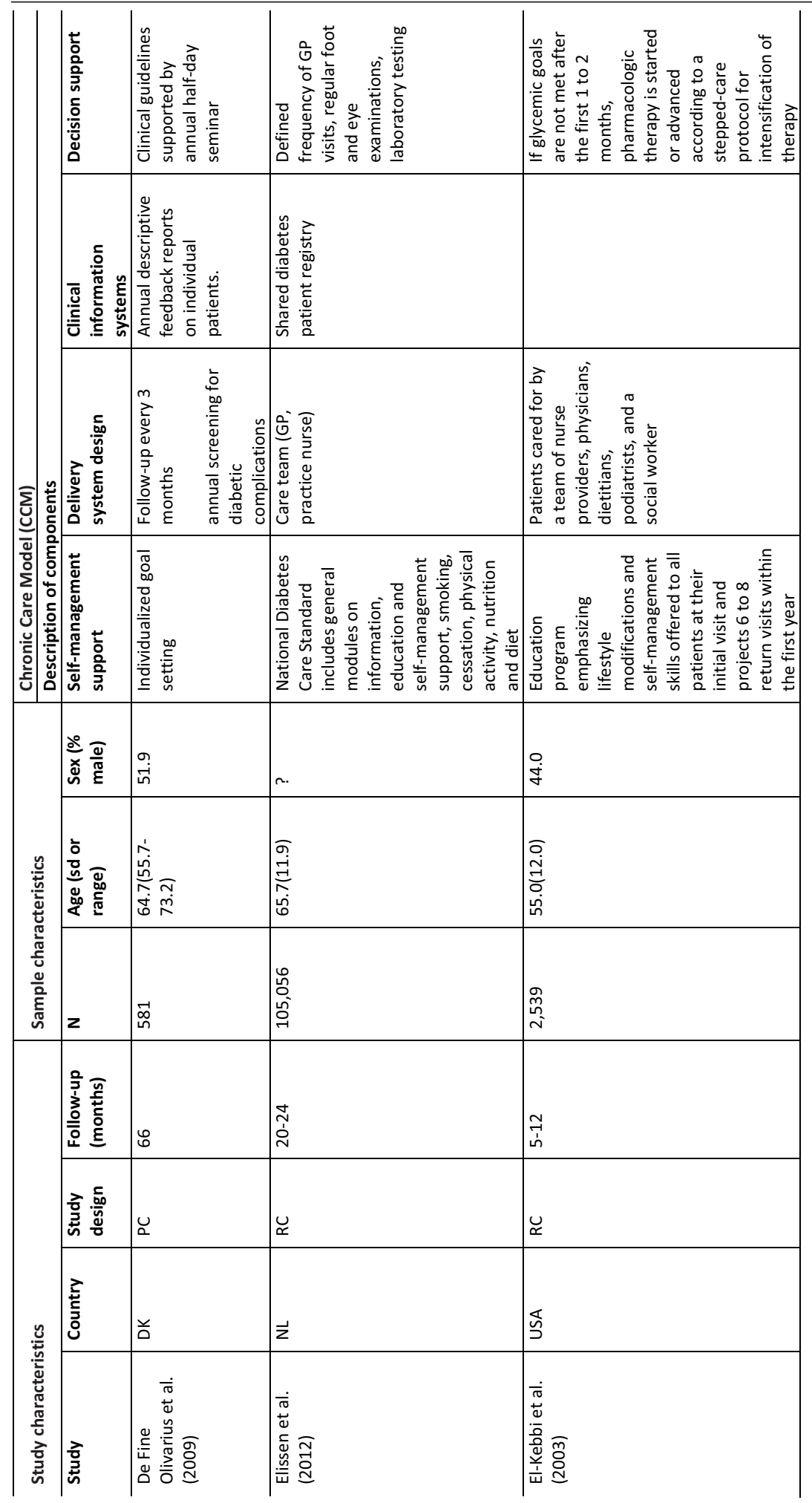


Relevant patient characteristics for guiding diabetes care: a systematic review

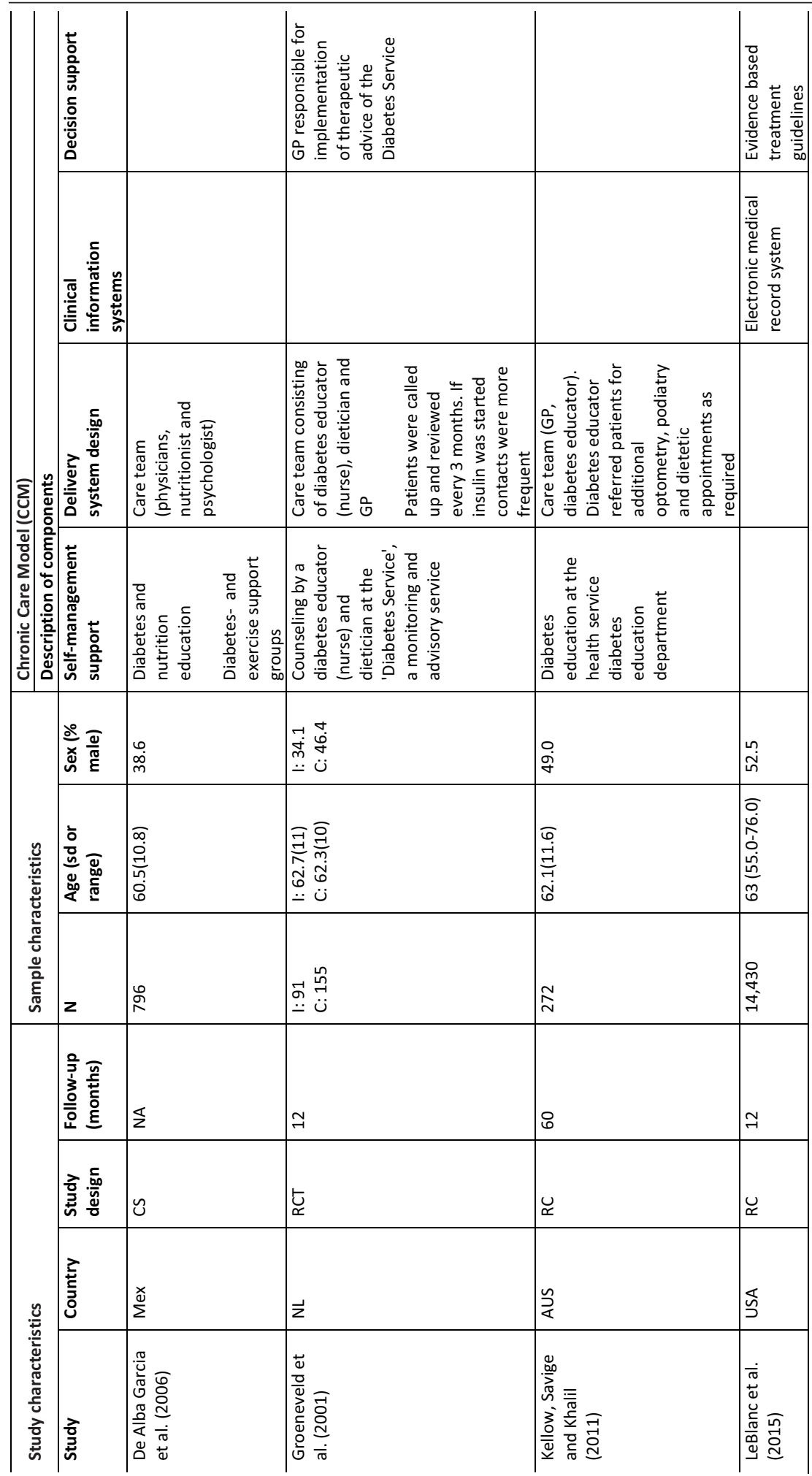




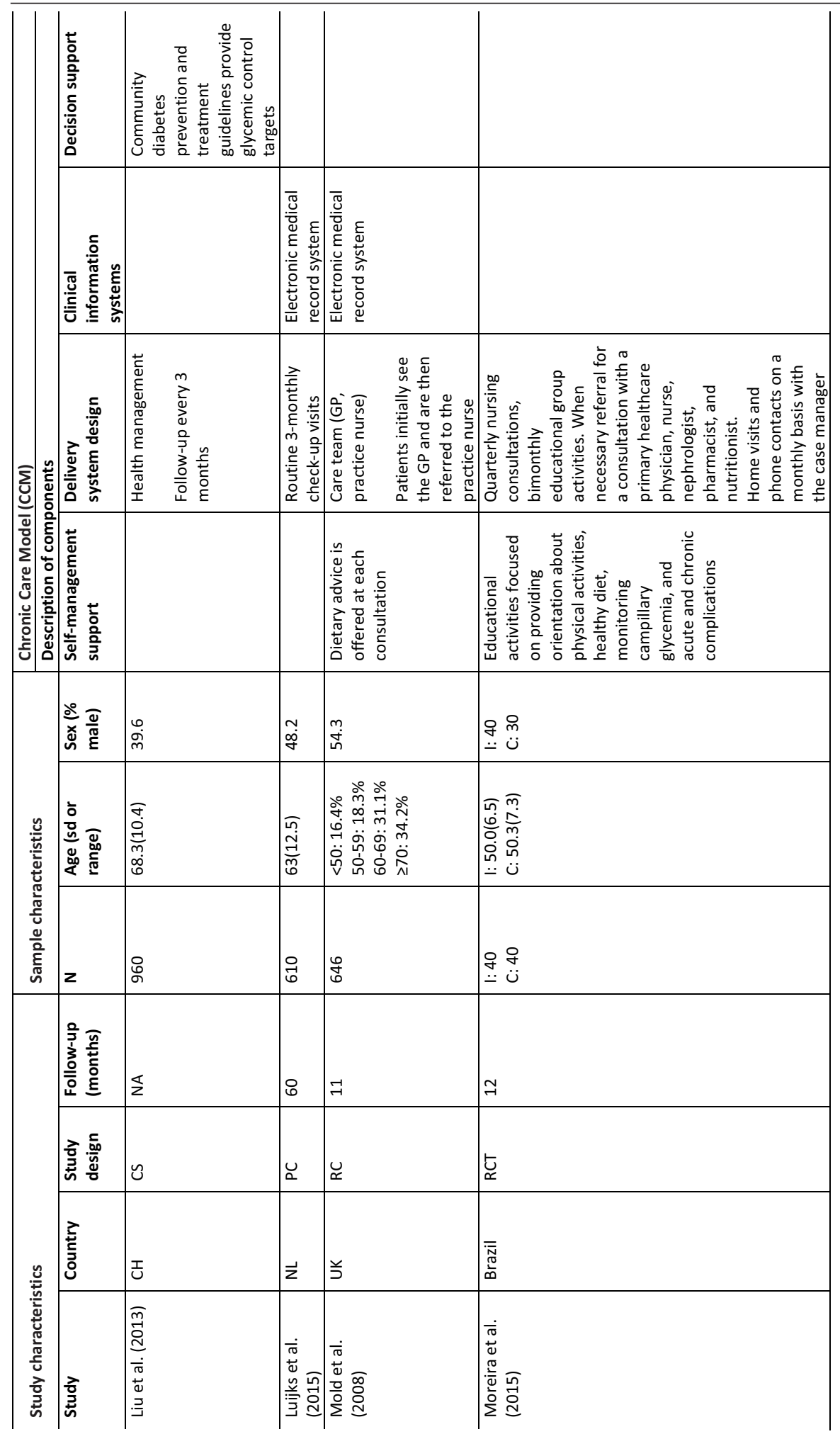


Relevant patient characteristics for guiding diabetes care: a systematic review

\begin{tabular}{|c|c|c|c|c|}
\hline & 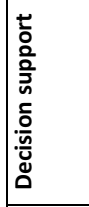 & 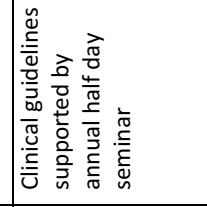 & 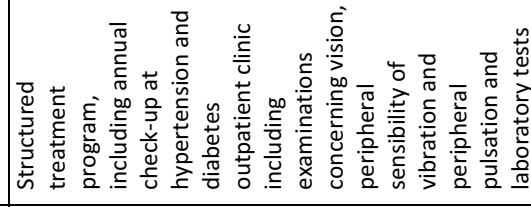 & \\
\hline & 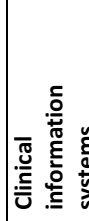 & 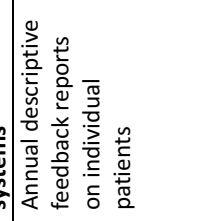 & & 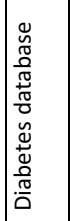 \\
\hline & 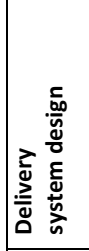 & 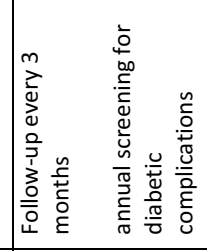 & 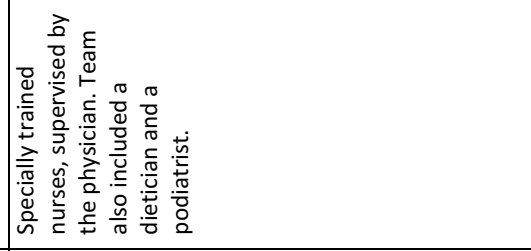 & 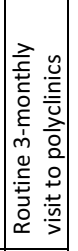 \\
\hline 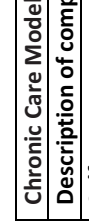 & 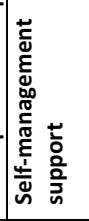 & 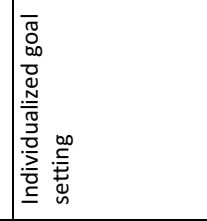 & 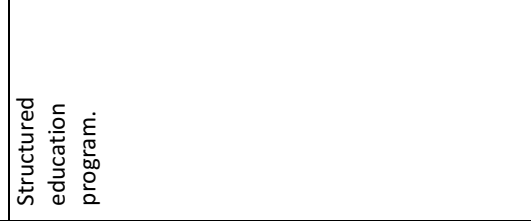 & \\
\hline & 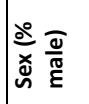 & 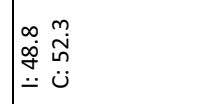 & 望 & $\begin{array}{l}\stackrel{j}{q} \\
\dot{j}\end{array}$ \\
\hline .气. & 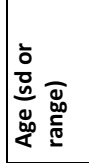 & 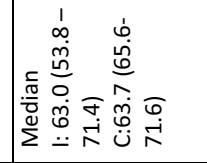 & 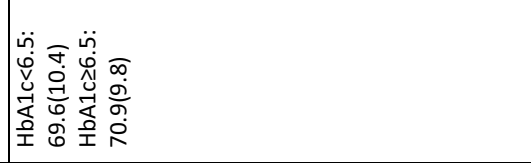 & 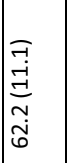 \\
\hline 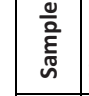 & $z$ & 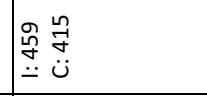 & 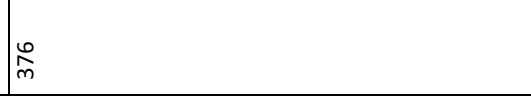 & 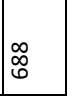 \\
\hline & 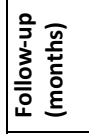 & $\approx$ & $\mathbb{z}$ & $\frac{\pi}{2}$ \\
\hline & 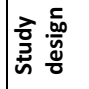 & $\underset{x}{E}$ & $\tilde{y}$ & ช \\
\hline$\stackrel{\mathscr{c}}{\underline{\underline{E}}}$ & 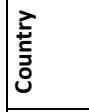 & 吕 & $\sum_{n}$ & 心 \\
\hline 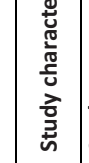 & 홀 & 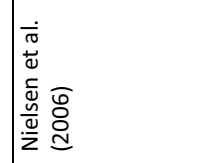 & 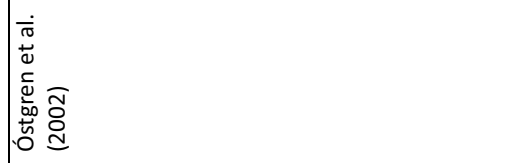 & 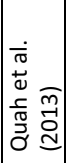 \\
\hline
\end{tabular}


Chapter 3

\begin{tabular}{|c|c|c|}
\hline & 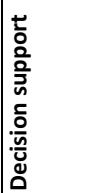 & 总 \\
\hline & 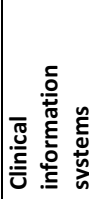 & 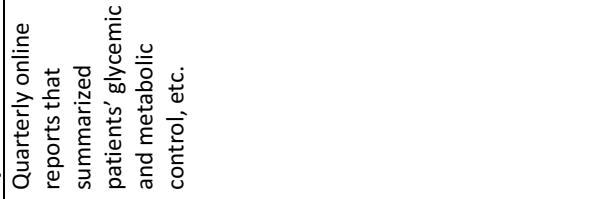 \\
\hline 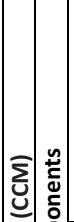 & 童 & 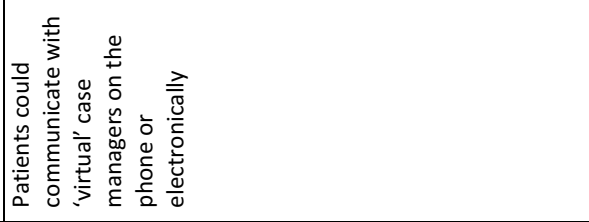 \\
\hline 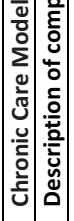 & 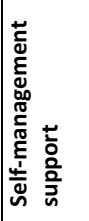 & 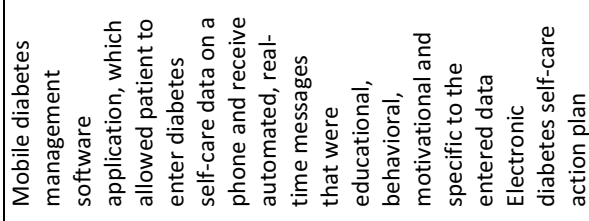 \\
\hline & 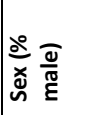 & 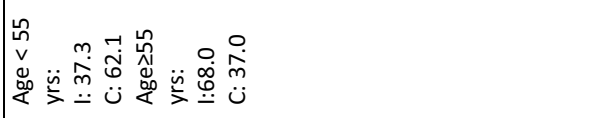 \\
\hline 总 & 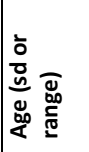 & 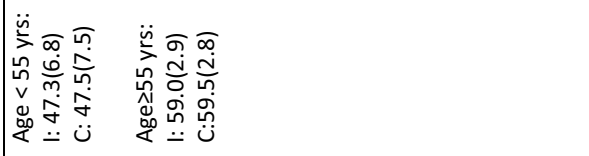 \\
\hline 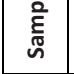 & $z$ & $\stackrel{\infty}{\exists}$ \\
\hline & 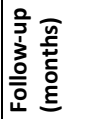 & $\approx$ \\
\hline & 突点 & $\underset{\approx}{t}$ \\
\hline 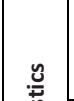 & 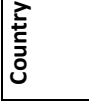 & 崩 \\
\hline 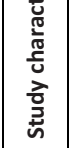 & के & 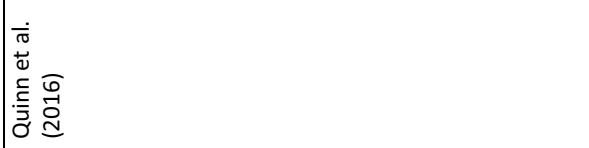 \\
\hline
\end{tabular}


Relevant patient characteristics for guiding diabetes care: a systematic review

\begin{tabular}{|c|c|c|c|}
\hline & 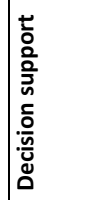 & 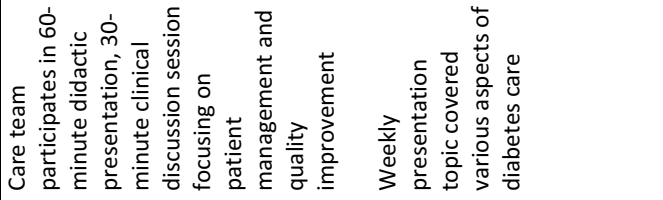 & \\
\hline & 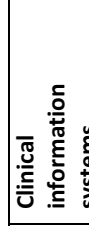 & 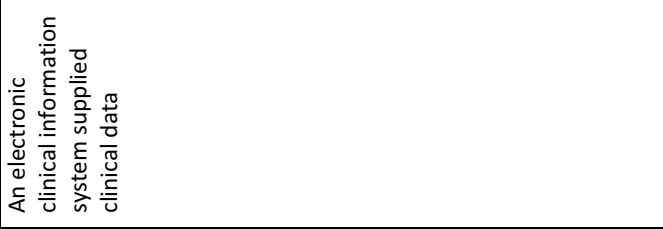 & \\
\hline 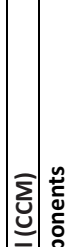 & 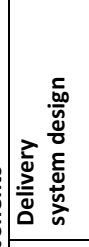 & 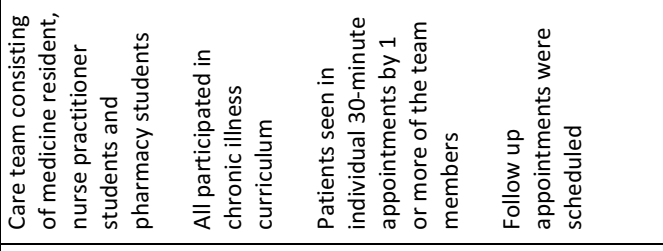 & \\
\hline 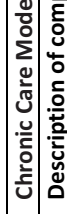 & 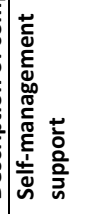 & 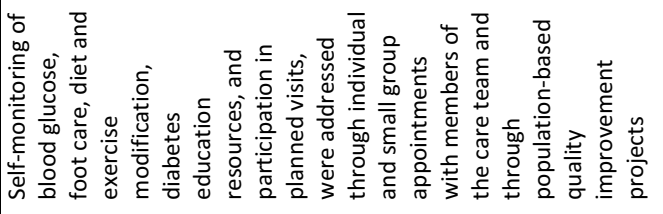 & 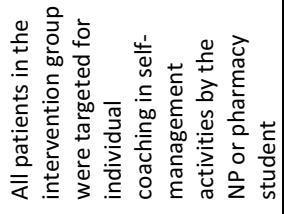 \\
\hline & 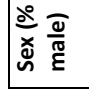 & $\stackrel{g}{\vec{f}}$ & \\
\hline 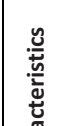 & 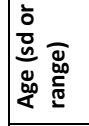 & 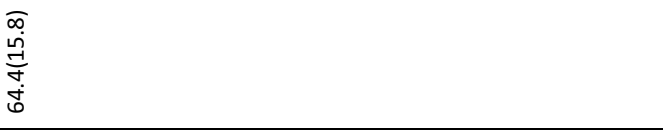 & \\
\hline & $z$ & 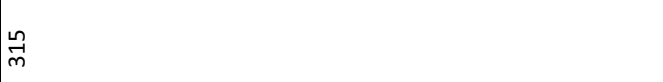 & \\
\hline \multirow{4}{*}{ 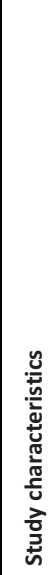 } & 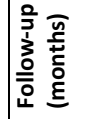 & $\stackrel{\infty}{\sim}$ & \\
\hline & 穿总 & ¿ & \\
\hline & 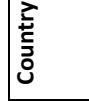 & 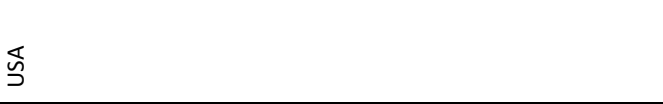 & \\
\hline & 흘 & 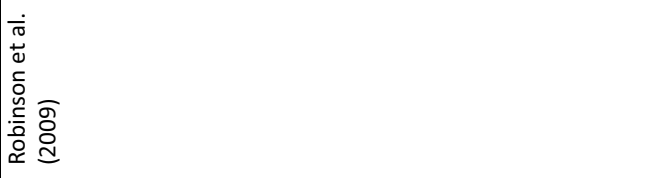 & \\
\hline
\end{tabular}




\begin{tabular}{|c|c|c|c|c|}
\hline & 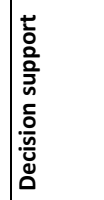 & 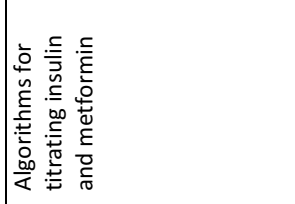 & & 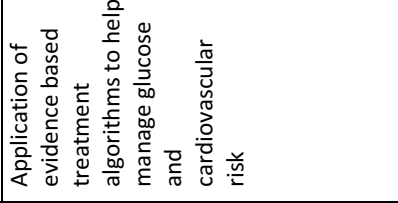 \\
\hline & 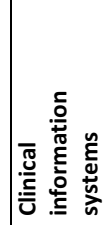 & 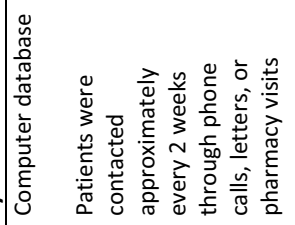 & & 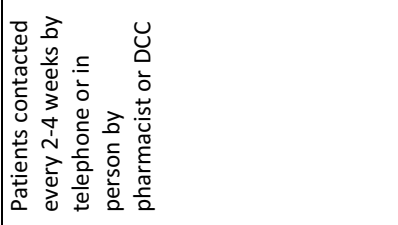 \\
\hline 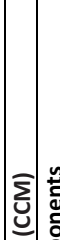 & 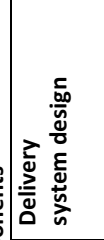 & 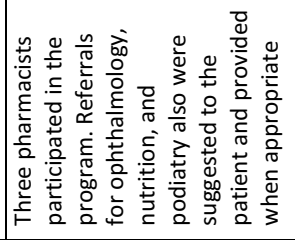 & 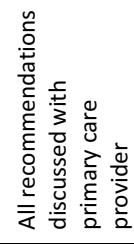 & 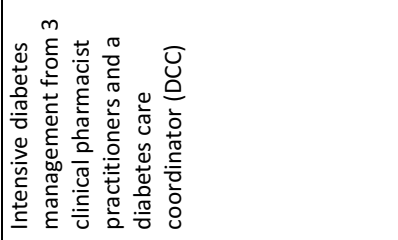 \\
\hline 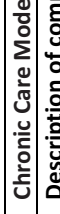 & 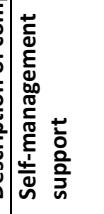 & 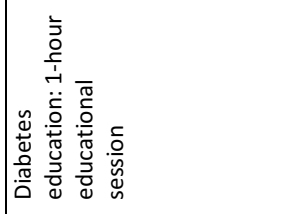 & & 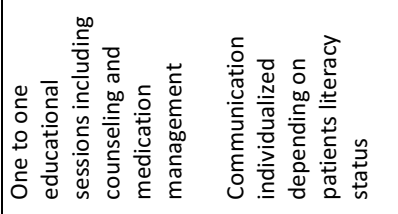 \\
\hline & 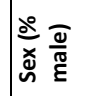 & ij & & 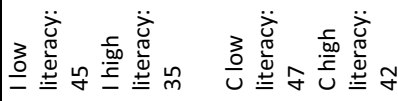 \\
\hline 苋 & 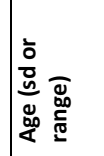 & 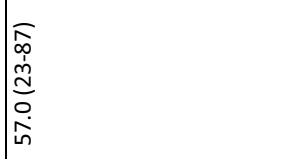 & & 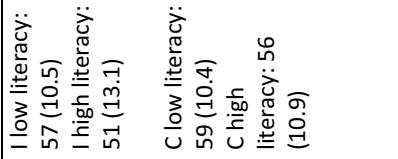 \\
\hline 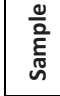 & $z$ & 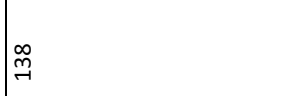 & & 兑 \\
\hline & 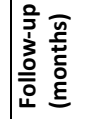 & 6 & & $\approx$ \\
\hline & 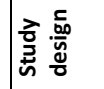 & $\breve{x}$ & & $\underset{\check{c}}{\breve{Z}}$ \\
\hline$\stackrel{\check{E}}{=}$ & 恙 & 焉 & & 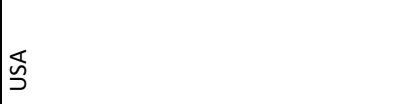 \\
\hline 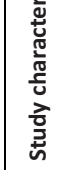 & 흘 & 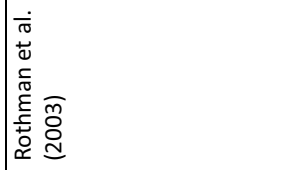 & & 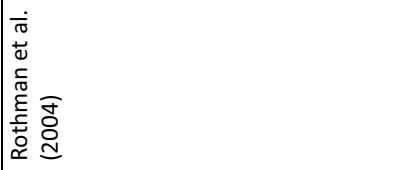 \\
\hline
\end{tabular}




\begin{tabular}{|c|c|c|c|}
\hline 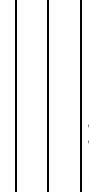 & 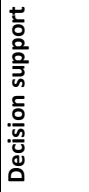 & 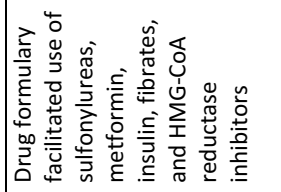 & \\
\hline & 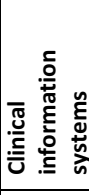 & 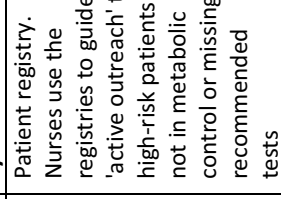 & \\
\hline 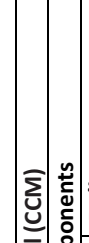 & 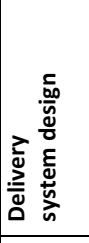 & 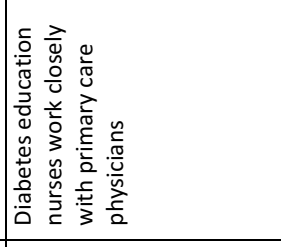 & 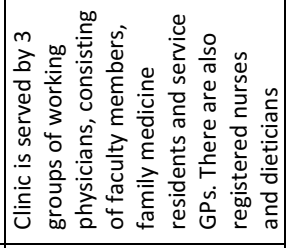 \\
\hline 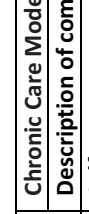 & 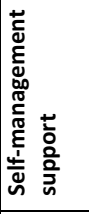 & 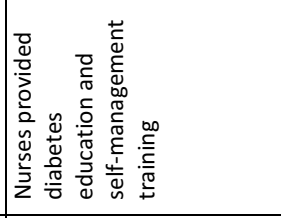 & 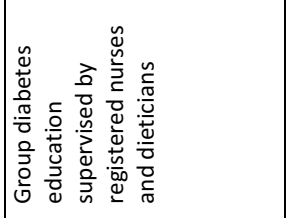 \\
\hline 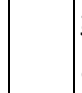 & 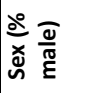 & 壱 & $\mid \begin{array}{l}\text { li } \\
\text { | }\end{array}$ \\
\hline 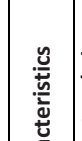 & 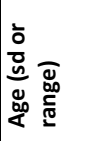 & $\begin{array}{l}\vec{b} \\
0 \\
0 \\
n\end{array}$ & 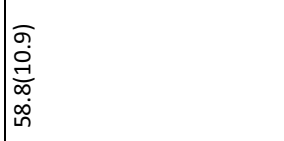 \\
\hline 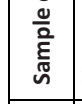 & $z$ & 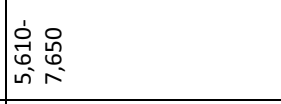 & 只 \\
\hline & 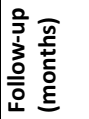 & F & $\frac{\mathbb{k}}{z}$ \\
\hline & 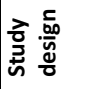 & 巡 & 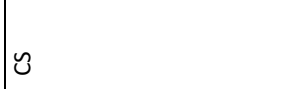 \\
\hline$\stackrel{\mathscr{c}}{\underline{E}}$ & ठ & 芯 & $I$ \\
\hline 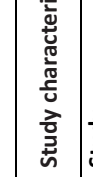 & 흘 & 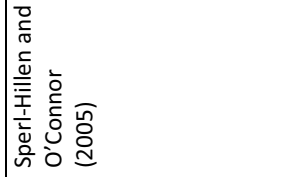 & 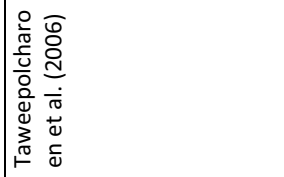 \\
\hline
\end{tabular}




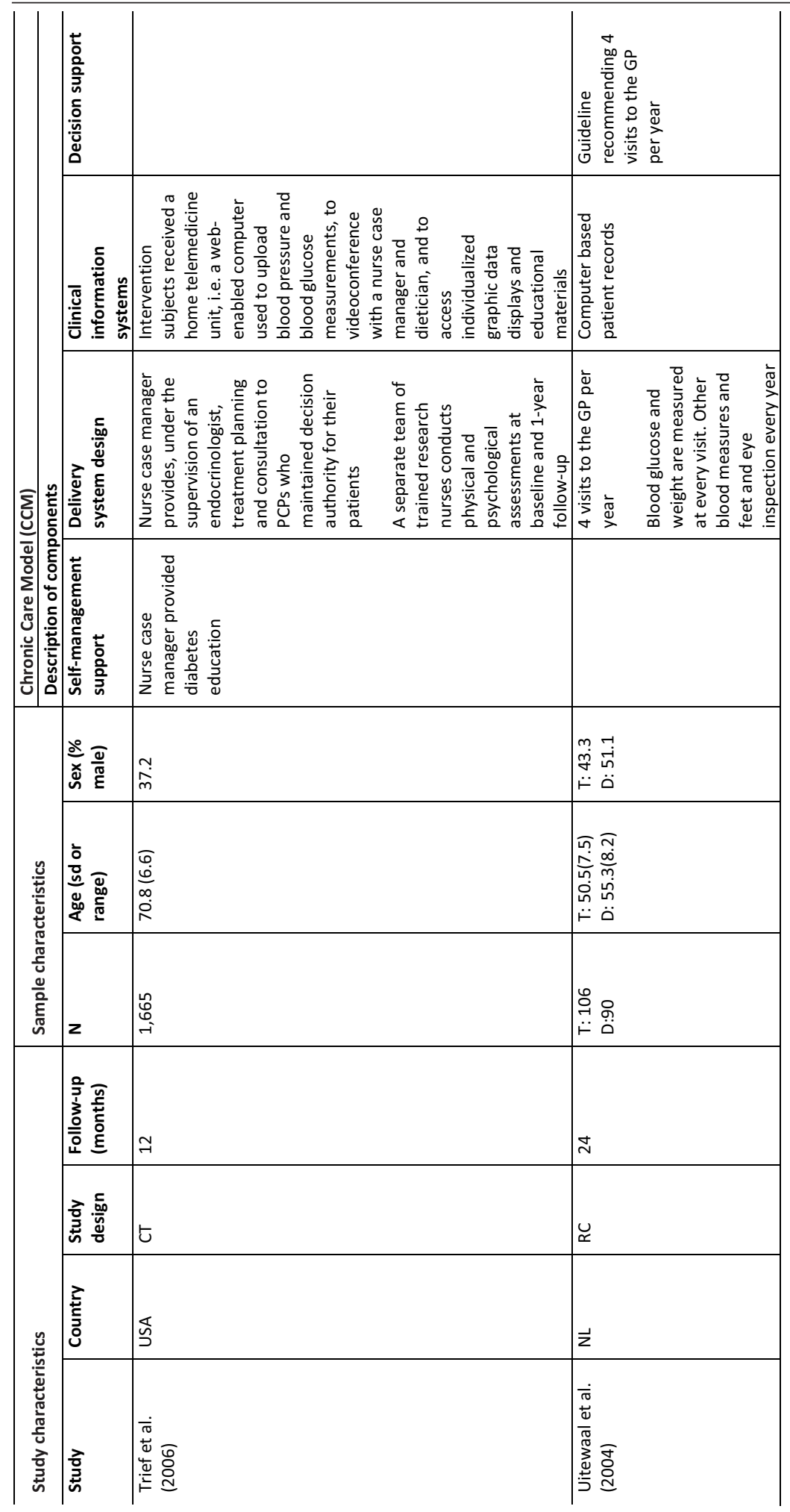


Relevant patient characteristics for guiding diabetes care: a systematic review

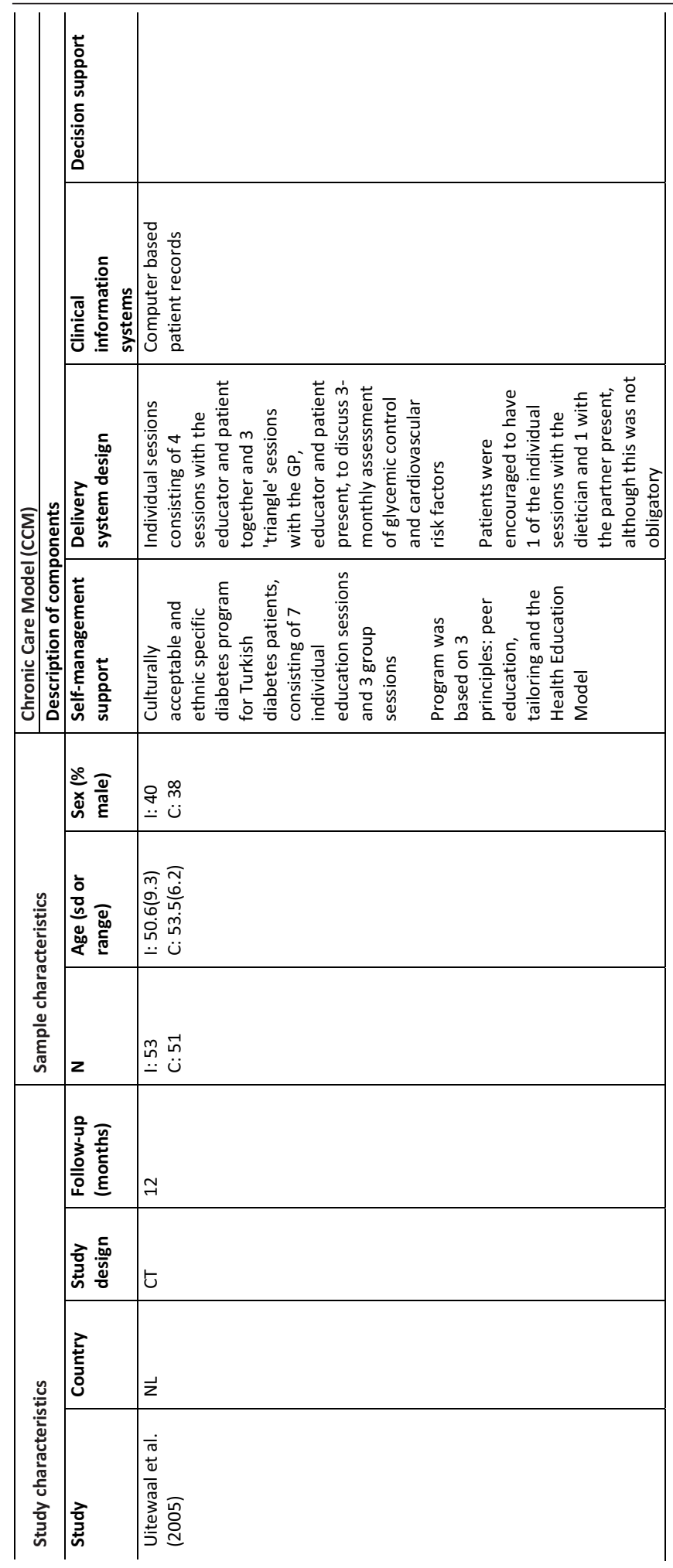


Chapter 3

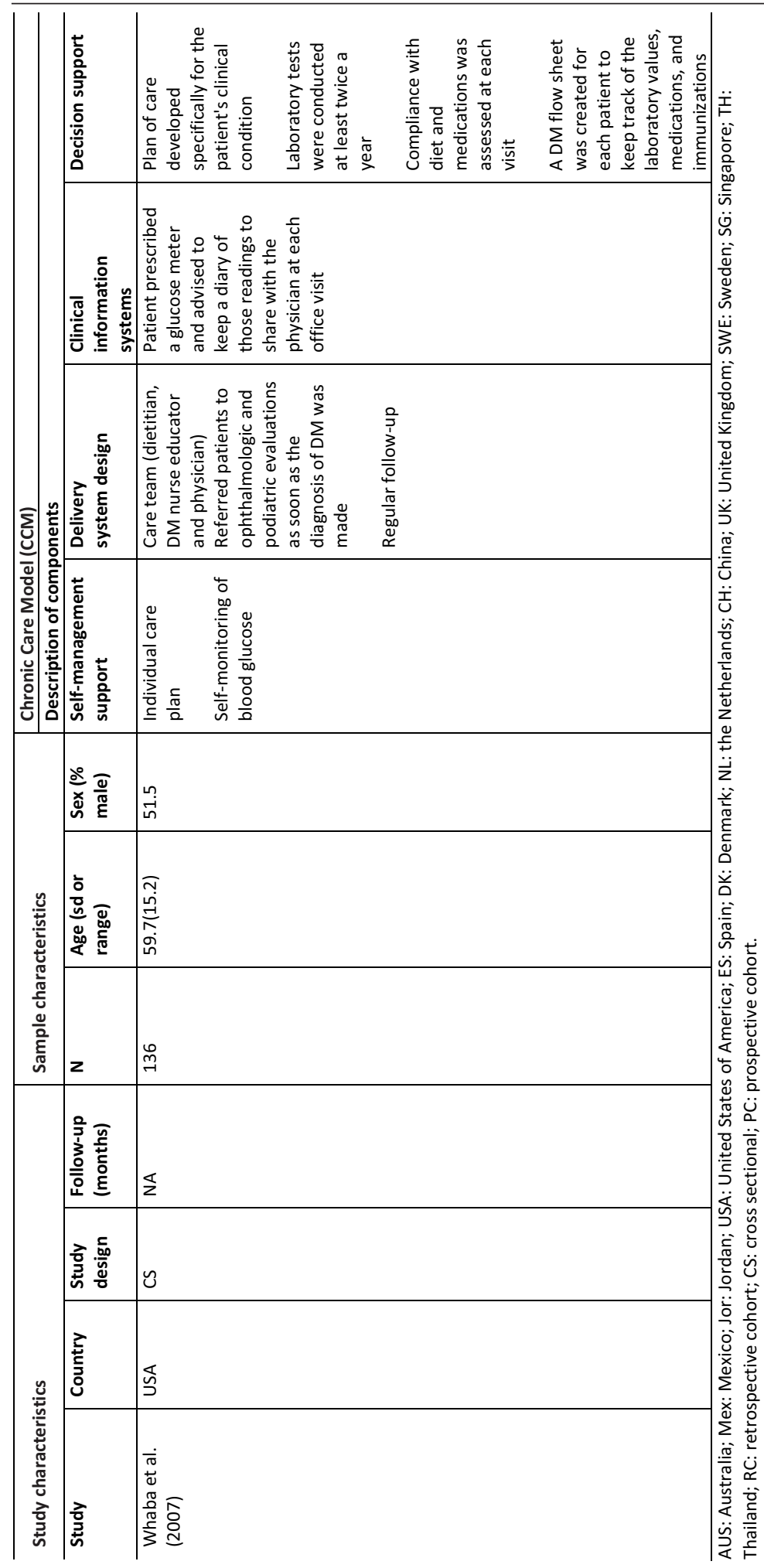


Three context-related characteristics were evaluated as potential effect modifiers of the relationship between integrated diabetes care programs and $\mathrm{HbA1c}$ : literacy status, income, and number schooling years. Literacy status was assessed by 1 study [46], which found that patients in the intervention group with low literacy status ( $\leq 6^{\text {th }}$ grade) had statistically significant lower HbA1c values at follow-up compared to patients with low literacy status receiving usual care. Monthly income and number of schooling years were also each assessed by one study. Patients with lower monthly income $(\leq \$ 118.26)$ and $\leq 4$ years of schooling at baseline receiving integrated diabetes care had significantly lower HbA1c values at follow-up compared to patient receiving usual care [39].

Three health-related characteristics were evaluated as potential effect modifiers of the relationship between integrated diabetes care programs and HbA1c: fasting blood glucose (FBG), depression and DM duration. Each characteristic was assessed by 1 study. Patients with high FBG (>10 mmol/L) at baseline receiving integrated diabetes care had significantly lower $\mathrm{HbA1c}$ levels at follow-up compared to patients receiving usual care [33]. For patients with a FBG $\leq 10 \mathrm{mmol} / \mathrm{L}$ no significant difference was found in $\mathrm{HbA1c}$ levels at follow-up between the intervention and control groups. Depression was not an effect modifier of the association between integrated diabetes care programs and HbA1c [49]. Patients with a DM duration $<5$ years receiving integrated diabetes care had significantly lower HbA1c levels at follow-up compared to patients receiving usual care [39].

No RCTs assessed context-related characteristics as potential effect modifiers of the relationship between integrated diabetes care programs and $\mathrm{HbA1c}$.

Prospective -and retrospective cohort studies. Eleven prospective -and retrospective cohort studies measured the effects of integrated diabetes care programs on $\mathrm{HbA1c}$ (Tables 4 and 5). Three studies compared the change in $\mathrm{HbA} 1 \mathrm{c}$ between levels of patient characteristics $[5,45$, 47]. The other 8 studies compared HbA1c levels at follow-up between levels of patient characteristics $[28,29,31,32,38,44,53,54]$

Most examined person-related characteristics were age $(n=11)$ and sex $(n=9)$. In 7 studies the effect of integrated diabetes care programs on $\mathrm{HbA1c}$ differed significantly across ranges of age: younger patients had higher $\mathrm{HbA1c}$ levels at follow-up compared to older patients $(n=5)$ and experienced greater change from baseline in $\operatorname{HbA1c}(n=2)[5,28,32,38,47,53,54]$. As to the latter, the direction of the measured change in $\mathrm{HbA1c}$ differed: one study found a significant improvement [47] and the other a significant increase [5] in HbA1c. Age was not a significant effect modifier in the other 4 studies [29, 31, 44, 45]. The effect of integrated care on $\mathrm{HbA1c}$ did not differ between men and women in 8 studies [28, 31, 32, 44, 45, 47, 53, 54]. In 1 study females had significantly higher HbA1c levels at follow-up compared to males [29].

Most examined health-related characteristics were medication use $(n=8)$, baseline $\mathrm{HbA1c}$ $(n=7)$, and duration of type 2 diabetes $(n=6)$. The effect of integrated diabetes care programs on $\mathrm{HbA1c}$ was different for people on insulin therapy. These patients had higher HbA1c levels at follow-up compared with patients on diet and/or oral therapy in 5 studies[28, 31, 32, 38, 54] and less desirable changes in HbA1c from baseline [47]. In two studies the relationship 
between integrated diabetes care programs and $\mathrm{HbA1c}$ did not differ between types of medication $[45,53]$. In the studies assessing baseline $\mathrm{HbA1c}$, patients with higher baseline HbA1c levels had higher HbA1c levels at follow-up ( $n=3)[28,32,54]$, but did have greater improvements in $\mathrm{HbA} 1 \mathrm{c}$ from baseline $(n=3)[5,45,47]$ compared to patients with lower baseline $\mathrm{HbA1C}$ levels. In one study baseline $\mathrm{HbA1c}$ was not a significant effect modifier [53]. The effect of integrated diabetes care programs on $\mathrm{HbA1c}$ differed significantly across ranges of diabetes duration in 5 studies. Patients with longer diabetes duration had significantly higher HbA1c levels at follow-up compared to patients with shorter diabetes duration $(n=5)$ $[5,28,32,38,54]$. In one study a significant opposite effect was found [45].

Health insurance status was assessed by 4 studies. It did not seem to significantly modify the observed effect of integrated care on HbA1c in 3 studies [28, 44, 45]. Patients with no health insurance coverage had less desirable changes in $\mathrm{HbA1c}$ than those with health insurance coverage [47]. No other context-related characteristics were examined by the included studies.

Cross-sectional studies. In total, 6 cross-sectional studies measured the modifying effect of patient characteristics on the relationship between integrated diabetes care programs and HbA1c (Tables 4 and 5).

Most examined person-related characteristics were age $(n=6)$, body mass index (BMI) $(n=6)$ and sex $(n=5)$. Four studies of integrated care programs found non-significant associations between age and $\mathrm{HbA} 1 \mathrm{c}[27,30,41,48]$. In 2 studies significant associations were found: in these studies, younger patients had higher HbA1c levels [52, 55]. The effect of integrated diabetes care programs on $\mathrm{HbA1C}$ did not significantly differ between levels of $\mathrm{BMI}$ in all studies [27, 30, 41, 48, 52, 55]. The effect on HbA1c did also not differ between men and women in 4 studies $[27,30,52,55]$. In 1 study females had significantly higher HbA1c levels compared to males [48].

Most examined health-related characteristics were duration of type 2 diabetes $(n=6)$ and medication use $(n=4)$. The effect of integrated care programs on $\mathrm{HbA1c}$ differed significantly across ranges of diabetes duration in 4 studies [27, 30, 48, 55]. Patients with longer diabetes duration had higher $\mathrm{HbA1c}$ levels compared to patients with shorter diabetes duration in these studies. In 2 studies diabetes duration was not a significant effect modifier [41, 52]. The effect of integrated care programs on $\mathrm{HbA1c}$ was also different for people on insulin therapy. These patients had higher HbA1c concentrations compared with patients on diet and/or oral therapy in 3 studies $[27,30,55]$. In 1 study type of medication was not a significant effect modifier [52].

No context-related characteristics were assessed by 3 or more studies. 


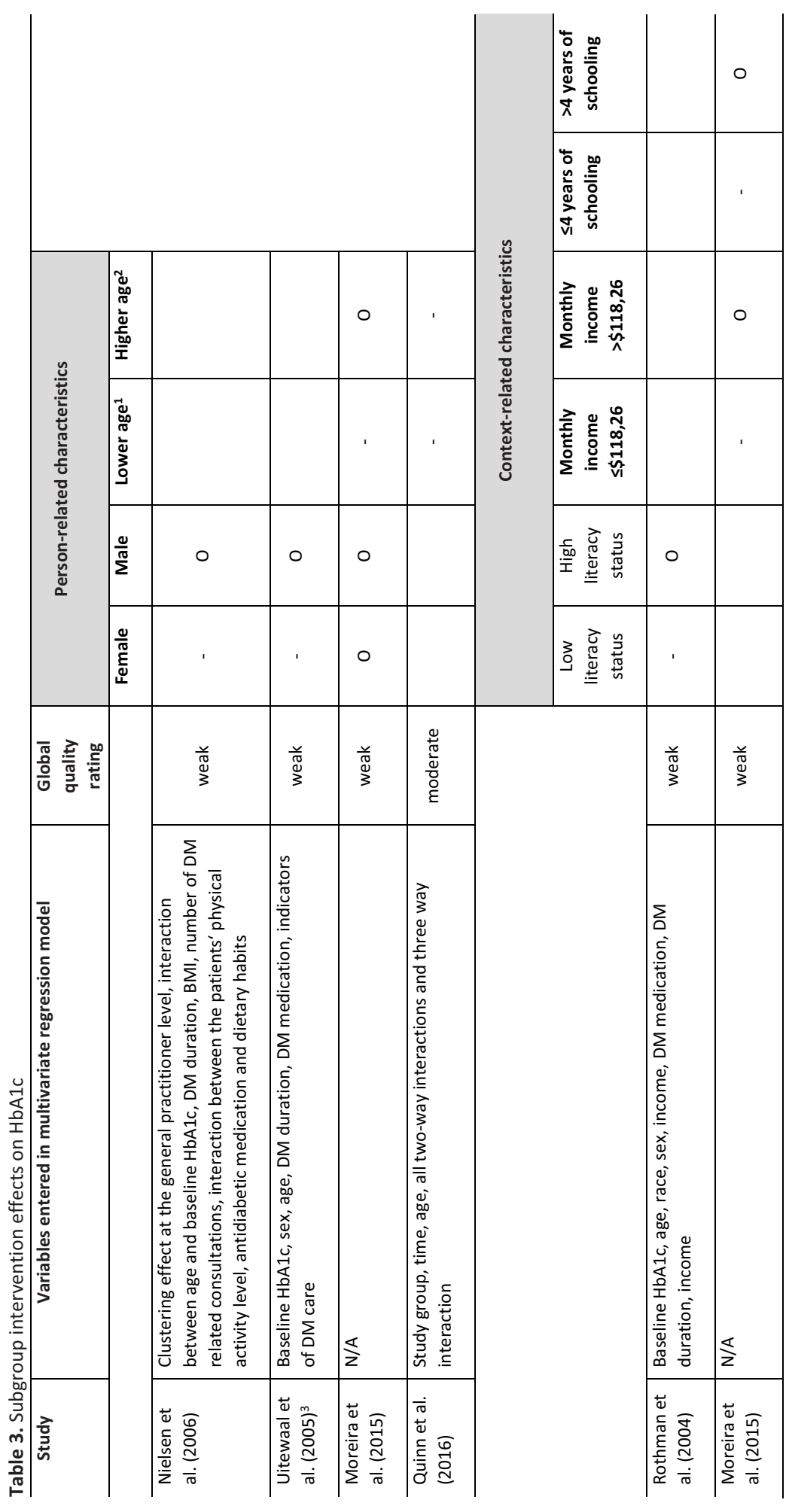




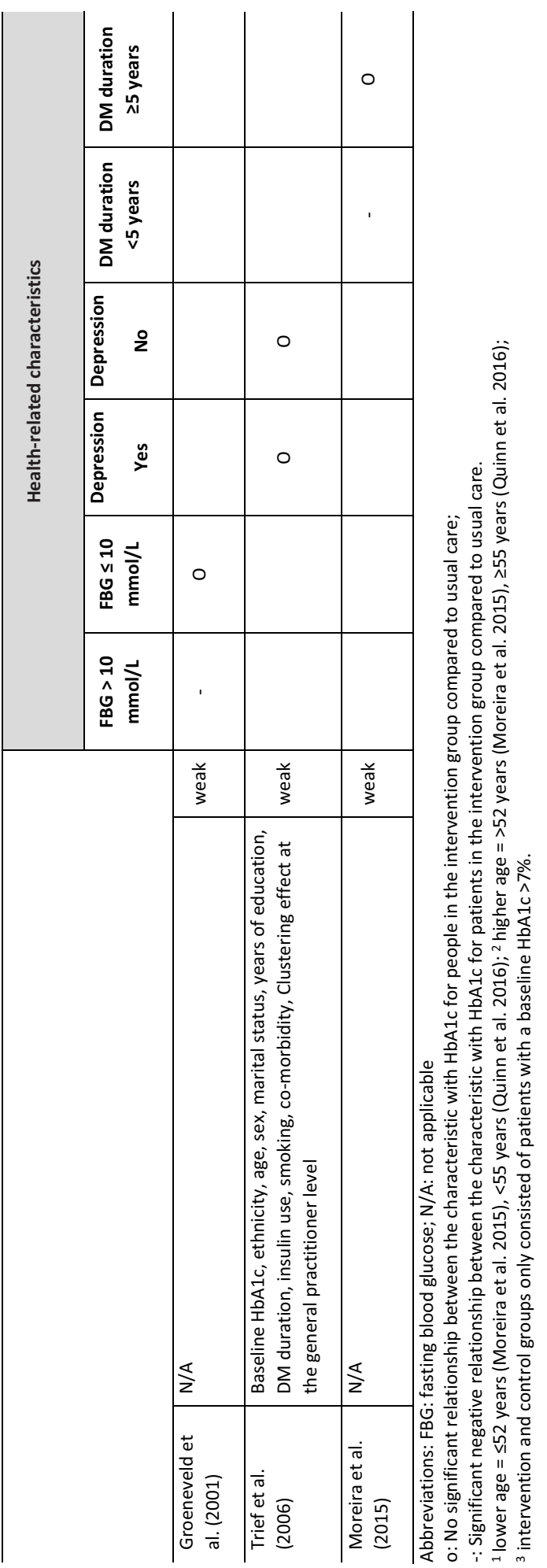




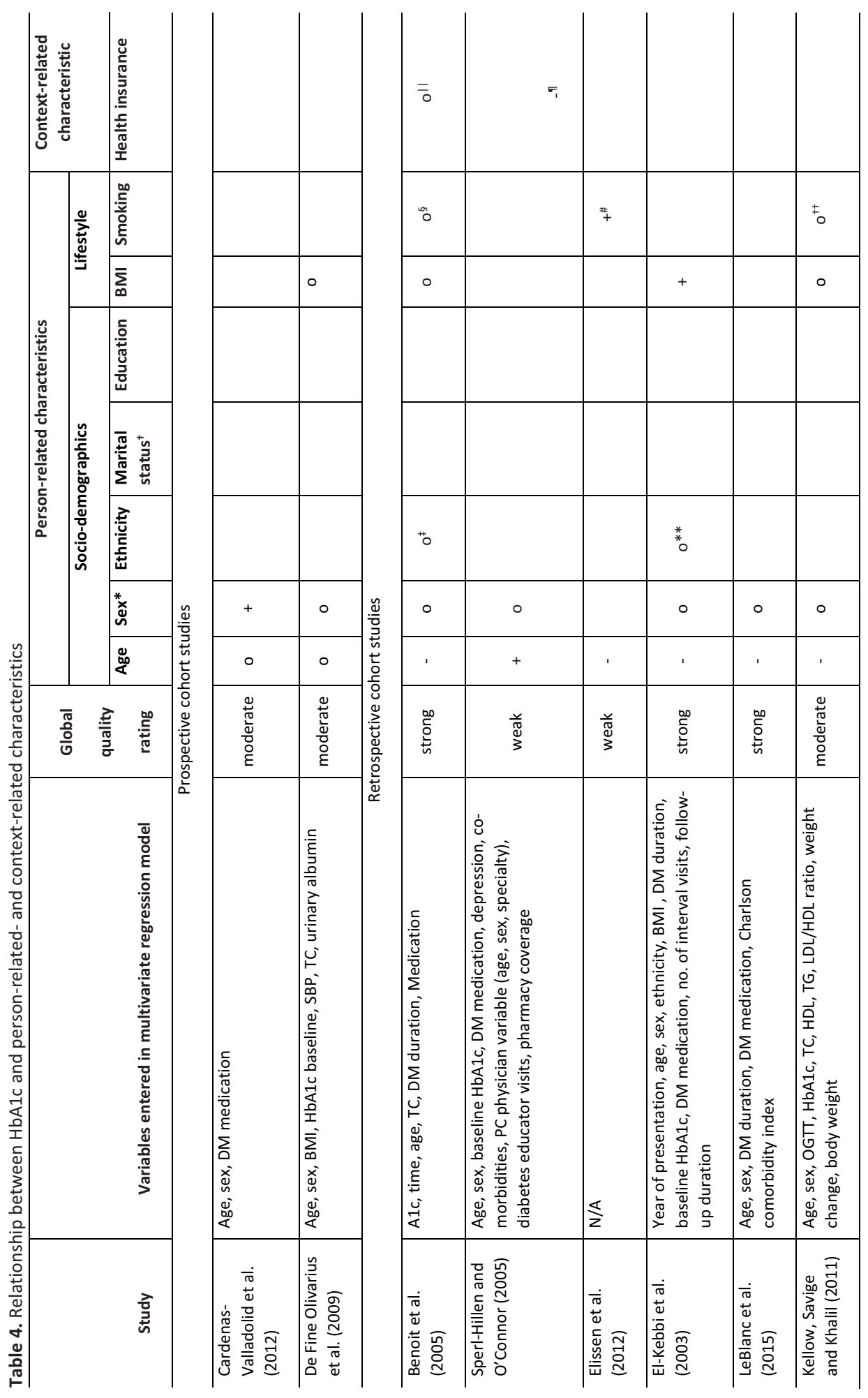




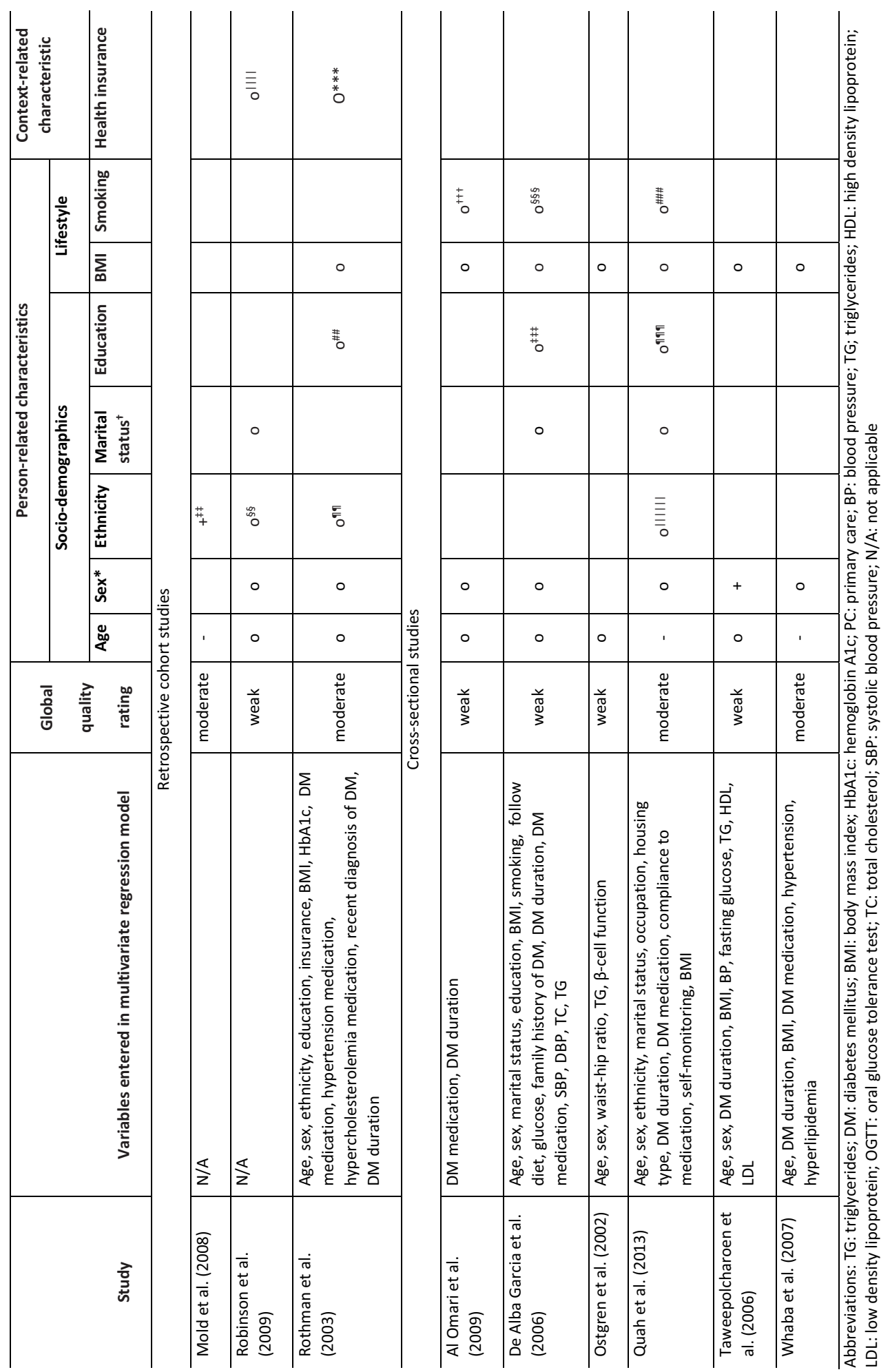




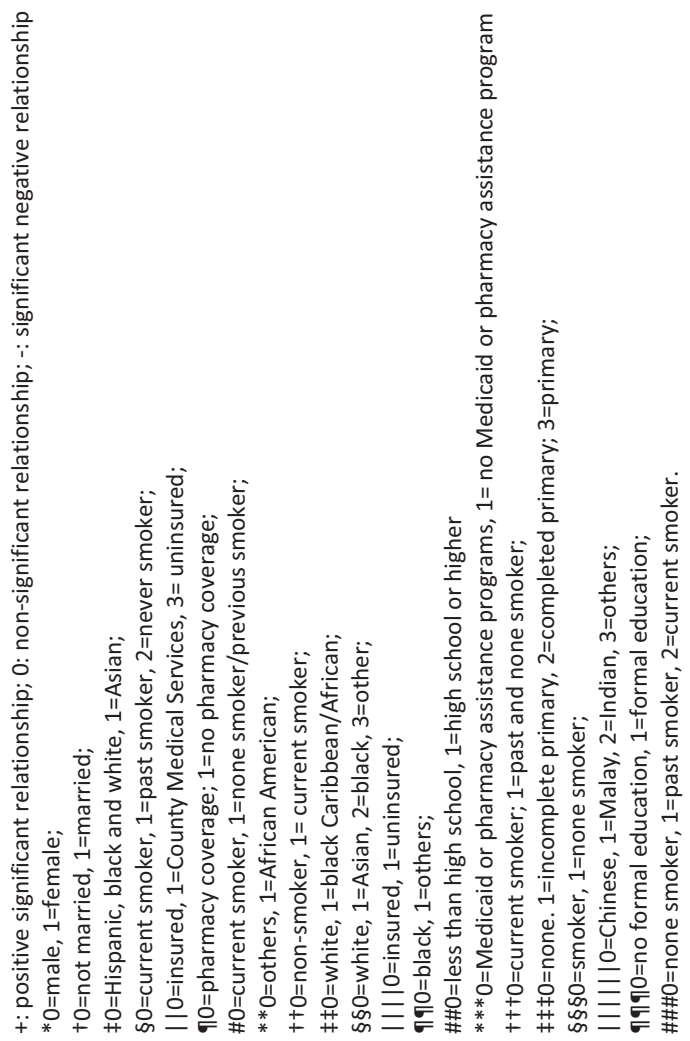




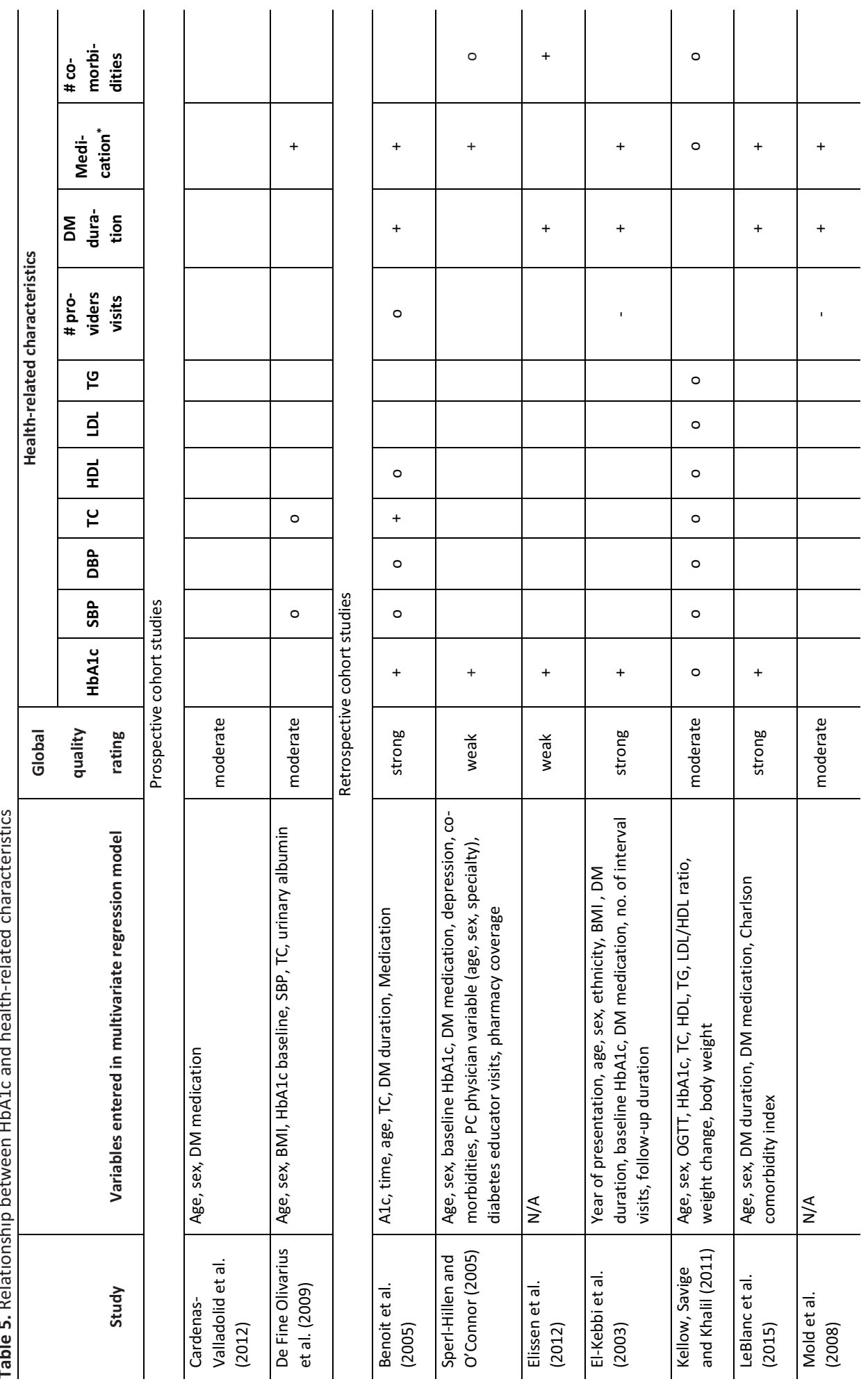



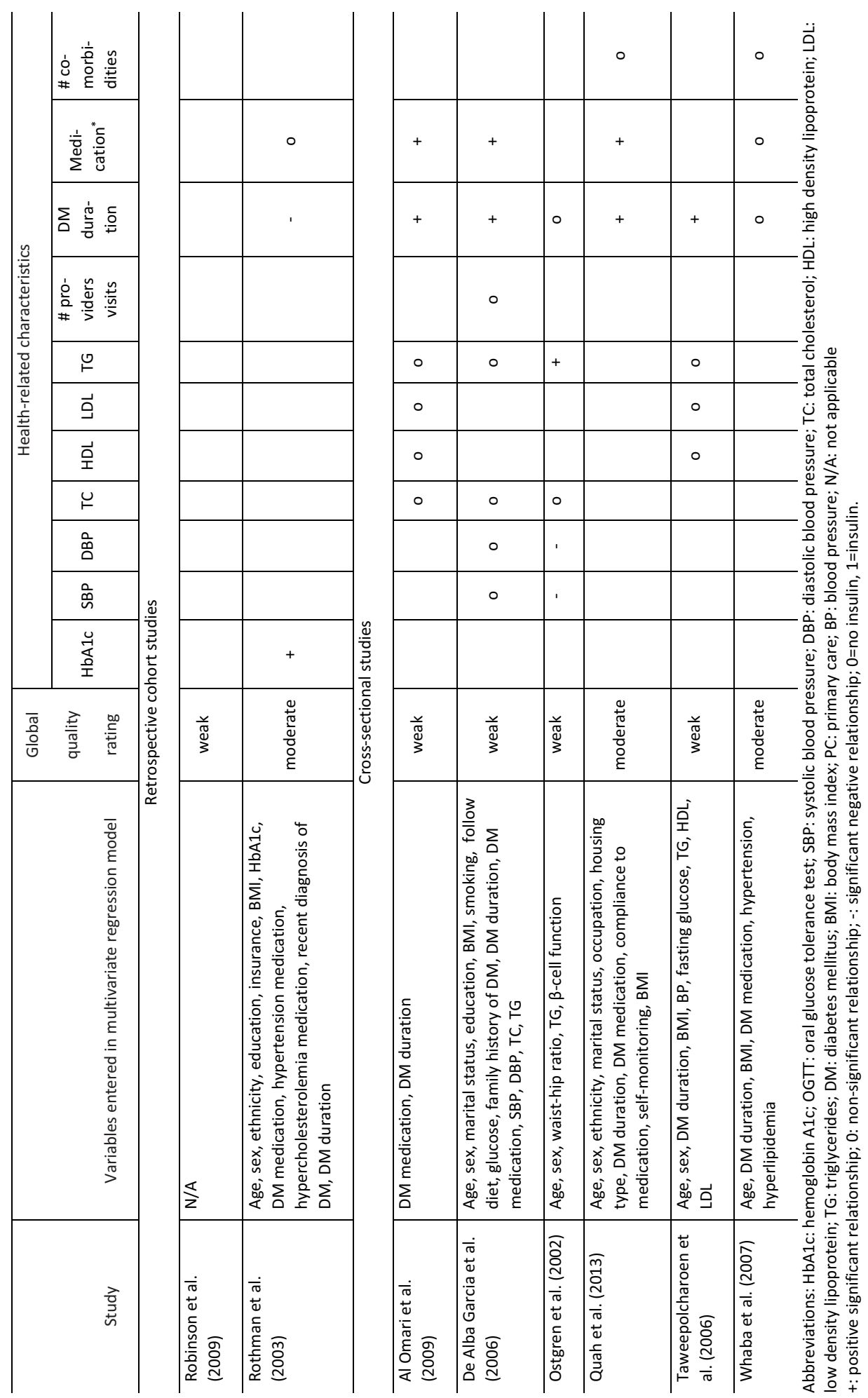


\section{LDL-cholesterol}

Three prospective -and retrospective cohort studies measured the effect of integrated diabetes care programs on LDL-c. The RCTs and cross-sectional studies included in this review did not measure this effect. In total, 11 patient characteristics were assessed by the studies. Only those results that were assessed by at least 2 studies will be discussed.

Prospective -and retrospective cohort studies. The person-related characteristic age was examined by 3 studies $[5,44,47]$. The relationship between age and LDL-c was inconsistent: a negative and positive as well as a non-significant relationship were found.

The modifying effect of baseline LDL-c on the relationship between integrated diabetes care programs and changes in LDL-c over baseline was assessed by 2 studies $[5,47]$. Both found that patients with higher baseline LDL-c had greater LDL-c improvements.

No context-related characteristics were assessed by the included studies.

\section{Systolic blood pressure}

Four retrospective - and prospective cohort studies measured the effect of integrated diabetes care programs on SBP. In total, 9 patient characteristics were assessed by the studies. Only those results that were assessed by at least 2 studies will be discussed.

Retrospective cohort -and prospective cohort studies. Age was measured by 3 studies [5, 38, 44]. These studies found that higher age was associated with higher SBP at follow-up [38, 44] and greater improvement [5]. The modifying effect of ethnicity on integrated care programs and SBP was measured by 2 studies [38, 44].The effect was unclear, as results were inconsistent between these studies. Four other characteristics were assessed, 1 contextrelated-, and 3 health-related characteristics, by 1 study each.

\section{Health care utilization}

Health care utilization was assessed by 3 studies: 1 RCT [40], 1 retrospective cohort study [50], and 1 cross-sectional study [36]. Together they measured the modifying effect of integrated care programs and health care utilization for 5 person-related characteristics, 1 context,- and 1 health-related characteristic. Most examined characteristic was sex, which was measured by 2 studies [36, 40]. Nielsen et al. found that females in the intervention group had statistically significant more GP consultations per year compared to females in the control group [40]. For males, no difference was found. Liu et al. found that the effect of integrated diabetes care programs on health care utilization was different between males and females [36]. Females had higher utilization of community health centers compared to males. 


\section{Discussion}

This paper presents a literature review on relevant patient characteristics for guiding tailored integrated type 2 diabetes care in primary care. $\mathrm{HbA1c}$ was considered an outcome in $93 \%$ of the 27 studies identified. Many different patient characteristics were investigated by these studies. Findings indicate that the effect of integrated primary care programs on $\mathrm{HbA1c}$ differs significantly according to a number of person and health-related characteristics. Younger age, longer disease duration, higher baseline $\mathrm{HbA1c}$ and insulin therapy were associated with higher $\mathrm{HbA1c}$ levels. Health insurance status, living situation and income were the only context-related characteristics in the included studies and were not frequently assessed.

Compared to HbA1c, LDL-c, SBP and health care utilization were included far less. It was found that higher baseline LDL-c lead to greater LDL-c improvement. Patients with higher age had higher SBP levels at follow-up as well as greater improvements in SBP compared to younger patients. The relationship between integrated care and health care utilization seemed to be modified by sex: women had more consultations per year compared to men.

Several factors might explain the elevated $\mathrm{HbA1c}$ levels in a subset of patients with type 2 diabetes. Younger patients tend be more non-adherent to oral medication therapy and experience less profound diabetes-related health problems than older patients [56] [57]. The latter might cause them to believe that a pro-active attitude towards their disease is less important. Moreover, younger patients and/or those with longer disease duration undergo a more rapid decline in beta cell function and pancreatic insulin secretion, resulting in the need for a more complex and intensive drug therapy [27, 53, 58, 59]. Higher HbA1c levels for patients on insulin therapy compared to patients on diet and/or oral therapy could be due to a delayed start or low intensity of insulin therapy [32, 60, 61]. Furthermore, maintaining glycemic control, while minimizing hypoglycemia and sticking to a diet might be difficult [55, 62].

High $\mathrm{HbA} 1 \mathrm{c}$ at baseline also seemed to be predictive of later HbA1c. First, type Type 2 diabetes is a heterogeneous disease in both pathogenesis and clinical manifestation [8], thus a high $\mathrm{HbA1c}$ at baseline and at follow-up could be due to decreased insulin sensitivity, secretion and $\beta$-cell dysfunction [63]. Second, unhealthy lifestyle habits, such as low physical activity, and a diet rich in carbohydrates have been associated with less glycemic control [8, 64]. Changing these lifestyle factors is easier said than done, making it difficult for patients to improve their glycemic control.

Several factors could explain the differences in levels of LDL-C, SBP and health care utilization between levels of patient characteristics. Prescription of statins usually follows when LDL-c level is $2.5 \mathrm{mmol} / \mathrm{I}$ or higher, possibly leading to greater improvements in LDL-C for those patients with high baseline LDL-c levels [65]. The higher SBP levels at follow-up for older patients may be due to less stringent treatment targets $[66,67]$. The greater health care utilization by women compared to men might be explained by the difference in perception of illness between men and women. According to some studies, it is more culturally and socially accepted for women to be ill than it is for men [68]. 
Overall, our results indicate the need to implement integrated diabetes care programs specifically tailored to the needs, values and preferences of younger patients and to those on insulin therapy, with longer disease duration and/or higher HbA1c levels and older patients with high SBP levels. These effect modifiers can help to provide the right care to the right person at the right time. At this moment, not every patient with these characteristics receives such care. Current practice might therefore not be suitable for all patients. Lack of motivation, family-support and feeling burned-out from managing diabetes are reported barriers to optimal self-management [69]. To tackle these barriers, diabetes treatment programs should take them into account by, for example, providing shared decision making and simple and specific instructions and advice, involving family members and offering online consultations or evening primary care opening hours. In addition to patients who find it difficult to keep their diabetes under control, there is a large group of patients who does manage to control their diabetes $[5,6]$. For these patients, fewer visits to primary care might have similar outcomes and thus should be taken into consideration by both the GP and the patient. Allowing care givers to provide care based on patient characteristics constitutes a promising approach for achieving the so called 'Triple Aim' by: [1] improving patient experience, by including patients' care needs, preferences, and abilities in treatment decisions; [2] improving population health and quality of life, by supporting tailored diabetes care; and [3] reducing the per capita cost of diabetes care, by reducing the over-, under- and misuse of health care services [70].

This review has several limitations that should be taken into account. First, given the scarceness of studies assessing the differences in the effect of integrated diabetes care programs on diabetes control measures by levels of patient characteristics, it was decided to include RCTs, prospective-, and retrospective cohort studies. However, this introduced significant heterogeneity and made it impossible to conduct a meta-analysis. Second, quality of the studies was weak for most studies. This was mainly due to the cross-sectional study design of more than one third of the studies and the use of less robust statistical methods. Fortunately, it is unlikely that these studies altered the results, as their findings were similar to those of the other, more robust studies. Third, very few context- and person-related characteristics were analyzed. Studies performed in a non-integrated diabetes care setting, found that context-related characteristics, such as socioeconomic status and social network, are associated with measures of diabetes control and are likely to be strong predictors of diabetes control [71, 72]. Person-related characteristics, such as low mastery and low selfefficacy, have been related to negative health outcomes $[73,74]$. Traditionally, researchers and care providers have looked at diabetes from a mostly biomedical viewpoint, which might explain the relatively scarce collection of context- and person-related characteristics in routinely collected individual patient data [15].

The current review provides a good understanding of which characteristics can help to identify patients with different health care needs and preferences. However, to implement an effective integrated type 2 diabetes tailored care program, it is necessary to know which context- and person-related characteristics are important to identify patients. Furthermore, 
implementation of an effective tailored diabetes care program is only possible by taking into account the care preferences of patients and caregivers. In the next phase of the PROFILe project [19], data rich in non-health-related characteristics will be analyzed to assess which of these are predictors of diabetes control measures and a discrete choice experiment will be conducted to gain knowledge on patients' care preferences as a first step towards patientcentered diabetes care. 


\section{References}

1. International Diabetes Federation. IDF Diabetes Atlas Seventh Edition Brussels: International Diabetes Federation 2015.

2. Tamayo T, Rosenbauer J, Wild SH, Spijkerman AM, Baan C, Forouhi NG, et al. Diabetes in Europe: an update. Diabetes research and clinical practice 2014; 103:206-217.

3. Shaw S, Rosen R, Rumbold B. What is integrated care? . London, UK: Nuffield Trust 2011.

4. Kodner DL. All together now: a conceptual exploration of integrated care. Healthcare quarterly 2009; 13 Spec No:6-15.

5. Elissen AMJ, Duimel-Peeters IGP, Spreeuwenberg C, Spreeuwenberg M, Vrijhoef HJM. Toward Tailored Disease Management for Type 2 Diabetes. American Journal of Managed Care 2012; 18:619-630.

6. Rothe U, Muller G, Schwarz PE, Seifert M, Kunath H, Koch R, et al. Evaluation of a diabetes management system based on practice guidelines, integrated care, and continuous quality management in a Federal State of Germany: a population-based approach to health care research. Diabetes Care 2008; 31:863-868.

7. Pimouguet C, Le Goff M, Thiebaut R, Dartigues JF, Helmer C. Effectiveness of diseasemanagement programs for improving diabetes care: a meta-analysis. CMAJ 2011; 183:E115-127.

8. Inzucchi SE, Bergenstal RM, Buse JB, Diamant M, Ferrannini E, Nauck M, et al. Management of hyperglycemia in type 2 diabetes: a patient-centered approach: position statement of the American Diabetes Association (ADA) and the European Association for the Study of Diabetes (EASD). Diabetes Care 2012; 35:1364-1379.

9. American geriatrics society expert panel on person-centered care. Person-centered care: a definition and essential elements. Journal of the American Geriatrics Society 2016; 64:15-18.

10. Coulourides Kogan A, Wilber K, Mosqueda L. Moving Toward Implementation of PersonCentered Care for Older Adults in Community-Based Medical and Social Service Settings: "You Only Get Things Done When Working in Concert with Clients". Journal of the American Geriatrics Society 2016; 64:e8-e14.

11. Commitee on Quality of Health Care in America; Institute of Medicine. Improving the 21st-century health care system. Crossing the Quality Chasm: A New Health System for the 21st Century. Washington, DC: National Academy Press 2001.

12. Tseng MM, Hu SJ. Mass Customization. Manufacturing Technology 2014; 836-843.

13. Epstein RM, Street RL, Jr. The values and value of patient-centered care. Annals of family medicine 2011; 9:100-103.

14. Riddle MC, Karl DM. Individualizing targets and tactics for high-risk patients with type 2 diabetes: practical lessons from ACCORD and other cardiovascular trials. Diabetes care 2012; 35:2100-2107.

15. Hasnain-Wynia R, Baker DW. Obtaining data on patient race, ethnicity, and primary language in health care organizations: current challenges and proposed solutions. Health services research 2006; 41:1501-1518.

16. Scheen AJ. Precision medicine: The future in diabetes care? Diabetes research and clinical practice 2016; 117:12-21.

17. Constand MK, MacDermid JC, Dal Bello-Haas V, Law M. Scoping review of patientcentered care approaches in healthcare. BMC health services research 2014; 14:271. 
18. Goldberger JJ, Buxton AE. Personalized medicine vs guideline-based medicine. Jama 2013; 309:2559-2560.

19. Elissen AM, Hertroijs DF, Schaper NC, Vrijhoef HJ, Ruwaard D. Profiling Patients' Healthcare Needs to Support Integrated, Person-Centered Models for Long-Term Disease Management (Profile): Research Design. Int J Integr Care 2016; 16:1.

20. Moher D, Liberati A, Tetzlaff J, Altman DG, Group P. Preferred reporting items for systematic reviews and meta-analyses: the PRISMA Statement. Open medicine : a peerreviewed, independent, open-access journal 2009; 3:e123-130.

21. Busetto L, Luijkx KG, Elissen AM, Vrijhoef HJ. Intervention types and outcomes of integrated care for diabetes mellitus type 2: a systematic review. Journal of evaluation in clinical practice 2016; 22:299-310.

22. Coulter A, Entwistle VA, Eccles A, Ryan S, Shepperd S, Perera R. Personalised care planning for adults with chronic or long-term health conditions. The Cochrane database of systematic reviews 2015; 3:CD010523.

23. McCulloch DK, Price MJ, Hindmarsh M, Wagner EH. A population-based approach to diabetes management in a primary care setting: early results and lessons learned. Effective clinical practice : ECP 1998; 1:12-22.

24. Austin B, Wagner E, Hindmarsh M, Davis C. Elements of Effective Chronic Care: A Model for Optimizing Outcomes for the Chronically III. Epilepsy \& behavior : E\&B 2000; 1:S15S20.

25. Armijo-Olivo S, Stiles CR, Hagen NA, Biondo PD, Cummings GG. Assessment of study quality for systematic reviews: a comparison of the Cochrane Collaboration Risk of Bias Tool and the Effective Public Health Practice Project Quality Assessment Tool: methodological research. Journal of evaluation in clinical practice 2012; 18:12-18.

26. Andersen R, Newman JF. Societal and individual determinants of medical care utilization in the United States. The Milbank Memorial Fund quarterly Health and society 1973; 51:95-124.

27. Al Omari M, Khader Y, Dauod AS, Al-Akour N, Khassawneh AH, Al-Ashker E, et al. Glycaemic control among patients with type 2 diabetes mellitus treated in primary care setting in Jordan. Primary care diabetes 2009; 3:173-179.

28. Benoit SR, Fleming R, Philis-Tsimikas A, Ji M. Predictors of glycemic control among patients with Type 2 diabetes: a longitudinal study. BMC public health 2005; 5:36.

29. Cardenas-Valladolid J, Salinero-Fort MA, Gomez-Campelo P, de Burgos-Lunar C, Abanades-Herranz JC, Arnal-Selfa R, et al. Effectiveness of standardized Nursing Care Plans in health outcomes in patients with type 2 Diabetes Mellitus: a two-year prospective follow-up study. PloS one 2012; 7:e43870.

30. De Alba Garcia JEG, Dallo FJ, Salcedo Rocha AL, Rodriguez CC, Perez N, Baer RD, et al. The relative effect of self-management practices on glycaemic control in type 2 diabetic patients in Mexico. Chronic illness 2006; 2:77-85.

31. De Fine Olivarius N, Siersma V, Hansen LJ, Drivsholm T, Horder M. Changes in levels of haemoglobin A1c during the first 6 years after diagnosis of clinical type 2 diabetes. Scandinavian journal of clinical and laboratory investigation 2009; 69:851-857.

32. El-Kebbi IM, Cook CB, Ziemer DC, Miller CD, Gallina DL, Phillips LS. Association of younger age with poor glycemic control and obesity in urban african americans with type 2 diabetes. Archives of internal medicine 2003; 163:69-75. 
33. Groeneveld Y, Petri H, Hermans J, Springer M. An assessment of structured care assistance in the management of patients with type 2 diabetes in general practice. Scandinavian journal of primary health care 2001; 19:25-30.

34. Kellow NJ, Savige GS, Khalil H. Predictors of poor glycaemic control during the initial five years post-diagnosis in rural adults with type 2 diabetes. Australian Journal of Rural Health 2011; 19:267-274.

35. LeBlanc ES, Rosales AG, Kachroo S, Mukherjee J, Funk KL, Nichols GA. Do patient or provider characteristics impact management of diabetes? The American journal of managed care 2015; 21:597-606.

36. Liu LJ, Li Y, Sha K, Wang Y, He X. Patient assessment of chronic illness care, glycemic control and the utilization of community health care among the patients with type 2 diabetes in Shanghai, China. PloS one 2013; 8:e73010.

37. Luijks H, Biermans M, Bor H, van Weel C, Lagro-Janssen T, de Grauw W, et al. The Effect of Comorbidity on Glycemic Control and Systolic Blood Pressure in Type 2 Diabetes: A Cohort Study with 5 Year Follow-Up in Primary Care. PloS one 2015; 10:e0138662.

38. Mold F, While A, Forbes A. The management of type 2 diabetes care: The challenge within primary care. Practical Diabetes International 2008; 25:28-36.

39. Moreira RC, Mantovani Mde F, Soriano JV. Nursing Case Management and Glycemic Control Among Brazilians With Type 2 Diabetes: Pragmatic Clinical Trial. Nursing research 2015; 64:272-281.

40. Nielsen ABS, de Fine Olivarius N, Gannik D, Hindsberger C, Hollnagel H. Structured personal diabetes care in primary health care affects only women's HbA1c. Diabetes care 2006; 29:963-969.

41. Ostgren CJ, Lindblad U, Ranstam J, Melander A, Rastam L. Glycaemic control, disease duration and beta-cell function in patients with Type 2 diabetes in a Swedish community. Skaraborg Hypertension and Diabetes Project. Diabetic medicine : a journal of the British Diabetic Association 2002; 19:125-129.

42. Quah JHM, Liu YP, Luo N, How CH, Tay EG. Younger adult type 2 diabetic patients have poorer glycaemic control: A cross-sectional study in a primary care setting in Singapore. BMC endocrine disorders 2013; 13.

43. Quinn CC, Shardell MD, Terrin ML, Barr EA, Park D, Shaikh F, et al. Mobile Diabetes Intervention for Glycemic Control in 45- to 64-Year-Old Persons With Type 2 Diabetes. Journal of applied gerontology : the official journal of the Southern Gerontological Society 2016; 35:227-243.

44. Robinson S, Baron RB, Cooper B, Janson S. Does health service use in a diabetes management program contribute to health disparities at a facility level? Optimizing resources with demographic predictors. Population health management 2009; 12:139147.

45. Rothman R, Malone R, Bryant B, Horlen C, Pignone M. Pharmacist-led, primary carebased disease management improves hemoglobin $A 1 \mathrm{c}$ in high-risk patients with diabetes. American Journal of Medical Quality 2003; 18:51-58.

46. Rothman RL, DeWalt DA, Malone R, Bryant B, Shintani A, Crigler B, et al. Influence of patient literacy on the effectiveness of a primary care-based diabetes disease management program. Jama 2004; 292:1711-1716.

47. Sperl-Hillen JM, O'Connor PJ. Factors driving diabetes care improvement in a large medical group: ten years of progress. The American journal of managed care 2005; 11:S177-185. 
48. Taweepolcharoen N, Sumrithe S, Kunentrasai N, Phraisuwanna S. Diabetes control in a university primary care setting in Thailand. Quality in Primary Care 2006; 14:219-223.

49. Trief PM, Morin PC, Izquierdo R, Teresi J, Eimicke JP, Goland R, et al. Depression and glycemic control in elderly ethnically diverse patients with diabetes: the IDEATel project. Diabetes care 2006; 29:830-835.

50. Uitewaal PJ, Bruijnzeels MA, Bernsen RM, Voorham AJ, Hoes AW, Thomas S. Diabetes care in Dutch general practice: differences between Turkish immigrants and Dutch patients. Eur J Public Health 2004; 14:15-18.

51. Uitewaal PJ, Voorham AJ, Bruijnzeels MA, Berghout A, Bernsen RM, Trienekens PH, et al. No clear effect of diabetes education on glycaemic control for Turkish type 2 diabetes patients: a controlled experiment in general practice. The Netherlands journal of medicine 2005; 63:428-434.

52. Wahba H, Chang YF. Factors Associated with Glycemic Control in Patients with Type 2 Diabetes Mellitus in Rural Areas of the United States. Insulin 2007; 2:134-141.

53. Kellow NJ, Savige GS, Khalil H. Predictors of poor glycaemic control during the initial five years post-diagnosis in rural adults with type 2 diabetes. The Australian journal of rural health 2011; 19:267-274.

54. LeBlanc ES, Rosales AG, Kachroo S, Mukherjee J, Funk KL, Nichols GA. Do patient or provider characteristics impact management of diabetes? American Journal of Managed Care 2015; 21:597-606.

55. Quah JHM, Liu YP, Luo N, How CH, Tay EG. Younger adult type 2 diabetic patients have poorer glycaemic control: A cross-sectional study in a primary care setting in Singapore. $B M C$ endocrine disorders 2013; 3:13-18.

56. Tunceli K, Iglay K, Zhao C, Brodovicz KG, Radican L. Factors associated with adherence to oral antihyperglycemic monotherapy in patients with type 2 diabetes mellitus in the United Kingdom. Diabetes research and clinical practice 2015; 109:e27-31.

57. Pyatak EA, Florindez D, Peters AL, Weigensberg MJ. "We are all gonna get diabetic these days": the impact of a living legacy of type 2 diabetes on Hispanic young adults' diabetes care. The Diabetes educator 2014; 40:648-658.

58. Fonseca VA. Defining and characterizing the progression of type 2 diabetes. Diabetes care 2009; 32 Suppl 2:S151-156.

59. Khattab M, Khader YS, Al-Khawaldeh A, Ajlouni K. Factors associated with poor glycemic control among patients with type 2 diabetes. Journal of diabetes and its complications 2010; 24:84-89.

60. Abraira C, Colwell JA, Nuttall FQ, Sawin CT, Nagel NJ, Comstock JP, et al. Veterans Affairs Cooperative Study on glycemic control and complications in type II diabetes (VA CSDM). Results of the feasibility trial. Veterans Affairs Cooperative Study in Type II Diabetes. Diabetes care 1995; 18:1113-1123.

61. Mosenzon O, Raz I. Intensification of insulin therapy for type 2 diabetic patients in primary care: basal-bolus regimen versus premix insulin analogs: when and for whom? Diabetes care 2013; 36:S212-218.

62. Jin J, Sklar GE, Min Sen Oh V, Chuen Li S. Factors affecting therapeutic compliance: A review from the patient's perspective. Therapeutics and clinical risk management 2008; 4:269-286.

63. Heianza Y, Arase Y, Fujihara K, Tsuji H, Saito K, Hsieh SD, et al. High normal HbA(1c) levels were associated with impaired insulin secretion without escalating insulin resistance in Japanese individuals: the Toranomon Hospital Health Management Center Study 8 
(TOPICS 8). Diabetic medicine : a journal of the British Diabetic Association 2012; 29:1285-1290.

64. Mozaffarian D, Kamineni A, Carnethon M, Djousse L, Mukamal KJ, Siscovick D. Lifestyle risk factors and new-onset diabetes mellitus in older adults: the cardiovascular health study. Archives of internal medicine 2009; 169:798-807.

65. The Dutch college of general practitioners. Multidisciplinary practice guideline cardiovascular risk management Houten: Bohn Stafleu van Loghum 2011.

66. James PA, Oparil S, Carter BL, Cushman WC, Dennison-Himmelfarb C, Handler J, et al. 2014 evidence-based guideline for the management of high blood pressure in adults: report from the panel members appointed to the Eighth Joint National Committee (JNC 8). Jama 2014; 311:507-520.

67. van Hateren KJ, Landman GW, Kleefstra N, Houweling ST, van der Meer K, Bilo HJ. Time for considering other blood pressure target values in elderly patients with type 2 diabetes? International journal of clinical practice 2012; 66:125-127.

68. De Visser RO, Smith JA, McDonnell EJ. 'That's not masculine': masculine capital and health-related behaviour. Journal of health psychology 2009; 14:1047-1058.

69. Browne JL, Scibilia R, Speight J. The needs, concerns, and characteristics of younger Australian adults with Type 2 diabetes. Diabetic medicine : a journal of the British Diabetic Association 2013; 30:620-626.

70. Berwick DM, Nolan TW, Whittington J. The triple aim: care, health, and cost. Health affairs 2008; 27:759-769.

71. Jotkowitz AB, Rabinowitz G, Raskin Segal A, Weitzman R, Epstein L, Porath A. Do patients with diabetes and low socioeconomic status receive less care and have worse outcomes? A national study. The American journal of medicine 2006; 119:665-669.

72. Nam S, Chesla C, Stotts NA, Kroon L, Janson SL. Barriers to diabetes management: patient and provider factors. Diabetes research and clinical practice 2011; 93:1-9.

73. Bosma $\mathrm{H}$, Theunissen MJ, Verdonk $\mathrm{P}$, Feron F. Low control beliefs in relation to school dropout and poor health: findings from the SIODO case-control study. BMC Public Health 2014; $14: 1237$.

74. Elissen AMJ, Hertroijs DFL, Schaper NC, Bosma H, Dagnelie PC, Henry RM, et al. Differences in biopsychosocial profiles of diabetes patients by level of glycaemic control and health-related quality of life: The Maastricht Study. PLoS One 2017; 12:e0182053. 


\section{Supplementary material}

Supplementary Table S1. Quality of included studies

\begin{tabular}{|c|c|c|c|c|c|c|c|c|}
\hline Study & $\begin{array}{l}\text { Study } \\
\text { design }\end{array}$ & $\begin{array}{l}\text { Selection } \\
\text { bias }\end{array}$ & $\begin{array}{l}\text { Study } \\
\text { design }\end{array}$ & Confounders & Blinding & $\begin{array}{l}\text { Data } \\
\text { collection }\end{array}$ & $\begin{array}{l}\text { Drop- } \\
\text { outs }\end{array}$ & Global \\
\hline $\begin{array}{l}\text { Al Omari et al. } \\
(2009)\end{array}$ & CS & + & - & - & 0 & + & NA & - \\
\hline Benoit et al. (2005) & $\mathrm{RC}$ & + & o & + & o & + & NA & + \\
\hline $\begin{array}{l}\text { Cardenas-Valladolid } \\
\text { et al. (2012) }\end{array}$ & PC & + & o & + & o & + & - & o \\
\hline $\begin{array}{l}\text { De Fine Olivarius et } \\
\text { al. (2009) }\end{array}$ & PC & + & o & + & - & + & + & $\mathrm{o}$ \\
\hline Elissen et al. (2012) & $\mathrm{RC}$ & o & o & - & + & + & - & - \\
\hline $\begin{array}{l}\text { El Kebbi et al. } \\
(2003)\end{array}$ & $\mathrm{RC}$ & o & o & + & + & + & NA & + \\
\hline $\begin{array}{l}\text { De Alba Garcia et } \\
\text { al. (2006) }\end{array}$ & CS & - & - & + & - & + & + & - \\
\hline $\begin{array}{l}\text { Groeneveld et al. } \\
\text { (2001) }\end{array}$ & $\mathrm{RCT}$ & o & + & - & - & + & o & - \\
\hline $\begin{array}{l}\text { Kellow, Savige and } \\
\text { Khalil(2011) }\end{array}$ & $\mathrm{RC}$ & o & o & o & + & + & - & o \\
\hline LeBlanc et al (2015) & $\mathrm{RC}$ & o & o & + & + & + & NA & + \\
\hline Liu et al. (2013) & CS & + & - & o & - & o & NA & - \\
\hline Luijks et al. (2015) & PC & + & o & + & o & + & + & + \\
\hline $\begin{array}{l}\text { Mold, While and } \\
\text { Forbes (2008) }\end{array}$ & $\mathrm{RC}$ & o & o & - & + & + & NA & o \\
\hline $\begin{array}{l}\text { Moreira et al. } \\
\text { (2015) }\end{array}$ & RCT & - & + & - & o & + & + & - \\
\hline Nielsen et al. (2006) & $\mathrm{RCT}$ & - & + & + & - & + & - & - \\
\hline $\begin{array}{l}\text { Ostgren et al. } \\
(2002)\end{array}$ & CS & + & - & - & - & + & NA & - \\
\hline Quah et al. (2013) & CS & o & - & + & o & o & NA & o \\
\hline Quinn et al. (2016) & $\mathrm{RCT}$ & o & + & - & o & + & o & o \\
\hline $\begin{array}{l}\text { Robinson et al. } \\
(2009)\end{array}$ & PC & - & o & - & - & + & - & - \\
\hline $\begin{array}{l}\text { Rothman et al. } \\
\text { (2003) }\end{array}$ & $\mathrm{RC}$ & - & o & + & o & + & + & o \\
\hline $\begin{array}{l}\text { Rothman et al. } \\
\text { (2004) }\end{array}$ & $\mathrm{RCT}$ & o & + & + & - & + & + & o \\
\hline $\begin{array}{l}\text { Sperl Hillen and } \\
\text { O'Connor (2005) }\end{array}$ & $\mathrm{RC}$ & + & - & o & o & + & + & o \\
\hline
\end{tabular}




\begin{tabular}{|c|c|c|c|c|c|c|c|c|}
\hline Study & $\begin{array}{l}\text { Study } \\
\text { design }\end{array}$ & $\begin{array}{l}\text { Selection } \\
\text { bias }\end{array}$ & $\begin{array}{l}\text { Study } \\
\text { design }\end{array}$ & Confounders & Blinding & $\begin{array}{l}\text { Data } \\
\text { collection }\end{array}$ & $\begin{array}{l}\text { Drop- } \\
\text { outs }\end{array}$ & Global \\
\hline $\begin{array}{l}\text { Taweepolcharoen et } \\
\text { al. (2006) }\end{array}$ & CS & + & - & - & + & + & NA & - \\
\hline Trief et al. (2006) & CT & - & 0 & + & + & + & + & o \\
\hline Uitewaal et al. (2004) & $\mathrm{RC}$ & - & o & - & o & + & NA & - \\
\hline Uitewaal et al. (2005) & CT & - & + & + & - & + & + & - \\
\hline $\begin{array}{l}\text { Whaba and Chang } \\
\text { (2007) }\end{array}$ & CS & - & 0 & o & o & + & NA & o \\
\hline $\begin{array}{l}\text { Sum } \\
(+/ 0 /-)\end{array}$ & & $9 / 9 / 9$ & $6 / 14 / 7$ & $13 / 4 / 10$ & $7 / 11 / 9$ & $25 / 2 / 0$ & $9 / 2 / 5$ & $4 / 11 / 12$ \\
\hline
\end{tabular}

Abbreviations: CS: cross-sectional; RC: retrospective cohort; PC: prospective cohort; RCT: randomized controlled trial; $\mathrm{CT}$ : controlled trial.

+: strong; o: moderate; -: weak. 


\section{Differences in biopsychosocial profile of diabetes patients by level of glycaemic control and health-related quality of life: a cross-sectional study}

\section{Published as:}

A.M.J. Elissen, D.F.L. Hertroijs, N.C. Schaper, H. Bosma, P.C. Dagnelie, R.M. Henry, R.M. van der Kallen, A. Koster, M.T. Schram, C.D.A. Stehouwer, J.S.A.G. Schouten, T.T.J.M. Berendschot \& D. Ruwaard. Differences in biopsychosocial profiles of diabetes patients by level of glycaemic control and health-related quality of life: The Maastricht Study. PloS One. 2017;12(7):1-17. 


\section{Abstract}

Aims: Tailored, patient-centred innovations are needed in the care for persons with type 2 diabetes mellitus (T2DM), in particular those with insufficient glycaemic control. Therefore, this study sought to assess their biopsychosocial characteristics and explore whether distinct biopsychosocial profiles exist within this subpopulation, which differ in health-related quality of life (HRQoL).

Methods: Cross-sectional study based on data from The Maastricht Study, a population-based cohort study focused on the aetiology, pathophysiology, complications, and comorbidities of T2DM. We analysed associations and clustering of glycaemic control and HRQoL with 38 independent variables (i.e. biopsychosocial characteristics) in different subgroups and using descriptive analyses, latent class analysis (LCA), and logistic regressions.

Results: Included were 840 persons with T2DM, mostly men (68.6\%) and with a mean age of 62.6 ( \pm 7.7 ) years. Mean $\mathrm{HbA1c}$ was $7.1 \%$ ( $\pm 3.2 \%)$; 308 patients $(36.7 \%)$ had insufficient glycaemic control (HbA1c>7.0\% [53 mmol/mol]). Compared to those with sufficient control, these patients had a significantly worse-off status on multiple biopsychosocial factors, including self-efficacy, income, education and several health-related characteristics. Two 'latent classes' were identified in the insufficient glycaemic control subgroup: with low respectively high HRQoL. Of the two, the low HRQoL class comprised about one-fourth of patients and had a significantly worse biopsychosocial profile.

Conclusions: Insufficient glycaemic control, particularly in combination with low HRQoL, is associated with a generally worse biopsychosocial profile. Further research is needed into the complex and multidimensional causal pathways explored in this study, so as to increase our understanding of the heterogeneous care needs and preferences of persons with T2DM, and translate this knowledge into tailored care and support arrangements. 


\section{Introduction}

Diabetes care in the Netherlands is widely regarded as a 'best practice' [1] and several developments were pivotal in shaping this care model. In 2003, an evidence-based standard for generic care for type 2 diabetes mellitus (T2DM) was established by the Netherlands Diabetes Federation - an umbrella organisation of diabetes care professionals, patients and researchers - providing the norm for high-quality, multidisciplinary diabetes care [2].

Another important change followed in 2007, when a bundled payment system was introduced allowing health insurers to contract the different components of generic diabetes management as an integrated care programme, based on the diabetes care standard [3-5]. Their main contracting partners in primary care are care groups, i.e. networks of general practitioners (GPs) comparable to Clinical Commissioning Groups (CCGs) in the United Kingdom. As part of their contract with health insurers, care groups assume clinical and financial responsibility for integrated diabetes care delivery and coordination [6]. Today, there are around 115 care groups with an integrated diabetes care contract, covering 85 percent of the approximately 900,000 Dutch citizens with diagnosed T2DM [6,7].

Since care groups emerged in Dutch primary care, many studies have been conducted to assess the quality of diabetes care provided by these groups. According to a recent evaluation [6], relevant process and outcome indicators have improved over the years in most groups and now seem to be stabilising. For example, a relatively steady share of around two-thirds of patients has sufficient glycaemic control (glycated haemoglobin (HbA1c) levels $\leq 7.0 \%$ [53 $\mathrm{mmol} / \mathrm{mol}]$ ) [6]. Within the limitations of current practice, it seems unlikely that this percentage will increase much further: both the former report [6] and the Euro Diabetes Index [1] showed that in general, Dutch GPs strictly adhere to the care standard, suggesting that the outcomes achieved represent near-optimal results.

The existence of plateau values in processes and outcomes points towards a need for further innovation: the current, highly standardised care approach leaves a considerable subgroup - about a third of patients with diagnosed T2DM, i.e. roughly 300,000 people in the Netherlands $[6,7]$ - unable to adequately manage glycaemic control. In the long-term, these patients have a higher risk of microvascular and macrovascular complications, and lower health-related quality of life (HRQoL) [8]. The phenomenon of differential treatment effects is not unique to Dutch diabetes care: multiple studies in different countries have recently shown that 'one-size-fits-all' diabetes management does not actually fit for all patients $[9,10]$. It remains unclear, however, which biopsychosocial factors are associated with more or less promising treatment outcomes.

The present study hypothesises that there is a broad range of patient characteristics influencing the ability of individuals to self-manage, their need for professional treatment and support, and, ultimately, their level of glycaemic control and HRQoL. In a first step towards leveraging these characteristics to develop more person-centred, tailored diabetes care, this study aims to: (1) gain insight into the biopsychosocial characteristics of patients with insufficient glycaemic control, as opposed to patients with sufficient control; and (2) explore 
whether distinct biopsychosocial profiles can be identified within the group of patients with insufficient glycaemic control, which are associated with different HRQoL. For the latter purpose, an explorative latent class analysis (LCA) was conducted. The study was based on a comprehensive subset of phenotyping data from the population-based The Maastricht Study.

\section{Materials and Methods}

\section{Study design and study population}

We conducted a cross-sectional study based on data from The Maastricht Study, an observational prospective population-based cohort study in the region of Maastricht in the southern part of the Netherlands. The rationale and methodology have been described previously [11]. In brief, the study focuses on the aetiology, pathophysiology, complications, and comorbidities of T2DM, and is characterised by an extensive phenotyping approach. Eligible for participation were all individuals aged between 40 and 75 years, and living in the Maastricht region. Participants were recruited through mass media campaigns and from the municipal registries and the regional Diabetes Patient Registry via mailings. Recruitment was stratified according to known T2DM status, with an oversampling of individuals with T2DM, for reasons of efficiency.

For this study, cross-sectional data were used from the first 975 participants with T2DM in The Maastricht Study, who completed the baseline survey between November 2010 and September 2013. The examinations of each participant were performed within a time window of three months. Participants were included in the present study if they were previously diagnosed with T2DM by a health professional (i.e. prior to participating in The Maastricht Study) and had an HbA1c measurement conducted at The Maastricht Study research centre. No further in- or exclusion criteria were used.

The Maastricht Study has been approved by the institutional medical ethical committee (NL31329.068.10) and the Minister of Health, Welfare and Sports of the Netherlands (Permit 131088-105234-PG). All participants gave written informed consent.

\section{Definition of dependent and independent variables}

The study was conducted in two steps, which differed in terms of the dependent variable. First, to gain insight into differences in patients' biopsychosocial characteristics by level of glycaemic control, we used participants' HbA1c level as dependent variable. Although there is growing interest in, amongst others, glycated albumin and fructosamin as alternative markers of glycaemic control, $\mathrm{HbA1c}$ remains the gold standard biomarker of glycaemia [12]. It has been used as a universally accepted means for monitoring glycaemic control for more than three decades [13].

We dichotomised $\mathrm{HbA} 1 \mathrm{c}$ based on the norm values in the Dutch diabetes care standard [2]. Thus, subgroups represented sufficient glycaemic control (HbA1c $\leq 7.0 \%$ [53 mmol/mol]) versus insufficient glycaemic control $(\mathrm{HbA} 1 \mathrm{c}>7.0 \%$ [53 mmol/mol]).Second, we explored whether there are distinct biopsychosocial profiles within the patient subgroup with 
insufficient glycaemic control, which differ in terms of HRQoL. Several HRQoL measures were used as dependent variable, given the potential effect of insufficient glycaemic control on HRQoL and the importance of this outcome to patients [8]. As LCA requires a categorical dependent variable, we dichotomised summary scores from three surveys focused on various domains of HRQoL: PAID, EQ-5D-3L and SF-36. The 20-items PAID (Problem Areas in Diabetes) survey assesses diabetes-related emotional distress; a sum score of 40 - indicating severe distress at the level of 'emotional burnout' - was used for dichotomisation [14]. Based on the EQ-5D-3L questionnaire, five binary variables were defined illustrating the presence or absence of problems related to mobility, self-care, usual activities, pain/discomfort and anxiety/depression [15]. Participants' SF-36 scores were aggregated into two summary measures of HRQoL, i.e. the Physical (PCS) and Mental Component Summary (MCS) scores [16]. The Dutch PCS and MCS norm scores - i.e. 50 and 42 points, respectively - were used as cut-off points for dichotomisation [17].

In both steps, independent variables comprised a comprehensive set of biopsychosocial characteristics considered potential predictors of health outcomes (in this case, glycaemic control and HRQoL) in patients with T2DM. To structure these characteristics in a meaningful way, we used Andersen and Newman's Behavioural Model of Health Service Use [18]. Given the strong reported associations between glycaemic control, HRQoL and health service use $[19,20]$, we assumed that applying this model could provide relevant insights for tailoring diabetes care. Anderson and Newman [18] distinguish three categories of individual determinants of health service use: person-related, context-related and health-related factors.

\section{Person-related characteristics}

Person-related (or predisposing) characteristics determine people's personal predisposition to use health services [18]. The variables in this category were: age (in years), sex (male/female), smoking behaviour, alcohol consumption, self-reported physical activity (in hours/week), mastery, self-efficacy and social adequacy. Smoking behaviour was categorised as non-, former or current smoker. Alcohol consumption was classified as none, low ( $\leq 7$ glasses/week for women; $\leq 14$ glasses per week for men) or high (>7 glasses/week for women; $>14$ glasses per week for men) based on the 2006 Health Council of the Netherlands guidelines for a healthy diet [21]. Self-efficacy and mastery are measures of a person's control beliefs: where self-efficacy is a person's belief that he is able to perform a (desired) action or behaviour, mastery refers to his belief that his actions matter for outcomes.[22] We measured self-efficacy by the sum of items scores on the Dutch adaptation [23] of the validated, 16-item Self-Efficacy Scale of Sherer et al. [24]: higher scores suggest more self-efficacy. Mastery was defined as participants' sum score on seven items of the Pearlin Mastery Scale, with higher total scores indicating a greater sense of personal mastery [25]. Social adequacy was measured using a shortened version (15 items) of the Dutch Personality Questionnaire, which was recoded so that higher sum scores indicate greater social adequacy [26]. 


\section{Context-related characteristics}

Context-related (or enabling) factors are largely socioeconomic variables that facilitate or hamper a person's service use and might affect glycaemic control [18]. Four enabling factors were analysed: household income (in euros per month), educational level, employment status and marital status. Household income was 'equivalised' using the Organisation for Economic Co-operation and Development (OECD) square root scale to reflect differences in needs between households of different size [27]. Hence, the median value of the income class to which a given household belonged was divided by the square root of household size. Income classes ranged from $<€ 750$ to $\geq € 5000$ per month, with each subsequent class representing a $€ 250$ income increase. Education was dichotomised as low/medium (elementary education, preparatory secondary vocational education, senior general secondary education or senior secondary vocational education) versus high (pre-university, higher professional or academic education) based on a participant's highest completed type of education. With regard to employment status, two categories were distinguished: employed persons (selfemployed/entrepreneurs, employees and civil servants) versus not employed persons (disabled, unemployed, rentiers, retirees, homemakers and others). Marital status could be either with partner (married or registered partners, or living together) or without partner (unmarried, widow(er), divorced, or other).

\section{Health-related characteristics}

The third category concerns health-related (or illness-level) factors, which - according to Anderson and Newman [18] - are the strongest predictors of health service use. Variables in this category were: diabetes duration (in years), diabetes-related complications, depression, HRQoL, and medication use, as well as multiple clinical measures determined by physical examination (i.e. weight, waist circumference, body mass index (BMI), and systolic and diastolic blood pressure) or laboratory assessment (i.e. HbA1c, total cholesterol, low-density lipoprotein (LDL) and high-density lipoprotein (HDL) cholesterol, and triglycerides).

Four diabetes-related complications were assessed - i.e. cardiovascular disease, neuropathic pain, retinopathy and chronic kidney disease - as described elsewhere [28,29]. Based on the Patient Health Questionnaire (PHQ) instrument for screening, diagnosing and measuring severity of depression, we categorised depression as: (1) no or minimal depressive symptoms (score 0-9); (2) minor depression (score 10-14); or (3) major depression ( $\geq 15$ ) [30,31]. Besides the dichotomised HRQoL measures described earlier, a weighted overall HRQoL score was calculated from the EQ-5D-3L items, ranging from -0.33 to 1.00 on the basis of a Dutch validation study [15]. Medication use was categorised as none, oral and injectable (non-insulin) pharmacological agents (i.e. alfaglucosidase inhibitors, biguanides, dipeptidyl peptidase-4 (DPP4) inhibitors, glucagon-like peptide 1 analogues, and/or sulphonylurea derivatives), or insulin (with/without oral and injectable (non-insulin) pharmacological agents). 


\section{Statistical analyses}

Descriptive analyses were conducted to assess the biopsychosocial profile of diabetes patients by level of glycaemic control ( $\mathrm{HbA} 1 \mathrm{c} \leq 7.0 \%$ [53 mmol$/ \mathrm{mol}] \mathrm{vs}>7.0 \%$ [53 $\mathrm{mmol} / \mathrm{mol}]$ ) in terms of the 38 included independent variables. Continuous variables are presented as means and standard deviations (SD); binary and categorical data as frequencies and valid percentages. Missing data were assumed to be missing at random and not imputed. Depending on the nature of the independent variables, different statistical tests were used to measure associations with glycaemic control. Thus, for continuous variables, independent samples ttests were used; for binary and categorical variables, group comparisons were performed by chi-squared test and one-way ANOVA, respectively. A p-value $<0.05$ was set as level of significance. Analyses were conducted using IBM SPSS Statistics for Windows, version 23.0 (Armonk, NY).

LCA, also known as finite mixture modelling, was used to explore the existence of biopsychosocial profiles in the insufficient glycaemic control subgroup ( $\mathrm{HbA} 1 \mathrm{c}>7.0 \%$ [53 $\mathrm{mmol} / \mathrm{mol}]$ ), which differ in HRQoL. First, a one-class model was applied, after which the number of classes was sequentially increased up to a five-class model. To decide on the most parsimonious and best-fitting model, the Bayesian Information Criterion (BIC) was used for comparison across models, where the lowest value indicates the best fit [32]. The Lo-MendellRubin likelihood ratio test (LMR-LRT) was also used to compare fit between neighbouring models. A significant $p$-value $(p<0.05)$ indicates an improvement in fit for inclusion of one or more classes [32]. Entropy was used to determine the quality of classification. Higher entropy values indicate less ambiguity in class allocation [33]. LCA models were fitted using Mplus, version 7.3 [34]. Based on the results of the LCA, posterior probability of belonging to a given 'latent class' was determined for each patient and used as dependent variable in univariable logistic regression analyses to examine significant differences in biopsychosocial profile between HRQoL classes. Odds ratios (ORs) with 95\% confidence intervals (Cls) were obtained using STATA version 14 [35].

\section{Results}

Of The Maastricht Study participants with T2DM, 840 persons met the inclusion criteria. The study flowchart is included in Supplement 1 (S1 Fig). Mean age of the study population was $62.6( \pm 7.7)$ years. Males were overrepresented $(68.6 \%)$. Mean HbA1c level was $7.1 \%( \pm 3.2 \%)$ [54 ( \pm 12$) \mathrm{mmol} / \mathrm{mol}$. Based on the Dutch diabetes care standard [2], 532 patients $(63.3 \%)$ had sufficient glycaemic control (HbA1c $\leq 7.0 \%$ [53 mmol/mol]), whereas 308 patients $(36.7 \%)$ had insufficient control (HbA1c>7.0\% [53 $\mathrm{mmol} / \mathrm{mol}])$.

\section{Biopsychosocial characteristics of diabetes patients by level of glycaemic control}

Table 1 shows the distribution of person-related characteristics across subgroups. Patients with sufficient glycaemic control had a significantly higher level of self-efficacy compared to those with insufficient control (59.4 \pm 8.2 vs. $58.1 \pm 8.3 ; p=0.047)$. There were no differences 
between subgroups in age, sex, smoking status, alcohol consumption, physical activity, mastery or social adequacy.

Table 1. Person-related patient characteristics by glycaemic control.

\begin{tabular}{|c|c|c|c|c|c|}
\hline Characteristic & $\mathbf{N}$ & $\begin{array}{l}\text { HbA1<=7.0\% } \\
{[53 \mathrm{mmol} / \mathrm{mol}]} \\
(\mathrm{N}=532)\end{array}$ & $\begin{array}{l}\text { HbA1c }>7.0 \% \\
{[53 \mathrm{mmol} / \mathrm{mol}]} \\
(\mathrm{N}=308)\end{array}$ & $\begin{array}{l}\text { Total } \\
(\mathrm{N}=840)\end{array}$ & p-value \\
\hline Age (years) & 840 & $62.9 \pm 7.6$ & $62.3 \pm 7.7$ & $62.6 \pm 7.7$ & 0.26 \\
\hline Sex & 840 & & & & 0.29 \\
\hline Men & & $358(67.3 \%)$ & $218(70.8 \%)$ & $576(68.6)$ & \\
\hline Women & & $174(32.7 \%)$ & $90(29.2 \%)$ & 264 (31.4) & \\
\hline Smoking status & 809 & & & & 0.29 \\
\hline Never & & $151(29.5 \%)$ & $73(24.5 \%)$ & $224(27.7)$ & \\
\hline Former & & $276(54.0 \%)$ & $172(57.7 \%)$ & $448(55.4)$ & \\
\hline Current & & $84(16.4 \%)$ & $53(17.8 \%)$ & 137 (16.9) & \\
\hline Alcohol consumption & 809 & & & & 0.27 \\
\hline None & & $153(29.9 \%)$ & $100(33.6 \%)$ & $253(31.3)$ & \\
\hline Low & & $264(51.7 \%)$ & $155(52.0 \%)$ & 419 (51.8) & \\
\hline High & & $94(18.4 \%)$ & 43 (14.4\%) & $137(16.9)$ & \\
\hline $\begin{array}{l}\text { Physical } \\
\text { (hours/week) }\end{array}$ & 672 & $12.1 \pm 7.7$ & $11.8 \pm 8.0$ & $12.0 \pm 7.8$ & 0.57 \\
\hline Self-efficacy & 672 & $59.4 \pm 8.2$ & $58.1 \pm 8.3$ & $58.9 \pm 8.2$ & $0.047^{*}$ \\
\hline Mastery & 680 & $25.6 \pm 4.8$ & $25.2 \pm 5.0$ & $25.5 \pm 4.9$ & 0.27 \\
\hline Social adequacy & 673 & $3.6 \pm 3.7$ & $3.5 \pm 3.7$ & $3.6 \pm 3.7$ & 0.75 \\
\hline
\end{tabular}

Continuous variables are presented as means and standard deviations (SD); binary and categorical data as frequencies and valid percentages. *Significant at the $\mathrm{P}<0.05$ level.

Table 2 shows the context-related characteristics of patients by HbA1c level. The sufficient glycaemic control subgroup had a significantly higher mean equivalent income (in euros) than the subgroup with insufficient control $(1,899 \pm 906$ vs. $1,736 \pm 763 ; p=0.03)$. Moreover, there were significantly more high-educated persons and fewer low-educated persons among those with sufficient glycaemic control $(p=0.047)$. No subgroup differences were identified with regard to employment or marital status.

Table 2. Context-related patient characteristics by glycaemic control.

\begin{tabular}{|c|c|c|c|c|c|}
\hline Characteristic & $\mathbf{N}$ & $\begin{array}{l}\text { HbA1<=7.0\% } \\
{[53 \mathrm{mmol} / \mathrm{mol}]} \\
(\mathrm{N}=532)\end{array}$ & $\begin{array}{l}\text { HbA1c }>7.0 \% \\
{[53 \mathrm{mmol} / \mathrm{mol}]} \\
(\mathrm{N}=308)\end{array}$ & $\begin{array}{l}\text { Total } \\
(\mathrm{N}=840)\end{array}$ & p-value \\
\hline Equivalent income (euros) & 551 & $1,899 \pm 906$ & $1,736 \pm 763$ & $1,841 \pm 861$ & $0.03 *$ \\
\hline Educational level & 809 & & & & $0.047^{*}$ \\
\hline Low/medium & & 373 (72.9) & $235(79.1)$ & $608(75.2)$ & \\
\hline High & & $139(27.1)$ & 62 (20.9\%) & $201(24.8)$ & \\
\hline Employment status & 694 & & & & 0.75 \\
\hline Not employed & & $306(68.6)$ & $173(69.8)$ & $479(69.0)$ & \\
\hline Employed & & 140 (31.4) & 75 (30.2) & $215(31.0)$ & \\
\hline Marital status & 816 & & & & 0.40 \\
\hline No partner & & $109(21.1)$ & $71(23.7)$ & $180(21.4)$ & \\
\hline Partner & & 407 (78.9) & $229(76.3)$ & $636(77.9)$ & \\
\hline
\end{tabular}


As to health-related characteristics (Tables 3-5), patients with insufficient glycaemic control had a significantly longer mean duration of diabetes ( $11.1 \pm 8.0$ vs. $6.9 \pm 5.9$ years; $p<0.001)$, as well as a higher prevalence of cardiovascular disease (34.1 vs. $25.9 \% ; p=0.014$ ), neuropathic pain ( 24.7 vs. $18.0 \%$; $=0.025)$, retinopathy ( 7.7 vs. $3.3 \%$; $p=0.007$ ) and chronic kidney disease (50.0 vs. $37.7 \% ; p<0.001$ ).

HRQoL was reduced in the insufficient glycaemic control subgroup compared to patients with sufficient control. Thus, mean PAID scores indicated higher diabetes-related emotional distress $(15.3 \pm 15.2$ vs. $9.3 \pm 11.6 ; p<0.001)$ and there was a significantly higher percentage of patients at an emotional burn-out level, as indicated by a PAID score $\geq 40$ (9.7 vs. $2.7 \%$; $\mathrm{p}<0.001$ ). Moreover, mean summary scores on all domains of HRQoL measured by the EQ-5D$3 \mathrm{~L}$ and SF-36 were significantly lower among patients with insufficient glycaemic control, as was the overall EQ-5D-3L index score.

Medication use was different between subgroups $(p<0.001)$ : in particular, the percentage of patients on insulin was greater in patients with insufficient glycaemic control compared to those with sufficient control (50.0 vs. $11.7 \%$ ). In terms of clinical measures, patients with insufficient glycaemic control differed significantly from their counterparts in terms of weight (91.6 \pm 17.7 vs. $87.1 \pm 15.2 ; p<0.001)$, waist circumference (108.9 \pm 14.6 vs. $105.1 \pm 12.6 ; p<0.001)$, BMI (30.9 \pm 5.3 vs. $29.5 \pm 4.7 ; p<0.001)$ and triglycerides ( $1.8 \pm 1.1$ vs. $1.7 \pm 0.9 ; p=0.047)$.

Table 3. Health-related patient characteristics by glycaemic control (continuous variables)

\begin{tabular}{|c|c|c|c|c|c|}
\hline Characteristic & $\mathbf{N}$ & $\begin{array}{l}\text { HbA1<=7.0\% } \\
{[53 \mathrm{mmol} / \mathrm{mol}]} \\
(\mathrm{N}=532)\end{array}$ & $\begin{array}{l}\text { HbA1c }>7.0 \% \\
{[53 \mathrm{mmol} / \mathrm{mol}]} \\
(\mathrm{N}=308)\end{array}$ & $\begin{array}{l}\text { Total } \\
(\mathrm{N}=840)\end{array}$ & p-value \\
\hline Diabetes duration & 663 & $6.88 \pm 5.89$ & $11.13 \pm 7.96$ & $8.5 \pm 7.0$ & $<0.001^{*}$ \\
\hline $\begin{array}{l}\text { Diabetes-related distress } \\
\text { (PAID) }\end{array}$ & 710 & $9.3 \pm 11.6$ & $15.3 \pm 15.2$ & $11.6 \pm 13.4$ & $<0.001^{*}$ \\
\hline EQ-5D-3L index score & 791 & $0.86 \pm 0.20$ & $0.83 \pm 0.19$ & $0.85 \pm 0.20$ & $0.05^{*}$ \\
\hline $\begin{array}{l}\text { SF-36 Physical component } \\
\text { score (total) }\end{array}$ & 785 & $47.24 \pm 9.47$ & $44.69 \pm 10.56$ & $46.3 \pm 9.9$ & $0.001^{*}$ \\
\hline $\begin{array}{l}\text { SF-36 Mental component } \\
\text { score (total) }\end{array}$ & 785 & $53.11 \pm 8.79$ & $51.55 \pm 9.44$ & $52.5 \pm 9.0$ & $0.02 *$ \\
\hline $\mathrm{HbA} 1 \mathrm{c}(\%[\mathrm{mmol} / \mathrm{mol}])$ & 840 & $6.5 \pm 2.5[47 \pm 4]$ & $8.1 \pm 3.2[65 \pm 12]$ & $\begin{array}{l}7.1 \pm 3.2 \\
{[54 \pm 12]}\end{array}$ & NA \\
\hline Total cholesterol ( $\mathrm{mmol} / \mathrm{l})$ & 840 & $4.3 \pm 0.9$ & $4.3 \pm 0.9$ & $4.3 \pm 0.9$ & 0.34 \\
\hline LDL cholesterol (mmol/l) & 840 & $2.3 \pm 0.8$ & $2.2 \pm 0.8$ & $2.3 \pm 0.8$ & 0.29 \\
\hline HDL cholesterol (mmol/l) & 840 & $1.3 \pm 0.3$ & $1.2 \pm 0.4$ & $1.2 \pm 0.4$ & 0.09 \\
\hline Triglycerides (mmol/l) & 840 & $1.7 \pm 0.9$ & $1.8 \pm 1.1$ & $1.7 \pm 0.9$ & $0.047^{*}$ \\
\hline Weight (kg) & 838 & $87.1 \pm 15.2$ & $91.6 \pm 17.7$ & $88.7 \pm 16.3$ & $<0.001^{*}$ \\
\hline Waist circumference $(\mathrm{cm})$ & 838 & $105.1 \pm 12.6$ & $108.9 \pm 14.6$ & $106.5 \pm 13.5$ & $<0.001^{*}$ \\
\hline BMI (in $\left.\mathrm{kg} / \mathrm{m}^{2}\right)$ & 838 & $29.5 \pm 4.7$ & $30.9 \pm 5.3$ & $30.0 \pm 5.0$ & $<0.001^{*}$ \\
\hline $\begin{array}{l}\text { Systolic blood pressure } \\
(\mathrm{mmHg})\end{array}$ & 840 & $142.3 \pm 17.8$ & $141.9 \pm 17.8$ & $142.2 \pm 17.8$ & 0.755 \\
\hline $\begin{array}{l}\text { Diastolic blood pressure } \\
(\mathrm{mmHg})\end{array}$ & 840 & $77.1 \pm 9.5$ & $76.3 \pm 9.5$ & $76.8 \pm 9.5$ & 0.265 \\
\hline
\end{tabular}


Table 4. Health-related patient characteristics by glycaemic control (binary variables)

\begin{tabular}{|c|c|c|c|c|c|c|}
\hline \multirow[t]{3}{*}{ Characteristic } & \multirow[t]{3}{*}{$\mathbf{N}$} & \multirow[t]{3}{*}{ Category } & $\mathrm{HbA} 1<=7.0 \%$ & HbA1c $>7.0 \%$ & \multirow{3}{*}{$\begin{array}{l}\text { Total } \\
(\mathrm{N}=840)\end{array}$} & \multirow[t]{3}{*}{ p-value } \\
\hline & & & [53 $\mathrm{mmol} / \mathrm{mol}]$ & [53 $\mathrm{mmol} / \mathrm{mol}]$ & & \\
\hline & & & $(\mathrm{N}=532)$ & $(\mathrm{N}=308)$ & & \\
\hline \multirow[t]{2}{*}{ Cardiovascular disease } & 817 & No & $371(74.1)$ & $193(65.9)$ & $\begin{array}{l}564 \\
(71.0)\end{array}$ & $0.01^{*}$ \\
\hline & & Yes & $130(25.9)$ & $100(34.1)$ & $\begin{array}{l}230 \\
(29.0)\end{array}$ & \\
\hline \multirow[t]{2}{*}{ Neuropathic pain } & 781 & No & $405(82.0)$ & $216(75.3)$ & $\begin{array}{l}621 \\
(79.5)\end{array}$ & $0.025^{*}$ \\
\hline & & Yes & $89(18.0)$ & $71(24.7)$ & $\begin{array}{l}160 \\
(20.5)\end{array}$ & \\
\hline \multirow[t]{2}{*}{ Retinopathy } & 762 & No & $472(96.7)$ & $253(92.3)$ & $\begin{array}{l}725 \\
(95.1)\end{array}$ & $0.01^{*}$ \\
\hline & & Yes & $16(3.3)$ & $21(7.7)$ & 37 (4.9) & \\
\hline \multirow[t]{2}{*}{ Chronic kidney disease } & 816 & No & $325(61.1)$ & $147(50.0)$ & $\begin{array}{l}472 \\
(57.8)\end{array}$ & $0.001^{*}$ \\
\hline & & Yes & $197(37.7)$ & $147(50.0)$ & $\begin{array}{l}344 \\
(42.2)\end{array}$ & \\
\hline \multirow[t]{2}{*}{$\begin{array}{l}\text { Diabetes-related distress } \\
\text { (PAID) }\end{array}$} & 710 & PAID score $<40$ & $430(97.3)$ & $242(90.3)$ & $\begin{array}{l}672 \\
(94.6)\end{array}$ & $<0.001^{*}$ \\
\hline & & PAID score $\geq 40$ & $12(2.7)$ & $26(9.7)$ & $38(5.4)$ & \\
\hline \multirow[t]{2}{*}{ EQ-5D-3L Mobility problems } & 796 & No & $356(70.5)$ & $186(63.9)$ & $\begin{array}{l}542 \\
(68.1)\end{array}$ & $0.055^{*}$ \\
\hline & & Yes & $149(29.5)$ & $105(36.1)$ & $\begin{array}{l}254 \\
(31.9)\end{array}$ & \\
\hline \multirow[t]{2}{*}{$\begin{array}{l}\text { EQ-5D-3L } \quad \text { Self-care } \\
\text { problems }\end{array}$} & 795 & No & $486(96.4)$ & $271(93.1)$ & $\begin{array}{l}757 \\
(95.2)\end{array}$ & $0.04 *$ \\
\hline & & Yes & $18(3.6)$ & $20(6.9)$ & $38(4.8)$ & \\
\hline \multirow[t]{2}{*}{$\begin{array}{l}\text { EQ-5D-3L Usual activities } \\
\text { problems }\end{array}$} & 796 & No & $430(85.3)$ & $217(74.3)$ & $\begin{array}{l}647 \\
(81.3)\end{array}$ & $<0.001^{*}$ \\
\hline & & Yes & $74(14.7)$ & $75(25.7)$ & $\begin{array}{l}149 \\
(18.7)\end{array}$ & \\
\hline \multirow[t]{2}{*}{ EQ-5D-3L Pain/discomfort } & 796 & No & $303(60.1)$ & $155(53.1)$ & $\begin{array}{l}458 \\
(57.5)\end{array}$ & $0.05^{*}$ \\
\hline & & Yes & 201 (39.9) & $137(46.9)$ & $\begin{array}{l}338 \\
(42.5)\end{array}$ & \\
\hline EQ-5D-3L & 796 & No & $430(85.3)$ & $229(78.4)$ & 659 & $0.01^{*}$ \\
\hline \multirow[t]{2}{*}{ Anxiety/depression } & & & & & $(82.8)$ & \\
\hline & & Yes & $74(14.7)$ & $63(21.6)$ & $\begin{array}{l}137 \\
(17.2)\end{array}$ & \\
\hline \multirow[t]{2}{*}{$\begin{array}{l}\text { SF-36 Physical component } \\
\text { score }\end{array}$} & 785 & $P C S \geq 50$ & $267(53.6)$ & $113(39.4)$ & $\begin{array}{l}380 \\
(48.4)\end{array}$ & $<0.001^{*}$ \\
\hline & & $P C S<50$ & $231(46.4)$ & $174(60.6)$ & $\begin{array}{l}405 \\
(51.6)\end{array}$ & \\
\hline \multirow[t]{2}{*}{$\begin{array}{l}\text { SF-36 Mental component } \\
\text { score }\end{array}$} & 785 & $M C S \geq 42$ & $446(89.6)$ & $244(85.0)$ & $\begin{array}{l}690 \\
(87.9)\end{array}$ & 0.06 \\
\hline & & $M C S<42$ & $52(10.4)$ & $43(15.0)$ & 95 (12.1) & \\
\hline
\end{tabular}

Binary variables are presented as frequencies and valid percentages. *Significant at the $\mathrm{P}<0.05$ level. 
Table 5. Health-related patient characteristics by glycaemic control (categorical variables)

\begin{tabular}{|c|c|c|c|c|c|c|}
\hline Characteristic & $\mathbf{N}$ & & $\begin{array}{l}\mathrm{HbA} 1<=7.0 \% \\
{[53 \mathrm{mmol} / \mathrm{mol}]} \\
(\mathrm{N}=532)\end{array}$ & $\begin{array}{l}\mathrm{HbA1c}>7.0 \% \\
{[53 \mathrm{mmol} / \mathrm{mol}]} \\
(\mathrm{N}=308)\end{array}$ & $\begin{array}{l}\text { Total } \\
(\mathrm{N}=840)\end{array}$ & $\mathrm{p}$-value \\
\hline \multirow[t]{3}{*}{ Depression } & 716 & No/minimal symptoms & $432(93.3)$ & $227(89.7)$ & $659(92.0)$ & 0.23 \\
\hline & & Minor depression & $19(4.1)$ & $15(5.9)$ & $34(4.7)$ & \\
\hline & & Major depression & $12(2.6)$ & $11(4.3)$ & $23(3.2)$ & \\
\hline Glucose-lowering & 839 & None & $66(12.4)$ & $10(3.2)$ & $76(9.1)$ & $<0.001^{*}$ \\
\hline \multirow[t]{2}{*}{ medication } & & $\begin{array}{l}\text { Oral and injectable } \\
\text { (non-insulin) }\end{array}$ & $403(75.9)$ & $144(46.8)$ & $547(65.2)$ & \\
\hline & & Insulin & $62(11.7)$ & $154(50.0)$ & $216(25.7)$ & \\
\hline
\end{tabular}

Categorical variables are presented as frequencies and valid percentages. *Significant at the $\mathrm{P}<0.05$ level.

HRQoL in patients with insufficient glycaemic control: biopsychosocial profiles

Among patients with insufficient glycaemic control ( $\mathrm{HbA} 1 \mathrm{c}>7.0 \%[53 \mathrm{mmol} / \mathrm{mol}] ; \mathrm{N}=308$ ), LCA was used to explore the existence of distinct biopsychosocial profiles, which differ in terms of HRQoL. LCA models were run with one to five classes. The model fit indices showed that the two- and three-class models had the best fit (S1 Table). The two-class model was chosen for further analysis, because of little distinction in patterns and item probabilities between class 2 and class 3 , as well as the small percentage of patients in class 3 based on most likely class membership (4.9\%).

Fig 1 shows the item response probability plot for the final two-class model. Values on the $y$-axes represent the likelihood, by class, of patients experiencing problems related to included HRQoL domains. Two distinct classes were identified: patients with 'low' HRQoL (28.6\%; N=88) versus patients with 'high' HRQoL (71.4\%; $\mathrm{N}=220)$. Classes differed most in the probability of experiencing problems with usual activities, anxiety and physical functioning, which was greater for patients with low HRQoL ( 70-90\%; Fig 1). On the other hand, the chance of problems with self-care and pain, as well as for severe diabetes-related distress (PAID score $\geq 40$ ), was relatively low and comparable in both classes, although consistently greater in the low HRQoL class. The likelihood of mobility issues was around $50 \%$ in the low HRQoL class versus circa $25 \%$ in the high HRQoL class. 


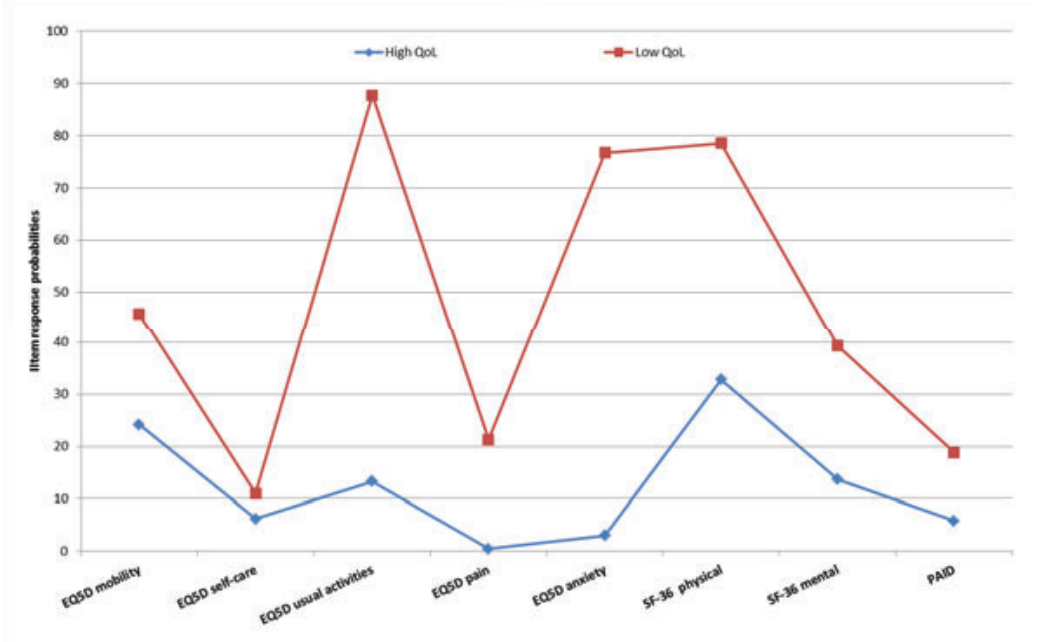

Figure 1. Two-class model for HRQoL in patients with insufficient glycaemic control (HbA1c $>7.0 \%[53 \mathrm{mmol} / \mathrm{mol}]$ ).

High HRQoL class, N=220 (71.4\%); low HRQoL class, $\mathrm{N}=88$ (28.6\%)

Tables 6-8 summarize the biopsychosocial characteristics of the identified HRQoL classes and show which characteristics were associated with HRQoL-based class membership (high HRQoL class is used as reference category). With regard to person-related characteristics, women had higher odds than men to be in the low HRQoL class (OR 2.32; $95 \% \mathrm{Cl} 1.36-3.94 ; \mathrm{p}=0.002$ ), as did current smokers compared to non-smokers (OR 2.24; $95 \% \mathrm{Cl} 1.03-4.88 ; \mathrm{p}=0.04$ ). Other person-related factors associated with greater odds of being in the low HRQoL class were no versus low or high alcohol consumption, less than 7 hours of physical activity per week versus 14 hours or more, and lower mastery, self-efficacy and social adequacy (Table 6).

Apart from marital status, all context-related characteristics (Table 7) were significantly different between HRQoL classes. Lower equivalent income was associated with higher odds of being in the low HRQoL class (OR 0.10; 95\% $\mathrm{Cl} 0.10-0.10 ; \mathrm{p}=0.007$ ), as was a low or medium educational level (OR 2.28; 95\% $\mathrm{Cl} 1.12-4.67 ; \mathrm{p}=0.02)$ and unemployment (OR $8.05 ; 95 \% \mathrm{Cl}$ 3.23-20.10; $p<0.001)$.

As for health-related characteristics (Table 8 ), a diabetes duration of $\geq 10$ years relative to $<5$ years was associated with higher odds for the low HRQoL class (OR 2.41; 95\% Cl 1.13-5.13; $\mathrm{p}=0.02$ ). Patients with cardiovascular disease, neuropathic pain or chronic kidney disease also had significantly higher odds to be in the low HRQoL class, as did patients with minor or major depression (ORs ranging from 2.08 to 6.21). Medication-wise, use of insulin instead of no or other diabetes medication was associated with higher odds for the low HRQoL class (OR 1.98; 95\% Cl 1.19-3.30; $\mathrm{p}=0.009$ ). Of the clinical measures, higher $\mathrm{HbA1c}, \mathrm{BMI}$, weight or waist circumference was associated with greater odds of belonging to the low HRQoL class (ORs from 1.02 to 1.12 ). 

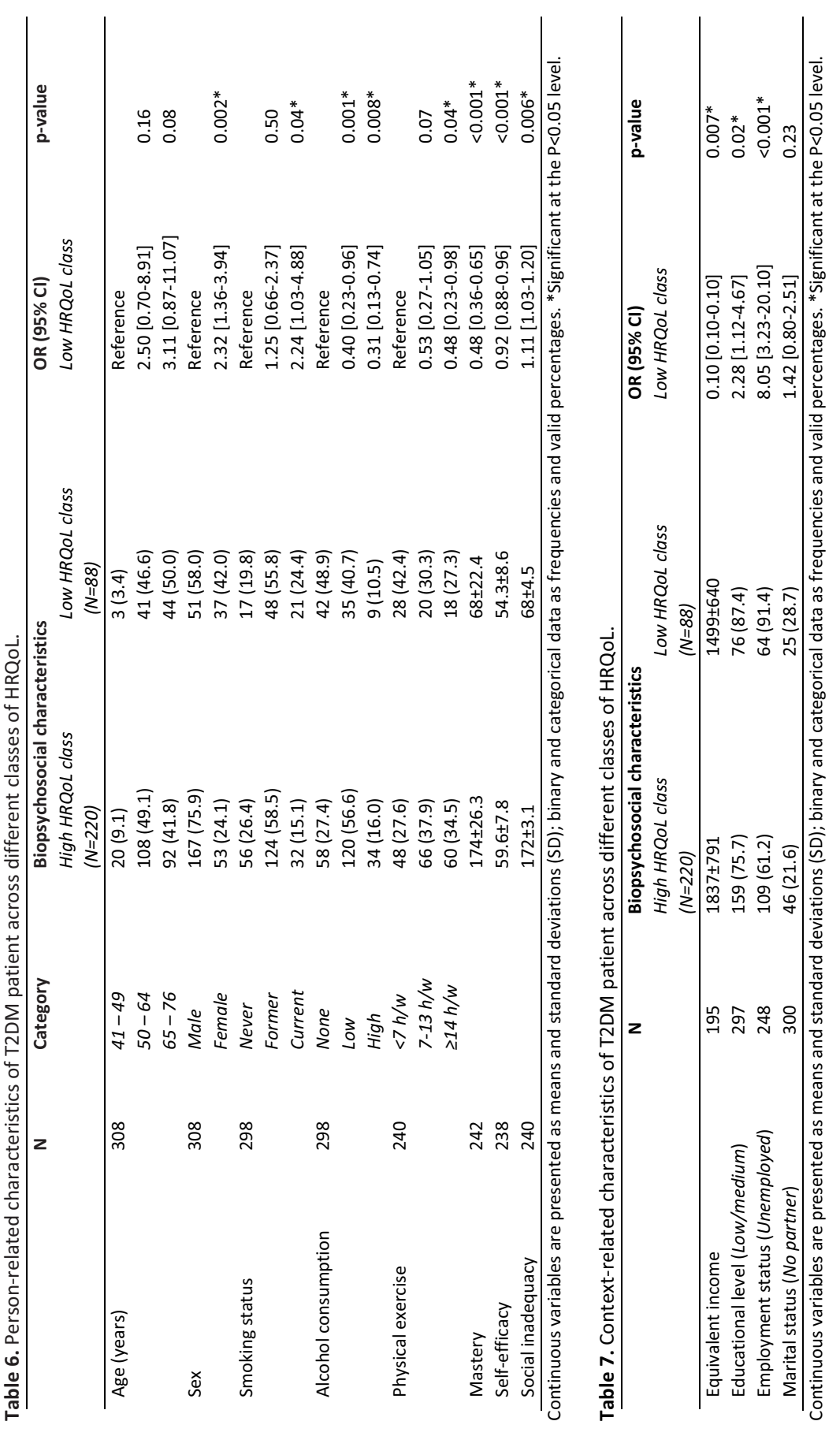


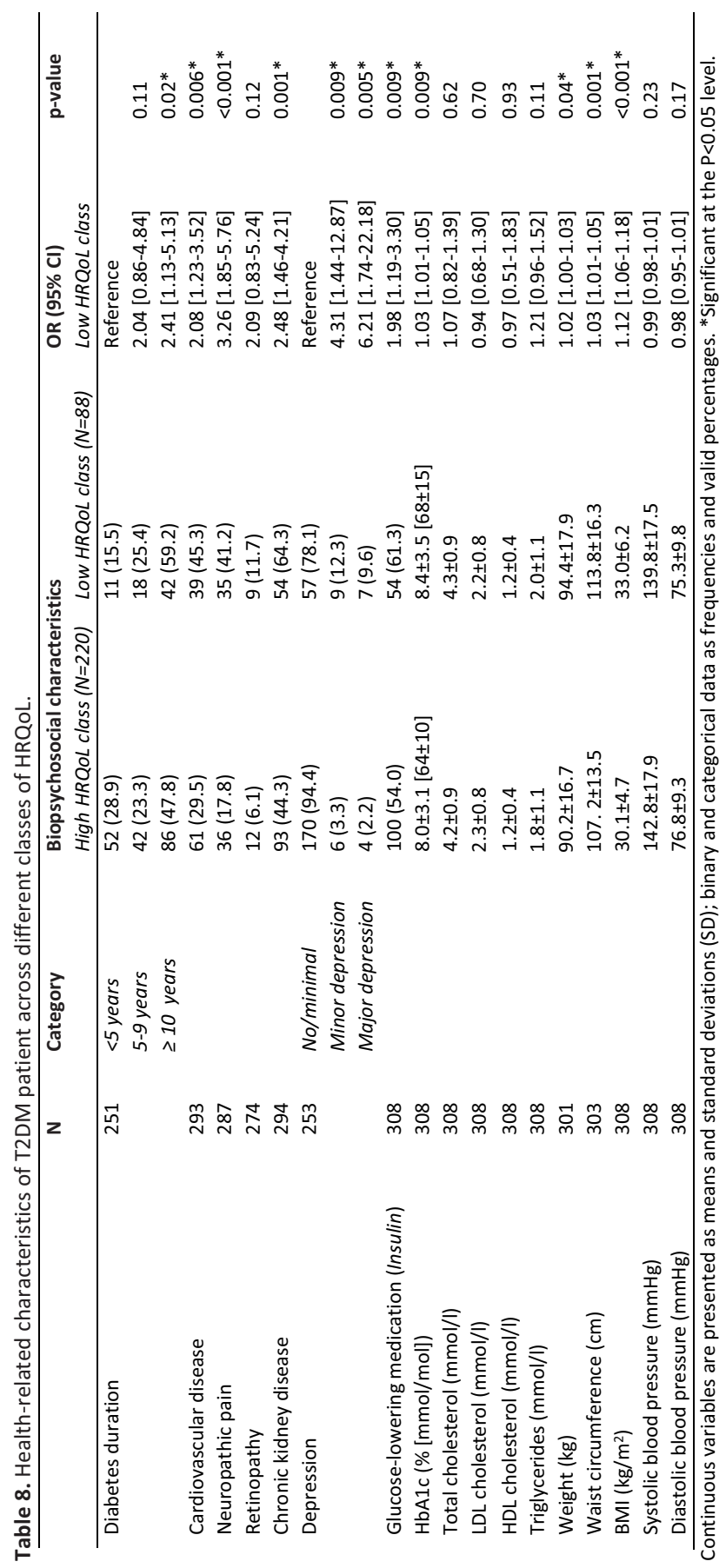




\section{Discussion}

Findings from this study suggest that significant differences exist in biopsychosocial characteristics between subgroups of diabetes patients by level of glycaemic control. Most characteristics were health-related, including HRQoL, complications, medication, and BMI. Of the assessed person- and context-related characteristics, self-efficacy respectively income and education level differed between glycaemic control subgroups, albeit modestly. Identified associations were consistently negative: a worse status on any of the significant variables was associated with less glycaemic control. Zooming in further on the insufficient glycaemic control subgroup, we identified two distinct patient classes in terms of HRQoL: one with a low probability of HRQoL problems and one with a higher probability of such problems. A broad range of biopsychosocial factors was associated with low HRQoL class membership, including lower levels of mastery, self-efficacy and social adequacy, lower income and education levels, longer disease duration, presence of various complications, and insulin use.

In 2012, the European Association for the Study of Diabetes (EASD) and American Diabetes Association (ADA) published a position statement on hyperglycaemia management in T2DM, which described the need to individualise treatment targets and strategies [8]. Yet in most countries, diabetes management remains highly standardised and does not comprehensively account for heterogeneity within the diabetes population [36,37]. Our findings support the need for more individualised management, by showing that patients with insufficient glycaemic control differ considerably from those with sufficient control. Differences exist not only in health-related variables, as emphasised by the EASD and ADA, but also on a psychosocial and socioeconomic level. Particularly lower self-efficacy, income and/or education levels seem to be associated with less glycaemic control. This is supported by previous research demonstrating the effects of self-efficacy on diabetes self-management and, consequently, glycaemic control [38]. Increasing evidence supports the notion that people's control beliefs are a fundamental mechanism underlying socioeconomic differences in health [39-41]. This might be particularly true for T2DM patients, as recent work suggests that among chronically ill, control beliefs are even more important determinants of HRQoL than social support or income [42].

To our knowledge, this is the first LCA among T2DM patients with insufficient glycaemic control. Findings suggest that in terms of HRQoL - described as an outcome that 'actually matters to patients' [43] - distinct classes exist within this subgroup: about a quarter of patients has serious problems in multiple HRQoL domains, whereas the others do not (yet) experience any limitations. This finding might partly explain why previous studies into the relation of glycaemic control with HRQoL, which did not account for 'latent subclasses', have found weak and inconsistent associations $[44,45]$. Looking at the specific domains in which problems were most likely to occur, i.e. with usual activities, anxiety and physical functioning, diabetes-related complications might be important predictors of low HRQoL. Indeed, previous research suggests that complications are more strongly associated with $\mathrm{HRQ}$ oL than $\mathrm{HbA1c}$, and that even minor complications can have a significant impact on HRQoL $[46,47]$. Given their higher complication rates and longer disease duration, it is not surprising that patients with insufficient glycaemic control - particularly those with low HRQoL - were more likely to use 
insulin. However, the overrepresentation of insulin users in this class might also suggest that insulin is an inadequate 'last resort' for some patients.

Patients with low versus high HRQoL in the insufficient glycaemic control subgroup also differed in person- and context-related characteristics - more profoundly even than when comparing patients by level of glycaemic control. Here again, control beliefs might mediate socioeconomic health differences. Living with diabetes poses many challenges for patients in areas like nutrition, glycaemic monitoring and medication adherence, which tend to become increasingly difficult and burdensome as glycaemic control deteriorates [48]. However, the knowledge, skills, confidence and means - both financially and socially - needed to adequately respond to these challenges are not distributed equally among the population, which might contribute to differences in HRQoL among those with insufficient glycaemic control. Indeed, estimates from the United Kingdom show that morbidity from diabetes-related complications is more than three times higher among the less well-off compared to the wealthiest [49].

This study has a number of strengths and limitations. We drew on the comprehensive phenotyping approach of The Maastricht Study [11] and used a relatively large sample size, allowing for the investigation of multiple subgroups and classes. Although there is no formal benchmark for adequate sample size in LCA, Finch and Bronk [50] concluded - based on a number of simulation studies - that 500 participants is 'a worthy goal in practice'. In terms of methods, LCA is a sophisticated analytic technique, which allowed us to improve understanding of previously unobserved subgroups in the diabetes population. An important advantage of LCA over traditional types of cluster analysis is its probability-based classification, which better captures uncertainty [51]. Given the complex and difficult to differentiate interactions that might exist between many of the included variables, investigating causal relations via multivariable analysis was beyond the scope of this explorative study. On one hand, this is a limitation of the study, as it precludes any conclusions about which patient characteristics are the strongest predictors of insufficient glycaemic control and/or low HRQoL, and which are confounders. On the other hand, our univariable exploration of a broad range of possibly relevant characteristics provides a sound basis for more targeted, hypothesis-driven future investigations of causal relations using multivariable models, and is in line with the biopsychosocial paradigm that is gaining increasing traction in health care [52]. Univariable analyses also enabled us to maintain a relatively large overall sample size, despite missing values in some independent variables. A final limitation relates to the relative underrepresentation of people with severe diabetic complications in The Maastricht Study. As a result, the study sample may be healthier than the average diabetes population, which could mean that some of the associations measured between patient factors and health outcomes are underestimations.

In conclusion, this explorative study shows that insufficient glycaemic control, particularly in combination with low HRQoL, is associated with a generally less positive biopsychosocial profile. Further studies, especially multivariable analyses, are needed to better understand the complex and multidimensional causal pathways between relevant biopsychosocial characteristics of T2DM patients and their health outcomes. Perhaps even more importantly, we need to learn more about the self-perceived care needs and preferences of different patient subgroups, and how we can meet them with well-aligned care and support strategies. With regard to the latter, a large-scale study is currently being conducted in the Netherlands 
('PROFILe'), which builds on the findings of the present study to develop an instrument supporting more tailored, person-centred chronic care [53] The first results of PROFILe are expected in 2017. 


\section{Supplementary material}

S1 Table. Statistical criteria for latent class models with 1 to 5 latent classes.

\begin{tabular}{l|l|l|l|l}
\hline $\begin{array}{l}\text { Number of } \\
\text { Classes }\end{array}$ & BIC $^{\mathrm{a}}$ & LMR-LRT $^{\mathrm{b}}$ & Entropy & $\begin{array}{l}\text { Percentage patients per class based on most } \\
\text { likely class membership }\end{array}$ \\
\hline $\mathbf{1}$ & 2.292 .709 & NA & NA & 100 \\
\hline $\mathbf{2}$ & 2140.802 & $-1123.434^{*}$ & 0.757 & $71.4-28.6$ \\
\hline $\mathbf{3}$ & 2164.218 & $-1021.695^{*}$ & 0.803 & $67.5-27.6-4.9$ \\
\hline $\mathbf{4}$ & 2196.614 & -1007.618 & 0.793 & $47.4-29.2-18.5-4.9$ \\
\hline $\mathbf{5}$ & 2235.191 & -998.030 & 0.821 & $46.7-29.2-14.0-6.5-3.6$ \\
\hline
\end{tabular}

a Bayesian Information Criterion; bLo-Mendell-Rubin Likelihood Ratio Test; *Significant at the $\mathrm{P}<0.05$ level. 


\section{References}

1. Cebolla Garrofé B, Björnberg A, Yung Phang A. Euro Diabetes Index 2014. Täby, Health Consumer Powerhouse Ltd; 2014.

2. Netherlands Diabetes Federation (NDF). NDF Care Standard. Transparency and quality of diabetes care for people with diabetes type 2 [NDF Zorgstandaard. Transparantie en kwaliteit van diabeteszorg voor mensen met diabetes type 2]. Amersfoort: NDF; 2015.

3. Struijs JN, Baan CA. Integrating care through bundled payments: lessons from the Netherlands. N Engl J Med. 2011;364(11): 990-991.

4. De Bakker DH, Struijs JN, Baan CA, Raams J, De Wildt JE, Vrijhoef HJ, et al. Early results from adoption of bundled payment for diabetes care in the Netherlands show improvement in care coordination. Health Aff (Millwood). 2012;31(2): 426-433

5. Struijs JN. How bundled health care payments are working in the Netherlands. NEJM Catalyst. 11 April 2016. Available from: http://catalyst.nejm.org/how-bundled-healthcare-payments-are-working-in-the-netherlands/. Cited 9 November 2016.

6. InEen. Transparent integrated care. Report 2015 Care Groups. Diabetes mellitus, VRM, COPD and asthma [Transparante ketenzorg. Rapportage 2015 zorggroepen. Diabetes mellitus, VRM, COPD en astma. Op weg naar genuanceerde rapportage van zorg]. Utrecht: InEen; 2016.

7. Kleefstra N, Landman GWD, Van Hateren KJJ, Meulepas M, Romeijnders A, Rutten GE, et al. Dutch diabetes prevalence estimates (DUDE-1). J Diabetes. 2016;8(6): 863-865

8. Inzucchi SE, Bergenstal RM, Buse JB, Diamant M, Ferrannini E, Nauck M, et al. Management of hyperglycemia in type 2 diabetes: a patient-centered approach. Diabetes Care. 2012;35(6): 1364-1379.

9. Elissen AMJ, Steuten LMG, Lemmens LC, Drewes HW, Lemmens KM, Meeuwissen JA, et al. Meta-analysis of the effectiveness of chronic care management for diabetes: investigating heterogeneity in outcomes. J Eval Clin Pract. 2013;19(5): 753-762.

10. Riddle MC, Karl DM. Individualizing targets and tactics for high-risk patients with type 2 diabetes. Practical lessons from ACCORD and other cardiovascular trials. Diabetes Care. 2012;35: 2100-2107.

11. Schram MT, Sep SJ, Van der Kallen CJ, Dagnelie PC, Koster A, Schaper N, et al. The Maastricht Study: an extensive phenotyping study on determinants of type 2 diabetes, its complications and its comorbidities. Eur J Epidemiol. 2014;29: 439-451.

12. Kohnert KD, Heinke P, Vogt L, Salzsieder E. Utility of different glycemic control metrics for optimizing management of diabetes. World J Diabetes. 2015;6(1): 17-29.

13. Pandey R, Dingari NC, Spegazzini N, Dasari RR, Horowitz GL, Barman I. Emerging trends in optical sensing of glycemic markers for diabetes monitoring. Trends Analyt Chem. 2015;64: 100-108.

14. Snoek F, Welch G. Problem Areas in Diabetes Questionnaire. Novo Nordisk 2006. Available from: http://www.dawnstudy.com/content/dam/Dawnstudy/AFFILIATE/www-dawnstudycom/Home/TOOLSANDRESOURCES/Documents/PAID_problem_areas_in_diabetes_ques tionnaire.pdf. Cited 12 October 2016.

15. Lamers LM, Stalmeier PFM, McDonnell J, Krabbe PFM, Van Busschbach JJ. Measuring the quality of life in cost-utility analyses: the Dutch EQ-5D tariff. Ned Tijdschr Geneeskd. 2005;149: 1574-1578. 
16. Ware JE, Kosinski M, Keller SD. SF-36 Physical and Mental Health Summary Scales: A User's Manual. Boston MA: The Health Institute; 1994.

17. National Institute for Public Health and the Environment (RIVM). Health-related quality of life: description and definitions. [Gezondheidsgerelateerde kwaliteit van leven: beschrijving en definities]; 2015 [cited 2016 Oct 12]. Database: Toolkit Regional Public Health Status and Foresight Report [Internet]. Available from: http://www.toolkitvtv.nl/inhoud/indicatoren-enbronnen/gezondheidstoestand/gezondheidsgerelateerde-kwaliteit-van-leven/.

18. Andersen RM, Newman JF. Societal and individual determinants of medical care utilization in the United States. Milbank Mem Fund Q Health Soc. 1973;51(1):95-124.

19. Banerji MA, Dunn JD. Impact of glycaemic control on healthcare resource utilization and costs of type 2 diabetes: current and future pharmacologic approaches to improving outcomes. Am Health Drug Benefits. 2013;6(7): 382-392

20. Testa MA, Simonson DC. Health economic benefits and quality of life during improved glycaemic control in patients with type 2 diabetes mellitus: a randomized, controlled, double-blind trial. JAMA. 1998;280(17): 1490-1496.

21. Health Council of the Netherlands. Guidelines for a healthy diet 2006. The Hague: Health Council of the Netherlands; 2006.

22. Skinner EA. A guide to constructs of control. J Pers Soc Psychol. 1996;71: 549-570.

23. Bosscher RJ, Laurijssen L, De Boer E. Competence at later age: an explorative study. [Competentie op latere leeftijd: Een exploratieve studie]. Bewegen \& Hulpverlening. 1992;9: 225-265.

24. Sherer M, Maddux JE, Mercandante B, Prentice-Dunn S, Jacobs B, Rogers RW. The selfefficacy scale: construction and validation. Psychol Rep. 1982;51:663-71.

25. Pearlin LI, Schooler C. The structure of coping. J Health Soc Behav. 1978;19(1): 2-21.

26. Luteijn F, Starren J, van Dijk H. Handleiding bij de NPV: tweede herziene versie. [Manual for the Dutch Personality Questionnaire: second revised edition]. Lisse: Swets en Zeitlinger; 2000.

27. OECD. Quality review of the OECD database on household incomes and poverty and the OECD earnings database. Part I. Paris: OECD Publishing; 2012.

28. Spauwen PJJ, Martens RJH, Stehouwer CDA, Verhey FR, Schram MT, Sep SJ, et al. Lower verbal intelligence is associated with diabetic complications and slower walking speed in people with type 2 diabetes: the Maastricht Study. Diabet Med. 2016;33(12): 1632-1639.

29. Martens RJ, Kooman JP, Stehouwer CD, Dagnelie PC, Van der Kallen CJ, Koster A, et al. Estimated GFR, Albuminuria, and Cognitive Performance: The Maastricht Study. Am J Kidney Dis. 2017;69(2): 179-191.

30. Patient Health Questionnaire (PHQ). Available from: http://www.cqaimh.org/pdf/tool_phq9.pdf accessed 17 September 2016. Cited 15 October 2016.

31. Löwe B, Unützer J, Callahan CM, Perkins AJ, Kroenke K. Monitoring depression treatment outcomes with the patient health questionnaire-9. Med Care. 2004;42: 1194-1201.

32. Nylund KL, Asparouhov T, Muthén B. Deciding on the number of classes in latent class analysis and growth mixture modeling. A Monte Carlo simulation study. Struct Equ Modeling. 2007;14: 535-69.

33. Celeux G, Soromenho G. An entropy criterion for assessing the number of clusters in a mixture model. J Classif. 1996;13: 195-212. 
34. Muthén LK, Muthén BO. Mplus User's Guide. Seventh Edition. Los Angeles CA: Muthén \& Muthén; 2012.

35. StataCorp. Stata Statistical Software: Release 14. College Station TX: StataCorp LP; 2015.

36. Elissen AM, Duimel-Peeters IG, Spreeuwenberg C, Spreeuwenberg M, Vrijhoef HJ. Toward tailored disease management for type 2 diabetes. Am J Manag Care. 2012;18(10):619-630.

37. Nolte E, Knai C, Hofmarcher M, Conklin A, Erler A, Elissen A, et al. Overcoming fragmentation in health care: chronic care in Austria, Germany and The Netherlands. Health Econ Policy Law. 2012;7(1): 125-46.

38. Beckerle CM, Lavin MA. Association of self-efficacy and self-care with glycaemic control in diabetes. Diabetes Spectr. 2013;26(3): 172-78.

39. Bosma H. Socioeconomic differences in health: are control beliefs fundamental mediators? In: Siegrist J, Marmot M, editors. Social inequalities in health: new evidence and policy implications. Oxford: Oxford University Press; 2006. Pp. 153-166.

40. Groffen DA, Bosma H, Tan FE, van den Akker M, Kempen GI, van Eijk JT. Material vs. psychosocial explanations of old-age educational differences in physical and mental functioning. Eur J Public Health. 2012;22(4): 587-592.

41. Klabbers G, Bosma H, Kempen GI, Benzeval M, van den Akker M, van Eijk JT. Do psychosocial profiles predict self-rated health, morbidity and mortality in late middleaged and older people? J Behav Med. 2014;37(3): 357-368.

42. Mertens VC, Bosma H, Groffen DA, van Eijk JT. Good friends, high income or resilience? What matters most for elderly patients? Eur J Public Health. 2012;22(5): 666-671.

43. Porter ME, Larsson S, Lee TH. Standardizing patient outcomes measurement. New Engl J Med. 2016;374: 504-506.

44. Lau CY, Qureshi AK, Scott SG Association between glycaemic control and quality of life in diabetes mellitus. J Postgrad Med. 2004;50(3): 189-193.

45. Dogan H, Harman E, Kocoglu H, Sargin G. Can metabolic control variables of diabetes patients predict their quality of life? J Am Soc Hypertens. 2016;10(1): 81-88.

46. Oliva J, Fernández-Bolaños A, Hidalgo A. Health-related quality of life in diabetic people with different vascular risk. BMC Public Health. 2012;12: 812.

47. Lloyd A, Sawyer W, Hopkinson P. Impact of long-term complications on quality of life in patients with type 2 diabetes not using insulin. Value Health. 2001;4(5): 392-400.

48. Rijken M, Jones M, Heijmans M, Dixon A. Supporting self-management. In: Nolte E, McKee $M$, editors. Caring for people with chronic conditions. A health system perspective. New York, NY: Open University Press; 2008. pp. 116-142.

49. World Health Organization. Gaining Health: The European Strategy for the Prevention and Control of Noncommunicable Diseases. Copenhagen: WHO Regional Office for Europe; 2006.

50. Finch WH, Bronk KC. Conducting confirmatory latent class analysis using Mplus. Struct Equ Modeling. 2011;18(1): 132-151.

51. Vermunt JK, Magidson J. Latent class analysis. In: Lewis-Beck M, Bryman A, Liao TF, editors. The Sage encyclopedia of social science research methods. Newbury Park, CA: Sage; 2004.

52. Smith RC. The biopsychosocial revolution. J Gen Intern Med. 2002;17(4): 309-310.

53. Elissen AMJ, Hertroijs DFL, Schaper NC, Vrijhoef HJM, Ruwaard D. Profiling patients' healthcare needs to support integrated, person-centered models for long-term disease management (profile): research design. Int J Integr Care. 2016; 
CHAPTER 5

\section{A risk score of BMI, glycated haemoglobin and triglycerides predicts future glycaemic control in type 2 diabetes}

\section{Published as:}

D.F.L. Hertroijs, A.M.J. Elissen, M.C.G.J. Brouwers, N.C. Schaper, S. Köhler, M.C. Popa, S. Asteriadis, S.H. Hendriks, H.G. Bilo \& D. Ruwaard. A risk score including body mass index, glycated haemoglobin and triglycerides predicts future glycaemic control in people with type 2 diabetes. Diabetes, Obesity and Metabolism. 2017;20(3):681-688. 


\section{Abstract}

Aim: To identify, predict and validate distinct glycaemic trajectories among patients with newly diagnosed type 2 diabetes treated in primary care, as a first step towards more effective patient-centred care.

Material and methods: We conducted a retrospective study on two cohorts using routinely collected individual patient data in primary care practices from two large Dutch diabetes patient registries. Participants included newly diagnosed, adult patients with type 2 diabetes between January 2006 and December 2014 ( $n=10,528$, development cohort; $n=3,777$, validation cohort). Latent growth mixture modeling (LGMM) identified distinct glycaemic 5year trajectories. Machine learning models were built to predict the trajectories with easily obtainable patient characteristics in daily clinical practice.

Results: Three different glycaemic trajectories were identified: 1) stable, adequate glycaemic control (76.5\% of patients); 2) improved glycaemic control (21.3\% of patients) and 3) deteriorated glycaemic control (2.2\% of patients). Similar trajectories could be discerned in the validation cohort. $\mathrm{BMI}, \mathrm{HbA} 1 \mathrm{c}$ and triglycerides were the most important predictors of trajectory membership. The predictive model, trained on the development cohort, had a receiver operating characteristic area under the curve (ROC-AUC) of 0.96 in the validation cohort, indicating excellent accuracy.

Conclusions: The developed model can effectively explain heterogeneity in future glycaemic response of patients with type 2 diabetes. It can therefore be used in clinical practice as a quick and easy tool to provide tailored diabetes care. 


\section{Introduction}

Archibold Garrod is considered the founding father of precision medicine. In 1931, he was the first to recognize interpersonal variation in disease development and impact. Garrod noted that "individual cases of any particular disease are not exactly alike; they resemble rather the drawings made from the same model by individual members of a drawing class" [1]. Nowadays, precision medicine is becoming more popular, due to an increase in electronic clinical data and decline of genome sequencing costs.[2, 3] In 2012, former UK Prime Minister David Cameron initiated the 100,000 Genomes Project and in 2015 former US president Barack Obama launched the Precision Medicine Initiative $[4,5]$. The aim of both initiatives is to predict the process of disease and to create personalized patient care by gaining more knowledge on genetic variation in disease.

Thus far, significant advances have been made, such as the discovery of certain genetic variations that are linked to the effectiveness of a drug or specific genes that predict cancer ris $[6,7]$. Nevertheless, the implementation of precision medicine based on solely genomics has proven to be difficult for certain diseases, such as type 2 diabetes. Recently, new efforts have been undertaken to unravel the genetic background of type 2 diabetes by studying not only common gene variants, but also infrequent and rare variants [8]. To date, only $10 \%$ of its heritability has been unveiled, which has been referred to as a "geneticist's nightmare" by some experts [9]. Consequently, precision medicine based on a genotyping approach is still far away for type 2 diabetes. Shifting to a phenotyping approach of precision medicine seems a more promising alternative, in particular in the short-term, to improve patients' health outcomes $[10,11]$. The US National Institutes of Health defines precision medicine as an emerging approach for disease treatment and prevention that takes into account not only individual variability in genes, but also a patient's environment and lifestyle [12]. Currently, such a phenotyping approach to precision medicine is only sparsely adopted in evidencebased guidelines for diabetes treatment. Barring some exceptions for persons of older age, these guidelines are usually highly standardized [13, 14].

As a first step towards more patient-centred care, the purpose of this study was threefold: a) to identify subgroups of people with newly diagnosed type 2 diabetes with distinct glycaemic trajectories; b) to predict trajectory membership using patient characteristics that are commonly assessed in diabetes primary care; and c) to validate these findings in a different cohort of patients with type 2 diabetes.

\section{Research design and methods}

\section{Study design and patients}

In this retrospective cohort study, patients were selected using the electronic health records (EHR) of two large Dutch diabetes care networks (DCN) that routinely collect individual patient data and have been frequently used for research [15-19]. General Practitioners (GP) and practice nurses from the participating practices recorded these data in the EHRs from the start 
of diabetes diagnosis. They use the information in the EHRs for the treatment and follow-up of their patients and as proof that they provided the care as agreed upon with health insurers for declaration purposes. Therefore, it can be considered accurate. Patients from both DCNs received managed diabetes primary care based on the Netherlands Diabetes Federation Care Standard [13], which describes the norm for generic multidisciplinary diabetes care.

The first DCN, the Zwolle Outpatient Diabetes project Integrating Available Care (ZODIAC),[20] was used as development cohort and contained the anonymous longitudinal health records of 93,981 adult ( $\geq 18$ years) patients with type 2 diabetes from 731 primary care practices in the city of Rotterdam, northern, north-western and eastern parts of the Netherlands. The data in the current study were collected during the yearly visits between 1 January 2006 and 31 December 2013. Those patients with a new diagnosis of type 2 diabetes during the study period and with at least one HbA1c measured +/- three months from diagnosis (baseline) were selected for further analysis.

The second DCN, the regional care group ZIO [18], was used as validation cohort. The ZIO database contained the anonymous longitudinal health records of 11,833 adult ( $\geq 18$ years) patients with type 2 diabetes from 95 primary care practices in Maastricht, in the south of the Netherlands. Data were collected and registered in the EHRs between 1 January 2009 and 31 December 2014. The inclusion criteria were the same as for the development cohort.

Both cohorts were open and dynamic, and patients were followed from diagnosis until the end of the study period or until censoring because no more HbA1c measurements were available (due to death, no show or change of practice). Patients' date of entry into the study (baseline) was fixed at their registered date of diagnosis of type 2 diabetes.

No ethical approval was needed for the study: as the data used were already available and patients were not physically involved in the research, the study is not subject to the Dutch Medical Research (Human Subjects) Act (WMO).

\section{Outcome}

The outcome of interest was glycaemic control trajectories, based on $\mathrm{HbA1c}$ values during a maximum of 4 (development cohort) or 5 years (validation cohort). Baseline $\mathrm{HbA1c}$ values were included if measured +/- three months from diagnosis. Follow-up HbA1c values were included if measured a year from the previous $\mathrm{HbA1}$ c measurement with a deviation of $+/$ three months.

\section{Predictors}

The baseline patients' characteristics were used as potential predictors for an individual's glycaemic trajectory membership. Characteristics included baseline age, sex and race, which was categorized into a binary variable of Caucasian or non-Caucasian, since participants were mainly Caucasian; non-Caucasian included Moroccan, Turkish, black African, Indian, Indonesian, and non-Indian in the development cohort and black, Indian, and other Asian in the validation cohort. $\mathrm{HbA} 1 \mathrm{c}$, systolic blood pressure (SBP), diastolic blood pressure (DBP), lipid profile (LDL, HDL, total cholesterol and triglycerides), and BMI were also included as 
baseline characteristics if measured +/- three months from diagnosis. Urinary albumin-tocreatinine ratio (ACR), presence of heart failure (only reported in development cohort), smoking (yes/no) and alcohol consumption ( $\leq 3$ glasses/day or $>3$ glasses/day) were included as baseline characteristics if measured +/- 12 months from diagnosis. Patient reported history of CVD in family members $<60$ years (yes/no) was included in the analysis if obtained at any point before diagnosis or maximum 12 months after diagnosis.

Outliers - most likely due to errors in recording - were removed based on cutoff points determined by diabetologists (MB and NS).

\section{Statistical methods}

To systematically identify latent trajectories of glycaemic control, latent growth mixture modeling (LGMM) was used. This method allows for the clustering of patients into an optimal number of growth trajectories [21]. Full information maximum likelihood (FIML) was used as a missing data estimation approach [22]. A protocol, as recommended previously [23, 24], was followed to identify the best LGMM model. A series of latent class growth analysis (LCGA) and LGMM models were estimated. LCGA assumes no within class variance, whereas LGMM freely estimates the within class variance [23]. The best model was determined by comparing the model fits of a progressive number of trajectories. Fit indices included the Akaike Information Criterion (AIC) [25], Bayesian Information Criterion (BIC) [26] and the Lo-Mendel-Rubinlikelihood ratio test (LMR-LRT) [27]. Lower values of the AIC and BIC, and/or a significant result on the LMR-LRT indicate a better model fit in terms of the number of trajectories. To determine model classification performance, entropy was used. Higher entropy values indicate less ambiguity in trajectory allocation [28]. The usefulness and clinical interpretation of each trajectory model was also taken into account. Analyses were performed using Mplus version 7.1. [29] and are reported according to the Guidelines for Reporting on Latent Trajectory Studies (GRoLTS) checklist [24]. Baseline characteristics were assessed for the development- and validation cohorts. Significant differences between cohorts were determined using two-sample t-tests and $x^{2}$. Analysis of variance (ANOVA) and chi-square tests were used to identify significant differences between glycaemic control trajectories within each cohort. To gain insight into the influence of glucose lowering drugs and insulin on the patterns of the trajectories, the percentage of patients with oral glucose lowering drugs and/or insulin prescriptions was compared at baseline and at each follow-up year between the trajectories of the development cohort using Chi-square tests.

For the development and validation of the prediction model, only patients with no missing baseline values were included. A five-fold cross validation was performed in the development cohort. Since there is no consensus on the best performing classifier, several machine learning classification methods were used [30]. The correlations between SBP and DBP, lipid profile characteristics, and CVD characteristics were calculated using the Spearman- (for nonnormally distributed variables) and Pearson (for normally distributed variables) correlation coefficients. If there was a significant correlation coefficient $\leq-0.4$ or $\geq 0.4$ between two potential predictors, only one potential predictor was included in the analysis to avoid over- 
adjustment. To examine the generalizability of the developed prediction model, an external validation was computed in the validation cohort. Receiver operating characteristic (ROC) curves were generated to show the discrimination of the models. To examine the agreement between predicted and observed trajectory membership, calibration slopes were produced. Diagnostic values (sensitivities and specificities) and prognostic values (positive predictive values (PPV), and negative predictive values (NPV)), were also calculated.

For further details regarding the analyses see supplementary material (eMethods).

\section{Results}

\section{Description of the development - and validation cohorts}

The initial development cohort included 20,414 patients who were diagnosed with type 2 diabetes between January 12006 and December 31 2013. Of these, 10,528 patients had a baseline $\mathrm{HbA} 1 \mathrm{c}$ measurement and were included in the analysis. The group of patients without a baseline $\mathrm{HbA} 1 \mathrm{c}$ measurement had significantly higher LDL levels (3.0 versus $2.9 \mathrm{mmol} / \mathrm{l}, 95 \%$ $\mathrm{Cl} 0.05-0.14$, p-value $<0.001$ ) and a lower percentage of women ( 46.9 versus $48.4 \% ; 95 \% \mathrm{Cl}$ $0.2 \%$ to $3.0 \%, p$-value $=0.031$ ). Other characteristics did not differ. The mean age of the included patients in the development cohort was 62.9 (SD 12.7) years and $51.6 \%$ were men (table 1).

The initial validation cohort included 4,164 patients who were diagnosed with type 2 diabetes between January 12009 and December 31 2014. Of these, 3,337 adult patients had a baseline $\mathrm{HbA1}$ c measurement and were therefore selected for inclusion in the analysis. The group of patients without a baseline $\mathrm{HbA1c}$ measurement were significantly older (64.9 versus 63.7 years, $95 \% \mathrm{Cl} 0.3-2.1$, $\mathrm{p}$-value $=0.009$ ) and had a lower percentage of CVD in the family (19 versus $24.2 \%, 95 \% \mathrm{Cl} 1.4 \%$ to $8.0 \%$, $\mathrm{p}$-value $=0.008$ ). Other characteristics did not differ. The mean age of the included patients in the validation cohort was 63.7 years (SD 12.2) and $52.3 \%$ were men (table 1 ).

In both the development- and validation cohort, date of diagnosis (and inclusion into the study) differed considerably between patients: some patients were, for example, diagnosed in 2009 and others in 2013, resulting in a variable follow-up. Due to this variable follow-up, $78.7 \%$ of the patients in the development cohort did not have a HbA1c measurement after 4 years of follow-up and $72.9 \%$ did not have a $\mathrm{HbA1c}$ measurement after 5 years of follow-up in the validation cohort (Supplemental Table S1). It was therefore decided to restrict follow-up in the development cohort to 4 years and in the validation cohort to 5 years. The median number of $\mathrm{HbA1C}$ measurements during the research period was 2 (interquartile range 2) in the development cohort and 3 (interquartile range 3 ) in the validation cohort. 
Table 1. Baseline patient characteristics of the development cohort and the validation cohort

\begin{tabular}{|c|c|c|c|}
\hline & Development cohort ${ }^{*}$ & Validation cohort ${ }^{*}$ & p-value \\
\hline $\mathrm{N}$ & 10,528 & 3,337 & \\
\hline $\begin{array}{l}\text { Age (years) (sd) } \\
\text { Not recorded }\end{array}$ & $\begin{array}{l}62.9(12.7) \\
0\end{array}$ & $\begin{array}{l}63.7(12.2) \\
0\end{array}$ & 0.001 \\
\hline $\begin{array}{l}\text { Male sex } \\
\text { Not recorded }\end{array}$ & $\begin{array}{l}5433(51.6) \\
0\end{array}$ & $\begin{array}{l}1744(52.3) \\
0\end{array}$ & $<0.001$ \\
\hline $\begin{array}{l}\text { Ethnic group }^{\dagger} \\
\text { Caucasian } \\
\text { Non-Caucasian } \\
\text { Not recorded } \\
\end{array}$ & $\begin{array}{l}6669(95.3) \\
330(4.7) \\
3539\end{array}$ & $\begin{array}{l}2913(95.5) \\
137(4.5) \\
287\end{array}$ & 0.797 \\
\hline $\begin{array}{l}\text { Smoking status }^{\dagger} \\
\text { Non-smoker } \\
\text { Current smoker } \\
\text { Not recorded }\end{array}$ & $\begin{array}{l}7748(80.1) \\
1928(19.9) \\
852\end{array}$ & $\begin{array}{l}2065(74.8) \\
695(25.2) \\
577\end{array}$ & $<0.001$ \\
\hline $\begin{array}{l}\mathrm{BMI}\left(\mathrm{kg} / \mathrm{m}^{2}\right)(\mathrm{sd}) \\
\text { Not recorded }\end{array}$ & $\begin{array}{l}30.4(5.5) \\
4443\end{array}$ & $\begin{array}{l}30.6(6.1) \\
595\end{array}$ & 0.073 \\
\hline $\begin{array}{l}\text { Alcohol consumption }^{+} \\
<3 \text { glasses/day } \\
\geq 3 \text { glasses/day } \\
\text { Not recorded }\end{array}$ & $\begin{array}{l}6029(76.3) \\
1876(23.7) \\
2623 \\
\end{array}$ & $\begin{array}{l}3147(94.6) \\
178(5.4) \\
12\end{array}$ & 0.308 \\
\hline $\begin{array}{l}\mathrm{HbA1c}(\mathrm{mmol} / \mathrm{mol})(\mathrm{sd}) \\
\text { Not recorded }\end{array}$ & $\begin{array}{l}53.0(15.3) \\
0\end{array}$ & $\begin{array}{l}56.9(18.8) \\
0\end{array}$ & $<0.0001$ \\
\hline $\begin{array}{l}\text { HbA1c }(\%)(s d) \\
\text { Not recorded }\end{array}$ & $\begin{array}{l}7.0(1.4) \\
0\end{array}$ & $\begin{array}{l}7.4(1.7) \\
0\end{array}$ & $<0.0001$ \\
\hline $\begin{array}{l}\text { SBP }(\mathrm{mmHg})(\mathrm{sd}) \\
\text { Not recorded }\end{array}$ & $\begin{array}{l}138.5(17.6) \\
3762\end{array}$ & $\begin{array}{l}138.4(18.8) \\
483\end{array}$ & 0.321 \\
\hline $\begin{array}{l}\mathrm{DBP}(\mathrm{mmHg})(\mathrm{sd}) \\
\text { Not recorded }\end{array}$ & $\begin{array}{l}80.8(10.0) \\
4014\end{array}$ & $\begin{array}{l}80.8(10.4) \\
489\end{array}$ & 0.801 \\
\hline $\begin{array}{l}\mathrm{LDL}(\mathrm{mmol} / \mathrm{mol})(\mathrm{sd}) \\
\text { Not recorded }\end{array}$ & $\begin{array}{l}2.9(1.0) \\
1910\end{array}$ & $\begin{array}{l}3.2(1.1) \\
663\end{array}$ & 0.954 \\
\hline $\begin{array}{l}\mathrm{HDL}(\mathrm{mmol} / \mathrm{mol})(\mathrm{sd}) \\
\text { Not recorded }\end{array}$ & $\begin{array}{l}1.23(0.4) \\
1536 \\
\end{array}$ & $\begin{array}{l}1.16(0.35) \\
638\end{array}$ & $<0.001$ \\
\hline $\begin{array}{l}\text { Total cholesterol }(\mathrm{mmol} / \mathrm{mol})(\mathrm{sd}) \\
\text { Not recorded }\end{array}$ & $\begin{array}{l}5.0(1.1) \\
1500\end{array}$ & $\begin{array}{l}5.3(1.3) \\
628\end{array}$ & $<0.001$ \\
\hline $\begin{array}{l}\text { Triglycerides }(\mathrm{mmol} / \mathrm{l})(\mathrm{sd}) \\
\text { Not recorded }\end{array}$ & $\begin{array}{l}2.0(1.2) \\
1809\end{array}$ & $\begin{array}{l}2.2(1.4) \\
659\end{array}$ & $<0.001$ \\
\hline $\begin{array}{l}\text { ACR }(\mathrm{mg} / \mathrm{mmol})(\mathrm{sd}) \\
\text { Not recorded }\end{array}$ & $\begin{array}{l}2.7(9.9) \\
2717\end{array}$ & $\begin{array}{l}2.3(9.8) \\
812\end{array}$ & 0.002 \\
\hline $\begin{array}{l}\text { eGFR }\left(\mathrm{ml} / \mathrm{min} / 1.73 \mathrm{~m}^{2}\right) \\
\text { Not recorded }\end{array}$ & $\begin{array}{l}80.1(21.6) \\
9620\end{array}$ & $\begin{array}{l}77.7(24.0) \\
454\end{array}$ & 0.005 \\
\hline $\begin{array}{l}\text { Heart failure } \\
\text { Yes } \\
\text { No } \\
\text { Not recorded }\end{array}$ & $\begin{array}{l}437(6.6) \\
6153(93.4) \\
3941\end{array}$ & - & - \\
\hline $\begin{array}{l}\text { CVD in family } \\
\text { Yes } \\
\text { No } \\
\text { Not recorded }\end{array}$ & $\begin{array}{l}2718(37.9) \\
4457(62.1) \\
3355\end{array}$ & $\begin{array}{l}810(24.3) \\
2521(75.7) \\
6\end{array}$ & 0.018 \\
\hline
\end{tabular}

${ }^{*}$ Values are numbers (percentages) unless stated otherwise. Percentages have been rounded and might not total $100 .{ }^{\dagger}$ Percentages are out of total with recorded values

$\mathrm{SBP}=$ systolic blood pressure; $\mathrm{DBP}=$ diastolic blood pressure; $\mathrm{ACR}=$ albumin-to-creatinine ratio; $\mathrm{CVD}$ = cardiovascular disease 


\section{Latent growth mixture modeling}

The model with the strongest fit in the development cohort was the 3-trajectory LGMM (Supplemental Table S2). The largest (76.5\%) and most stable trajectory showed a pattern of good glycaemic control ( $\mathrm{HbA} 1 \mathrm{c} \leq 7 \%(53 \mathrm{mmol} / \mathrm{mol})$ ) over time (figure 1$)$. This trajectory was named stable, adequate glycaemic control. The middle trajectory, including $21.3 \%$ of the population, was named improved glycaemic control, because patients in this trajectory adequately responded to glycaemic treatment and subsequently remained stable at a $\mathrm{HbA} 1 \mathrm{c}$ level just above $7 \%$ ( $53 \mathrm{mmol} / \mathrm{mol}$ ). The smallest trajectory $(2.2 \%)$ showed very high $\mathrm{HbA} 1 \mathrm{c}$ at diagnosis of diabetes, but adequately responded to treatment. However, two years past diagnosis, $\mathrm{HbA} 1 \mathrm{c}$ started to increase again to levels $>7 \%$ (53 $\mathrm{mmol} / \mathrm{mol}$ ). This trajectory was named deteriorated glycaemic control. The mean intercepts and slopes for each class are presented in Supplemental Table S3. All intercepts and slope growth parameters were statistically significant. The observed individual trajectories and estimated mean trajectory of the 3-trajectory model are shown in eFigure 1 in the supplement.

In the validation cohort, also a 3-trajectory model was identified based on model fit (Supplemental Table S4) and population trajectory distribution (figure 1). This model was similar in shape and population distribution to the 3-trajectory model of the development cohort. All intercepts and slope growth parameters were statistically significant (Supplemental Table S3).

Supplemental Figures S1 to S5 show all fitted trajectory models in the development and validation cohorts with linear and quadratic slopes, in accordance with the GRoLTS guidelines.[24]

There were significant differences between trajectories at all time points in the percentages of patients with oral glucose lowering drugs and insulin prescriptions $(p<0.0001)$. Supplemental Figures S6 and S7 show that more oral glucose lowering drugs and insulin were prescribed to patients in the deteriorated- and improved glycaemic control trajectories compared to the stable, adequate glycaemic control trajectory. Prescription of oral glucose lowering drugs increased over time in all trajectories. 


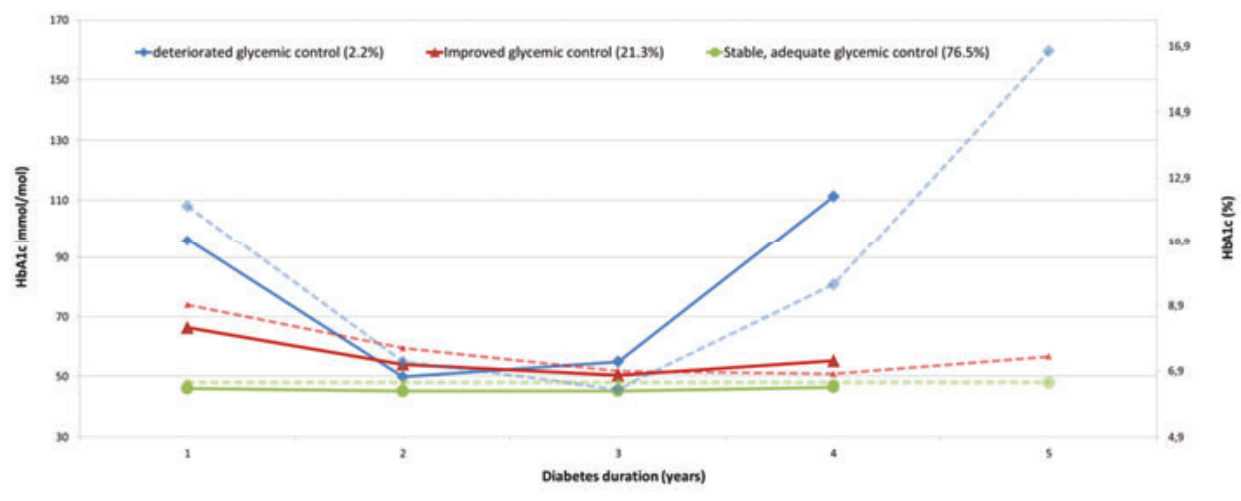

Figure 1. Latent class growth trajectories of the best-fitting models of the development - and validation cohorts identified by LGMM. Solid lines = derivation cohort; dashed lines = validation cohort

\section{Classification into glycaemic control trajectories}

In both cohorts, patients in the deteriorated glycaemic control trajectory were more frequently male, current smokers and younger. Their baseline $\mathrm{HbA1c}$, triglycerides and total cholesterol levels were higher compared to the other trajectories (table 2).

After excluding significant correlations between patient characteristics (Supplemental Table S5), 13 baseline characteristics were retained in the analyses as potential predictors: age, gender, race, $\mathrm{HbA1C}$, SBP, LDL, triglycerides, ACR, BMI, smoking, alcohol, CVD, and CVD in family members. The five-fold cross validation in the development cohort showed that the K-nearest neighbour (KNN) machine learning classifier had the highest accuracy (92.3\%) (Supplemental Table S6). Using this classifier, the 13-patient feature prediction model had good to excellent diagnostic and prognostic properties with sensitivities between 78.4 and 98.3\%, specificities between 81.2 and 99.4\%, PPVs between 78.0 and $94.7 \%$ and NPVs between 93.7 and 99.5\% (Supplemental Table S7). Baseline BMI, HbA1c and triglycerides were the most salient characteristics for predicting trajectory membership according to their weight (table 3). The 13-patient feature prediction model had a ROC-AUC of 0.96 (Figure 2). The external validity of the model with the three most salient patient characteristics (3-patient feature prediction model) was determined in the validation cohort. The linear discriminant classifier (LDC) had the highest accuracy (92.0\%) (Supplemental Table S8). Sensitivities were between 67.9 and $99.1 \%$, specificities between 85.3 and $98.6 \%$, PPVs between 45.8 and $96.1 \%$ and NPVs between 91.9 and $99.4 \%$ (eTable 9 in the supplement). The ROC-AUC was 0.95 (Figure 2). The calibration plot in the validation cohort, showed a good fit for all three trajectories (Supplemental Figure S8). The developed tool can be found on the webpage http://www.patientprofiles.nl which provides the opportunity to fill in different BMI-, HbA1c, and triglycerides values, and view the related trajectory. 
Table 2. Baseline characteristics of the development cohort and the validation cohort according to the different trajectories of $\mathrm{HbA} 1 \mathrm{c}$

\begin{tabular}{|c|c|c|c|c|c|c|c|c|}
\hline & \multicolumn{3}{|c|}{$\begin{array}{l}\text { Latent trajectories development } \\
\text { cohort }^{*}\end{array}$} & \multirow[b]{2}{*}{$\begin{array}{l}\mathrm{p}- \\
\text { value }\end{array}$} & \multicolumn{3}{|c|}{$\begin{array}{c}\text { Latent trajectories validation } \\
\text { cohort }^{*}\end{array}$} & \multirow[b]{2}{*}{$\begin{array}{l}\mathrm{p}- \\
\text { value }\end{array}$} \\
\hline & $\begin{array}{l}\text { Stable, } \\
\text { adequate } \\
\text { glycaemic } \\
\text { control }\end{array}$ & $\begin{array}{l}\text { Improved } \\
\text { glycaemic } \\
\text { control }\end{array}$ & $\begin{array}{l}\text { Deteriorated } \\
\text { glycaemic } \\
\text { control }\end{array}$ & & $\begin{array}{l}\text { Stable, } \\
\text { adequate } \\
\text { glycaemic } \\
\text { control }\end{array}$ & $\begin{array}{l}\text { Improved } \\
\text { glycaemic } \\
\text { control }\end{array}$ & $\begin{array}{l}\text { Deteriorated } \\
\text { glycaemic } \\
\text { control }\end{array}$ & \\
\hline$N$ & $\begin{array}{l}8,049 \\
(76.5) \\
\end{array}$ & $\begin{array}{l}2,246 \\
(21.3) \\
\end{array}$ & $\begin{array}{l}233 \\
(2.2)\end{array}$ & & $\begin{array}{l}2,516 \\
(75.4)\end{array}$ & $\begin{array}{l}702 \\
(21.0) \\
\end{array}$ & $\begin{array}{l}119 \\
(3.6)\end{array}$ & \\
\hline Age (years) (sd) & $\begin{array}{l}63.8 \\
(12.3)\end{array}$ & $\begin{array}{l}60.3 \\
(13.6)\end{array}$ & $\begin{array}{l}59.3 \\
(12.6) \\
\end{array}$ & $<0.001$ & $\begin{array}{l}64.9 \\
(11.6)\end{array}$ & $\begin{array}{l}60.3 \\
(13.5)\end{array}$ & $\begin{array}{l}59.7 \\
(12.2)\end{array}$ & $<0.001$ \\
\hline Male sex (\%) & $\begin{array}{l}4,026 \\
(50.0) \\
\end{array}$ & $\begin{array}{l}1,261 \\
(56.1) \\
\end{array}$ & $\begin{array}{l}146 \\
(62.7) \\
\end{array}$ & $<0.001$ & $\begin{array}{l}1,249 \\
(49.6) \\
\end{array}$ & $\begin{array}{l}417 \\
(59.4) \\
\end{array}$ & $\begin{array}{l}78 \\
(65.5) \\
\end{array}$ & $<0.001$ \\
\hline $\begin{array}{l}\text { Ethnic group }^{\dagger} \\
\text { Caucasian } \\
\text { Non-caucasian }\end{array}$ & $\begin{array}{l}5,116 \\
(95.7) \\
230 \\
(4.3)\end{array}$ & $\begin{array}{l}1415 \\
(94.0) \\
90 \\
(6.0)\end{array}$ & $\begin{array}{l}138 \\
(93.2) \\
10 \\
(6.8) \\
\end{array}$ & 0.013 & $\begin{array}{l}2,185 \\
(95.4) \\
106 \\
(4.6)\end{array}$ & $\begin{array}{l}623 \\
(96) \\
26 \\
(4.0)\end{array}$ & $\begin{array}{l}105 \\
(95.5) \\
5 \\
(4.5)\end{array}$ & 0.797 \\
\hline $\begin{array}{l}\text { Smoking status }{ }^{\dagger} \\
\text { Non-smoker } \\
\text { Current smoker }\end{array}$ & $\begin{array}{l}6,008 \\
(80.9) \\
1,416 \\
(19.1)\end{array}$ & $\begin{array}{l}1595 \\
(77.8) \\
455 \\
(22.2)\end{array}$ & $\begin{array}{l}145 \\
(71.8) \\
57 \\
(28.2)\end{array}$ & $<0.001$ & $\begin{array}{l}1,585 \\
(76.9) \\
477 \\
(23.1)\end{array}$ & $\begin{array}{l}415 \\
(69.5) \\
182 \\
(30.5)\end{array}$ & $\begin{array}{l}65 \\
(64.4) \\
36 \\
(35.6)\end{array}$ & $<0.001$ \\
\hline BMI $\left(\mathrm{kg} / \mathrm{m}^{2}\right)(\mathrm{sd})$ & $30.3(5.3)$ & $30.8(6.1)$ & $29.2(4.8)$ & 0.103 & $30.4(6.1)$ & $31.0(5.7)$ & $31.1(6.3)$ & 0.073 \\
\hline $\begin{array}{l}\text { Alcohol } \\
\text { consumption }\end{array}$ & & & & 0.553 & & & & 0.308 \\
\hline$<3$ glasses/day & $\begin{array}{l}4,595 \\
(76.0)\end{array}$ & $\begin{array}{l}1,301 \\
(76.9)\end{array}$ & $\begin{array}{l}133 \\
(78.7)\end{array}$ & & $\begin{array}{l}2,375 \\
(94.8)\end{array}$ & $\begin{array}{l}664 \\
(94.7)\end{array}$ & $\begin{array}{l}108 \\
(91.5)\end{array}$ & \\
\hline$\geq 3$ glasses/day & $\begin{array}{l}1,450 \\
(24.0)\end{array}$ & $\begin{array}{l}390 \\
(23.1)\end{array}$ & $\begin{array}{l}36 \\
(21.3)\end{array}$ & & $\begin{array}{l}131 \\
(5.2)\end{array}$ & $\begin{array}{l}37 \\
(5.3)\end{array}$ & $\begin{array}{l}10 \\
(8.5)\end{array}$ & \\
\hline $\begin{array}{l}\mathrm{HbA1c} \\
(\mathrm{mmol} / \mathrm{mol})(\mathrm{sd})\end{array}$ & $46.5(5.7)$ & $\begin{array}{l}70.3 \\
(14.1) \\
\end{array}$ & $107.2(15.2)$ & $<0.001$ & $48.4(5.8)$ & $\begin{array}{l}78.0 \\
(16.9) \\
\end{array}$ & $112.5(16.7)$ & $<0.001$ \\
\hline HbA1c (\%) (sd) & $6.4(0.5)$ & $8.6(1.3)$ & $11.9(1.4)$ & $<0.001$ & $6.6(0.5)$ & $9.3(1.5)$ & $12.5(1.5)$ & $<0.001$ \\
\hline $\mathrm{SBD}(\mathrm{mm} \mathrm{Hg})(\mathrm{sd})$ & $\begin{array}{l}138.5 \\
(17.3) \\
\end{array}$ & $\begin{array}{l}138.8 \\
(18.5) \\
\end{array}$ & $\begin{array}{l}137.2 \\
(17.7) \\
\end{array}$ & 0.460 & $\begin{array}{l}138.2 \\
(18.7) \\
\end{array}$ & $\begin{array}{l}139.8 \\
(19.2) \\
\end{array}$ & $\begin{array}{l}135.3 \\
(17.4) \\
\end{array}$ & 0.321 \\
\hline $\mathrm{DBP}(\mathrm{mm} \mathrm{Hg})(\mathrm{sd})$ & $\begin{array}{l}80.5 \\
(9.8) \\
\end{array}$ & $\begin{array}{l}81.7 \\
(10.6) \\
\end{array}$ & $\begin{array}{l}82.3 \\
(10.3) \\
\end{array}$ & 0.003 & $\begin{array}{l}80.3 \\
(10.5) \\
\end{array}$ & $\begin{array}{l}82.6 \\
(10.3) \\
\end{array}$ & $\begin{array}{l}81.7 \\
(9.8) \\
\end{array}$ & 0.238 \\
\hline $\begin{array}{l}\mathrm{LDL}(\mathrm{mmol} / \mathrm{mol}) \\
\text { (sd) }\end{array}$ & $2.9(1.0)$ & $3.0(1.0)$ & $3.3(1.0)$ & $<0.001$ & $3.2(1.1)$ & $3.3(1.1)$ & $3.5(1.2)$ & 0.954 \\
\hline $\begin{array}{l}\mathrm{HDL}(\mathrm{mmol} / \mathrm{mol}) \\
\text { (sd) }\end{array}$ & $1.3(0.4)$ & $1.1(0.3)$ & $1.2(0.3)$ & $<0.001$ & $1.2(0.4)$ & $1.0(0.3)$ & $1.1(0.3)$ & $<0.001$ \\
\hline $\begin{array}{l}\text { Totaal } \\
\text { cholesterol } \\
(\mathrm{mmol} / \mathrm{mol})(\mathrm{sd})\end{array}$ & $4.9(1.1)$ & $5.1(1.3)$ & $5.4(1.2)$ & $<0.001$ & $5.3(1.2)$ & $5.4(1.3)$ & $5.9(1.7)$ & 0.003 \\
\hline
\end{tabular}




\begin{tabular}{|c|c|c|c|c|c|c|c|c|}
\hline & \multicolumn{3}{|c|}{$\begin{array}{l}\text { Latent trajectories development } \\
\text { cohort }^{*}\end{array}$} & \multirow[b]{2}{*}{$\begin{array}{l}\mathrm{p}- \\
\text { value }\end{array}$} & \multicolumn{3}{|c|}{$\begin{array}{l}\text { Latent trajectories validation } \\
\text { cohort }^{*}\end{array}$} & \multirow[b]{2}{*}{$\begin{array}{l}p- \\
\text { value }\end{array}$} \\
\hline & $\begin{array}{l}\text { Stable, } \\
\text { adequate } \\
\text { glycaemic } \\
\text { control }\end{array}$ & $\begin{array}{l}\text { Improved } \\
\text { glycaemic } \\
\text { control }\end{array}$ & $\begin{array}{l}\text { Deteriorated } \\
\text { glycaemic } \\
\text { control }\end{array}$ & & $\begin{array}{l}\text { Stable, } \\
\text { adequate } \\
\text { glycaemic } \\
\text { control }\end{array}$ & $\begin{array}{l}\text { Improved } \\
\text { glycaemic } \\
\text { control }\end{array}$ & $\begin{array}{l}\text { Deteriorated } \\
\text { glycaemic } \\
\text { control }\end{array}$ & \\
\hline $\begin{array}{l}\text { Triglycerides } \\
\text { (mmol/l) (sd) }\end{array}$ & $1.9(1.1)$ & $2.2(1.4)$ & $2.4(1.8)$ & $<0.001$ & $2.1(1.2)$ & $2.6(1.6)$ & $3.6(2.9)$ & $<0.001$ \\
\hline $\begin{array}{l}\text { ACR }(\mathrm{mg} / \mathrm{mmol}) \\
\text { (sd) }\end{array}$ & $2.4(9.2)$ & $3.8(12.2)$ & $3.4(8.4)$ & $<0.001$ & $2.2(10.3)$ & $2.3(7.1)$ & $3.7(12.5)$ & 0.002 \\
\hline $\begin{array}{l}\text { Heart failure }{ }^{\dagger} \\
\text { Yes } \\
\text { No }\end{array}$ & $\begin{array}{l}337 \\
(6.7) \\
4,697 \\
(93.3)\end{array}$ & $\begin{array}{l}92 \\
(6.5) \\
1,328 \\
(93.5)\end{array}$ & $\begin{array}{l}8 \\
(5.9) \\
128 \\
(94.1)\end{array}$ & 0.901 & - & - & - & - \\
\hline $\begin{array}{l}\text { CVD in family } \\
\text { Yes } \\
\text { No }\end{array}$ & $\begin{array}{l}2,072 \\
(37.8) \\
3,409 \\
(62.2)\end{array}$ & $\begin{array}{l}591 \\
(38.6) \\
942 \\
(61.4)\end{array}$ & $\begin{array}{l}55 \\
(34.2) \\
106 \\
(65.8)\end{array}$ & 0.534 & $\begin{array}{l}603 \\
(24.0) \\
1,909 \\
(76.0)\end{array}$ & $\begin{array}{l}189 \\
(27.0) \\
512 \\
(73.0)\end{array}$ & $\begin{array}{l}18 \\
(15.3) \\
100 \\
(84.7)\end{array}$ & 0.018 \\
\hline
\end{tabular}

${ }^{*}$ Values are numbers (percentages) unless stated otherwise. Percentages have been rounded and might not total 100. ${ }^{+}$Percentages are out of total with recorded values

$\mathrm{SBD}=$ systolic blood pressure; $\mathrm{DBP}=$ diastolic blood pressure; $\mathrm{ACR}=$ albumin-to-creatinine ratio; $\mathrm{CVD}=$ cardiovascular disease.

Table 3. Patient feature ranking of the 5 -fold cross validation as observed in the development cohort

\begin{tabular}{ccc}
\hline Ranking & Patient baseline characteristics & Patient feature weight \\
\hline 1 & BMI & 0.3571 \\
2 & HbA1c & 0.1571 \\
3 & Triglyceridess & 0.1148 \\
4 & LDL & 0.0754 \\
5 & Age & 0.0749 \\
6 & SBP & 0.0737 \\
7 & ACR & 0.0618 \\
8 & Sex & 0.0142 \\
9 & Alcohol consumption & 0.0142 \\
10 & Smoking & 0.0142 \\
11 & CVD in family & 0.0142 \\
12 & Heart failure & 0.0142 \\
13 & Race & 0.0142 \\
\hline
\end{tabular}

$\mathrm{SBP}=$ systolic blood pressure; $\mathrm{ACR}$ = albumin-to-creatinine ratio;

$\mathrm{CVD}=$ cardiovascular disease. 


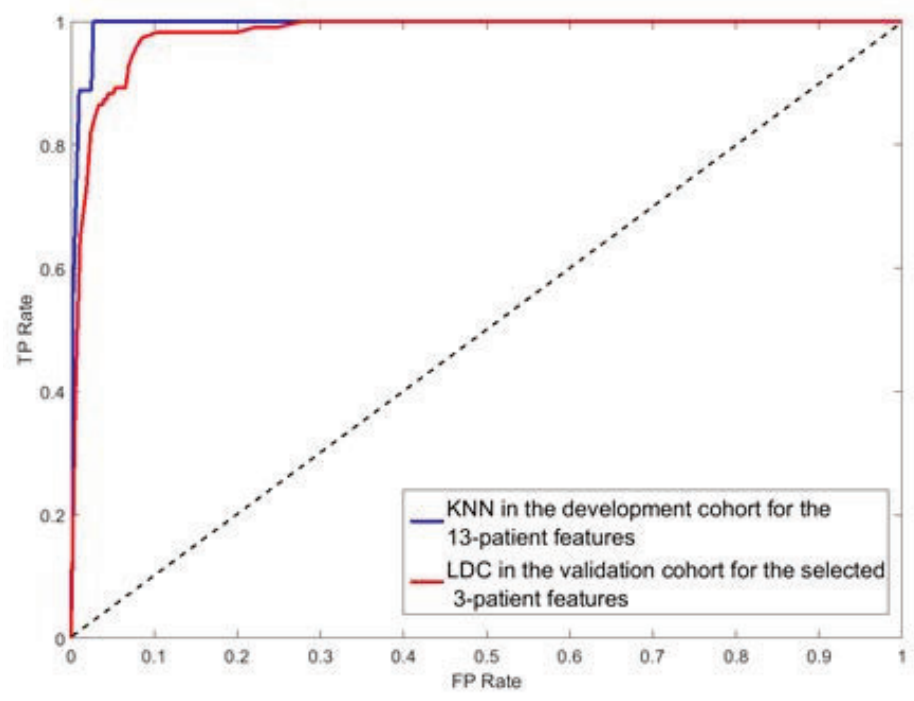

Figure 2. Receiver operating characteristic (ROC) curve of the 13-patient feature prediction model and the 3patient feature prediction model.

$\mathrm{TP}=$ true positive; $\mathrm{FP}=$ false positive; $\mathrm{KNN}=\mathrm{K}$-nearest neighbor LDC = Linear discriminant classifier

\section{Discussion}

In this retrospective cohort study of patients with newly diagnosed type 2 diabetes treated in primary care, three distinct glycaemic trajectories were identified during the first 5 years after diagnosis: 1) stable, adequate glycaemic control; 2) improved glycaemic control, and 3) deteriorated glycaemic control. Our most important finding was that trajectory membership can be predicted with good to excellent accuracy using no more than three patient characteristics (baseline $\mathrm{BMI}, \mathrm{HbA} 1 \mathrm{c}$, and triglycerides). The generalization ability of the model, obtained by training the model on the development cohort and testing it on the validation cohort, was also excellent.

To our knowledge, only two previous studies have examined latent glycaemic trajectories in patients with type 2 diabetes [31, 32]. Both studies identified four glycaemic trajectories, which shared notable similarities with the trajectory patterns we observed in the current study. The similarities between the previous and current studies were most notable for the stable, adequate glycaemic control trajectory. In both previous studies, this trajectory was identified and included $83 \%$ of their patients, slightly higher than the $72 \%$ we found. These results indicate that current practice enables a majority of patients to reach and maintain recommended glycaemic control levels. Our study shows that this group of patients can be identified at diagnosis by applying a model that has a high PPV and NPV.

These findings have important implications for more precision medicine in type 2 diabetes. The main goal of precision medicine is to develop models that can predict disease development or disease outcomes in order to tailor treatment [3]. Our model uses three 
relative simple clinical characteristics, $\mathrm{BMI}, \mathrm{HbA1c}$ and triglycerides to divide patients into three groups, each with different future glycaemic trajectories. Predicting patients' future glycaemic control enables care professionals to provide tailored diabetes management. For patients classified in the stable, adequate glycaemic control group, for example, less intensive monitoring might suffice, whereas patients classified in the deteriorated glycaemic control group could benefit more from frequent monitoring. Previous research suggests that less frequent monitoring of patients with stable, adequate glycaemic control - that is, biannually instead of quarterly check-ups by a GP - is possible without negative effects on health, allowing for considerable cost reductions [33]. More in general, our model enables tailoring of a range of diabetes care components to patients' care needs, including pharmacotherapy, lifestyle advice, and self-management support.

This study is subject to a number of strengths and limitations. In the current study we applied a unique approach by combining LGMM with machine learning techniques. There were three follow-up HbA1c measurements in the development cohort and four in the validation cohort, allowing for the identification of heterogeneity in future glycaemic response. Prescription of glucose lowering drugs and insulin may have influenced the patterns of the trajectories. HbA1c levels in in the stable, adequate- and improved glycaemic control trajectories remained stable or improved, possibly due to an increase in oral- and insulin prescriptions over time. In the deteriorated glycaemic control trajectory, however, HbA1c increased, despite an increase in glucose lowering drugs and insulin prescriptions. Disease progression or difficulties adhering to drug treatment and healthy lifestyle could be explanations for this [34, 35].

The external validation is an important strength of our study, considering that many research findings are based solely on the basis of a single study [36]. A limitation was that both cohorts consisted of a predominantly white population. When compared to whites, other races tend to have higher $\mathrm{HbA1C}$ values [37], and their inclusion might have resulted in glycaemic control trajectories that differ in size and shape. One of the previous studies that examined latent glycaemic control trajectories [31], included a mixed-race population, with approximately $50 \%$ non-whites. However, as stated before, the identified trajectories in this study are similar to the trajectories in the current study.

So far, predictive models and tools based on machine learning techniques have not been widely used in clinical decision support systems [38]. One of the reasons could be that data obtained from EHRs are considered a byproduct of health care delivery, rather than a resource to improve its performance [39]. Besides, most machine learning models are complex and difficult to interpret, since they heavily depend on aspects related to feature distribution, data availability, and data representation [40]. In the current study we built and validated a simple and interpretable algorithm with excellent accuracy. Despite the high PPV and NPV in the stable, adequate glycaemic control trajectory, the PPV in the deteriorated glycaemic control trajectory was only $45.8 \%$ in the validation cohort. This implies that more than half the patients classified in this trajectory do not belong there (false positives), which is a point for 
further refinement. The counterpart is that the NPV is high, implicating that membership of this trajectory can be ruled out with high certainty.

In conclusion, only three patient characteristics (BMI, HbA1c and triglycerides) are needed to accurately predict glycaemic response of patients with newly diagnosed type 2 diabetes. The model can be used in practice as a quick, easy and accurate tool to determine patients' care needs and provide tailored diabetes treatment. 


\section{References}

1. Garrod AE. The inborn factors if disease: an essay. Oxford, UK: Oxford University Press; 1931.

2. Dance A. Medical histories. Nature 2016; 537:S52-53.

3. Joyner MJ, Paneth N. Seven Questions for Personalized Medicine. Jama 2015; 314:9991000.

4. Collins FS, Varmus H. A new initiative on precision medicine. N Engl J Med 2015; 372:793795.

5. Torjesen I. Genomes of 100,000 people will be sequenced to create an open access research resource. Bmj 2013; 347:f6690.

6. Kwak EL, Bang YJ, Camidge DR, Shaw AT, Solomon B, Maki RG, et al. Anaplastic lymphoma kinase inhibition in non-small-cell lung cancer. N Engl J Med 2010; 363:16931703.

7. Rebbeck TR, Mitra N, Wan F, Sinilnikova OM, Healey S, McGuffog L, et al. Association of type and location of BRCA1 and BRCA2 mutations with risk of breast and ovarian cancer. JAMA 2015; 313:1347-1361.

8. Fuchsberger C, Flannick J, Teslovich TM, Mahajan A, Agarwala V, Gaulton KJ, et al. The genetic architecture of type 2 diabetes. Nature 2016; 536:41-47.

9. Rich SS. Diabetes: Still a geneticist's nightmare. Nature 2016; 536:37-38.

10. Inzucchi SE, Bergenstal RM, Buse JB, Diamant M, Ferrannini E, Nauck M, et al. Management of hyperglycemia in type 2 diabetes: a patient-centered approach: position statement of the American Diabetes Association (ADA) and the European Association for the Study of Diabetes (EASD). Diabetes Care 2012; 35:1364-1379.

11. Riddle MC, Karl DM. Individualizing targets and tactics for high-risk patients with type 2 diabetes: practical lessons from ACCORD and other cardiovascular trials. Diabetes care 2012; 35:2100-2107.

12. Lister Hill National Center for Biomedical Communications, U.S. National Library of Medicine, National Institutes of Health, Department of Health \& Human Services. Help me understand genetics: precision medicine. https://ghr.nlm.nih.gov/primer 2017.

13. Netherlands Diabetes Federation. NDF care standard. transparancy and quality of diabets care for people with diabetes type 2 [NDF Zorgstandaard. Transparantie en kwaliteit van diabeteszorg voor mensen met type 2 diabetes]. Amersfoort: Netherlands Diabetes Federation 2015.

14. Virkamaki A, Saltevo J. Finnish Current Care Guideline for Diabetes: interactive approach to improve individualised treatment. Diabetologia 2011; 54:1264-1265.

15. Hendriks SH, van Dijk PR, van Hateren KJ, van Pelt JL, Groenier KH, Bilo HJ, et al. Highsensitive troponin $\mathrm{T}$ is associated with all-cause and cardiovascular mortality in stable outpatients with type 2 diabetes (ZODIAC-37). American heart journal 2016; 174:43-50.

16. Landman GW, van Dijk PR, Drion I, van Hateren KJ, Struck J, Groenier KH, et al. Midregional fragment of proadrenomedullin, new-onset albuminuria, and cardiovascular and all-cause mortality in patients with type 2 diabetes (ZODIAC-30). Diabetes care 2014; 37:839-845.

17. Roelofsen $\mathrm{Y}$, van Vugt M, Hendriks SH, van Hateren KJ, Groenier KH, Snoek FJ, et al. Demographical, Clinical, and Psychological Characteristics of Users and Nonusers of an Online Platform for T2DM Patients (e-VitaDM-3/ZODIAC-44). Journal of diabetes research 2016; 2016:6343927. 
18. Steuten LM, Vrijhoef HJ, Landewe-Cleuren S, Schaper N, Van Merode GG, Spreeuwenberg $\mathrm{C}$. A disease management programme for patients with diabetes mellitus is associated with improved quality of care within existing budgets. Diabetic medicine : a journal of the British Diabetic Association 2007; 24:1112-1120.

19. Elissen AM, Duimel-Peeters IG, Spreeuwenberg C, Spreeuwenberg M, Vrijhoef HJ. Toward tailored disease management for type 2 diabetes. Am J Manag Care 2012; 18:619-630.

20. Ubink-Veltmaat LJ, Bilo HJ, Groenier KH, Rischen RO, Meyboom-de Jong B. Shared care with task delegation to nurses for type 2 diabetes: prospective observational study. Neth J Med 2005; 63:103-110.

21. Nagin DS, Odgers CL. Group-based trajectory modeling in clinical research. Annual review of clinical psychology 2010; 6:109-138.

22. Muthén B. On structural equation modeling with data that are not missing completely at random. Psychometrika 1987; 52:431-462.

23. Jung T, Wickrama KAS. An introduction to latent class growth analysis and growth mixture modeling. Social and Personality Psychology Compass 2008; 2:302-317.

24. van de Schoot R, Sijbrandij M, Winter SD, Depaoli S, Vermunt JK. The GRoLTS-checklist: guidelines for reporting on latent trajectory studies. Structural Equation Modeling 2016; 24:451-467.

25. Akaike $\mathrm{H}$. Information theory as an extension of the maxium likelihood principle. In: Petrov BN, F Csaki, eds. Second international symposium on information theory Budapest, Hungary: Akademiai Kiado 1973: 267.

26. Schwarz G. Estimating the dimension of a model. The Annals of Statistics 1978; 6:461464.

27. Lo $\mathrm{Y}$, Mendell N, Rubin D. Testing the number of components in a normal mixture. Biometrika 2001; 88:767-778.

28. Depaoli S. Mixture class recovery in GMM under varying degrees of class separation: frequentist versus Bayesian estimation. Psychological methods 2013; 18:186-219.

29. Muthén LK, Muthén BO. Mplus User's Guide. Seventh Edition Los Angeles, CA: Muthén \& Muthén; 2012.

30. Brazdil PB, Soares C. A comparison of ranking methods for classification algorithm selection. Machine Learning: ECML, 2000. Berlin Heidelberg: Springer Berlin Heidelberg 2003: 63-75.

31. Laiteerapong N, Karter AJ, Moffet HH, Cooper JM, Gibbons RD, Liu JY, et al. Ten-year hemoglobin A1c trajectories and outcomes in type 2 diabetes mellitus: The Diabetes \& Aging Study. Journal of diabetes and its complications 2017; 31:94-100.

32. Walraven I, Mast MR, Hoekstra T, Jansen AP, van der Heijden AA, Rauh SP, et al. Distinct HbA1c trajectories in a type 2 diabetes cohort. Acta Diabetol 2015; 52:267-275.

33. Wermeling PR, Gorter KJ, Stellato RK, de Wit GA, Beulens JW, Rutten GE. Effectiveness and cost-effectiveness of 3-monthly versus 6-monthly monitoring of well-controlled type 2 diabetes patients: a pragmatic randomised controlled patient-preference equivalence trial in primary care (EFFIMODI study). Diabetes Obes Metab 2014; 16:841-849.

34. 34. Jin J, Sklar GE, Min Sen Oh V, Chuen Li S. Factors affecting therapeutic compliance: A review from the patient's perspective. Ther Clin Risk Manag 2008; 4:269-286.

35. Look ARG, Wing RR, Bolin P, Brancati FL, Bray GA, Clark JM, et al. Cardiovascular effects of intensive lifestyle intervention in type 2 diabetes. The New England journal of medicine 2013; 369:145-154. 
36. Ioannidis JP. Why most published research findings are false. PLoS medicine 2005; 2:e124.

37. Campbell JA, Walker RJ, Smalls BL, Egede LE. Glucose control in diabetes: the impact of racial differences on monitoring and outcomes. Endocrine 2012; 42:471-482.

38. Miotto R, Li L, Kidd BA, Dudley JT. Deep Patient: An Unsupervised Representation to Predict the Future of Patients from the Electronic Health Records. Scientific reports 2016; 6:26094.

39. Murdoch TB, Detsky AS. The inevitable application of big data to health care. Jama 2013; 309:1351-1352.

40. Luo G. Automatically explaining machine learning prediction results: a demonstration on type 2 diabetes risk prediction. Health information science and systems 2016; 4:2. 


\section{Supplementary Material:}

\section{Detailed description analysis}

\section{Latent growth mixture modeling}

Latent growth mixture modeling (LGMM) was used to systematically identify latent trajectories of glycemic control. This method allows for the clustering of patients into an optimal number of growth trajectories. [1] Most of the missing data is assumed to be unrelated to the outcome variable HbA1c (missing at random (MAR)). [2] Consequently, full information maximum likelihood (FIML) was used as a missing data estimation approach. [3] FIML requires the missing values to be MAR. A protocol, recommended by others, $[4,5]$ was followed to identify the best LGMM model. First, a series of latent class growth analysis (LCGA) models were estimated. LCGA assumes no within class variance, whereas LGMM freely estimates the within class variance. [4] The growth parameter variances across each trajectory in the LCGA models were therefore fixed to zero. Second, LGMM models that allowed for variation in growth parameters were estimated. In both the LCGA and LGMM models the residual variances and the variance-covariance matrix were fixed across classes. Models were rerun with different starting values to ensure that the final class model solution had been converged to the maximum of the maximum likelihood distribution. The best model was determined by comparing the model fits of a progressive number of trajectories. Fit indices included the Akaike Information Criterion (AIC), [6] Bayesian Information Criterion (BIC) [7] and the Lo-Mendel-Rubin-likelihood ratio test (LMR-LRT). [8] Lower values of the $A I C$ and $B I C$, and/or a significant result on the LMR-LRT indicate a better model fit in terms of the number of trajectories. To determine model classification performance, entropy was used. Higher entropy values indicate a clearer trajectory membership classification. [9] The usefulness and clinical interpretation of each newly added trajectory were also taken into account.

\section{Machine learning classification methods}

To develop the prediction model, a 5-fold cross validation was performed in the development cohort. Several machine learning classification methods were used, because there is no consensus on the best performing classifier. [10] Furthermore, a sparse autoencoder (SAE) algorithm [11] was added on top of the row features to determine if this lead to an improved representation of the included features. SAE is a technique which aims to minimize the reconstruction error between the input and the output in an unsupervised way. It is useful at estimating the underlying data distribution. By placing constraints on the network, such as sparsity, the algorithm can learn an interesting structure of the data. One important parameter of the SAE algorithm is the number of considered hidden units $(H)$, which represents the dimensionality of the new feature set. Experiments were performed with several values of the $\mathrm{H}$ parameter. Only results with the best $\mathrm{H}$ parameter are reported. To examine the generalizability of the developed prediction model, an external validation 
was computed in the development cohort. Receiver operating characteristic (ROC) curves were generated to show the discrimination of the models. To examine the agreement between predicted and observed trajectory membership, calibration slopes were produced. Prognostic values (sensitivities, specificities, positive predictive value (PPV), and negative predictive value (NPV), were also calculated.

Table S1. Average time between diagnosis of type 2 diabetes and HbA1c measurement per follow-up year and the number of patients per follow-up year

\begin{tabular}{|c|c|c|c|c|}
\hline \multirow[b]{2}{*}{ Year } & \multicolumn{2}{|c|}{ development cohort } & \multicolumn{2}{|c|}{ Validation cohort } \\
\hline & $\begin{array}{l}\text { Average time between } \\
\text { diagnosis and HbA1c } \\
\text { measurement (years) (sd) }\end{array}$ & $\begin{array}{l}\text { Number of patients } \\
\text { (\%) }\end{array}$ & $\begin{array}{l}\text { Average time between } \\
\text { diagnosis and HbA1c } \\
\text { measurement (years) (sd) }\end{array}$ & $\begin{array}{l}\text { Number of patients } \\
\text { (\%) }\end{array}$ \\
\hline 1 & $0.06(0.1)$ & 10528 & $0.06(0.07)$ & 3777 \\
\hline 2 & $1.02(0.13)$ & $4600(44.8)$ & $0.92(0.14)$ & $2428(72.8)$ \\
\hline 3 & $2.01(0.14)$ & $3244(30.8)$ & $1.91(0.11)$ & $1935(51.2)$ \\
\hline 4 & $3.01(0.14)$ & $2245(21.3)$ & $2.90(0.11)$ & $1490(39.4)$ \\
\hline 5 & - & - & $3.90(0.11)$ & $1023(27.1)$ \\
\hline
\end{tabular}

Table S2. Development cohort fit indices using latent class growth analyses (LCGA) and latent growth mixture modeling (LGMM) with intercept and slope growth parameters estimated $(n=10.258)$

\begin{tabular}{|c|c|c|c|c|c|c|}
\hline & Loglikelihood & AIC & BIC & Entropy & LMR & $\begin{array}{l}\text { Cases per class } \\
(\%)\end{array}$ \\
\hline \multicolumn{7}{|l|}{ LCGA } \\
\hline 1-class & -79382 & 158778 & 158829 & - & - & 100 \\
\hline 2-class & -76810 & 153643 & 153723 & 0.955 & $<0.0001$ & $90 / 10$ \\
\hline 3-class & -75879 & 151789 & 151898 & 0.870 & $<0.0001$ & $82 / 10 / 8$ \\
\hline 4-class & -75321 & 150680 & 150818 & 0.862 & $<0.0001$ & $77 / 13 / 7 / 3$ \\
\hline 5-class & -74872 & 149790 & 149957 & 0.754 & 0.0256 & $61 / 25 / 7 / 4 / 3$ \\
\hline 6-class & -74673 & 149401 & 149597 & 0.771 & 0.1936 & $60 / 26 / 7 / 3 / 3 / 1$ \\
\hline \multicolumn{7}{|l|}{ LGMM } \\
\hline $\begin{array}{l}\text { 1-class } \\
\text { RI = c1 } \\
\text { RLS = c1 }\end{array}$ & -77787 & 155600 & 155694 & - & - & 100 \\
\hline $\begin{array}{l}\text { 2-class } \\
\begin{array}{l}\mathrm{RI}=\mathrm{c} 1 \text { \& c2 } \\
\mathrm{RIS}=\mathrm{c} 1 \text { \& c2 } \\
\mathrm{RQS}=\mathrm{c} 2\end{array}\end{array}$ & -74685 & 149409 & 149547 & 0.866 & 0.0003 & $85 / 15$ \\
\hline $\begin{array}{l}\text { 3-class } \\
\begin{array}{l}\mathrm{RI}=\mathrm{c} 1, \mathrm{c} 2 \text { \& c3 } \\
\mathrm{RLS}=\mathrm{c} 1 \text { \& c2 } \\
\mathrm{RQS}=\mathrm{c} 2\end{array}\end{array}$ & -73355 & 146758 & 146933 & 0.758 & $<0.0001$ & $72 / 25 / 3$ \\
\hline $\begin{array}{l}\text { 4-class } \\
\mathrm{RI}=\mathrm{c} 1, \mathrm{c} 2, \mathrm{c} 3 \& \mathrm{c4} \\
\mathrm{RLS}=\mathrm{c} 1, \mathrm{c} 2 \& \mathrm{c} 4 \\
\mathrm{RQS}=\mathrm{c} 2 \& \mathrm{c} 4\end{array}$ & -73159 & 146381 & 146606 & 0.771 & 0.1215 & $68 / 25 / 7 / 1$ \\
\hline
\end{tabular}


Table S3. Intercept and slope growth parameters in each latent class in the 3-class models of the development and validation cohorts

\begin{tabular}{|c|c|c|c|c|c|c|c|c|}
\hline & \multicolumn{4}{|c|}{ Development cohort (ZODIAC) } & \multicolumn{4}{|c|}{ Validation cohort (ZIO) } \\
\hline & \multirow[b]{2}{*}{ B } & \multirow[b]{2}{*}{ SE } & \multicolumn{2}{|c|}{$95 \% \mathrm{Cl}$} & \multirow[b]{2}{*}{ B } & \multirow[b]{2}{*}{ SE } & \multicolumn{2}{|c|}{$95 \% \mathrm{Cl}$} \\
\hline & & & Lower & Upper & & & Lower & Upper \\
\hline \multicolumn{9}{|c|}{ 1. Glycemic deterioration } \\
\hline Intercept (mean)* & 96.0 & 7.1 & 82.2 & 110.0 & 107.9 & 7.2 & 93.8 & 122.0 \\
\hline Slope (mean) * & -122.9 & 3.7 & -130.2 & -115.6 & -118.9 & 8.5 & 135.5 & -102.1 \\
\hline Quadratic term (mean) * & 25.6 & 0.9 & 23.8 & 27.4 & 22.0 & 2.3 & 17.5 & 26.5 \\
\hline \multicolumn{9}{|c|}{ 2. Insufficient glycemic control } \\
\hline Intercept (mean) * & 66.3 & 3.3 & 59.7 & 72.8 & 73.9 & 2.3 & 69.4 & 78.4 \\
\hline Slope (mean)* & -25.1 & 1.6 & -28.2 & -22.0 & -24.6 & 1.4 & -27.3 & 21.9 \\
\hline Quadratic term (mean) * & 4.3 & 0.3 & 3.7 & 4.9 & 3.4 & 0.2 & 3.0 & 3.8 \\
\hline \multicolumn{9}{|c|}{ 3. Sufficient glycemic control } \\
\hline Intercept (mean) * & 46.5 & 0.4 & 45.7 & 47.3 & 48.2 & 0.3 & 47.6 & 48.8 \\
\hline Slope (mean) ${ }^{*}$ & -3.0 & 0.2 & -3.4 & -2.6 & -2.6 & 0.2 & -3.0 & -2.2 \\
\hline Quadratic term (mean) * & 0.6 & 0.04 & 0.5 & 0.7 & 0.3 & 0.03 & 0.2 & 0.4 \\
\hline
\end{tabular}

*significant at the $p<0.05$ level. 
Table S4. Validation cohort fit indices using latent class growth analyses (LCGA) and latent growth mixture modeling (LGMM) with intercept and slope growth parameters estimated ( $n=3.337)$

\begin{tabular}{|c|c|c|c|c|c|c|}
\hline & Loglikelihood & AIC & BIC & Entropy & LMR & $\begin{array}{l}\text { Cases per class } \\
\text { (\%) }\end{array}$ \\
\hline \multicolumn{7}{|l|}{ LCGA } \\
\hline 1-class & -38874 & 77765 & 77814 & - & - & 100 \\
\hline 2-class & -37885 & 75794 & 75867 & 0.901 & 0.0022 & $90 / 10$ \\
\hline 3-class & -37474 & 74981 & 75079 & 0.743 & 0.0866 & $71 / 25 / 4$ \\
\hline 4-class & -37147 & 74335 & 74457 & 0.787 & 0.0267 & $68 / 24 / 5 / 3$ \\
\hline 5-class & -36956 & 73960 & 74107 & 0.762 & 0.3827 & $57 / 33 / 5 / 4 / 1$ \\
\hline \multicolumn{7}{|l|}{ LGMM } \\
\hline $\begin{array}{l}\text { 1-class } \\
\mathrm{RI}=\mathrm{c} 1 \\
\mathrm{RLS}=\mathrm{c} 1 \\
\mathrm{RQS}=\mathrm{c} 1\end{array}$ & -37604 & 75230 & 75297 & - & - & 100 \\
\hline $\begin{array}{l}\text { 2-class } \\
\begin{array}{l}\mathrm{RI}=\mathrm{c} 1 \& \mathrm{c} 2 \\
\mathrm{RLS}=\mathrm{c} 1 \& \mathrm{c} 2 \\
\mathrm{RQS}=\mathrm{c} 1 \& \mathrm{c} 2\end{array}\end{array}$ & -36122 & 72283 & 72400 & 0.815 & $<0.0001$ & $75 / 25$ \\
\hline $\begin{array}{l}\text { 3-class } \\
\mathrm{RI}=\mathrm{c} 1, \mathrm{c} 2 \& \mathrm{c} 3 \\
\mathrm{RLS}=\mathrm{c} 1 \& \mathrm{c} 2 \\
\mathrm{RQS}=\mathrm{c} 1 \& \mathrm{c} 2\end{array}$ & -35963 & 71979 & 72137 & 0.827 & 0.0005 & $72 / 24 / 4$ \\
\hline $\begin{array}{l}\text { 4-class } \\
\mathrm{RI}=\mathrm{c} 1, \mathrm{c} 2, \mathrm{c} 3 \& \mathrm{c4} \\
\mathrm{RLS}=\mathrm{c} 1, \mathrm{c} 2 \& \mathrm{c} 4 \\
\mathrm{RQS}=\mathrm{c} 1, \mathrm{c} 2 \& \mathrm{c} 4\end{array}$ & -35879 & 71824 & 72026 & 0.842 & 0.0009 & $71 / 24 / 4 / 1$ \\
\hline $\begin{array}{l}\text { 5-class } \\
\mathrm{RI}=\mathrm{c} 1, \mathrm{c} 2, \mathrm{c} 3, \mathrm{c} 4 \& \mathrm{c} 5 \\
\mathrm{RLS}=\mathrm{c} 1, \mathrm{c} 2, \mathrm{c} 4 \& \mathrm{c} 5 \\
\mathrm{RQS}=\mathrm{c} 1, \mathrm{c} 2, \mathrm{c} 4 \& \mathrm{c5}\end{array}$ & -35834 & 71749 & 71993 & 0.822 & 0.0414 & $70 / 22 / 4 / 4 / 1$ \\
\hline $\begin{array}{l}\text { 6-class } \\
\text { RI }=\mathrm{c} 1, \mathrm{c} 2, \mathrm{c} 3, \mathrm{c4}, \mathrm{c5} \& \mathrm{c} 6 \\
\mathrm{RLS}=\mathrm{c} 1, \mathrm{c} 2, \mathrm{c4}, \mathrm{c5} \& \mathrm{c} 6 \\
\mathrm{RQS}=\mathrm{c} 1, \mathrm{c} 2, \mathrm{c4}, \mathrm{c5} \& \mathrm{c} 6\end{array}$ & -35812 & 71718 & 72006 & 0.811 & 0.5481 & $69 / 20 / 5 / 3 / 2 / 1$ \\
\hline
\end{tabular}

Unless specified, all other growth parameter variances were fixed at zero. LCGA: latent class growth analyses; LGMM: latent growth mixture modeling; $c 1=$ class $1 ; \mathrm{c} 2$ = class $2 ; \mathrm{c} 3$ = class $3 ; \mathrm{c4}=$ class $4 ; \mathrm{c5}$ = class $5 ; \mathrm{c} 6$ = class 6 ; RI: random intercept; RLS: random linear slope, RQS: random quadratic slope AIC: Akaike's information criteria; BIC: Bayesian information criteria; LMR: Lo-Mendell-Rubin likelihood ratio test.

Table S5. Correlations between SBP, DBP, lipid profile features and CDV features

\begin{tabular}{|c|c|c|c|c|c|c|c|c|}
\hline & SBP & DBP & LDL-C & HDL-c* & $\begin{array}{l}\text { Total } \\
\text { cholesterol }\end{array}$ & TG* & $\begin{array}{l}\text { Heart } \\
\text { failure }\end{array}$ & $\begin{array}{l}\text { CVD in } \\
\text { family }\end{array}$ \\
\hline SBP & - & $0.504 * * *$ & 0.082 & 0.059 & 0.104 & 0.032 & -0.049 & -0.028 \\
\hline DBP & $0.504 * * *$ & - & 0.123 & 0.136 & 0.145 & 0.136 & -0.126 & 0.031 \\
\hline LDL-c & 0.082 & 0.123 & - & 0.089 & 0.902 & 0.124 & -0.050 & -0.039 \\
\hline HDL-C & 0.059 & 0.136 & 0.089 & - & 0.194 & $\begin{array}{l}- \\
0.426 * * *\end{array}$ & -0.053 & -0.056 \\
\hline $\begin{array}{l}\text { Total } \\
\text { cholesterol }\end{array}$ & 0.104 & 0.145 & $0.902 * * *$ & 0.194 & - & 0.323 & -0.049 & -0.032 \\
\hline TG* & 0.032 & 0.136 & 0.124 & $-0.426 * * *$ & 0.323 & - & 0.011 & 0.054 \\
\hline Heart failure & -0.049 & -0.126 & -0.050 & -0.053 & -0.049 & 0.011 & - & 0.032 \\
\hline CVD in family & -0.028 & 0.031 & -0.039 & -0.056 & -0.032 & 0.054 & 0.032 & - \\
\hline
\end{tabular}

*Not normally distributed $=$ Spearman correlation coefficient (all other variables are normally distributed $=$ Pearson correlation coefficient)

$* * *$ significant at the $\mathrm{p}<0.01$ level

$\mathrm{SBD}=$ systolic blood pressure; $\mathrm{DBP}=$ diastolic blood pressure; $\mathrm{LDL}-\mathrm{C}=\mathrm{LDL}$ cholesterol; HDL-c = HDL cholesterol; $\mathrm{TG}=$ triglycerides; $\mathrm{CVD}=$ cardiovascular disease. 
Table S6. Accuracy of different machine learning classifiers of the prediction of glycemic control trajectories in the development cohort using 13 patient features

\begin{tabular}{|l|c|c|c|c|c|c|c|c|c|}
\hline & Fisher & KNN & Parzen & QDC & LDC & SVM & $\begin{array}{l}\text { SVM } \\
\text { (RBF) }\end{array}$ & $\begin{array}{l}\text { Logistic } \\
\text { Regression }\end{array}$ & Stacked SVM \\
\hline Accuracy (\%) & 79.73 & $\mathbf{9 2 . 2 8}$ & 89.77 & 90.86 & $91.66 \%$ & 75.98 & 75.98 & 91.43 & 81.43 \\
\hline
\end{tabular}

KNN = K-nearest neighbor; $Q D C=$ quadratic discriminant classifier; $L D C=$ linear discriminant classifier; $S V M=$ supper vector machine; RBF = radial basis function.

Table S7. Sensitivity, specificity, PPV, NPV of the 13-patient feature model as observed in the development cohort

\begin{tabular}{lccc}
\hline & \multicolumn{3}{c}{ Trajectories } \\
\cline { 2 - 4 } & $\begin{array}{c}\text { Stable, adequate } \\
\text { glycemic control }\end{array}$ & Improved glycemic control & Deteriorated glycemic control \\
\hline Sensitivity (\%) & 98.3 & 78.4 & 81.3 \\
Specificity (\%) & 81.2 & 97.8 & 99.4 \\
PPV (\%) & 94.7 & 78.4 & 78.0 \\
NPV (\%) & 93.7 & 94.2 & 99.5 \\
\hline
\end{tabular}

PPV = positive predictive value;

$\mathrm{NPV}=$ negative predictive value.

Table S8. Accuracy of different machine learning classifiers of the prediction of glycemic control trajectories in the validation cohort using 3 patient features

\begin{tabular}{|l|l|l|l|l|l|l|}
\hline & Fisher & KNN & Parzen & QDC & LDC & $\begin{array}{l}\text { Logistic } \\
\text { Regression }\end{array}$ \\
\hline Accuracy & $81.11 \%$ & $91.46 \%$ & $91.86 \%$ & $90.96 \%$ & $\mathbf{9 2 . 0 0 \%}$ & $\mathbf{9 2 . 0 0 \%}$ \\
\hline
\end{tabular}

KNN = K-nearest neighbor; QDC = quadratic discriminant classifier $; \mathrm{LDC}=$ linear discriminant classifier; SVM= supper vector machine.

Table S9. Sensitivity, specificity, PPV, NPV of the 3-patient feature model as observed in the validation cohort

\begin{tabular}{lccc}
\hline & & \multicolumn{2}{c}{ Trajectories } \\
\cline { 2 - 4 } & $\begin{array}{c}\text { Stable, adequate } \\
\text { glycemic control }\end{array}$ & Improved glycemic control & Deteriorated glycemic control \\
\hline Sensitivity (\%) & 99.1 & 67.9 & 87.4 \\
Specificity (\%) & 85.3 & 98.6 & 95.8 \\
PPV (\%) & 96.1 & 92.9 & 45.8 \\
NPV (\%) & 96.1 & 91.9 & 99.4 \\
\hline
\end{tabular}

PPV = positive predictive value;

$\mathrm{NPV}=$ negative predictive value. 


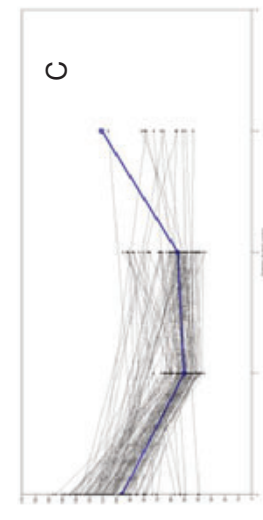

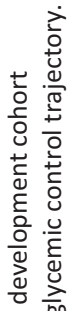

造

음

$\stackrel{0}{\circ}$

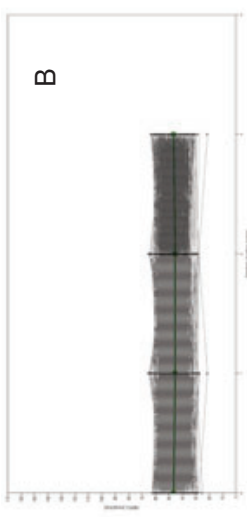

$\ddot{z}$

$\mp$ के

茴

$\frac{\pi}{2}$

눙

$\frac{\pi}{4}$

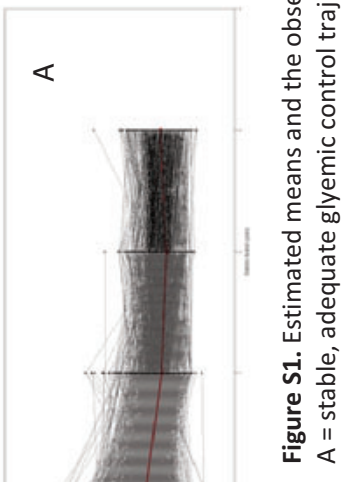




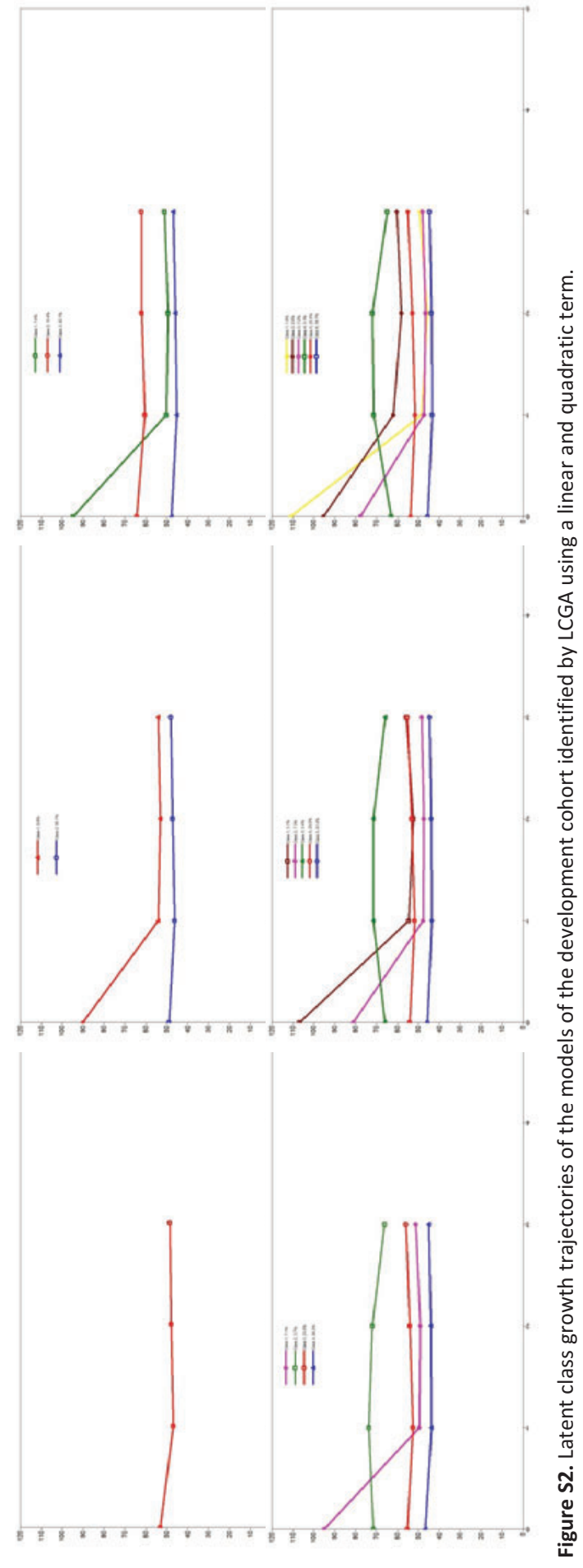



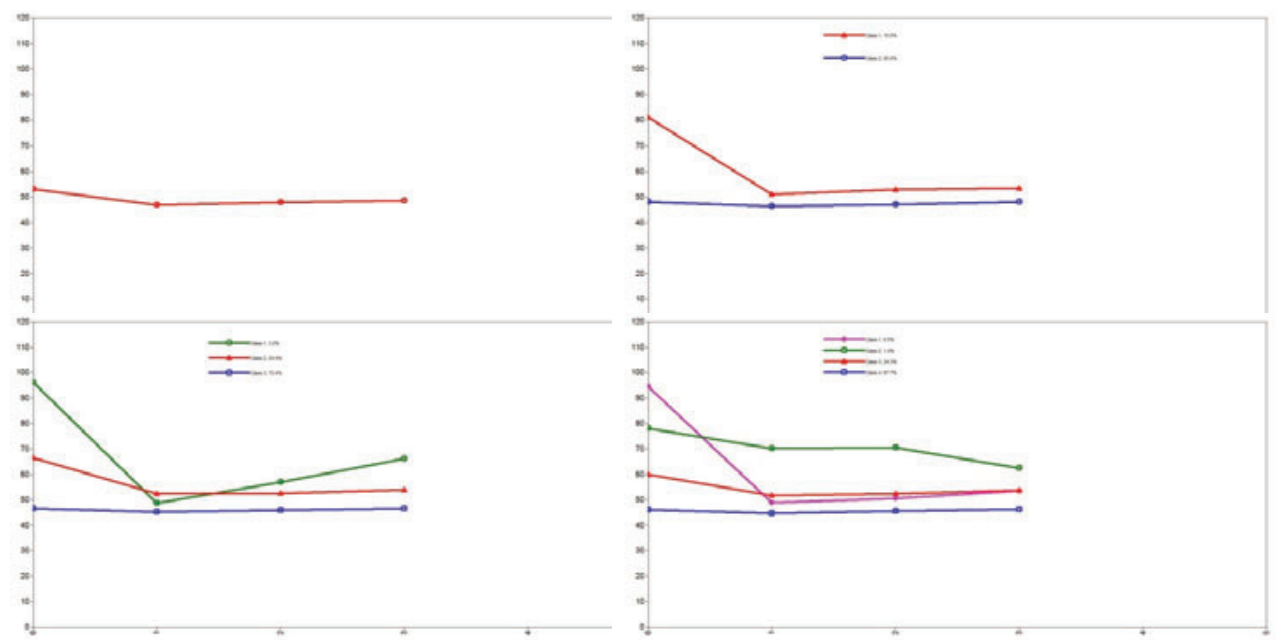

Figure S3. Latent class growth trajectories of the models of the development cohort identified by LGMM. 


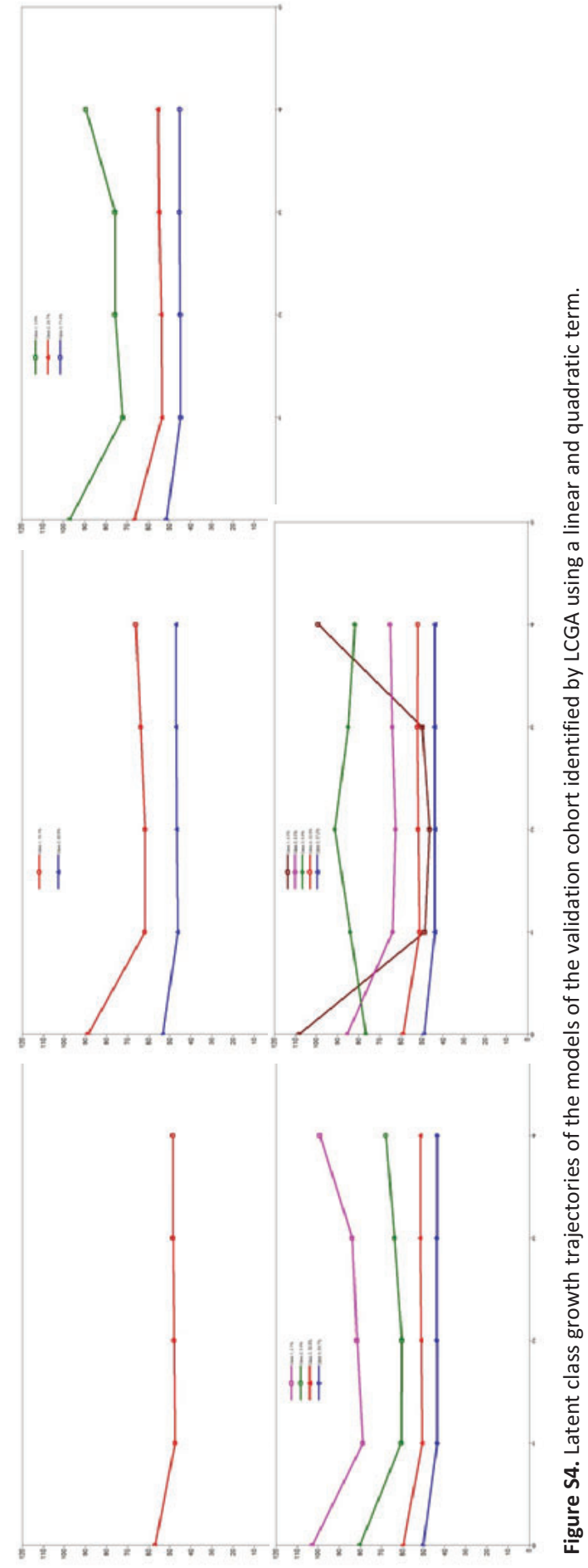



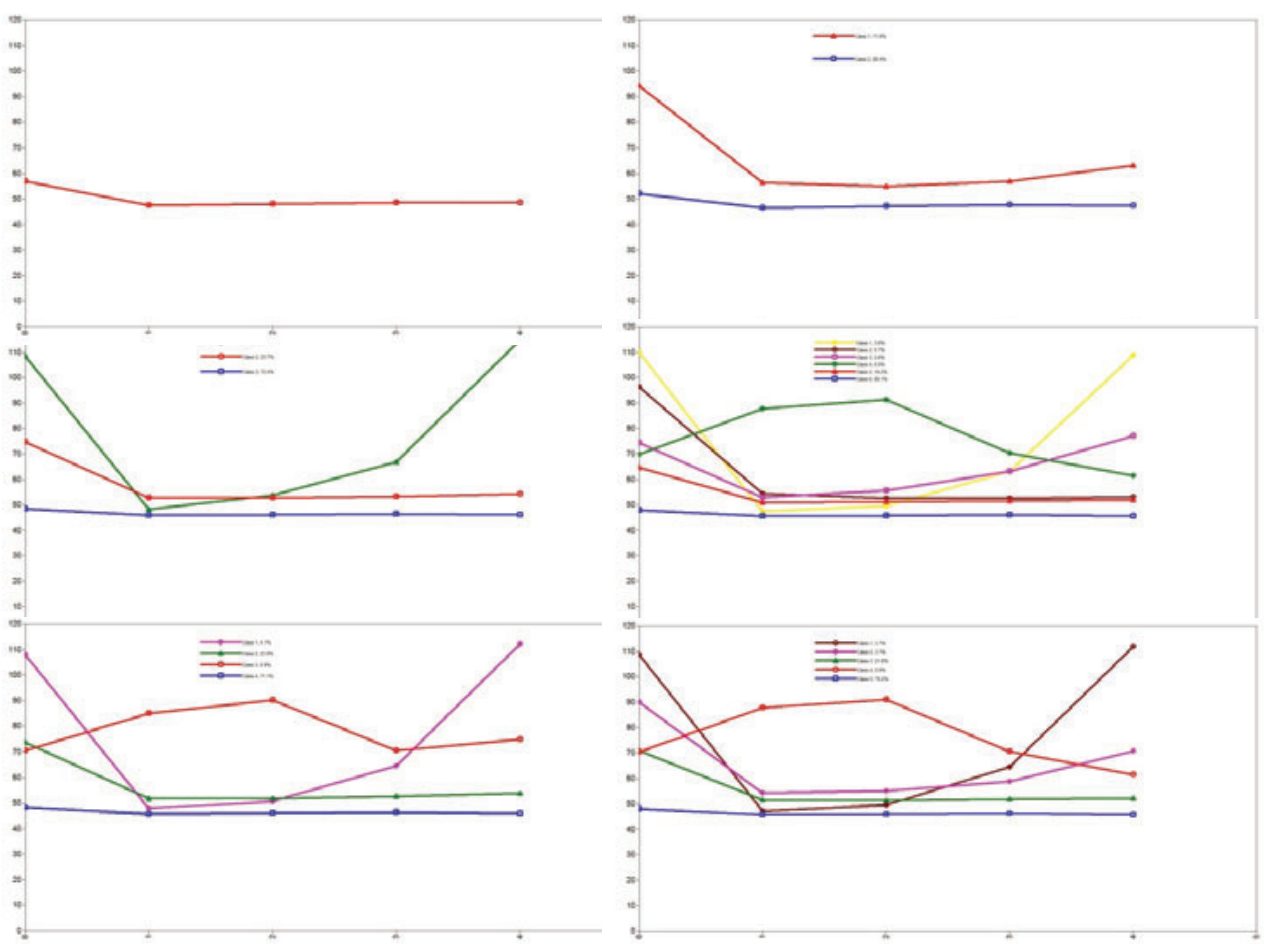

Figure S5. Latent class growth trajectories of the models of the validation cohort identified by LGMM.

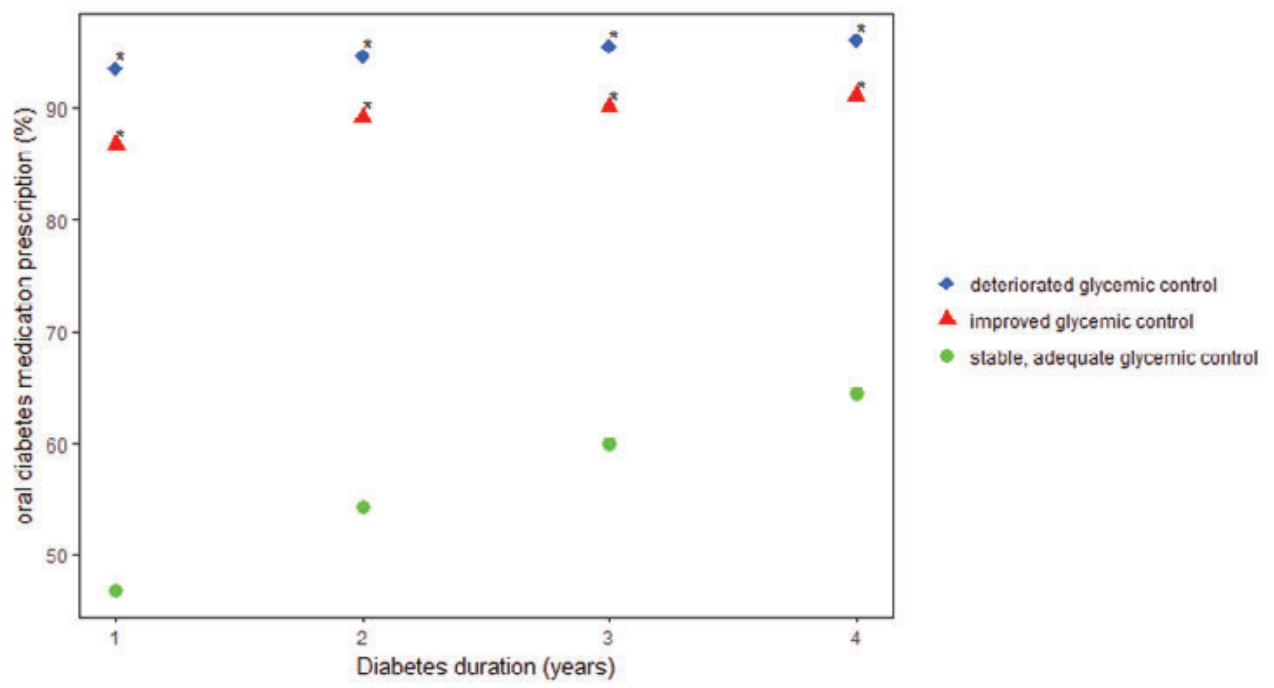

Figure S6. Yearly prescriptions of glucose lowering drugs per trajectory

*significant at the $\mathrm{p}<0.0001$ compared to the stable, adequate glycemic control trajectory. 


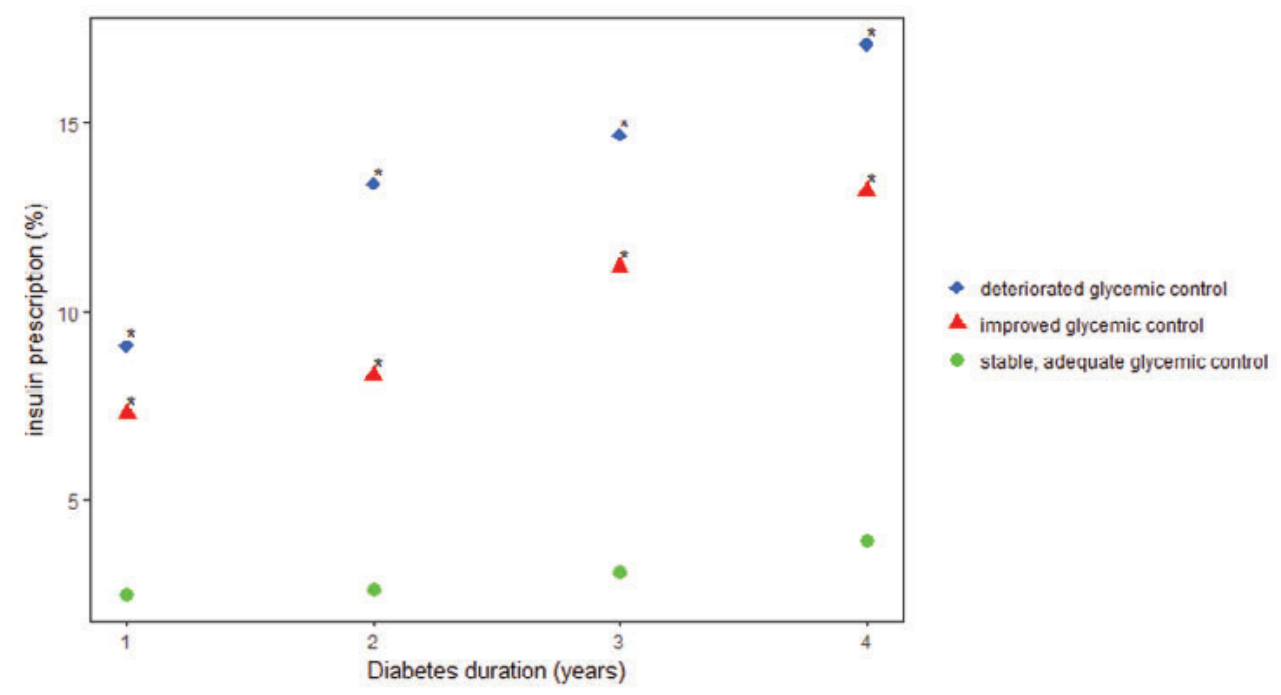

Figure S7. Yearly prescriptions of insulin per trajectory

*significant at the $p<0.0001$ compared to the stable, adequate glycemic control trajectory . 


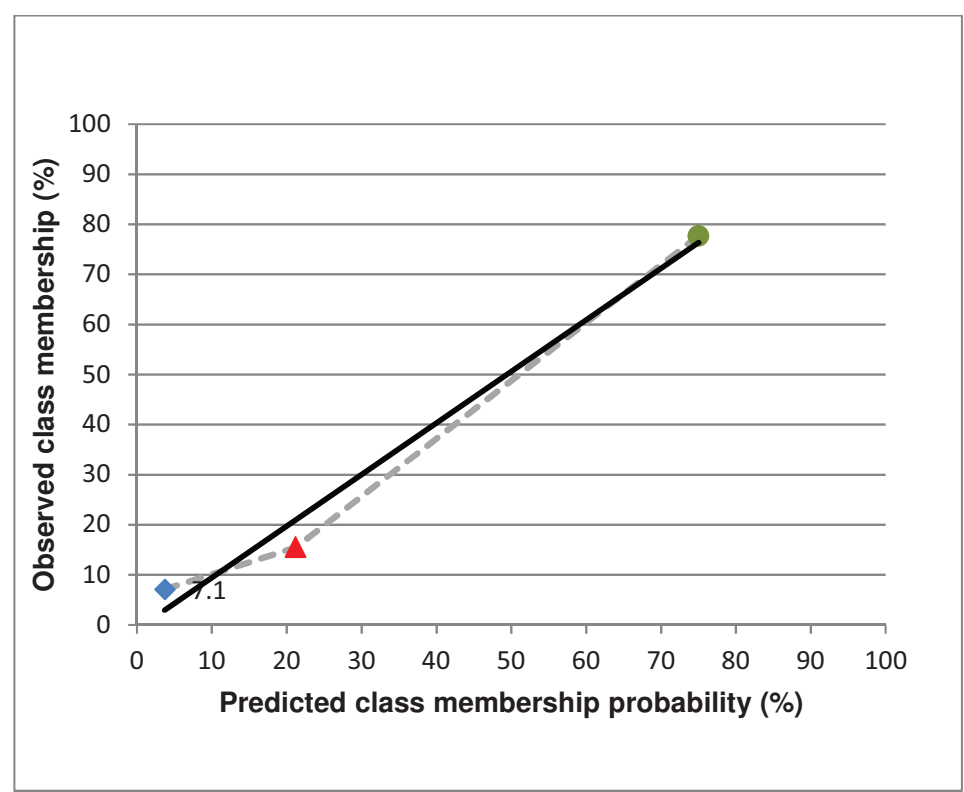

Figure S8. Calibration plot of the 3-patient feature prediction model as observed in the validation cohort $\checkmark$ Deteriorated glycemic control trajectory; $\Delta$ improved glycemic control trajectory; stable, adequate glycemic control trajectory. 


\section{References}

1. Nagin DS, Odgers CL. Group-based trajectory modeling in clinical research. Annual review of clinical psychology 2010; 6:109-138.

2. Little RJ, Rubin DB. Statistical analysis with missing data. New York: Wiley; 2002.

3. Muthén B. On structural equation modeling with data that are not missing completely at random. Psychometrika 1987; 52:431-462.

4. Jung $T$, Wickrama KAS. An introduction to latent class growth analysis and growth mixture modeling. Social and Personality Psychology Compass 2008; 2:302-317.

5. van de Schoot R, Sijbrandij M, Winter SD, Depaoli S, Vermunt JK. The GRoLTS-checklist: guidelines for reporting on latent trajectory studies. Structural Equation Modeling 2016; 00:1-17.

6. Akaike H. Information theory as an extension of the maxium likelihood principle. In: Petrov BN, F Csaki, eds. Second international symposium on information theory Budapest, Hungary: Akademiai Kiado 1973: 267.

7. Schwarz G. Estimating the dimension of a model. The Annals of Statistics 1978; 6:461-464.

8. Lo Y, Mendell N, Rubin D. Testing the number of components in a normal mixture. Biometrika 2001; 88:767-778.

9. Depaoli S. Mixture class recovery in GMM under varying degrees of class separation: frequentist versus Bayesian estimation. Psychological methods 2013; 18:186-219.

10. Brazdil PB, Soares C. A comparison of ranking methods for classification algorithm selection. Machine Learning: ECML, 2000. Berlin Heidelberg: Springer Berlin Heidelberg 2003: 63-75.

11. Masci J, Meier U, Ciresan D, Schmidhuber J. Stacked convolutional auto-encoders for hierarchical feature extraction. 21st International Conference on Artificial Neural Networks (ICAN '11). Espoo, Finland. 2011: 52-59. 


\section{Relevant patient characteristics for estimating healthcare needs according to healthcare providers and people with type 2 diabetes: a Delphi survey}

Under review as:

D.F.L. Hertroijs, M.C.G.J. Brouwers, A.M.J. Elissen, N.C. Schaper \& D. Ruwaard. Relevant patient characteristics for estimating healthcare needs according to healthcare providers and people with type 2 diabetes: a Delphi survey. 


\section{Abstract}

Background: Recently, there has been growing interest in providing more tailored, patientcentered care for the treatment of type 2 T2DM mellitus (T2DM). Yet it remains unclear which patient characteristics should be determined to guide such an approach. Therefore, the opinions of healthcare providers (HCP) and people with T2DM about relevant patient characteristics for estimating healthcare needs of people with T2DM were assessed and compared.

Methods: Two separate online Delphi studies were conducted according to the RAND-UCLA Appropriateness Method: one with HCPs $(n=22)$ from Dutch primary and secondary care and one with people with T2DM treated in Dutch primary care $(n=46)$. The relevance of patient characteristics for estimating healthcare needs, defined as the number of yearly consultations, was assessed on a 5-point Likert scale. Characteristics with a median of 4 or 5 and an interquartile range $\leq 1.5$ were considered relevant with consensus. Participants were also asked to select the top 5 of most relevant patient characteristics. To determine the overall top 5 , the mean relative importance score of each characteristic was calculated.

Results: In two Delphi rounds, 28 and 15 patient characteristics were rated by HCPs and people with T2DM, respectively. Both HCPs and people with T2DM found health-related characteristics relevant for estimating healthcare needs of people with T2DM. However, HCPs preferred to estimate healthcare needs using person- and context-related characteristics. They ranked self-efficacy as the most relevant estimator. In contrast, people with T2DM were more in favor of health-related characteristics and ranked $\mathrm{HbA1c}$ as the most relevant estimator.

Conclusions: The findings show that there is discrepancy in opinions on relevant patient characteristics for estimating healthcare needs between HCPs and people with T2DM. To achieve more tailored, patient-centered care, it is important that both groups agree on the topics to be discussed during patient consultations. 


\section{Background}

Type 2 mellitus (T2DM) is one of the most prevalent chronic conditions and a worldwide public health priority [1, 2]. In Europe, an estimated 59.8 million individuals suffer from T2DM. This number is expected to rise to 71.1 million by the year 2040, largely due to the aging of Europe's population [1, 2]. People with T2DM are at high risk for developing complications, such as cardiovascular disease and kidney failure, which in turn lead to increased healthcare costs [2, 3]. Maintaining a good glycemic-, blood pressure-, and lipid control could prevent these complications $[4,5]$.

A large proportion of T2DM care is based on self-management, which is defined as the active participation of people with T2DM in their treatment [6]. In accordance with evidencebased care protocols for T2DM treatment, people with T2DM regularly visit healthcare providers (HCP) who should assist them in obtaining the knowledge and skills to self-manage their disease with confidence (e.g. day-to-day blood glucose monitoring, medication intake and lifestyle adjustment) [7, 8]. Adhering to these behaviors has been positively correlated with glycemic control $[9,10]$. However, the guidelines for T2DM treatment are usually highly standardized, resulting in differential treatment effects [11, 12]. This indicates a need for more patient-centered care, in which patient characteristics are used to predict the healthcare needs of people with T2DM and to adjust care, including self-management education and support, accordingly. Recently, there has been growing interest in providing patient-centered care for the treatment of T2DM [13-15]. Thus far, it is unclear which patient characteristics should be identified to implement such an approach. Several studies have pointed towards psychosocial characteristics, such as self-esteem, self-efficacy and quality of life to tailor care $[16,17]$, whereas others emphasize the relevance of biomedical characteristics, such as body mass index (BMI) and $\mathrm{HbA1c}[18,19]$.

As a first step towards more patient-centered care for people with T2DM, the Dutch PROFILe (PROFiling people with type 2 diabetes healthcare needs to support Integrated, person-centered models for Long-term disease management) project started in 2014. PROFILe aims to develop, validate and test so-called 'patient profiles' as an instrument for tailored T2DM management in practice [20]. Based on the assessment of patient characteristics, people with T2DM with similar healthcare needs, preferences and abilities can be stratified into the appropriate profile, for which optimal combinations of professional-led care and selfmanagement support can be developed. To identify relevant patient- and disease individual characteristics a systematic literature review was conducted [21] and the associations of 38 of such characteristics with $\mathrm{HbA} 1 \mathrm{c}$ were analyzed using cross-sectional data of people with T2DM [17]. Furthermore, the electronic health records of people with T2DM were used to identify latent glycemic control trajectories, which are unobserved trajectories that capture the glycemic control of individuals, and to build a model that predicts these trajectories using patient- and disease individual characteristics [22]. Another, more qualitative approach is to gain insight into the opinions of HCPs and people with T2DM regarding this subject. To achieve true translational research, it is important to include the voices of HCPs and people with T2DM 
in research due to their experiential knowledge [23]. Therefore and within the context of the PROFILe project, the objective of this study was to assess and compare the opinions of HCPs and people with T2DM about relevant patient characteristics for estimating healthcare needs in primary care.

\section{Methods}

\section{Participants}

Two separate Delphi studies were conducted: one with HCPs and one with people with T2DM.

The first Delphi study was conducted from September through October 2016 and included a purposive and representative sample of HCPs (general practitioners, practice nurses [who support the general practitioner in primary care], specially trained diabetes nurses, dieticians, internists, psychologists and pharmacists) recommended in the care protocols to be part of the multidisciplinary care team for the treatment of T2DM. The authors composed a list of HCPs $(n=20)$ from their own network who treat or used to treat people with T2DM in the Dutch healthcare system and/or have extensive knowledge on the organization of T2DM care in the Netherlands. These HCPs were asked to participate and to recommend colleagues $(n=6)$ who might be willing to participate as well. Furthermore, the Dutch Professional Association of T2DM Care Providers (EADV) and the Dutch Dietician Nutrition Organization (DNO) were contacted for recommendations on HCPs interested in participation $(n=8)$. In total, $34 \mathrm{HCPS}$ were invited to participate.

The second Delphi study focused on people with T2DM with a diagnosis of T2DM and took place between June and August 2017. For the recruitment of people with T2DM, we contacted one general practitioner with a practice in the north of the Netherlands in which 109 people with T2DM were treated. People with T2DM who also had a diagnosis of dementia were excluded from participation, all other people with T2DM were asked if they were willing to participate.

\section{Procedure}

Both Delphi studies were conducted according to the RAND/UCLA appropriateness method and consisted of two rounds [24].

\section{First round}

In the first round, participants (i.e. both HCPs and people with T2DM) received a survey which consisted of questions rating the relevance of patient characteristics for estimating the healthcare needs of people with T2DM on a Likert scale ranging from 1 (totally irrelevant) to 5 (extremely relevant). Healthcare needs was defined as the number of yearly consultations needed with a general practitioner and/or practice nurse. Besides rating each characteristic, participants were asked for their opinion on why they considered certain patient characteristics to be more or less relevant for estimating healthcare needs. They were also asked to select the top 5 of most relevant patient characteristics for estimating healthcare 
needs and to report other characteristics that they found relevant, but were not included in the survey. A questionnaire on demographic characteristics of the participants was also included.

\section{Second round}

In the second round, participants received a summary of the results of all partaking individuals in the first round. This allowed them to re-assess their original opinion about the level of relevance of characteristics on which no consensus was reached between participants.

Next, participants were asked to rate the importance of the characteristics with no consensus and, if any, of the characteristics that were added by the participants in the first round. They were again asked to report the top 5 of most important characteristics for estimating healthcare needs.

\section{Characteristics}

\section{Healthcare provider survey}

The healthcare provider survey of the first round was composed of 18 characteristics that were found to be associated with or able to predict glycemic control in previously conducted empirical research $[17,21,22]$. To structure these characteristics, they were divided into the three categories of the Anderson and Newman model assumed to be predictors of health services use: person-, context- and health-related patient characteristics[25]. In the personrelated category, age, sex and self-efficacy were included. Two context-related characteristics were analyzed: income and educational level. Characteristics included in the health-related category were: HbA1c, systolic blood pressure, LDL-cholesterol, triglycerides, BMI, cardiovascular disease, nephropathy, retinopathy, neuropathy, T2DM duration, T2DM medication, diabetes-related distress and quality of life. The HCP survey of the second round included characteristics of which no consensus was reached in the first round and characteristics that were added by the HCPs in the first round, if any.

\section{Patient survey}

To improve understandability we included similar, but fewer characteristics in the patient survey of the first round compared to the healthcare provider survey. Except for $\mathrm{HbA1C}$ and BMI (which was named 'weight' in the patient survey), all other health-related characteristics were excluded from the survey, because we felt that not all people with T2DM would be able to understand the meaning of these characteristics. The T2DM-related complications nephropathy, retinopathy, neuropathy and cardiovascular disease were simplified by summarizing them in one characteristic called 'having other diseases'. In addition, we added the top 5 of most relevant characteristics for estimating healthcare needs as rated by HCPs to the patient survey, but only if we felt people with T2DM would understand the meaning of these characteristics. In total, the patient survey in the first round consisted of 13 characteristics. The patient survey of the second round included characteristics of which no 
consensus was reached in the first round and characteristics that were added by the people with T2DM in the first round, if any.

\section{Statistical analyses}

Descriptive analyses were conducted to assess the demographic characteristics of the participants. The relevance of the person-, context-, and health-related characteristics for the questions with a 5-point Likert scale was classified into three categories based on median scores: not relevant (median 1-2), uncertain (median 3) and relevant (median 4-5). To determine the level of consensus between participants, the interquartile range (IQR) was calculated for each characteristic. An IQR $\leq 1.5$ was considered as consensus, meaning that at least $50 \%$ of all ratings are situated within 1.5 points around the median rating of the participants [26]. Characteristics with a median of 3 and/or an $I Q R>1.5$ in the first round were considered not relevant and presented again in the second round.

To determine the overall top 5 of most relevant characteristics for estimating healthcare needs of both Delphi studies, each characteristic was awarded points based on the top 5 placement of each individual. A characteristic that was considered as most relevant by an individual received 5 points, the second most relevant characteristic 4 points, etc. The mean relative importance score of each characteristic was assessed by dividing the total awarded points for each characteristic by the total number of participants included in each Delphi study.

All analyses were performed using R Studio version 1.0.153.

\section{Results}

First, the results of the Delphi study with HCPs are given, followed by the results of the Delphi study with people with T2DM and finally the outcomes of both Delphi studies are compared.

\section{Healthcare providers}

Demographic characteristics HCPS

In total, 23 of the 34 (67.6\%) invited HCPs agreed to participate. One healthcare provider did not complete the first survey round and was therefore excluded; twenty-two HCPs completed all Delphi rounds. Demographic characteristics of the HCPs are shown in Table 1. Mean age was 51.4 years (SD 9.5), $14 \mathrm{HCPs}$ (63.6\%) were female and the median period of professional experience was 15 years (range 1-35). 
Table 1. Characteristics of healthcare providers who responded to the survey $(n=22)$

\begin{tabular}{l|l}
\hline Characteristic & $\mathrm{N}$ \\
\hline $\begin{array}{l}\text { Sex } \mathrm{n}(\%) \\
\text { Female }\end{array}$ & $14(63.6)$ \\
Male & $8(36.3)$ \\
\hline Age, mean (sd) & $51.4(9.5)$ \\
\hline Profession $\mathrm{n}(\%)$ & \\
General practitioner & $4(18.1)$ \\
Practice nurse & $4(18.1)$ \\
Diabetes nurse & $3(13.6)$ \\
Dietician & $6(27.3)$ \\
Internist & $3(13.6)$ \\
Psychologist & $1(4.5)$ \\
Pharmacist & $1(4.5)$ \\
\hline Professional experience in diabetes care, & $15(1-35)$ \\
median number of years (range) & \\
\hline Work setting $\mathrm{n}(\%)$ & \\
Primary care & $14(63.6)$ \\
Hospital & $5(22.7)$ \\
Primary care and hospital & $1(4.5)$ \\
Other & $2(9.1)$ \\
\hline
\end{tabular}

\section{Delphi rounds 1 and 2 healthcare providers}

The results of round 1 in the HCPs are shown in Table 2, 18 characteristics were rated as relevant. Of these, 15 characteristics were considered relevant with consensus (median $\geq 4$, IQR $\leq 1.5$ ) for estimating healthcare needs. The highest ratings of relevance were observed for self-efficacy and nephropathy. Consensus between participants was not reached for the three characteristics: sex, income and triglycerides. Therefore, these characteristics were presented again in the second Delphi round. There were no characteristics considered irrelevant with consensus. HCPs added the characteristics social support $(n=7)$ (e.g. family relations and living situation), comorbidities $(n=4)$, cultural background $(n=3)$, lifestyle $(n=2)$, profession $(n=2)$, language barrier $(n=2)$, 'taking responsibility for disease' (e.g. taking medications and following a healthy diet) $(n=2)$, financial situation $(n=1)$, psychological characteristics $(n=1)$ and emotional characteristics $(n=1)$. These were included in the HCP survey of the second round.

In the second round characteristics with no consensus in the first round $(n=3)$ were reassessed and the characteristics added by HCPs were rated for the first time (Table 2). HCPs reached consensus on the characteristics sex and triglycerides, which they found irrelevant for estimating healthcare needs. Consensus was also reached for income, which they found not relevant for estimating healthcare needs. All characteristics that were added by HCPs were considered relevant with consensus, except for the characteristic profession for which the relevance was found uncertain. Both rounds combined, HCPs rated a total of 28 characteristics.

The top 5 of most relevant patient characteristics according to HCPs consisted of: lifestyle, 'taking responsibility of disease' and social support (context-related characteristics) as well as self-efficacy and health-related characteristic quality of life (person-related characteristics). 
Table 2. Results of Delphi round 1 and round 2 for healthcare providers

\begin{tabular}{|c|c|c|c|c|}
\hline & \multicolumn{2}{|c|}{ Round 1} & \multicolumn{2}{|c|}{ Round 2} \\
\hline & Median & IQR & Median & IQR \\
\hline \multicolumn{5}{|l|}{ Person-related characteristics } \\
\hline Age & 4 & 0 & & \\
\hline Sex & 3 & 1 & 2 & 1 \\
\hline Self-efficacy & 5 & 1 & & \\
\hline Lifestyle & & & 5 & 1 \\
\hline Taking responsibility for disease & & & 5 & 1 \\
\hline \multicolumn{5}{|l|}{ Context-related characteristics } \\
\hline Educational level & 4 & 1 & & \\
\hline Income & 3 & 1 & & \\
\hline Social support & & & 4 & 1 \\
\hline Cultural background & & & 4 & 1 \\
\hline Profession & & & 3 & 1 \\
\hline Financial situation & & & 4 & 1 \\
\hline Language barrier & & & 4 & 0 \\
\hline \multicolumn{5}{|l|}{ Health-related characteristics } \\
\hline Quality of life & 4 & 1 & & \\
\hline HbA1c & 4 & 0 & & \\
\hline Systolic blood pressure & 4 & 0 & & \\
\hline LDL-cholesterol & 4 & 1 & & \\
\hline Triglycerides & 3 & 1.75 & 2 & 1 \\
\hline Body mass index & 4 & 1 & & \\
\hline Cardiovascular disease & 4 & 1 & & \\
\hline Nephropathy & 5 & 1 & & \\
\hline Retinopathy & 4 & 1 & & \\
\hline Neuropathy & 4 & 1 & & \\
\hline Diabetes duration & 4 & 1 & & \\
\hline Diabetes medication & 4 & 0 & & \\
\hline Diabetes related distress & 4 & 0 & & \\
\hline Co-morbidity & & & 4 & 1 \\
\hline Psychological characteristics & & & 4 & 0 \\
\hline Emotional characteristics & & & 4 & 0 \\
\hline
\end{tabular}

Relevance of characteristics: median 1-2 = not relevant, median $3=$ uncertain and median 4-5 = relevant. IQR $\leq 1.5$ = consensus, $I Q R>1.5=$ no consensus.

Characteristics with a median of 3 and/or IQR $>1.5$ in the first round, were presented again in the Delphi survey second round. Characteristics that were added by HCPs in the first round were presented in the Delphi survey in the second round.

\section{People with T2DM}

\section{Demographic characteristics people with T2DM}

A hundred people with T2DM were invited to participate in the study, of whom 48 agreed (48\%). People with T2DM who did not agree to participate had a significantly shorter average T2DM duration compared with people with T2DM who did agree to participate (7.9 vs. 11.7 years, 95\% $\mathrm{Cl}:-7.04--0.44, \mathrm{p}$-value $=0.027)$. Other characteristics did not differ. The first Delphi round was completed by 46 people with T2DM and the second round by 41 people with T2DM. Mean age was 68.8 years (SD 9.9), 25 (54.3\%) people with T2DM were female (Table 3). 
Table 3. Characteristics of people with T2DM who responded to the survey $(n=46)$

\begin{tabular}{l|l}
\hline Characteristic & \\
\hline $\begin{array}{l}\text { Sex n (\%) } \\
\text { Female }\end{array}$ & $25(54.3)$ \\
Male & $21(45.7)$ \\
\hline Age, mean (sd) & $68.8(9.9)$ \\
\hline Country of birth n (\%) & $45(97.8)$ \\
Netherlands & $1(2.2)$ \\
Other & \\
\hline Educational level $n(\%)^{*}$ & $9(20.5)$ \\
Higher professional education & $7(15.9)$ \\
Middle professional education & $21(47.7)$ \\
High School & $7(15.9)$ \\
Elementary school/no education & 2 \\
Not recorded & $11.7(9.6)$ \\
\hline Diabetes duration, mean years (sd) & $11(23.9)$ \\
\hline Diabetes medication $n$ (\%) & $26(56.2)$ \\
None & $2(4.3)$ \\
Glucose-lowering drugs only & $7(15.2)$ \\
\hline Insulin only & \\
Glucose-lowering drugs and insulin & \\
\hline${ }^{*}$ percentages are out of total with recorded values
\end{tabular}

\section{Delphi rounds 1 and 2 people with T2DM}

As previously described, similar, but fewer characteristics were included in the patient survey compared with the healthcare provider survey. In addition, we added the top 5 of most relevant characteristics for estimating healthcare needs as rated by HCPs to the patient survey, except for lifestyle and 'taking responsibility for disease', because we felt people with T2DM would confuse these with weight and self-efficacy, respectively. In total, people with T2DM rated 13 characteristics in the first Delphi round (Table 4). Eight characteristics were considered relevant with consensus. Consensus between people with T2DM was not reached about the relevance of age, sex, income and social support. Therefore, these characteristics were presented again in the second Delphi round. Educational level was considered irrelevant with consensus for estimating healthcare needs. People with T2DM added the characteristics genetics and insecurity/fear to the final Delphi round.

People with T2DM rated six characteristics in the second Delphi round. Sex was considered irrelevant with consensus. No consensus was reached on the remaining five characteristics (Table 4). Both rounds combined, people with T2DM rated a total of 15 characteristics.

The top 5 of most relevant patient characteristics according to people with T2DM consisted of: HbA1c, T2DM medication, quality of life and co-morbidities (health-related characteristics) as well as self-efficacy (person-related characteristic). 
Table 4. Results of Delphi rounds 1 and 2 for people with T2DM

\begin{tabular}{|c|c|c|c|c|}
\hline & \multicolumn{2}{|c|}{ Round 1} & \multicolumn{2}{|c|}{ Round 2} \\
\hline & Median & IQR & Median & IQR \\
\hline \multicolumn{5}{|c|}{ Person-related characteristics } \\
\hline Age & 2 & 2 & 3 & 2 \\
\hline Sex & 2 & 1.75 & 2 & 1 \\
\hline Self-efficacy & 4 & 1 & & \\
\hline \multicolumn{5}{|c|}{ Context-related characteristics } \\
\hline Educational level & 2 & 1 & & \\
\hline Income & 2 & 2 & 2 & 2 \\
\hline Social support & 3 & 2 & 3 & 2 \\
\hline \multicolumn{5}{|c|}{ Health-related characteristics } \\
\hline Quality of life & 4 & 1 & & \\
\hline HbA1c & 4 & 0 & & \\
\hline Weight & 4 & 0.75 & & \\
\hline Diabetes duration & 4 & 1 & & \\
\hline Diabetes medication & 4 & 1 & & \\
\hline Diabetes related distress & 4 & 1 & & \\
\hline Comorbidity & 4 & 1 & & \\
\hline Genetics & & & 4 & 2 \\
\hline Insecurity/fear & & & 3 & 2 \\
\hline
\end{tabular}

Relevance of characteristics: median 1-2 = not relevant, median $3=$ uncertain and median $4-5=$ relevant. $I Q R \leq 1.5$ = consensus, $I Q R>1.5=$ no consensus.

Characteristics with a median of 3 and/or IQR $>1.5$ in the first round, were presented again in the Delphi survey second round. Characteristics that were added by HCPs in the first round were presented in the Delphi survey in the second round.

\section{Comparison between HCPs and people with T2DM}

Of the total set $(n=30)$ of unique characteristics included across the two surveys, 28 were rated by HCPs and 15 by people with T2DM. Out of all these characteristics, 13 were rated by both the HCP and the people with T2DM. In both groups, eight of these characteristics achieved consensus for relevance, including all health-related characteristics. Both groups agreed that sex was irrelevant for estimating healthcare needs. There were also some discrepancies between HCPs and people with T2DM on person- and context-related characteristics. HCPs found age, educational level and social support relevant with consensus, but people with T2DM found educational level irrelevant with consensus and were uncertain about the usage of age and social support to estimate healthcare needs.

Figure 1 shows the mean relative importance scores of the five most relevant characteristics for estimating healthcare needs according to HCPs (A) and people with T2DM (B). The top 5 according to HCPs mainly consisted of person- and context-related characteristics, whereas for people with T2DM the top 5 mainly consisted of health-related characteristics. HCPs rated self-efficacy as the most relevant patient characteristic with a mean relative importance score of 3.09, whereas people with T2DM rated $\mathrm{HbA} 1 \mathrm{c}$ as the most relevant characteristic with a relative mean importance score of 2.11 . 
Person-reloted characteristics

$\square$ |Health-related characteristics

Context-related characteristics

4

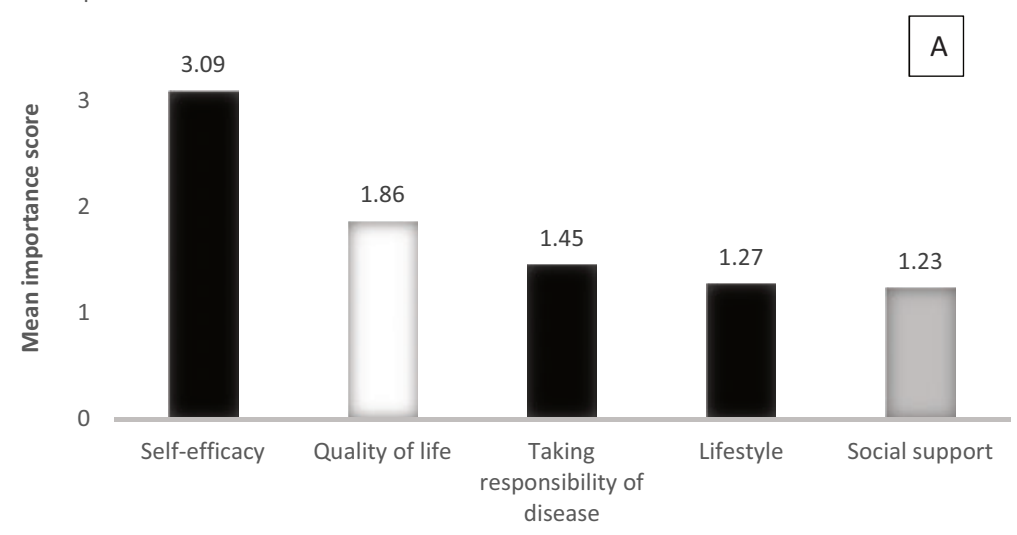

4

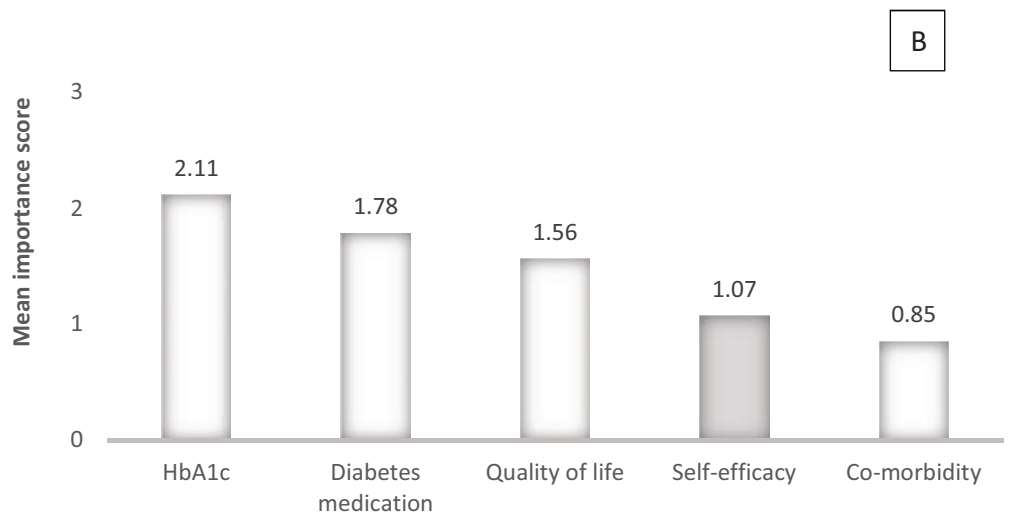

Figure 1. Most relevant 5 characteristics for estimating healthcare needs according to HCPs (A) and people with type 2 diabetes (B).

\section{Discussion}

\section{Principal findings}

In the present study, HCPs and people with T2DM were asked to give their opinion about the relevance of patient characteristics for estimating healthcare needs of people with T2DM. In two Delphi rounds, 28 and 15 patient characteristics were rated by HCPs and people with T2DM, respectively. Except for triglycerides, genetics and insecurity/fear, all health-related characteristics were found to be relevant with consensus for estimating healthcare needs by both HCPs and people with T2DM. 
Discrepancies in opinions between HCPs and people with T2DM were observed for personand context-related characteristics. HCPs found $75 \%$ of these characteristics relevant for estimating healthcare needs, whereas people with T2DM only found $17 \%$ relevant. A striking discrepancy was also seen in the top 5 of most relevant patient characteristics for estimating healthcare needs between HCPs and people with T2DM. The top 5 of HCPs mostly consisted of person- and context-related characteristics and they thought that self-efficacy was most relevant for estimating healthcare needs. In contrast, the top 5 of people with T2DM mostly consisted of health-related characteristics and they ranked $\mathrm{HbA} 1 \mathrm{c}$ as the most relevant estimator.

\section{Comparison with other studies}

Previous research has suggested that more emphasis should be placed on person- and context-related characteristics in the treatment of T2DM [27, 28]. Self-efficacy for example, which was rated as the most relevant characteristic for estimating healthcare needs by HCPs in the current study and defined as an individual's confidence in being able to carry out a behavior, has been associated with lower HbA1c levels and T2DM management- and problem solving behavior $[29,30]$. A healthcare provider's knowledge on the self-efficacy of people with T2DM and other person- and context-related characteristics could enhance selfmanagement education -and support and the development of mutually accepted treatment goals, referred to as shared decision making (SDM) [28, 31-34]. Similar to the outcome of the current study, most HCPs agree on such a broad, whole person approach to the treatment of $\operatorname{T2DM}[35,36]$. However, from the current study it remains unclear whether HCPs practice such an approach. Previous research has shown that HCPs often lack the time, skills and resources to provide self-management education -and support and SDM is not yet embedded in clinical practice [37]. Instead, patient consultations with a healthcare provider seem to focus on clinically orientated issues, such as optimal blood glucose levels [31]. Past qualitative research has shown that people with T2DM were unable to describe the role of the practice nurse beyond clinical checks [38]. They also were not sure what else they could expect from their practice nurse. On the other hand, it could be that HCPs do discuss person- and contextrelated characteristics during patient consultations, but people with T2DM might be unaware of this or not open to it. These arguments might explain why people with T2DM considered $\mathrm{HbA} 1 \mathrm{c}$ as the most relevant characteristic for estimating the healthcare needs of people with T2DM in the current study.

\section{Strengths and limitations}

A strength of this study was the unique inclusion of HCPs as well as people with T2DM. A Delphi panel is often referred to as an 'expert panel' and assumed to include professionally and scientifically qualified participants [39]. People with T2DM do not fall under this category. We did, however, decide to include them, because of their relevant knowledge and experience on the topic and because knowing the opinions of both groups can improve the development of patient-centered care. On the other hand, the Delphi method is context free, which could 
explain the differences in opinion between HCPs and people with T2DM. We do not know for example, if people with T2DM were trying to see things from the HCPs' perspective, despite the provided instructions that asked them to make their own judgement. In that case, a true qualitative method would have been better to elicit people with T2DM' views.

Given the scale of this study, we decided to only select patients from one primary care practice. This does mean that the included patients all live in the same region and are treated by the same HCPs, which makes it difficult to generalize the results to people with T2DM in other countries and other regions Dutch regions. However, since Dutch general practitioners and especially practice nurses (who treat more patients with diabetes than the GP) strictly adhere to the guidelines for T2DM treatment [40], it is likely that the included patients received T2DM care similar to the care of patients from other primary care practices. Moreover, as patients within the practice differ in terms of which HCP they most frequently see for their T2DM - there is one GP and three practice nurses providing T2DM care - we expect the influence of provider attitude and interpersonal style on patients' opinions to be limited. The included HCPs formed a multidisciplinary Delphi panel. In the Netherlands multidisciplinary cooperation within T2DM teams - comprising not only general practitioners and practice nurses, but also T2DM nurses, dieticians, psychologists and, to a limited extent, internists - forms an important part of T2DM care [41]. They refer people with T2DM to each other and mutually discuss treatment plans. The diversity of our panelists represented the range of HCPs that are involved in the treatment of people with T2DM and their opinions. Only Dutch HCPs were included. We tried to arrange face-to-face meetings with the participants, to allow for more in-depth discussion about the ratings and investigate areas of disagreement. Due to time-constraints of the participants, the decision was made to conduct an online Delphi survey instead. To gain more understanding of the ratings, we did include open questions. Finally, the patient characteristics that were included in the Delphi surveys were derived from studies that were previously conducted as part of the PROFILe project, which included an indepth systematic literature search [21]. It is, however, possible that we missed relevant patient characteristics for estimating healthcare needs of people with T2DM. Research has, for example, suggested that environmental factors, such as social stratification and political context, have an impact on people's health [28, 42]. These factors are, however, difficult for HCPs and people with T2DM to influence, and were therefore not included in the surveys. Furthermore, participants were given the chance to provide a list of patient characteristics that they found relevant for estimating healthcare needs of people with T2DM and were not included in the survey of the first round.

\section{Clinical implications and future research}

The findings of this study complement the results derived from previous empirical research on relevant patient characteristics for estimating healthcare needs. They are important for both HCPs involved in the treatment of people with T2DM and researchers focusing on the development of patient-centered care. The findings suggest that there is discrepancy in opinions on relevant patient characteristics for estimating healthcare needs between HCPs 
and people with T2DM. To improve SDM and encourage patient-centered care, it is important that both groups agree on what topics should be discussed during patient consultations. People with T2DM have previously reported that they would like their healthcare provider to show more interest in their life and provide more explanation and involvement in T2DM management, such as providing lifestyle advice and discussing treatment options [31, 38]. Indeed, a recent study on the implementation of a structured T2DM consultation model with a focus on person- and context-related patient characteristics, led to an increase in patient involvement and a substantial number of satisfied people with T2DM [43]. In the current study, HCPs and people with T2DM agreed that self-efficacy and quality of life are relevant patient characteristics for estimating healthcare needs. The measurement of these characteristics should therefore to be included in routine care, for example as part of the intake of people with newly diagnosed T2DM. To save time, people with T2DM could fill in questionnaires that measure these characteristics before their visit with a HCP. Identifying self-efficacy and quality of life in diabetes management allows HCPs to know which aspects of the lives of people with T2DM are most important and which activities they are facing most difficulties with [44]. This has important implications on targeting person-centered education interventions.

Future research should focus on improving the skills and tools HCPs need to take into account patient's person- and context-related patient characteristics and gaining more understanding on the preferences of people with T2DM regarding diabetes care. In the next step of the PROFILe project, a discrete choice experiment will be conducted to elicit preferences of people with T2DM for each of the identified latent glycemic control trajectories [20]. In combination with a consultation model, where person- and context-related characteristics will be discussed, this will enable HCPs to provide patient-centered care by taking into account people with T2DM' care preferences, abilities, - and needs. 


\section{References}

1. IDF Diabetes Atlas Seventh Edition. International Diabetes Federation 2015.

2. Tamayo T, Rosenbauer J, Wild SH, Spijkerman AM, Baan C, Forouhi NG, et al. Diabetes in Europe: an update. Diabetes Res Clin Pract 2014; 103:206-217.

3. Zhang $P$, Zhang X, Brown J, Vistisen D, Sicree R, Shaw J, et al. Global healthcare expenditure on diabetes for 2010 and 2030. Diabetes Res Clin Pract 2010; 87:293-301.

4. Morgen CL, Currie CJ, Peters JR. Relationship between diabetes and mortality: a population study using record linkage. Diabetes care 2008; 23:1103-1107.

5. Stratton IM, Adler Al, Neil HA, Matthews DR, Manley SE, Cull CA, et al. Association of glycaemia with macrovascular and microvascular complications of type 2 diabetes (UKPDS 35): prospective observational study. BMJ 2000; 321:405-412.

6. Koch T, Jenkin P, Kralik D. Chronic illness self-management: locating the 'self'. Journal of advanced nursing 2004; 48:484-492.

7. Nederlands huisartsen genootschap. NHG-standaard Diabetes mellitus type 2 (vierde (partitiële) herziening). 2018.

8. Netherlands Diabetes Federation. NDF Care Standard. Transparancy and quality of diabetes care for people with diabetes type 2 [NDF Zorgstandaard. Transparantie en kwaliteit van diabeteszorg voor mensen met type 2 diabetes. . Amersfoort: Netherlands Diabetes Federation 2105.

9. Boule NG, Haddad E, Kenny GP, Wells GA, Sigal RJ. Effects of exercise on glycemic control and body mass in type 2 diabetes mellitus: a meta-analysis of controlled clinical trials. Jama 2001; 286:1218-1227.

10. Povey RC, Clark-Carter D. Diabetes and healthy eating: a systematic review of the literature. The Diabetes educator 2007; 33:931-959; discussion 960-931.

11. Pimouguet C, Le Goff M, Thiebaut R, Dartigues JF, Helmer C. Effectiveness of diseasemanagement programs for improving diabetes care: a meta-analysis. CMAJ 2011; 183:E115-127.

12. Rothe U, Muller G, Schwarz PE, Seifert M, Kunath H, Koch R, et al. Evaluation of a diabetes management system based on practice guidelines, integrated care, and continuous quality management in a Federal State of Germany: a population-based approach to health care research. Diabetes Care 2008; 31:863-868.

13. Rutten GEHM, Alzaid A. Person-centered type 2 diabetes care: time for a paradigm shift. The Lancet Diabetes \& Endocrinology 2017; S2213-8587:30193-30196.

14. Inzucchi SE, Bergenstal RM, Buse JB, Diamant M, Ferrannini E, Nauck M, et al. Management of hyperglycemia in type 2 diabetes, 2015: a patient-centered approach: update to a position statement of the American Diabetes Association and the European Association for the Study of Diabetes. Diabetes care 2015; 38:140-149.

15. Wermeling PR, Gorter KJ, Stellato RK, de Wit GA, Beulens JW, Rutten GE. Effectiveness and cost-effectiveness of 3-monthly versus 6-monthly monitoring of well-controlled type 2 diabetes patients: a pragmatic randomised controlled patient-preference equivalence trial in primary care (EFFIMODI study). Diabetes Obes Metab 2014; 16:841849.

16. Klabbers G, Bosma H, Kempen GI, Benzeval M, Van den Akker M, van Eijk JT. Do psychosocial profiles predict self-rated health, morbidity and mortality in late middleaged and older people? J Behav Med 2014; 37:357-368. 
17. Elissen AMJ, Hertroijs DFL, Schaper NC, Bosma H, Dagnelie PC, Henry RM, et al. Differences in biopsychosocial profiles of diabetes patients by level of glycaemic control and health-related quality of life: The Maastricht Study. PLoS One 2017; 12:e0182053.

18. Laiteerapong N, Karter AJ, Moffet HH, Cooper JM, Gibbons RD, Liu JY, et al. Ten-year hemoglobin A1c trajectories and outcomes in type 2 diabetes mellitus: The Diabetes \& Aging Study. J Diabetes Complications 2017; 31:94-100.

19. Walraven I, Mast MR, Hoekstra T, Jansen AP, van der Heijden AA, Rauh SP, et al. Distinct HbA1c trajectories in a type 2 diabetes cohort. Acta Diabetol 2015; 52:267-275.

20. Elissen AM, Hertroijs DF, Schaper NC, Vrijhoef HJ, Ruwaard D. Profiling Patients' Healthcare Needs to Support Integrated, Person-Centered Models for Long-Term Disease Management (Profile): Research Design. Int J Integr Care 2016; 16:1.

21. Hertroijs DFL, Elissen AMJ, Brouwers M, Schaper NC, Ruwaard D. Relevant patient characteristics for guiding tailored integrated diabetes primary care: a systematic review. Prim Health Care Res Dev 2018:1-24.

22. Hertroijs DFL, Elissen AMJ, Brouwers M, Schaper NC, Kohler S, Popa MC, et al. A risk score including body mass index, glycated haemoglobin and triglycerides predicts future glycaemic control in people with type 2 diabetes. Diabetes Obes Metab 2018; 20:681-688.

23. van der Scheer L, Garcia E, van der Laan AL, van der Burg S, Boenink M. The Benefits of Patient Involvement for Translational Research. Health Care Anal 2017; 25:225-241.

24. Fitch K, Bernstein S, Aguilar MD, Burnand B, LaCalle JR, Lazaro P, et al. The RAND/UCLA appropriateness method user's manual. Santa Monica, CA: RAND 2001.

25. Andersen R, Newman JF. Societal and individual determinants of medical utilization in the United States. Milbank Mem Fun Q Health Soc 1973; 51:95-124.

26. Von der Gracht HA. Consensus measurement in Delphi studies. Review and implications for future quality assurance. . Technological Forecast and Social Change 2012; 79:15251536.

27. Inzucchi SE, Bergenstal RM, Buse JB, Diamant M, Ferrannini E, Nauck M, et al. Management of hyperglycemia in type 2 diabetes: a patient-centered approach: position statement of the American Diabetes Association (ADA) and the European Association for the Study of Diabetes (EASD). Diabetes Care 2012; 35:1364-1379.

28. Marrero DG, Ard J, Delamater AM, Peragallo-Dittko V, Mayer-Davis EJ, Nwankwo R, et al. Twenty-first century behavioral medicine: a context for empowering clinicians and patients with diabetes: a consensus report. Diabetes Care 2013; 36:463-470.

29. Strychar I, Elisha B, Schmitz N. Type 2 diabetes self-management: role of diet selfefficacy. Canadian Journal of Diabetes 2012; 36:337-344.

30. Bandura A. Self-efficacy: toward a unifying theory of behavioral change. Psychol Rev 1977; 84:191-215.

31. Brundisini F, Vanstone M, Hulan D, DeJean D, Giacomini M. Type 2 diabetes patients' and providers' differing perspectives on medication nonadherence: a qualitative metasynthesis. BMC Health Serv Res 2015; 15:516.

32. Cavanaugh K, Wallston KA, Gebretsadik T, Shintani A, Huizinga MM, Davis D, et al. Addressing literacy and numeracy to improve diabetes care: two randomized controlled trials. Diabetes care 2009; 32:2149-2155.

33. King DK, Glasgow RE, Toobert DJ, Strycker LA, Estabrooks PA, Osuna D, et al. Selfefficacy, problem solving, and social-environmental support are associated with diabetes self-management behaviors. Diabetes care 2010; 33:751-753. 
34. Moore Beckerle C, Lavin MA. Association of self-efficacy and self-care with glycemic control in diabetes. Diabetes Spectrum 2013; 26:172-178.

35. Alghafri TS, Alharthi SM, Al-Balushi S, Al-Farsi Y, Al-Busaidi Z, Bannerman E, et al. Health professionals' perceptions about physical activity promotion in diabetes care within primary health care settings in Oman. Heliyon 2017; 3:e00495.

36. Kristensen MAT, Holge-Hazelton B, Waldorff FB, Guassora AD. How general practitioners perceive and assess self-care in patients with multiple chronic conditions: a qualitative study. BMC Fam Pract 2017; 18:109.

37. Stiggelbout AM, Van der Weijden T, De Wit MP, Frosch D, Legare F, Montori VM, et al. Shared decision making: really putting patients at the centre of healthcare. BMJ 2012; 344:e256.

38. Boyle E, Saunders R, Drury V. A qualitative study of patient experiences of type 2 diabetes care delivered comparatively by general practice nurses and medical practitioners. Journal of Clinical Nursing 2015; 25:1977-1986.

39. Mullen PM. Delphi: myths and reality. J Health Organ Manag 2003; 17:37-52.

40. InEen. Transparent integrated care. Report 2015 Care Groups. Diabetes mellitus, VRM, COPD and asthma [Transparante ketenzorg. Rapportage 2015 zorggroepen. Diabetes mellitus, VRM, COPD and asthma. Op weg naar genuanceerde rapportage van zorg]. Utrecht: InEen 2016.

41. Struijs JN, Baan CA. Integrating care through bundled payments--lessons from The Netherlands. N Engl J Med 2011; 364:990-991.

42. Bosma H. Social epidemiology: Shuttling between upstream and downstream: A personal and narrative review. OA Epidemiology 2014; 2:5.

43. Rutten G, van Vugt HA, de Weerdt I, de Koning E. Implementation of a Structured Diabetes Consultation Model to Facilitate a Person-Centered Approach: Results From a Nationwide Dutch Study. Diabetes Care 2018; 41:688-695.

44. Morrison G, Weston P. Self-efficacy: A tool for people with

45. diabetes managed by continuous subcutaneous insulin infusion. Journal of Diabetes Nursing 2013; 17:32-37. 



\section{Preferences of people with type 2 diabetes for diabetes care: a discrete choice experiment}

Accepted for publication as:

D.F.L. Hertroijs, A.M.J. Elissen, M.C.G.J. Brouwers, M. Hiligsmann, N.C. Schaper \& D. Ruwaard. Preferences of people with type 2 diabetes for diabetes care: a discrete choice experiment. Diabetic Medicine. 


\section{Abstract}

Aim: Limited knowledge exists on the preferences of people with type 2 diabetes towards diabetes care. Consequently, these care preferences cannot yet be considered in the development of tailored diabetes care approaches. Therefore, this study aimed to assess care preferences and their determinants in people with type 2 diabetes.

Methods: A discrete choice experiment was conducted to elicit people's preferences. People with type 2 diabetes, treated in 30 Dutch primary care practices, were asked to choose repeatedly between two hypothetical diabetes care packages, which differed in six attributes: role division in daily diabetes care planning, lifestyle education method, type of medication management support, consultation frequency, emotional support, and time spend on selfmanagement. A mixed-logit model was used to estimate the relative importance of the included attributes. Preference heterogeneity among people with different person- and disease-related characteristics was investigated.

Results: In total, 288 participants completed the experiment. They preferred to plan their daily diabetes care together with a healthcare provider, to receive individual lifestyle education, medication- and emotional support from a healthcare provider, one consultation visit every three months, and to spend less time on self-management. Participants did not prefer to receive emotional support from a psychologist. Heterogeneity in preferences could partly be explained by differences in sex, education level and glucose-lowering drug use.

Conclusion: People with type 2 diabetes have a preference for traditional care models. Emotional support was identified as the most important attribute to the participants. It is therefore important to adequately guide them when changes in diabetes care organisation are implemented. 


\section{Introduction}

In the Netherlands, around one million people (6\%) currently live with diabetes of whom approximately $94 \%$ have type 2 diabetes [1]. The majority (85\%) of them are treated in primary care by a team consisting of a general practitioner and a practice nurse [1-4]. In general, primary care providers strictly adhere to the guidelines from the Dutch college of General Practitioners on type 2 diabetes and the Dutch Diabetes Federation Health Care Standard for type 2 diabetes $[3,5,6]$. These care protocols recommend primary healthcare providers to monitor people with type 2 diabetes two to four times per year, including an annual check-up by the general practitioner.

Internationally, Dutch diabetes care is considered to be of very high quality, mainly due its multidisciplinary approach [5], but it also has its drawbacks. Barring some exceptions for older people, the diabetes guidelines are highly standardised [3]. This is in contrast to the NICE guidelines and the latest consensus report by the American Diabetes Association and the European Association for the Study of Diabetes on the management of type 2 diabetes, which are more lenient towards the type of glucose-lowering drugs that are prescribed $[7,8]$. Not all people seem to benefit from this 'one-size-fits-all' approach, leading to differential treatment effects [9]. Furthermore, current type 2 diabetes care places a heavy financial burden on society, health systems, individuals and employees [10]. Thus, ways need to be found to provide the right care, to the right person, at the right time, creating more sustainable diabetes care.

There is increasing consensus that patient-centred care, defined as "care that is respectful of and responsive to individual patient care preferences, needs, and values and ensuring that patient values guide all clinical decisions" [11], could prevent the over-, under-, and misuse of diabetes care and improve the management of type 2 diabetes [12]. Patient preferences, defined as what patients want from their healthcare [13], can help healthcare providers and their patients develop mutually accepted treatment goals leading to improved health outcomes [13]. The number of studies on care preferences of people with type 2 diabetes has increased substantially in the past decade [14]. However, most of these studies assessed pharmaceutical care preferences, such as dosing schedule and risk of side effects [15]. Limited knowledge exists on the preferences of people with type 2 diabetes-related to more general treatment attributes, such as the frequency of consultations or emotional support. Consequently, these care preferences cannot yet be considered in the development of tailored diabetes care approaches. Therefore, the first aim of the present study was to assess preferences of people with type 2 diabetes towards the non-pharmaceutical aspects of diabetes care using a discrete choice experiment. Because people often have diverse preferences for health care interventions and preferences tend to change through the course of an illness [16], the second aim was to examine whether these preferences are characterised by heterogeneity, and if so, to what extent this heterogeneity could be explained by relevant characteristics of people with type 2 diabetes. 


\section{Participants and methods}

\section{Population and study design}

Eighty-four primary care practices in Maastricht and surrounding areas, in the south of the Netherlands, received an email asking for permission to invite their patients with type 2 diabetes to participate in the study. Thirty practices were willing to participate. The practices were also asked to provide data from their electronic health register on patients' biomedical characteristics (body mass index, $\mathrm{HbA1c}$, triglycerides, and prescriptions of glucose-lowering drugs) and date of diabetes diagnosis. Subsequently, patients received an invitation via regular mail including a letter containing information about the study, an informed consent document, a discrete choice experiment survey to elicit their preferences, a questionnaire on their background characteristics and a return envelope. One month after the first mailing, a reminder was sent via regular mail to those who had not returned the informed consent document and/or the questionnaires. Data collection took place from October to December 2017. Approval of the study was obtained from the Medical Ethical Committee of the Maastricht University Medical Center (METC 17-04-104).

\section{Discrete choice experiment}

A discrete choice experiment is an increasingly used method to elicit participants' preferences in health care [17]. In a discrete choice experiment, participants have to answer a series of choice tasks. Each choice task consists of at least two scenarios with several attributes (e.g. frequency of consultations and emotional support approach) that vary along different levels (e.g. one consultation every six months or yearly consultations). Participants are asked to choose the preferred scenario in each choice task.

\section{Identification of attributes and levels}

In this study, a 3-step process was followed to identify the attributes. First, a list of diabetes care attributes was compiled by conducting a literature review on preferences of people towards diabetes care regarding non-pharmaceutical treatment attributes. Second, to complement the attribute list, five telephone interviews with healthcare providers were held. Attributes were identified by asking healthcare providers to describe the steps they take during consultations with people with type 2 diabetes. Third, three focus groups, with four to six participants with type 2 diabetes each, were organized to determine the most important attributes of diabetes care. During the focus groups, the list of previously identified attributes (based on steps 1 and 2) was presented. In addition, participants were asked to name attributes of diabetes care that were not included on the list. The final list consisted of $>10$ potential attributes for inclusion. However, to ensure that participants were able to consider all attributes listed when making their choice, most discrete choice experiments contain fewer than 10 attributes [18]. To scale back the attribute list, the nominal group technique was used: participants in the focus groups were asked to individually select a top 5 of attributes from the final list [19]. These attributes were awarded points: from 5 points for the most important 
attribute to 1 point for the least important attribute. Per attribute, the mean importance score was then calculated by dividing the total awarded points per attribute by the total number of participants in all focus groups. This process led to the inclusion of six attributes (role division in daily diabetes care planning, lifestyle education method, type of medication management support, consultation frequency, emotional support, and time spend on self-management) with three to four levels each (Table 1). The levels were discussed and determined by the researchers $(\mathrm{DH}, \mathrm{AE}$ and $\mathrm{MB})$, taking into account their clinical plausibility. In a face-to-face pilot study including eight participants with type 2 diabetes, the participants' understanding of the attributes and levels was tested, as well as the task complexity and length of the discrete choice experiment questionnaire. Minor adjustments to some levels of the attributes were made accordingly.

Table 1. Attributes and levels used in the discrete choice experiment

\begin{tabular}{l|ll}
\hline Attribute & \multicolumn{2}{|l}{ Levels } \\
\hline Role division in diabetes care planning & - & Person with type 2 diabetes and healthcare provider \\
& - & Person with type 2 diabetes \\
& - & healthcare provider only \\
\hline Lifestyle education method & - & Individual education \\
& - & Group education \\
& - & Digital education (app or website) \\
\hline Type of medication management support & - & Via healthcare provider \\
& - & Via aid (app, website, medicine box) \\
& - & No help \\
\hline Consultation frequency & - & One visit every two months with practice nurse \\
& - & One visit every three months with practice nurse \\
& - & One visit every six months with general practitioner \\
& - & Yearly visit with general practitioner \\
\hline Emotional support approach & - & general practitioner or practice nurse \\
& - & Psychologist \\
& - & No emotional support \\
\hline Time spend on self-management & - & 30 minutes \\
& - & 1 hour \\
\hline
\end{tabular}

\section{Experimental design}

The attributes and levels were combined to construct choice tasks. Ngene was used to create a Bayesian efficient design to maximize the D-efficiency (a summary measure of the variance covariance matrix) of the chosen choice tasks. By incorporating prior information about the preferences of the attribute levels (positive or negative sign) the precision of the estimated parameters for a given number of choice tasks was maximized, thus increasing the statistical efficiency of the design. The prior information was derived from the pilot results. The D-score of our design was 0.16 .

\section{Instrumental design}

The design contained 30 choice tasks and was blocked into three 10-choice task survey versions. Participants were randomly assigned to one of the three survey versions. In each choice task, participants had to choose between two care plans (A and B). The fourth choice task was repeated at the end of the discrete choice experiment survey to assess the test-retest 
reliability of participants' choices. Thus, each participant received a total of 11 choice tasks. Participants who answered less than $50 \%$ of the choice tasks were excluded from the analysis. See Fig 1. for an example of a choice task.

\begin{tabular}{|c|c|c|}
\hline Attributes & Care package $\mathrm{A}$ & Care package $\mathrm{B}$ \\
\hline $\begin{array}{l}\text { Who makes plans for my daily } \\
\text { diabetes care? }\end{array}$ & The patient and HCP & The HCP only \\
\hline $\begin{array}{l}\text { How is lifestyle information provided } \\
\text { to me? }\end{array}$ & Individual education & Group education \\
\hline $\begin{array}{l}\text { How do I receive help to take my } \\
\text { medication according to plan? }\end{array}$ & Via HCP & $\begin{array}{l}\text { Via aid (app, website, } \\
\text { medicine box) }\end{array}$ \\
\hline $\begin{array}{l}\text { How often do I go to consultation for } \\
\text { my disease? }\end{array}$ & $\begin{array}{c}1 \text { visit per } 2 \text { months with } \\
\text { PN }\end{array}$ & Yearly visit with GP \\
\hline How do I receive emotional support? & Psychologist & No emotional support \\
\hline \multirow[t]{3}{*}{$\begin{array}{l}\text { How much time do I invest in my } \\
\text { disease per day (e.g. physical } \\
\text { activity, nutrition, medication) }\end{array}$} & 30 minutes & 2 hours \\
\hline & \multicolumn{2}{|c|}{ I choose: } \\
\hline & $\square$ Care package A & $\square$ Care package B \\
\hline
\end{tabular}

Figure 1. Example of a discrete choice experiment choice task. HCP: healthcare provider, PN: practice nurse, GP: general practitioner

\section{Statistical analyses}

Participants' characteristics are presented as means (SDs) for continuous variables and counts and percentages for dichotomous variables. Descriptive statistics were performed in R Studio version 1.0.153.

For the discrete choice experiment, a panel mixed-logit model was estimated, allowing for the determination of the mean preferences of the sample. The level of each attribute that was most similar to current guideline-informed diabetes care in the Netherlands was used as the reference attribute parameter. A positive regression coefficient (beta) suggests that participants prefer more of that level within an attribute, whereas a negative coefficient suggests that participants prefer less of that level within an attribute. To determine the relevant importance of each attribute, the relative importance score was calculated based on the difference between the highest and lowest coefficients of each attribute divided by the total amount of these differences. A significant $(p<0.05)$ standard deviation (SD) of the attribute levels indicates preference heterogeneity.

In subgroup analyses, preliminary joint models were estimated using interaction terms to investigate potential preference heterogeneity among people with different person and disease-related characteristics. Person-related characteristics included age $(<65$ years and $\geq 65$ years), sex, and education level (low/medium and high). Disease-related characteristics 
included glucose-lowering drugs (diet with or without oral glucose-lowering drugs and insulin with or without oral glucose-lowering drugs), type 2 diabetes duration (recently diagnosed [ $\leq$ 5 years] and longstanding [>5 years]), and predicted glycaemic control trajectory (stable, adequate glycaemic control-, improved glycaemic control-, and deteriorated glycaemic control trajectory). Participants' glycaemic control trajectories were predicted using a risk score (including BMI, $\mathrm{HbA} 1 \mathrm{c}$ and plasma triglycerides measured +/- 3 months from diagnosis) that was previously developed to stratify people with recently diagnosed diabetes into one of the three glycaemic control trajectories [20]. Due to the low number of participants in the deteriorated glycaemic control trajectory $(n=6)$, this group was not included in the subgroup analysis. Parameters estimated for the interaction terms that are statistically different from zero ( $5 \%$ level) indicate a difference in preference between subgroups. The discrete choice experiment analyses were performed in NLOGIT version 5. For further details regarding the analysis, see the online supplementary file.

\section{Results}

Thirty (35.7\%) care practices gave permission to invite a total of 929 people with type 2 diabetes. Of these, 24 people had an incorrect address and four lived in Belgium. Thus, 901 people received an invitation (Fig. 2). Of these, 288 participants answered $\geq 50 \%$ of the choice tasks. In total, $80 \%$ of participants passed the test-retest task. Their preferences did not differ from those who did not pass the test. Therefore, all 288 participants were included in the analyses. The average age of the participants was 67.4 (SD 10.7) years, 65\% were men, and more than two thirds (72\%) had a low or medium education level. Further characteristics of the population are presented in Table 2. 


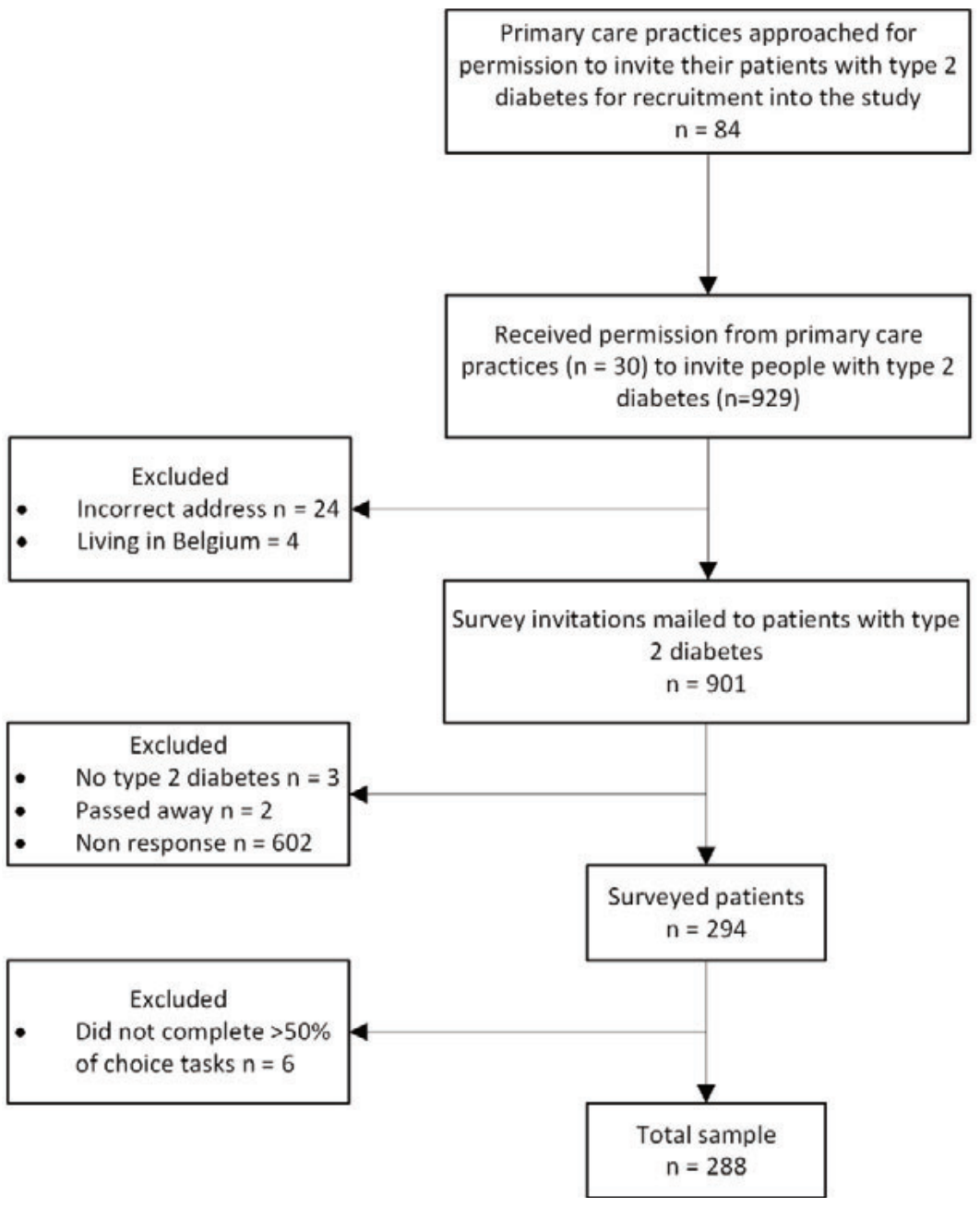

Figure 2. Study flow chart. 
Table 2. Demographic and clinical characteristics of the study population

\begin{tabular}{|c|c|}
\hline Characteristic & $\begin{array}{l}\text { Participants } \\
\quad(n=288)\end{array}$ \\
\hline Age, mean (SD) & $67.4(10.7)$ \\
\hline \multicolumn{2}{|l|}{ Age, $n(\%)$} \\
\hline$\geq 65$ years & $168(58.9)$ \\
\hline Missing, $n$ & 3 \\
\hline Men, n (\%) & $187(64.9)$ \\
\hline Missing, $n$ & 0 \\
\hline \multicolumn{2}{|l|}{ Country of birth, $\mathrm{n}(\%)$} \\
\hline The Netherlands & $240(90.6)$ \\
\hline Other & $25(9.4)$ \\
\hline Missing, $\mathrm{n}$ & 23 \\
\hline \multicolumn{2}{|l|}{ Education } \\
\hline Low/medium & $188(72.0)$ \\
\hline High & $73(28.0)$ \\
\hline Missing, $\mathrm{n}$ & 27 \\
\hline $\mathrm{BMI}, \mathrm{kg} / \mathrm{m}^{2}$, mean (SD) & $30.4(5.0)$ \\
\hline Missing, $\mathrm{n}$ & 0 \\
\hline $\mathrm{HbA1c}, \mathrm{mmol} / \mathrm{mol}$, mean (SD) & $52.0(10.0)$ \\
\hline $\mathrm{HbA1c}, \%$ & $6.8(3.0)$ \\
\hline Missing, $\mathrm{n}$ & 0 \\
\hline Triglycerides, mmol/L, mean (SD) & $2.1(1.2)$ \\
\hline Not recorded, $\mathrm{n}$ & 1 \\
\hline \multicolumn{2}{|l|}{ Diabetes duration, $\mathrm{n}(\%)$} \\
\hline Recently diagnosed type 2 diabetes ( $\leq 5$ years) & $174(60.4)$ \\
\hline Longstanding type 2 diabetes ( $>5$ years) & $114(39.6)$ \\
\hline Missing, $\mathrm{n}$ & 0 \\
\hline \multicolumn{2}{|l|}{ Diabetes medication, $\mathrm{n}(\%)$} \\
\hline Diet and/or oral glucose-lowering drugs & $206(84.8)$ \\
\hline Oral glucose-lowering drugs and insulin & $37(15.2)$ \\
\hline Missing, $\mathrm{n}$ & 45 \\
\hline \multicolumn{2}{|l|}{ Glycaemic control trajectory, n (\%) } \\
\hline Stable, adequate glycaemic control & $75(77.3)$ \\
\hline Improved glycaemic control & $16(6.0)$ \\
\hline Deteriorated glycaemic control & $6(6.2)$ \\
\hline Missing, $\mathrm{n}$ & 191 \\
\hline
\end{tabular}

SD: standard deviation, low/medium education: elementary, preparatory secondary vocational, senior general secondary education or senior secondary vocational education, high education: pre-university, higher professional or academic education, BMI: body mass index.

\section{Diabetes care preferences in the overall population}

The results from the panel mixed-logit model are presented in Table 3. Participants showed a preference for planning their daily diabetes care together with a healthcare provider and did not prefer to plan their daily diabetes care by themselves. They preferred individual-based lifestyle education provided by a healthcare provider over group-based lifestyle education. Participants preferred medication management support from a healthcare provider, but not by an aid (i.e. an app, website or medicine box). Of the different possibilities in consultation frequency, participants preferred one visit every three months with a practice nurse. They did 
not prefer yearly consultation visits or one consultation every six months with a general practitioner. They preferred receiving emotional support from a general practitioner or practice nurse, but they clearly indicated wanting to avoid emotional support delivered by a psychologist. This attribute had the highest negative beta $(-0.68)$. When deciding on their diabetes care preferences, participants were mostly driven by emotional support (mean relative importance: $25.4 \%$ ) and frequency of consultations (mean relative importance: 24.2\%). The statistically significant standard deviation for all but three attribute levels (digital education, one visit every 2 months with practice nurse, and no emotional support), indicated that there was significant preference heterogeneity within the population.

\section{Subgroup analysis}

The subgroup analyses indicated that the observed heterogeneity in the discrete choice experiment was (at least in part) explained by age, sex, education level, and type of glucoselowering drugs (Supplementary Table 1-6).

Men least preferred planning their daily diabetes care by themselves ( $\beta$ men -0.54 vs $\beta$ women -0.19; $p=0.016$ ). Preference for having their daily diabetes care planned by a healthcare provider, was also stronger and statistically significant for men compared to women ( $\beta$ men 0.16 vs $\beta$ women - 0.14; $p=0.012$ ) Participants treated with glucose-lowering drugs had a preference to let their general practitioner plan their daily diabetes care. This preference was stronger for participants treated with insulin ( $\beta$ treated with oral glucose lowering drugs 0.02 vs $\beta$ treated with insulin 0.23; $p=0.032$ ). Participants treated with insulin also significantly did not prefer to plan their daily diabetes care by themselves to the same degree as participants using oral glucose-lowering drugs ( $\beta$ treated with oral glucose lowering drugs -0.33 vs $\beta$ treated with insulin $-0.85 ; p=0.007$ ). In terms of medication management support, participants treated with insulin preferred less not receiving any support, whereas participants treated with oral glucose-lowering drugs were indecisive about their preference for medication management support ( $\beta$ treated with oral glucose lowering drugs 0.02 vs $\beta$ treated with insulin $-0.38 ; p=0.021$ ). Participants with a high education level preferred to receive digital lifestyle education, in contrast to participants with low- and medium education levels who least preferred receiving digital lifestyle education ( $\beta$ high education 0.17 vs $\beta$ low/medium education $-0.05 ; p=0.030$ ).

No significant differences in preference estimates were found according to age $(<65, \geq 65)$, diabetes duration (recently diagnosed, longstanding) and predicted glycaemic control trajectories (stable adequate, improved). 
Table 3. Results from the panel mixed logit model

\begin{tabular}{|c|c|c|c|c|}
\hline \multirow[t]{2}{*}{ Attribute } & & \multicolumn{2}{|c|}{ Preference estimates } & \multirow{2}{*}{$\begin{array}{l}\text { Mean relative importance } \\
\qquad(\%)\end{array}$} \\
\hline & & Coefficient & $95 \% \mathrm{Cl}$ & \\
\hline Role division in diabetes care planning & & & & 16.3 \\
\hline Person with type 2 diabetes and & Mean & 0.37 & 0.13 to 0.61 & \\
\hline \multicolumn{5}{|l|}{ Healthcare provider (reference) } \\
\hline & SD & - & - & \\
\hline \multirow[t]{2}{*}{ Person with type 2 diabetes } & Mean & -0.41 & -0.54 to -0.28 & \\
\hline & SD & 0.55 & 0.40 to 0.70 & \\
\hline \multirow[t]{2}{*}{ Healthcare provider } & Mean & 0.04 & -0.07 to 0.15 & \\
\hline & SD & 0.22 & -0.02 to 0.46 & \\
\hline Lifestyle education method & & & & 18.1 \\
\hline \multirow[t]{2}{*}{ Individual education (reference) } & Mean & 0.43 & 0.23 to 0.63 & \\
\hline & SD & - & - & \\
\hline \multirow[t]{2}{*}{ Group education } & Mean & -0.44 & -0.54 to -0.33 & \\
\hline & SD & 0.22 & 0.03 to 0.41 & \\
\hline \multirow[t]{2}{*}{ Digital education } & Mean & 0.01 & -0.09 to 0.10 & \\
\hline & SD & 0.11 & -0.13 to 0.35 & \\
\hline Type of medication management support & & & & 8.5 \\
\hline \multirow[t]{2}{*}{ Via healthcare provider (reference) } & Mean & 0.22 & $0.00-0.44$ & \\
\hline & SD & - & - & \\
\hline \multirow[t]{2}{*}{ Via aid (app, website, medicine box) } & Mean & -0.19 & -0.30 to -0.08 & \\
\hline & SD & 0.23 & 0.01 to 0.45 & \\
\hline \multirow[t]{2}{*}{ No help } & Mean & -0.03 & -0.14 to 0.08 & \\
\hline & SD & 0.35 & 0.17 to 0.52 & \\
\hline Consultation frequency & & & & 24.2 \\
\hline \multirow{2}{*}{$\begin{array}{l}\text { One visit every three months with practice } \\
\text { nurse (reference) }\end{array}$} & Mean & 0.55 & 0.13 to 0.97 & \\
\hline & SD & - & - & \\
\hline \multirow{2}{*}{$\begin{array}{l}\text { One visit every two months with practice } \\
\text { nurse }\end{array}$} & Mean & 0.20 & 0.07 to 0.33 & \\
\hline & SD & 0.08 & -0.21 to 0.38 & \\
\hline \multirow{2}{*}{$\begin{array}{l}\text { One visit every six months with general } \\
\text { practitioner }\end{array}$} & Mean & -0.15 & -0.27 to -0.02 & \\
\hline & SD & 0.37 & 0.15 to 0.58 & \\
\hline \multirow[t]{2}{*}{ Yearly visit with general practitioner } & Mean & -0.61 & -0.77 to -0.44 & \\
\hline & SD & 0.69 & 0.50 to 0.88 & \\
\hline Emotional support & & & & 25.4 \\
\hline \multirow{2}{*}{$\begin{array}{l}\text { General practitioner or practice nurse } \\
\text { (reference) }\end{array}$} & Mean & 0.54 & 0.26 to 0.81 & \\
\hline & SD & - & - & \\
\hline \multirow[t]{2}{*}{ Psychologist } & Mean & -0.68 & -0.81 to -0.54 & \\
\hline & SD & 0.37 & 0.20 to 0.54 & \\
\hline \multirow[t]{2}{*}{ No emotional support } & Mean & 0.14 & -0.00 to 0.28 & \\
\hline & SD & 0.09 & -0.57 to 0.75 & \\
\hline \multirow[t]{2}{*}{ Time spend on self-management* } & Mean & -0.004 & -0.006 to -0.002 & 7.5 \\
\hline & SD & 0.01 & 0.009 to 0.01 & \\
\hline
\end{tabular}

$\mathrm{Cl}$, confidence interval.* The time spend on self-management attribute was coded as a continuous variable in the choice model. Nevertheless, in the choice tasks it was presented at three possible levels: 30 minutes, 1 hour and 2 hours. 


\section{Discussion}

In the present study, preferences of people with type 2 diabetes towards diabetes care were investigated using a discrete choice experiment. Our outcomes can be helpful to provide person-centred type 2 diabetes care.

Previous research has shown that people's preferences regarding health care are influenced by their experience of care [21]. In the Netherlands, people seem to be satisfied with the primary health care they receive, with more than $85 \%$ of people claiming to have confidence in their general practitioner [22]. It is therefore not surprising that our participants preferred to receive current care, such as one consultation visit per three months. Another reason for the preference towards current care could be that people who receive care do not know what they want beyond what they already know. In past qualitative research, people were unable to describe the role of the practice nurse beyond clinical checks and they indicated not knowing what else they could expect from their practice nurse [23]. Nevertheless, healthcare needs to adapt to the growing number of people with chronic disease by moving from a standardised to a more personalised approach [11, 24]. Previous research has shown that most people with type 2 diabetes are able to maintain adequate glycaemic control when consultations with healthcare providers are reduced [25]. Such changes in diabetes care organisation are needed to keep healthcare sustainable. Taking into consideration that people with type 2 diabetes prefer current care, it is important to discuss these changes with them when implemented.

In the current study, emotional support was identified as the most important attribute. Strikingly, our participants clearly indicated that they did not prefer to receive emotional support from a psychologist, even though mental health problems and type 2 diabetes frequently co-occur [26]. It is possible that the prevalence of mental health problems in the current study was low, because of the relatively low average $\mathrm{HbA1c}$ values in this study (i.e. $52 \mathrm{mmol} / \mathrm{mol}$ (7\%). Hyperglycaemia and mental health disorders are positively correlated [27]. Moreover, care from a general practitioner / practice nurse is viewed as more accessible, more comprehensive, since it manages both physical and mental problems, and less stigmatizing compared to care from a psychologist [28], which might also explain why participants showed a preference for receiving emotional support from a general practitioner or practice nurse.

Participants in this study preferred individual- over group lifestyle education. The few nonpharmaceutical preference studies that have previously been conducted, found the same result $[29,30]$. However, literature is indecisive when it comes to the best education method for people with type 2 diabetes [31]. Both individual as well as group education methods have been shown to improve glycaemic control. In this respect, it would be preferable to give patients the option of whether they want to learn individually or in a group.

Participants also preferred one visit every two or three months over one visit every six months. However, it is frequently presumed that due to the digital revolution, face-to-face interactions with Healthcare providers will become less common and exchanges will 
increasingly be mediated by electronic devices [32]. Although innovations in e-health technology have the potential to improve access to many types of healthcare services, it needs to be taken into account that connectivity and comfort levels with e-health applications differs between people [33]. Indeed, subgroup analyses in this study revealed that participants with lower education levels had a tendency towards wanting to avoid digital lifestyle education.

Other explanations for the observed preference heterogeneity were sex and type of glucose-lowering drugs. Men and participants treated with insulin had a stronger aversion to planning their daily diabetes care by themselves than women and participants treated with oral glucose-lowering drugs, respectively. For participants treated with insulin, this seems selfevident as insulin use requires more knowledge and skills [34]. A possible explanation for the difference found between men and women could be that more men than women with type 2 diabetes live alone (considering the facts that there are more men than women with type 2 diabetes and that more men than women live alone) [35]. Socially isolated individuals are more prone to have newly diagnosed and prevalent type 2 diabetes [36].

This study has several strengths and limitations. One of the major strengths of our study is the use of a discrete choice experiment to elicit people's preferences. This method takes trade-offs into account, which are difficult to measure in other methods, such as simple rating scale exercises [17]. It has, however, been criticized for being too difficult to understand [37]. This can lead to inaccurate choices that do not reflect true preferences and, as a recent metaanalysis revealed, affect response rates [38], which might have led to selective non-response. Deciding about health-related services is different and more complex than other, more every day decisions, such as where to buy a bike or what to order for lunch. To improve the comprehension of the discrete choice experiment and the precision of the parameter estimates in this study, a face-to-face pilot study was conducted and an explanation on how to complete the choice tasks was provided, as well as an example choice task. In total, $80 \%$ of participants passed the test-retest task, which provides an indication that the true preferences of the participants are reflected in this discrete choice experiment. Another strength of our study is the participation of multiple primary care practices. These practices were located in different neighbourhoods, thereby representing patients with various socio-economic backgrounds. However, our study only included participants from the south of the Netherlands. Compared to other parts of the Netherlands, the south has a predominantly Caucasian population. It is therefore unclear to what extent the preferences of the participants in our study represent the preferences of the general population with type 2 diabetes of the Netherlands or elsewhere.

\section{Conclusion}

Emotional support was identified as the most important attributes to the participants in this study, followed by frequency of consultations. In future research, it would therefore be interesting to compare diabetes care preferences between people with and without mental health problems. Furthermore, this discrete choice experiment revealed that people with type 
2 diabetes prefer to receive the care they currently receive. Therefore, it is important to adequately guide people when changes in diabetes care are implemented to keep healthcare sustainable. Heterogeneity in preferences was detected and could be explained by differences in sex, education level and type of glucose-lowering drugs. This information can be used to tailor type 2 diabetes care by identifying subgroups of people with varying preferences towards type 2 diabetes care. For example, digital lifestyle education could replace some of the consultation visits for people with high education levels, whereas people with lower education levels might benefit more from frequent individual lifestyle education with a healthcare provider. This could potentially lead to more person-centred care. 


\section{References}

1. Kleefstra N, Landman GW, Van Hateren KJ, Meulepas M, Romeijnders A, Rutten GE, et al. Dutch diabetes prevalence estimates (DUDE-1). J Diabetes 2016; 8:863-865.

2. Hek K, Ursum J, Tol J, Verheij RA. Eerstelijnszorggebruik voor diabetes: een overzicht. NIVEL Zorgregistraties eerste lijn 2016.

3. Nederlands huisartsen genootschap. NHG-standaard Diabetes mellitus type 2 (vierde (partitiële) herziening). 2018.

4. Bakker K, Bilo HJG. Diabetes care in the Netherlands: now and in the future. Practical Diabetes Int 2004; 21:88-91.

5. Cebolla Garrofé B, Björnberg A, Yung Phang A. Euro Diabetes Index 2014. Täby, Health Consumer Powerhouse Ltd 2014.

6. Netherlands Diabetes Federation. NDF Care Standard. Transparancy and quality of diabetes care for people with diabetes type 2 [NDF Zorgstandaard. Transparantie en kwaliteit van diabeteszorg voor mensen met type 2 diabetes] Amersfoort: Netherlands Diabetes Federation 2015.

7. National Institute for Health and Clinical Excellence. Managing blood glucose in adults with type 2 diabetes. 2018.

8. Davies MJ, D'Alessio DA, Fradkin J, Kernan WN, Mathieu C, Mingrone G, et al. Management of hyperglycaemia in type 2 diabetes, 2018. A consensus report by the American Diabetes Association (ADA) and the European Association for the Study of Diabetes (EASD). Diabetologia 2018; 61:2461-2498.

9. Elissen AM, Duimel-Peeters IG, Spreeuwenberg C, Spreeuwenberg M, Vrijhoef HJ. Toward tailored disease management for type 2 diabetes. Am J Manag Care 2012; 18:619-630.

10. Seuring T, Archangelidi O, Suhrcke M. The Economic Costs of Type 2 Diabetes: A Global Systematic Review. Pharmacoeconomics 2015; 33:811-831.

11. Institute of Medicine (U.S.). Committee on Quality of Health Care in America. Crossing the quality chasm : a new health system for the 21st century. Washington, D.C.: National Academy Press; 2001.

12. Inzucchi SE, Bergenstal RM, Buse JB, Diamant M, Ferrannini E, Nauck M, et al. Management of hyperglycemia in type 2 diabetes: a patient-centered approach: position statement of the American Diabetes Association (ADA) and the European Association for the Study of Diabetes (EASD). Diabetes Care 2012; 35:1364-1379.

13. Street RL, Jr., Elwyn G, Epstein RM. Patient preferences and healthcare outcomes: an ecological perspective. Expert Rev Pharmacoecon Outcomes Res 2012; 12:167-180.

14. Joy SM, Little E, Maruthur NM, Purnell TS, Bridges JF. Patient preferences for the treatment of type 2 diabetes: a scoping review. Pharmacoeconomics 2013; 31:877-892.

15. Purnell TS, Joy S, Little E, Bridges JF, Maruthur N. Patient preferences for noninsulin diabetes medications: a systematic review. Diabetes Care 2014; 37:2055-2062.

16. Say RE, Thomson R. The importance of patient preferences in treatment decisions-challenges for doctors. BMJ 2003; 327:542-545.

17. Lancsar E, Louviere J. Conducting discrete choice experiments to inform healthcare decision making: a user's guide. Pharmacoeconomics 2008; 26:661-677.

18. DeShazo JR, Fermo G. Designing choice sets for stated preference methods: the effects of complexity on choice consistency. Journal of Environmental Economics and Management 2002; 44:123-143. 
19. Hiligsmann M, van Durme C, Geusens P, Dellaert BG, Dirksen CD, van der Weijden $T$, et al. Nominal group technique to select attributes for discrete choice experiments: an example for drug treatment choice in osteoporosis. Patient Prefer Adherence 2013; 7:133-139.

20. Hertroijs DFL, Elissen AMJ, Brouwers M, Schaper NC, Kohler S, Popa MC, et al. A risk score including body mass index, glycated haemoglobin and triglycerides predicts future glycaemic control in people with type 2 diabetes. Diabetes Obes Metab 2018; 20:681688.

21. Bernhardsson S, Larsson MEH, Johansson K, Oberg B. "In the physio we trust": A qualitative study on patients' preferences for physiotherapy. Physiother Theory Pract 2017; 33:535-549.

22. Brabers AEM, van der Schors W, de Jong JD. Barometer vertrouwen in de gezondheidszorg. https://www.nivel.nl/nl/panels/barometer-vertrouwen-degezondheidszorg: NIVEL 2016.

23. Boyle E, Saunders R, Drury V. A qualitative study of patient experiences of type 2 diabetes care delivered comparatively by general practice nurses and medical practitioners. Journal of Clinical Nursing 2015; 25:1977-1986.

24. Rutten G, van Vugt HA, de Weerdt I, de Koning E. Implementation of a Structured Diabetes Consultation Model to Facilitate a Person-Centered Approach: Results From a Nationwide Dutch Study. Diabetes Care 2018; 41:688-695.

25. Wermeling PR, Gorter KJ, Stellato RK, de Wit GA, Beulens JW, Rutten GE. Effectiveness and cost-effectiveness of 3-monthly versus 6-monthly monitoring of well-controlled type 2 diabetes patients: a pragmatic randomised controlled patient-preference equivalence trial in primary care (EFFIMODI study). Diabetes Obes Metab 2014; 16:841-849.

26. Nouwen A, Winkley K, Twisk J, Lloyd CE, Peyrot M, Ismail K, et al. Type 2 diabetes mellitus as a risk factor for the onset of depression: a systematic review and metaanalysis. Diabetologia 2010; 53:2480-2486.

27. Uchendu C, Blake H. Effectiveness of cognitive-behavioural therapy on glycaemic control and psychological outcomes in adults with diabetes mellitus: a systematic review and meta-analysis of randomized controlled trials. Diabet Med 2017; 34:328-339.

28. Henderson C, Noblett J, Parke H, Clement S, Caffrey A, Gale-Grant O, et al. Mental health-related stigma in health care and mental health-care settings. Lancet Psychiatry 2014; 1:467-482.

29. Salampessy BH, Veldwijk J, Jantine Schuit A, van den Brekel-Dijkstra K, Neslo RE, Ardine de Wit G, et al. The Predictive Value of Discrete Choice Experiments in Public Health: An Exploratory Application. Patient 2015; 8:521-529.

30. Veldwijk J, Lambooij MS, van Gils PF, Struijs JN, Smit HA, de Wit GA. Type 2 diabetes patients' preferences and willingness to pay for lifestyle programs: a discrete choice experiment. BMC Public Health 2013; 13:1099.

31. Lawal M, Lawal F. Individual versus group diabetes education: Assessing the evidence. Diabetes Nursing 2016; 20:247-250.

32. Weiner JP. Doctor-patient communication in the e-health era. Isr J Health Policy Res 2012; 1:33.

33. Fortney JC, Burgess JF, Jr., Bosworth HB, Booth BM, Kaboli PJ. A re-conceptualization of access for 21st century healthcare. J Gen Intern Med 2011; 26 Suppl 2:639-647.

34. Ellis $\mathrm{K}$, Mulnier $\mathrm{H}$, Forbes A. Perceptions of insulin use in type 2 diabetes in primary care: a thematic synthesis. BMC Fam Pract 2018; 19:70. 
35. Volksgezondheid en zorg. Prevalentie diabetes naar leeftijd en geslacht. 2017

36. Brinkhues S, Dukers-Muijrers N, Hoebe C, van der Kallen CJH, Dagnelie PC, Koster A, et al. Socially isolated individuals are more prone to have newly diagnosed and prevalent type 2 diabetes mellitus - the Maastricht study. BMC Public Health 2017; 17:955.

37. Mangham LJ, Hanson K, McPake B. How to do (or not to do) ... Designing a discrete choice experiment for application in a low-income country. Health Policy Plan 2009; 24:151-158.

38. Watson V, Becker F, de Bekker-Grob E. Discrete Choice Experiment Response Rates: A Meta-analysis. Health Econ 2017; 26:810-817. 


\section{Supplementary material}

\section{Detailed description analysis}

Participant characteristics are presented as means (SDs) for continuous variables and counts and percentages for dichotomous variables. Descriptive statistics were performed in R Studio version 1.0.153.

For the DCE, a panel mixed-logit model was estimated, allowing for the determination of the mean preferences of the sample. A panel mixed-logit model adjusts for within-subject correlation and accounts for unobserved preference heterogeneity by attaching a random component to the model attributes, which allows the model parameters to vary between individuals [1]. A significant $(p<0.05)$ standard deviation (SD) of the attribute levels indicates preference heterogeneity. The attribute 'time spend on self-management' was analyzed as a continuous variable, because a linear relationship exists between its levels. All other attributes were included as effects-coded categorical variables assumed to be normally distributed. Effects coding was used to account for nonlinearities [2]. Compared to dummy coding, effects coding codes the reference category -1 , so the mean of the attributes is normalized to zero [3]. The level of each attribute that was most similar to current guideline-informed diabetes care in the Netherlands was used as the reference attribute parameter. A positive regression coefficient (beta) suggests that participants prefer more of that level within an attribute, whereas a negative coefficient suggests that participants prefer less of that level within an attribute. To determine the relevant importance of each attribute, the relative importance score was calculated based on the difference between the highest and lowest coefficients of each attribute divided by the total amount of these differences.

In subgroup analyses, preliminary joint models were estimated using interaction terms to investigate potential preference heterogeneity among people with different person-relatedand disease-related characteristics. Person-related characteristics included age ( $<65$ years and $\geq 65$ years), sex, and education level (low/medium and high). Disease-related characteristics included glucose-lowering drugs (diet with or without oral glucose-lowering drugs and insulin with or without oral glucose-lowering drugs), type 2 diabetes duration (recently diagnosed [ $\leq$ 5 years] and longstanding [ $>5$ years]), and predicted glycaemic control trajectory (stable, adequate glycaemic control-, improved glycaemic control-, and deteriorated glycaemic control trajectory). Participants' glycaemic control trajectories were predicted using a risk score, including BMI, $\mathrm{HbA} 1 \mathrm{c}$ and plasma triglycerides measured +/- 3 months from diagnosis (this was previously developed as part of the PROFILe project to stratify people with type 2 diabetes with recently diagnosed diabetes into one of the three glycaemic control trajectories [4]). Due to the low number of participants in the deteriorated glycaemic control trajectory $(n=6)$, this group was not included in the subgroup analysis. Parameters estimated for the interaction terms that are statistically different from zero ( $5 \%$ level) indicate a difference in preference between subgroups. The DCE analyses were performed in NLOGIT version 5 [5]. 
Supplementary Table 1. Results from the panel mixed logit model stratified on age

\begin{tabular}{|c|c|c|c|c|c|}
\hline \multirow[t]{2}{*}{ Attributes } & \multicolumn{2}{|c|}{$\begin{array}{l}<65 \text { years } \\
(n=117)\end{array}$} & \multicolumn{2}{|c|}{$\begin{array}{c}\geq 65 \text { years } \\
(n=168)\end{array}$} & \multirow[t]{2}{*}{$\begin{array}{l}\text { P-value of the } \\
\text { interaction test }\end{array}$} \\
\hline & Coefficient & $95 \% \mathrm{Cl}$ & Coefficient & $95 \% \mathrm{Cl}$ & \\
\hline Constant & -0.29 & & -0.25 & & - \\
\hline \multicolumn{6}{|l|}{$\begin{array}{l}\text { Role division in diabetes } \\
\text { care planning }\end{array}$} \\
\hline $\begin{array}{l}\text { Person with type } 2 \\
\text { diabetes and HCP (ref) }\end{array}$ & 0.48 & - & 0.27 & - & - \\
\hline $\begin{array}{l}\text { Person with type } 2 \\
\text { diabetes }\end{array}$ & -0.51 & $-0.71--0.30$ & -0.34 & $-0.50--0.18$ & 0.147 \\
\hline $\mathrm{HCP}$ & 0.03 & $-0.16--0.21$ & 0.07 & $-0.06-0.21$ & 0.887 \\
\hline \multicolumn{6}{|l|}{$\begin{array}{l}\text { Lifestyle education } \\
\text { method }\end{array}$} \\
\hline Individual education (ref) & 0.40 & - & 0.47 & - & - \\
\hline Group education & -0.50 & $-0.68--0.31$ & -0.41 & $-0.54--0.28$ & 0.775 \\
\hline $\begin{array}{l}\text { Digital education (app or } \\
\text { website) }\end{array}$ & 0.10 & $-0.06-0.26$ & -0.06 & $-0.17-0.06$ & 0.151 \\
\hline \multicolumn{6}{|l|}{$\begin{array}{l}\text { Type of medication } \\
\text { management support }\end{array}$} \\
\hline Via HCP (ref) & 0.04 & - & 0.31 & - & - \\
\hline $\begin{array}{l}\text { Via aid (app, website, } \\
\text { medicine box) }\end{array}$ & -0.08 & $-0.25-0.09$ & -0.29 & $-0.43--0.14$ & 0.133 \\
\hline No help & -0.04 & $-0.21-0.13$ & -0.02 & $-0.16-0.12$ & 0.998 \\
\hline \multicolumn{6}{|l|}{ Consultation frequency } \\
\hline $\begin{array}{l}\text { 3-monthly visit with PN } \\
\text { (ref) }\end{array}$ & 0.63 & - & 0.51 & - & - \\
\hline 2-monthly visit with PN & 0.15 & $-0.06-0.35$ & 0.24 & $0.07-0.40$ & 0.306 \\
\hline 6-monthly visit with GP & -0.07 & $-0.25-0.12$ & -0.19 & $-0.35--0.02$ & 0.186 \\
\hline Yearly visit with GP & -0.71 & $-0.98--0.45$ & -0.56 & $-0.76--0.35$ & 0.427 \\
\hline \multicolumn{6}{|l|}{$\begin{array}{l}\text { Emotional support } \\
\text { approach }\end{array}$} \\
\hline GP or PN (ref) & 0.50 & - & 0.57 & - & - \\
\hline Psychologist & -0.62 & $-0.83--0.40$ & -0.73 & $-0.90--0.55$ & 0.232 \\
\hline No emotional support & 0.12 & $-0.11-0.35$ & 0.16 & $-0.02-0.34$ & 0.546 \\
\hline $\begin{array}{l}\text { Time spend on self- } \\
\text { management }\end{array}$ & -0.004 & $-0.01-0.0001$ & -0.005 & $-0.007--0.002$ & 0.121 \\
\hline
\end{tabular}

HCP: healthcare provider, PN: practice nurse, GP: general practitioner. 
Supplementary Table 2. Results from the panel mixed logit model stratified on sex

\begin{tabular}{|c|c|c|c|c|c|}
\hline \multirow[t]{2}{*}{ Attributes } & \multicolumn{2}{|c|}{$\begin{array}{l}\text { Female } \\
(n=101)\end{array}$} & \multicolumn{2}{|c|}{$\begin{array}{c}\text { Male } \\
(n=187)\end{array}$} & \multirow{2}{*}{$\begin{array}{c}\text { P-value of the } \\
\text { interaction } \\
\text { test }\end{array}$} \\
\hline & Coefficient & $95 \% \mathrm{Cl}$ & Coefficient & $95 \% \mathrm{Cl}$ & \\
\hline Constant & -0.17 & - & -0.34 & - & - \\
\hline \multicolumn{6}{|l|}{$\begin{array}{l}\text { Role division in diabetes } \\
\text { care planning }\end{array}$} \\
\hline $\begin{array}{l}\text { Person with type } 2 \\
\text { diabetes and HCP (ref) }\end{array}$ & 0.33 & - & 0.38 & - & - \\
\hline $\begin{array}{l}\text { Person with type } 2 \\
\text { diabetes }\end{array}$ & -0.19 & $-0.39-0.002$ & -0.54 & $-0.70--0.37$ & 0.016 \\
\hline $\mathrm{HCP}$ & -0.14 & $-0.31-0.036$ & 0.16 & $0.01-0.31$ & 0.012 \\
\hline \multicolumn{6}{|l|}{$\begin{array}{l}\text { Lifestyle education } \\
\text { method }\end{array}$} \\
\hline Individual education (ref) & 0.43 & - & 0.44 & - & - \\
\hline Group education & -0.37 & $-0.54--0.20$ & -0.49 & $-0.63--0.35$ & 0.607 \\
\hline $\begin{array}{l}\text { Digital education (app or } \\
\text { website) }\end{array}$ & -0.06 & $-0.21--0.09$ & 0.05 & $-0.07-0.17$ & 0.219 \\
\hline \multicolumn{6}{|l|}{$\begin{array}{l}\text { Type of medication } \\
\text { management support }\end{array}$} \\
\hline Via HCP (ref) & 0.18 & - & 0.25 & - & - \\
\hline $\begin{array}{l}\text { Via aid (app, website, } \\
\text { medicine box) }\end{array}$ & -0.23 & $-0.41--0.04$ & -0.19 & $-0.33--0.04$ & 0.596 \\
\hline No help & 0.05 & $-0.12--0.20$ & $-0.06(0.07)$ & $-0.21-0.09$ & 0.427 \\
\hline \multicolumn{6}{|l|}{ Consultation frequency } \\
\hline $\begin{array}{l}\text { 3-monthly visit with PN } \\
\text { (ref) }\end{array}$ & 0.50 & - & 0.61 & - & - \\
\hline 2-monthly visit with PN & 0.23 & $0.02-0.44$ & 0.17 & $0.007-0.34$ & 0.494 \\
\hline 6-monthly visit with GP & -0.23 & $-0.43--0.04$ & -0.08 & $-0.25-0.08$ & 0.373 \\
\hline Yearly visit with GP & -0.50 & $-0.74--0.24$ & -0.70 & $-0.90--0.46$ & 0.928 \\
\hline \multicolumn{6}{|l|}{$\begin{array}{l}\text { Emotional support } \\
\text { approach }\end{array}$} \\
\hline GP or PN (ref) & 0.51 & - & 0.56 & - & - \\
\hline Psychologist & -0.64 & $-0.84--0.44$ & -0.71 & $-0.89--0.52$ & 0.567 \\
\hline No emotional support & 0.13 & $-0.08-0.36$ & 0.15 & $-0.04-0.34$ & 0.874 \\
\hline $\begin{array}{l}\text { Time spend on self- } \\
\text { management }\end{array}$ & -0.005 & $-0.008--0.002$ & -0.004 & $-0.006--0.001$ & 0.188 \\
\hline
\end{tabular}

HCP: healthcare provider, PN: practice nurse, GP: general practitioner. 
Supplementary Table 3. Results from the panel mixed logit model stratified on education level

\begin{tabular}{|c|c|c|c|c|c|}
\hline \multirow[t]{2}{*}{ Attributes } & \multicolumn{2}{|c|}{$\begin{array}{l}\text { High } \\
(n=73)\end{array}$} & \multicolumn{2}{|c|}{$\begin{array}{l}\text { Low/medium } \\
(n=188)\end{array}$} & \multirow{2}{*}{$\begin{array}{c}\text { P-value of the } \\
\text { interaction } \\
\text { test }\end{array}$} \\
\hline & Coefficient & $95 \% \mathrm{Cl}$ & Coefficient & $95 \% \mathrm{Cl}$ & \\
\hline Constant & -0.19 & - & -0.29 & - & - \\
\hline \multicolumn{6}{|l|}{$\begin{array}{l}\text { Role division in diabetes } \\
\text { care planning }\end{array}$} \\
\hline $\begin{array}{l}\text { Person with type } 2 \\
\text { diabetes and HCP (ref) }\end{array}$ & 0.47 & - & 0.32 & - & - \\
\hline $\begin{array}{l}\text { Person with type } 2 \\
\text { diabetes }\end{array}$ & -0.44 & $-0.66--0.21$ & -0.39 & $-0.53--0.24$ & 0.951 \\
\hline $\mathrm{HCP}$ & -0.03 & $-0.23-0.16$ & 0.07 & $-0.05-0.20$ & 0.999 \\
\hline \multicolumn{6}{|l|}{$\begin{array}{l}\text { Lifestyle education } \\
\text { method }\end{array}$} \\
\hline $\begin{array}{l}\text { Individual education } \\
\text { (ref) }\end{array}$ & 0.42 & - & 0.45 & - & - \\
\hline Group education & -0.59 & $-0.79--0.39$ & -0.40 & $-0.53--0.28$ & 0.217 \\
\hline $\begin{array}{l}\text { Digital education (app or } \\
\text { website) }\end{array}$ & 0.17 & $0.005-0.34$ & -0.05 & $-0.16-0.08$ & 0.030 \\
\hline \multicolumn{6}{|l|}{$\begin{array}{l}\text { Type of medication } \\
\text { management support }\end{array}$} \\
\hline Via HCP (ref) & 0.08 & - & 0.30 & - & - \\
\hline $\begin{array}{l}\text { Via aid (app, website, } \\
\text { medicine box) }\end{array}$ & -0.06 & $-0.25-0.12$ & -0.26 & $-0.39--0.13$ & 0.085 \\
\hline No help & -0.02 & $-0.21-0.17$ & -0.04 & $-0.17-0.08$ & 0.999 \\
\hline \multicolumn{6}{|l|}{ Consultation frequency } \\
\hline $\begin{array}{l}\text { 3-monthly visit with PN } \\
\text { (ref) }\end{array}$ & 0.44 & - & 0.61 & - & - \\
\hline 2-monthly visit with PN & 0.14 & $-0.08-0.37$ & 0.25 & $0.10-0.40$ & 0.409 \\
\hline 6-monthly visit with GP & -0.03 & $-0.24-0.19$ & -0.22 & $-0.36--0.08$ & 0.063 \\
\hline Yearly visit with GP & -0.55 & $-0.83--0.27$ & -0.64 & $-0.83--0.44$ & 0.473 \\
\hline \multicolumn{6}{|l|}{$\begin{array}{l}\text { Emotional support } \\
\text { approach }\end{array}$} \\
\hline GP or PN (ref) & 0.39 & - & 0.62 & - & - \\
\hline Psychologist & -0.50 & $-0.71--0.29$ & -0.74 & $-0.90--0.58$ & 0.242 \\
\hline No emotional support & 0.11 & $-0.14-0.36$ & 0.12 & $-0.05-0.28$ & 0.439 \\
\hline $\begin{array}{l}\text { Time spend on self- } \\
\text { management }\end{array}$ & -0.007 & $-0.01--0.003$ & -0.004 & $-0.006--0.001$ & 0.153 \\
\hline
\end{tabular}

HCP: healthcare provider, $\mathrm{PN}$ : practice nurse, GP: general practitioner. 
Supplementary Table 4. Results from the panel mixed logit model stratified on diabetes medication

\begin{tabular}{|c|c|c|c|c|c|}
\hline \multirow[t]{2}{*}{ Attributes } & \multicolumn{2}{|c|}{$\begin{array}{c}\text { Diet and/or glucose lowering } \\
\text { drugs } \\
(n=206)\end{array}$} & \multicolumn{2}{|c|}{$\begin{array}{l}\text { Insulin with or without glucose } \\
\text { lowering drugs } \\
(n=37)\end{array}$} & \multirow[t]{2}{*}{$\begin{array}{l}\text { P-value of the } \\
\text { interaction } \\
\text { test }\end{array}$} \\
\hline & Coefficient & $95 \% \mathrm{Cl}$ & Coefficient & $95 \% \mathrm{Cl}$ & \\
\hline Constant & $-0.32 * *$ & - & $-0.23 *$ & - & - \\
\hline \multicolumn{6}{|l|}{$\begin{array}{l}\text { Role division in diabetes } \\
\text { care planning }\end{array}$} \\
\hline $\begin{array}{l}\text { Person with type } 2 \\
\text { diabetes and HCP (ref) }\end{array}$ & 0.31 & - & 0.62 & - & - \\
\hline $\begin{array}{l}\text { Person with type } 2 \\
\text { diabetes }\end{array}$ & -0.33 & $-0.46--0.2$ & -0.85 & $-1.19--0.50$ & 0.007 \\
\hline $\mathrm{HCP}$ & 0.02 & $-0.09-0.13$ & 0.23 & $-0.02-0.48$ & 0.032 \\
\hline \multicolumn{6}{|l|}{$\begin{array}{l}\text { Lifestyle education } \\
\text { method }\end{array}$} \\
\hline Individual education (ref) & 0.44 & - & 0.37 & - & - \\
\hline Group education & -0.43 & $-0.54--0.32$ & -0.54 & $-0.80--0.29$ & 0.914 \\
\hline $\begin{array}{l}\text { Digital education (app or } \\
\text { website) }\end{array}$ & -0.01 & $-0.11-0.08$ & 0.17 & $-0.04-0.38$ & 0.177 \\
\hline \multicolumn{6}{|l|}{$\begin{array}{l}\text { Type of medication } \\
\text { management support }\end{array}$} \\
\hline Via HCP (ref) & 0.18 & - & 0.52 & - & - \\
\hline $\begin{array}{l}\text { Via aid (app, website, } \\
\text { medicine box) }\end{array}$ & -0.20 & $-0.32--0.08$ & -0.14 & $-0.38-0.11$ & 0.314 \\
\hline No help & 0.02 & $-0.09-0.13$ & -0.38 & $-0.63--0.12$ & 0.021 \\
\hline \multicolumn{6}{|l|}{ Consultation frequency } \\
\hline $\begin{array}{l}\text { 3-monthly visit with PN } \\
\text { (ref) }\end{array}$ & 0.47 & - & 0.94 & - & - \\
\hline 2-monthly visit with PN & 0.20 & $0.07-0.34$ & 0.34 & $0.05-0.63$ & 0.603 \\
\hline 6-monthly visit with GP & -0.11 & $-0.24-0.02$ & -0.43 & $-0.70--0.16$ & 0.121 \\
\hline Yearly visit with GP & -0.56 & $-0.72--0.40$ & -0.85 & $-1.25--0.46$ & 0.142 \\
\hline \multicolumn{6}{|l|}{$\begin{array}{l}\text { Emotional support } \\
\text { approach }\end{array}$} \\
\hline GP or PN (ref) & 0.49 & - & 0.74 & - & - \\
\hline Psychologist & -0.67 & $-0.83-0.54$ & -0.63 & $-0.93--0.33$ & 0.792 \\
\hline No emotional support & 0.18 & $0.03-0.33$ & -0.11 & $-0.42-0.19$ & 0.888 \\
\hline $\begin{array}{l}\text { Time spend on self- } \\
\text { management }\end{array}$ & -0.31 & $-0.006--0.011$ & -0.005 & $-0.009--0.0002$ & 0.259 \\
\hline
\end{tabular}

HCP: healthcare provider, PN: practice nurse, GP: general practitioner. 
Supplementary Table 5. Results from the panel mixed logit model stratified on diabetes duration

\begin{tabular}{|c|c|c|c|c|c|}
\hline \multirow[t]{2}{*}{ Attributes } & \multicolumn{2}{|c|}{ Recently diagnosed T2DM ( $n=174)$} & \multicolumn{2}{|c|}{ Longstanding T2DM ( $n=114)$} & \multirow{2}{*}{$\begin{array}{l}\text { P-value of } \\
\text { the } \\
\text { interaction } \\
\text { test }\end{array}$} \\
\hline & Coefficient & $95 \% \mathrm{Cl}$ & Coefficient & $95 \% \mathrm{Cl}$ & \\
\hline Constant & -0.30 & - & -0.25 & - & - \\
\hline \multicolumn{6}{|l|}{$\begin{array}{l}\text { Role division in } \\
\text { diabetes care planning }\end{array}$} \\
\hline $\begin{array}{l}\text { Person with type } 2 \\
\text { diabetes and HCP (ref) }\end{array}$ & 0.40 & - & 0.33 & - & - \\
\hline $\begin{array}{l}\text { Person with type } 2 \\
\text { diabetes }\end{array}$ & -0.39 & $-0.56--0.22$ & -0.47 & $-0.69--0.25$ & 0.393 \\
\hline $\mathrm{HCP}$ & -0.01 & $-0.16-0.13$ & 0.14 & $-0.04-0.33$ & 0.169 \\
\hline \multicolumn{6}{|l|}{$\begin{array}{l}\text { Lifestyle education } \\
\text { method }\end{array}$} \\
\hline $\begin{array}{l}\text { Individual education } \\
\text { (ref) }\end{array}$ & 0.48 & - & 0.39 & - & \\
\hline Group education & -0.50 & $-0.65--0.35$ & -0.37 & $-0.54--0.20$ & 0.755 \\
\hline $\begin{array}{l}\text { Digital education (app } \\
\text { or website) }\end{array}$ & $0.02(0.06)$ & $-0.10-0.15$ & -0.02 & $-0.17-0.13$ & 0.733 \\
\hline \multicolumn{6}{|l|}{$\begin{array}{l}\text { Type of medication } \\
\text { management support }\end{array}$} \\
\hline Via HCP (ref) & 0.17 & - & 0.33 & - & \\
\hline $\begin{array}{l}\text { Via aid (app, website, } \\
\text { medicine box) }\end{array}$ & -0.19 & $-0.34--0.04$ & -0.21 & $-0.40--0.03$ & 0.394 \\
\hline No help & 0.02 & $-0.12-0.17$ & -0.12 & $-0.30-0.05$ & 0.270 \\
\hline \multicolumn{6}{|l|}{$\begin{array}{l}\text { Consultation } \\
\text { frequency }\end{array}$} \\
\hline $\begin{array}{l}\text { 3-monthly visit with PN } \\
\text { (ref) }\end{array}$ & 0.51 & - & 0.64 & - & - \\
\hline 2-monthly visit with PN & 0.21 & $0.04-0.38$ & 0.21 & $0.0001-0.43$ & 0.774 \\
\hline 6-monthly visit with GP & -0.07 & $-0.24-0.09$ & -0.27 & $-0.47--0.06$ & 0.241 \\
\hline Yearly visit with GP & -0.65 & $-0.87--0.44$ & -0.58 & $-0.86--0.30$ & 0.412 \\
\hline \multicolumn{6}{|l|}{$\begin{array}{l}\text { Emotional support } \\
\text { approach }\end{array}$} \\
\hline GP or PN (ref) & 0.52 & - & 0.61 & - & - \\
\hline Psychologist & -0.64 & $-0.82--0.46$ & -0.80 & $-1.02--0.58$ & 0.065 \\
\hline No emotional support & 0.12 & $-0.06-0.31$ & 0.19 & $-0.04-0.42$ & 0.238 \\
\hline $\begin{array}{l}\text { Time spend on self- } \\
\text { management }\end{array}$ & -0.003 & $-0.006--0.000$ & -0.007 & $-0.01--0.003$ & 0.07 \\
\hline
\end{tabular}

HCP: healthcare provider, $\mathrm{PN}$ : practice nurse, GP: general practitioner. 
Supplementary Table 6. Results from the panel mixed logit model stratified on glycaemic control trajectory

\begin{tabular}{|c|c|c|c|c|c|}
\hline \multirow[t]{2}{*}{ Attributes } & \multicolumn{2}{|c|}{$\begin{array}{l}\text { Stable, adequate glycaemic } \\
\text { control }(n=75)\end{array}$} & \multicolumn{2}{|c|}{ improved glycaemic control $(n=16)$} & \multirow[t]{2}{*}{$\begin{array}{l}\text { P-value of the } \\
\text { interaction test }\end{array}$} \\
\hline & Coefficient & $95 \% \mathrm{Cl}$ & Coeffecient & $95 \% \mathrm{Cl}$ & \\
\hline Constant & -0.44 & - & -0.33 & - & - \\
\hline \multicolumn{6}{|l|}{$\begin{array}{l}\text { Role division in diabetes } \\
\text { care planning }\end{array}$} \\
\hline $\begin{array}{l}\text { Person with type } 2 \\
\text { diabetes and HCP (ref) }\end{array}$ & 0.53 & - & 0.45 & - & - \\
\hline $\begin{array}{l}\text { Person with type } 2 \\
\text { diabetes }\end{array}$ & -0.41 & $-0.70--0.13$ & -0.44 & $-1.14-0.25$ & 0.858 \\
\hline $\mathrm{HCP}$ & -0.12 & $-0.37-0.12$ & -0.01 & $-0.60-0.58$ & 0.945 \\
\hline \multicolumn{6}{|l|}{$\begin{array}{l}\text { Lifestyle education } \\
\text { method }\end{array}$} \\
\hline Individual education (ref) & 0.48 & - & 0.73 & - & - \\
\hline Group education & -0.57 & $-0.84--0.31$ & -0.90 & $-1.79-0.002$ & 0.572 \\
\hline $\begin{array}{l}\text { Digital education (app or } \\
\text { website) }\end{array}$ & 0.09 & $-0.12-0.29$ & 0.17 & $-0.37-0.71$ & 0.598 \\
\hline \multicolumn{6}{|l|}{$\begin{array}{l}\text { Type of medication } \\
\text { management support }\end{array}$} \\
\hline Via HCP (ref) & 0.09 & - & 0.42 & - & - \\
\hline $\begin{array}{l}\text { Via aid (app, website, } \\
\text { medicine box) }\end{array}$ & -0.12 & $-0.37-0.13$ & 0.11 & $-0.52-0.75$ & 0.886 \\
\hline No help & 0.03 & $-0.22-0.29$ & -0.43 & $-1.28-0.41$ & 0.619 \\
\hline \multicolumn{6}{|l|}{ Consultation frequency } \\
\hline $\begin{array}{l}\text { 3-monthly visit with PN } \\
\text { (ref) }\end{array}$ & 0.53 & - & 1.33 & - & - \\
\hline 2-monthly visit with PN & 0.10 & $-0.18-0.38$ & 0.72 & $-0.22-1.65$ & 0.629 \\
\hline 6-monthly visit with GP & 0.01 & $-0.28-0.30$ & -0.72 & $-1.62-0.18$ & 0.614 \\
\hline Yearly visit with GP & -0.64 & $-0.99--0.30$ & -1.33 & $-2.74-0.08$ & 0.888 \\
\hline \multicolumn{6}{|l|}{$\begin{array}{l}\text { Emotional support } \\
\text { approach }\end{array}$} \\
\hline GP or PN (ref) & 0.84 & & 0.08 & - & - \\
\hline Psychologist & -0.88 & $-1.21--0.54$ & -0.67 & $-1.60-0.25$ & 0.336 \\
\hline No emotional support & 0.04 & $-0.27-0.35$ & 0.59 & $-0.26-1.44$ & 0.183 \\
\hline $\begin{array}{l}\text { Time spend on self- } \\
\text { management }\end{array}$ & -0.004 & $\begin{array}{l}-0.008- \\
0.0003\end{array}$ & -0.001 & $-0.02-0.01$ & 0.360 \\
\hline
\end{tabular}

HCP: healthcare provider, PN: practice nurse, GP: general practitioner. 


\section{References}

1. Hauber AB, Gonzalez JM, Groothuis-Oudshoorn CG, Prior T, Marshall DA, Cunningham C, et al. Statistical Methods for the Analysis of Discrete Choice Experiments: A Report of the ISPOR Conjoint Analysis Good Research Practices Task Force. Value Health 2016; 19:300315.

2. Muhlbacher A, Johnson FR. Choice Experiments to Quantify Preferences for Health and Healthcare: State of the Practice. Appl Health Econ Health Policy 2016; 14:253-266.

3. Bech M, Gyrd-Hansen D. Effects coding in discrete choice experiments. Health Econ 2005; 14:1079-1083.

4. Hertroijs DFL, Elissen AMJ, Brouwers M, Schaper NC, Kohler S, Popa MC, et al. A risk score including body mass index, glycated haemoglobin and triglycerides predicts future glycaemic control in people with type 2 diabetes. Diabetes Obes Metab 2018; 20:681688.

5. Brinkhues S, Dukers-Muijrers N, Hoebe C, van der Kallen CJH, Dagnelie PC, Koster A, et al. Socially isolated individuals are more prone to have newly diagnosed and prevalent type 2 diabetes mellitus - the Maastricht study. BMC Public Health 2017; 17:955. 



\section{CHAPTER 8}

\section{Tailored health care: Two perspectives on the development and use of patient profiles}

\section{Published as:}

T. Dekkers \& D.F.L. Hertroijs. Tailored Healthcare: Two perspectives on development and use of patient profiles. Advances in Therapy. 2018; 35(9):1453-1459 


\section{Abstract}

Calls for a more tailored approach to the management of cardiometabolic- and musculoskeletal diseases have been increasing. Although tailored care is a centuries old concept, it is still unclear how it should be best practiced. The current paper introduces two phenotype-based Dutch approaches to support tailored care. One approach focuses on patients with type 2 diabetes, the other on patients undergoing total joint replacement. Using the patient profiling approach, both projects propose that care can be tailored by the assessment of biopsychosocial patient characteristics, stratification of patients into subgroups of patients with similar care needs, abilities, and preferences (so-called patient profiles), and tailoring of care in concordance with the common care preferences of these profiles. In this article, the advantages and disadvantages of the method are discussed to enable researchers or clinicians who want to extent the patient profiling approach to other patient populations to carefully evaluate these in relation to their project's focus and available resources. 


\section{Introduction}

Tailored care was first described 4000 years BC in sacred texts from India known as 'the Vedas' [1]. It was then called 'Ayurvedic medicine' and its aim was to tailor treatment to each person's 'prakiti' (or constitution) in order to maintain a balance between body, mind and spirit. Nowadays, the aim of tailored care is to improve patients' health outcomes and care experience by taking the individual needs and preferences into account in developing a treatment plan. Due to the aging population and associated growing burden of cardiometabolic and musculoskeletal diseases [2], calls for a more tailored approach to the management of diseases have been increasing [3-5]. Although tailored care is millennia old, it is still unclear what the best approach is.

Currently, the majority of patients receives standardized care, based on evidence-based, disease-specific guidelines $[6,7]$. However, there is a growing body of evidence that shows the inherent limitations of this 'one-size-fits-all' approach. For example, patients differ in the amount and type of information they need and which aspects of care they prioritize [8-10]. While healthcare professionals do tailor communication during medical consultation to some extent, neither care needs nor preferences are routinely accommodated $[10,11]$. Thus, we need to think of other ways to deliver care. A tailored approach based on the phenotyping of patients may be such an approach. In this approach, patients' biopsychosocial characteristics are used to identify subgroups of patients with similar care needs, abilities, and preferences, for whom tailored solutions can be developed.

In the current paper we introduce two phenotype-based Dutch approaches to support tailored care. One approach focuses on patients with type 2 diabetes, the other on patients who undergo total joint replacement. Both use the term patient profiles to represent identified subgroups of patients, which form the basis for the development of tailored care, and are set to deliver final results in 2018-2019. Here, we outline the common steps in patient profiling, with a detailed description of their development, focusing on the differences in the patient characteristics assessed to identify the profiles and the process by which patients were stratified into subgroups.

\section{Patient profiling}

The aim of patient profiling is to enable care providers to provide the right care, to the right person, at the right time. It draws on the concept of 'mass customization', where goods and services are delivered to a large number of clients with enough variety and customization that nearly everyone finds exactly what they want [12]. Starbucks, Levi's, and Burger King are prominent examples of companies that have implemented this concept of targeting 'markets of a few' [13]. At Starbucks, for example, customers can customize their coffee by choosing from a variety of sizes, flavors and toppings. In healthcare, mass customization is less wellknown, but with many patients with specific diseases that have varying care needs, abilities, and preferences, it could be a solution for delivering more tailored healthcare.

Patient profiling uses the individual's preferences to tailor the content, context and delivery mode of care to improve care experience and health outcomes [14-16], including quality of life, as well as reducing the per capita costs of care. The development of the tailored 
care based on profiles consists of four steps: 1) identification of the target population; 2) assessment; 3 ) stratification, and 4) tailoring (see Figure 1). After defining the population (e.g. patients with type 2 diabetes treated in primary care), care providers assess relevant phenotypic patient characteristics, such as body weight, quality of life and self-efficacy, which are predictive of relevant outcomes, such as glycemic control and patient satisfaction. Subsequently, these characteristics are used to stratify patients into profiles. This approach results in subgroups of patients who are more homogeneous than the population as a whole in terms of care needs, abilities, and preferences, while acknowledging that a certain amount of heterogeneity within these subgroups will remain. In the last step, the patient's care is adapted depending on his or her profile.

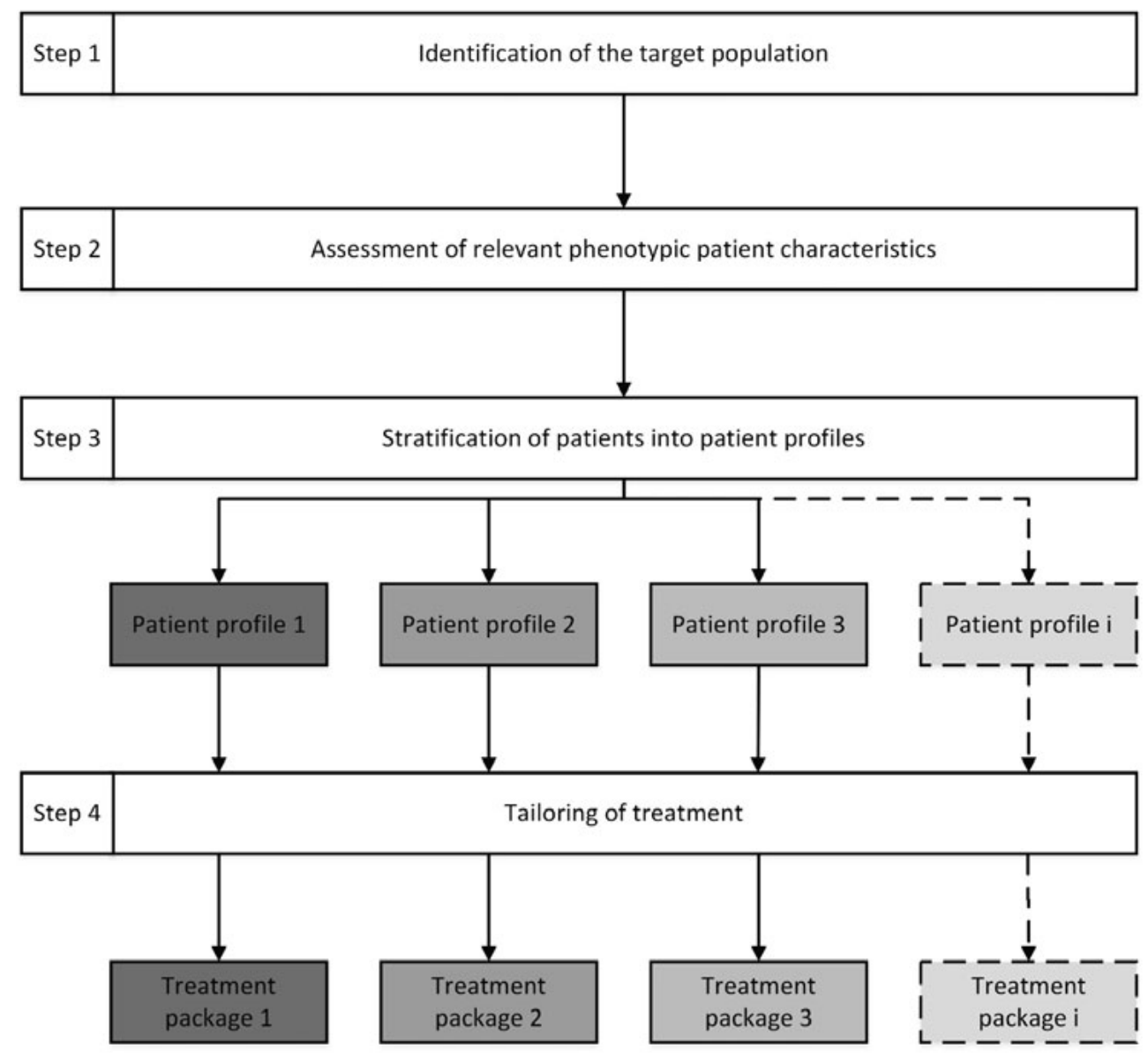

Figure 1. The patient profiling approach. Treatment packages may differ in frequency of consultations, education material, e.g. 


\section{Comparison of two patient profiles studies}

In the following section, two ongoing research projects that use the modus operandi as described above are explained. Both projects apply different techniques to do so. One uses a quantitative and the other a mixed-method approach. The current conceptual article is based on the two projects and does not directly contain any studies with human participants or animals performed by any of the authors for which ethical approval was required. An overview of both approaches can be found in Table 1.

\section{Patient profiles: a quantitative approach}

The Dutch PROFILe (PROFiling patients' healthcare needs to support Integrated, personcentered models for Long-term disease management) project started in 2014 and is a 4-year public-private research collaboration between a university, hospital, pharmaceutical company and two diabetes care networks (DCN). PROFILe aims to develop, validate and test patient profiles as an instrument for tailored diabetes management in primary care [17]. The two DCNs both routinely collect patient data. One DCN was considered the development cohort ( $n=10.528)$, and the other the validation cohort $(n=3.777)$.

A quantitative approach was used to develop the patient profiles. In the first step, the longitudinal electronic health records of the development cohort were used to conduct growth mixture modeling [18]. This technique identified three subgroups of patients based on glycemic control trajectories starting from the point of diagnosis: 1) stable, adequate glycaemic control; 2) improved glycaemic control; and 3) deteriorated glycaemic control. Glycaemic control trajectories were chosen as the outcome, because the researchers hypothesized that patients with different glycaemic control trajectories prefer different configurations of diabetes care and support. The identified subgroups were validated in the validation cohort. Second, to explore which phenotypic patient characteristics should be assessed to determine a patient profile and to stratify patients into the right trajectory, machine learning methods were applied. Using the most salient characteristics (baseline body mass index, $\mathrm{HbA1c}$ and triglycerides), an algorithm was built to predict the identified glycemic control trajectories, which was subsequently validated in the validation cohort. The project is currently on the third step 'tailoring': the adaption of care per patient profile. A so called 'discrete choice experiment (DCE)' is conducted among 300 patients to provide insight into the patients' preferences for specific configurations of diabetes care and support (e.g. frequency of professional monitoring, involved providers, information provision). These care preferences are paired with the corresponding patient profiles. To diminish heterogeneity within each profile, the influence of psychosocial characteristics, such as self-efficacy and quality of life, on the preferences is also determined.

In the final step of the PROFILe project, a clustered-randomized controlled trial will be performed at primary care practices in the Netherlands to assess the perceived benefits, risks and the feasibility of implementing patient profiles as an instrument to safely and successfully provide tailored type 2 diabetes management. 
Table 1. Overview of two approaches to develop and use patient profiles

\begin{tabular}{|c|c|c|}
\hline & $\begin{array}{l}\text { Quantitative approach (PROFILe } \\
\text { project) }\end{array}$ & $\begin{array}{l}\text { Mixed-method approach } \\
\text { (Tailored Healthcare project) }\end{array}$ \\
\hline Objective & $\begin{array}{l}\text { To develop, validate and test patient } \\
\text { profiles as an instrument to support } \\
\text { more tailored type } 2 \text { diabetes } \\
\text { management in primary care. }\end{array}$ & $\begin{array}{l}\text { To define and validate patient profiles, and to test the } \\
\text { effect of integrating profiles in healthcare services, } \\
\text { materials, and systems on total joint replacement } \\
\text { patients' satisfaction with care provision. }\end{array}$ \\
\hline \multicolumn{3}{|c|}{ Patient profile development } \\
\hline Target population & $\begin{array}{l}\text { Adult patients with type } 2 \text { diabetes } \\
\text { treated in primary care. }\end{array}$ & $\begin{array}{l}\text { Older adults undergoing lower limb joint replacement } \\
\text { surgery. }\end{array}$ \\
\hline $\begin{array}{l}\text { Identification of } \\
\text { subgroups }\end{array}$ & Growth mixture modeling & K-means clustering \\
\hline Population size & $\begin{array}{l}\sim 10,000 \text { (development cohort) } \\
\sim 3,000 \text { (validation cohort }\end{array}$ & $\begin{array}{l}\sim 200 \text { (retrospective cohort) } \\
\sim 30 \text { (qualitative interviews) }\end{array}$ \\
\hline $\begin{array}{l}\text { Prediction of } \\
\text { subgroups }\end{array}$ & Machine learning & Recursive partitioning \\
\hline
\end{tabular}

\section{Patient profile use in practice}

\begin{tabular}{|l|l|l|}
\hline $\begin{array}{l}\text { Assessment: Which } \\
\text { patient } \\
\text { characteristics are } \\
\text { assessed? }\end{array}$ & Body mass index & Coping style \\
\cline { 2 - 3 } & Glycated haemoglobin & Anxiety \\
\cline { 2 - 3 } & Triglycerides & Communication preferences \\
\hline $\begin{array}{l}\text { Stratification: } \\
\text { How are patients } \\
\text { stratified into } \\
\text { subgroups? }\end{array}$ & $\begin{array}{l}\text { Healthcare provider enters patients } \\
\text { BMl, HbA1c and triglycerides levels } \\
\text { into a tool, which enables him/her } \\
\text { to view the related subgroup with a } \\
\text { similar glycemic control trajectory. }\end{array}$ & $\begin{array}{l}\text { Healthcare provider enters the patient's scores as } \\
\text { determined during the consultation in a decision tree. } \\
\text { Alternatively, patients fill out a self-reported } \\
\text { questionnaire which is scored according to the decision } \\
\text { tree decision rules. A suggestion for the patient's } \\
\text { subgroup is provided along with the level of certainty. }\end{array}$ \\
\hline $\begin{array}{l}\text { Tailoring: } \\
\text { How is care } \\
\text { tailored? }\end{array}$ & $\begin{array}{l}\text { Daily diabetes care planning, } \\
\text { lifestyle information, help taking } \\
\text { medication, frequency of } \\
\text { consultations and emotional support } \\
\text { are tailored according to the } \\
\text { preferences per subgroup. }\end{array}$ & $\begin{array}{l}\text { Preoperative education materials and supportive systems } \\
\text { for postoperative (tele)rehabilitation are tailored to the } \\
\text { preferences per subgroup. }\end{array}$ \\
\hline
\end{tabular}




\section{Patient profiles: a mixed-method approach}

The Tailored healthcare through customer profiling project is a 4-year public-private research collaboration between a hospital, medical device manufacturer, technical university, and the creative industry. Its main aims are to define a validated set of design-oriented patient profiles and to test the effect of integrating these profiles in healthcare services (e.g. educational materials and telerehabilitation systems) on satisfaction with care provision following joint replacement surgery.

A mixed-method approach was used to develop the profiles. As a first step, self-reported communication preferences, experiences with pain and stress, self-efficacy, clinical symptoms, and surgical outcomes of patients who had underwent joint replacement surgery were assessed. To stratify patients in groups with similar preferences and experiences, $k$ means cluster analysis was used. The resulting subgroups were validated by comparing the average subgroup characteristics to patients' actual and ideal hospital experience as expressed in qualitative interviews. To ease classification of future patients to the relevant subgroup by health professionals, recursive partitioning was used to build a decision tree [19]. By asking three questions (which assess active coping skills, experienced helplessness, information needs) either during the consultation or via a self-reported questionnaire, health professionals can quickly stratify future patients to one of the subgroups and deliver care that is better aligned to the patient's preferences, even when time-constrained.

The final 'tailoring' step in this project consists of developing modular variations of existing patient education materials and supportive telerehabilitation systems by design engineers. From their iterative work, it will be determined how preferences should be embedded in tailored design. The envisioned benefit of profile usage (i.e. improved satisfaction) will be examined in a pilot validation of the developed tailored prototypes.

\section{Discussion}

The current paper describes two ongoing research projects that develop and use patient profiles to tailor healthcare. Both propose that care can be tailored by the assessment of biopsychosocial patient characteristics, stratification of patients into profiles, and tailoring of care in concordance with the common care preferences of these profiles. Patients stratified into a high-risk profile could, for example, receive more intensive disease management, to address their care needs and preferences. Vice versa more emphasizes on self-management could be established for patients of the low-risk profile. It is expected that such tailored approaches will benefit clinical practice by efficiently allocating resources to where they are most needed.

The projects discussed use different methods of profiling, both of which have important advantages and disadvantages. The identification of patient profiles in each approach was carried out in different ways: in the quantitative approach, profiles were identified based on a disease-related health outcome, assuming that patients within a profile share the same preferences for care provision, whereas in the mixed-method approach, profiles were identified based on preferences, assuming patients within a profile show similar diseaserelated health outcomes. If these assumptions are not met, additional research might be required to identify separate 'sub'profiles based on preferences for care provision 
(quantitative approach) or disease-related health outcomes (mixed method approach) within the previously identified profiles.

Thus, future work on patient profiling should carefully specify the intended goal of the patient profiles, as this influences which characteristics should be assessed and consequently, which profiles are identified. The different methods of data collection also affect the time, energy, and monetary investments required for profile development. The mixed-method approach employed in the Tailored Healthcare project requires less patients to be enrolled in the study which curbs the burden. Therefore, we assume that this approach is more suitable for individual clinics that may serve fewer patients. On the other hand, accurate stratification into subgroups tends to be more reliable in data produced by larger samples, like those used in the quantitative approach of the PROFILe project. These methods may be most suitable for large clinics, or multi-centre collaborations. Again, we stress the importance of clarifying the goals and expected results of any patient profiling approach in considering these cost and benefits.

\section{Conclusion}

The concept of tailored healthcare has been around for centuries. Still, only recently have modern techniques emerged to transform raw data of electronic health records into usable information for care management [20]. It are techniques like these (e.g. machine learning, natural language processing[20], and neural network analysis [21]) that enable healthcare professionals and researchers alike to explore new approaches such as patient profiling, described in this paper.

It is expected that patient profiling will result in tailored care. As such, it constitutes a promising method for achieving the so called 'Triple Aim' by: 1) improving patient experience, by including patients' care needs and preferences in treatment decisions; 2) improving population health and quality of life, by supporting tailored care; and 3) reducing the per capita cost of care, by reducing the over-, under- and misuse of health care services[22]. Healthcare practitioners who currently provide care to diabetes type 2 or lower limb joint replacement patients can soon use insights from both projects to gain an improved understanding about their patients and to find support in aligning their practice to their patients' needs. Researchers or clinicians who want to extent the profiling approach to other patient populations should carefully evaluate these expected advantages in relation to their focus and available resources. 


\section{References}

1. Dance A. Medical histories. Nature. 2016;537(7619):S52-53.

2. Prince MJ, Wu F, Guo Y, et al. The burden of disease in older people and implications for health policy and practice. Lancet. 2015;385(9967):549-562.

3. Inzucchi SE, Bergenstal RM, Buse JB, et al. Management of hyperglycemia in type 2 diabetes: a patient-centered approach: position statement of the American Diabetes Association (ADA) and the European Association for the Study of Diabetes (EASD). Diabetes care. 2012;35(6):1364-1379.

4. Kim J, Davis JW. Prostate cancer screening--time to abandon one-size-fits-all approach? Jama. 2011;306(24):2717-2718.

5. Zwijnenberg NC, Damman OC, Spreeuwenberg P, Hendriks M, Rademakers JJ. Different patient subgroup, different ranking? Which quality indicators do patients find important when choosing a hospital for hip- or knee arthroplasty? BMC health services research. 2011;11:299.

6. Netherlands Diabetes Federation. NDF care standard. transparancy and quality of diabets care for people with diabetes type 2 [NDF Zorgstandaard. Transparantie en kwaliteit van diabeteszorg voor mensen met type 2 diabetes]. In. Amersfoort: Netherlands Diabetes Federation; 2015.

7. Dutch Orthopaedic Association. Guidelines Total hip arthroplasty [Richtlijnen Totale heupprothese]. In 's-Hertogenbosch: Dutch Orthopaedic Association; 2010.

8. Elissen AM, Duimel-Peeters IG, Spreeuwenberg C, Spreeuwenberg M, Vrijhoef HJ. Toward tailored disease management for type 2 diabetes. The American journal of managed care. 2012;18(10):619-630.

9. Rothe $U$, Muller $G$, Schwarz PE, et al. Evaluation of a diabetes management system based on practice guidelines, integrated care, and continuous quality management in a Federal State of Germany: a population-based approach to health care research. Diabetes care. 2008;31(5):863-868.

10. Hawker GA. Who, when, and why total joint replacement surgery? The patient's perspective. Current opinion in rheumatology. 2006;18(5):526-530.

11. Dekkers T, Melles M, Mathijssen NMC, Vehmeijer SBW, de Ridder H. Tailoring the orthopeadic consultation: How perceived patient characteristics influence surgeons' communication. Patient Education and Counseling. 2018;101(3):428-438.

12. Tseng MM, Hu SJ. Mass Customization. Manufacturing Technology. 2014;836-843.

13. Sollecito WA. McLauhlin and Kaluzny's continuous quality improvement. Fourth ed. Burlington, MA, USA: Jones \& Barlett Learning; 2013.

14. Hawkins RP, Kreuter M, Resnicow K, Fishbein M, Dijkstra A. Understanding tailoring in communicating about health. Health education research. 2008;23(3):454-466.

15. Kreuter MW, Strecher VJ, Glassman B. One size does not fit all: the case for tailoring print materials. Annals of behavioral medicine. 1999;21(4):276-283.

16. Noar SM, Harrington NG, Aldrich RS. The role of message tailoring in the development of persuasive health communication messages. Communication yearbook. 2009;33:73-133.

17. Elissen AM, Hertroijs DF, Schaper NC, Vrijhoef HJ, Ruwaard D. Profiling patients' healthcare needs to support integrated, person-centered models for long-term disease management (PROFILe): Research design. International journal of integrated care. $2016 ; 16(2): 1$. 
18. Hetroijs DFL, Elissen AMJ, Brouwers M, et al. A risk score including body mass index, glycated haemoglobin and triglycerides predicts future glycaemic control in people with type 2 diabetes. Diabetes, obesity and metabolism. 2018;20(3):681-688.

19. Therneau TM, Atkinson EJ. An introduction to recursive partitioning using the rpart routines. Division of Biostatistics 61, Mayo Clinic; 2017.

20. Halamka JD. Early experiences with big data at an academic medical center. Health affairs. 2014;33(7):1132-1138.

21. Miller DD, Brown EW. Artificial Intelligence in Medical Practice: The Question to the Answer? Am J Med. 2018;131(2):129-133.

22. Berwick DM, Nolan TW, Whittington J. The triple aim: care, health, and cost. Health affairs. 2008;27(3):759-769. 


\section{CHAPTER 9}

General discussion 


\section{Introduction}

Type 2 diabetes is one of the most prevalent chronic diseases worldwide and can have severe short- and long-term consequences for the patient. In the Netherlands, evidence-based care protocols exist to optimize the management of type 2 diabetes. These protocols, however, are highly standardized $[1,2]$. The overall aim of this dissertation was to develop and validate patient profiles as a tool to establish tailored care for patients with type 2 diabetes. This aim has been operationalized according to three themes: 1) determination of relevant health-, person-, and context-related patient characteristics; 2) validation of these patient characteristics; and 3) assessment of the preferences of patients for type 2 diabetes care. This general discussion presents and discusses the main findings of this dissertation, theoretical considerations, several methodical strengths and limitations of the studies, and implications for practice, research, and policy.

\section{Main findings}

\section{Development of the patient profiles}

With regard to relevant patient characteristics for patient profiling, our systematic literature review revealed that age, glucose-lowering drugs use, diabetes duration and baseline $\mathrm{HbA} 1 \mathrm{c}$ influence the $\mathrm{Hba1c}$ levels of patients with type 2 diabetes. These are mostly health-related characteristics, which does not necessarily mean that person-related characteristics, such as age and sex, and context-related characteristics, such as self-efficacy and social support, are less important predictors. Most included studies simply did not consider these characteristics when studying possible relationships with glycaemic control. In The Maastricht Study, a crosssectional epidemiological study, person- and context-related patient characteristics in addition to health-related characteristics were measured in patients with type 2 diabetes. We found that patients with insufficient glycaemic control had a worse biopsychosocial profile (e.g. more diabetes-related distress and complications, higher body mass index, and lower self-efficacy) than patients with sufficient glycaemic control. Zooming in on the group of patients with insufficient glycaemic control, we further identified two health-related quality of life (HRQoL) classes: one with a low probability of HRQoL problems and one with a higher probability in several HRQoL domains. Patients belonging to the low HRQoL class had a worse biopsychosocial profile than those belonging to the high HRQoL class.

Using the electronic health records (EHRs) of a large Dutch diabetes care network, i.e. the Zwolle Outpatient Diabetes project Integrating Available Care (ZODIAC), we identified three distinct glycaemic control trajectories in patients with newly diagnosed type 2 diabetes: 1 ) stable, adequate glycaemic control (76.5\%); 2 ) improved glycaemic control (21.3\%); and 3) deteriorated glycaemic control (2.2\%). Trajectory membership could accurately be predicted with three easily obtainable patient characteristics: baseline $\mathrm{BMI}, \mathrm{HbA} 1 \mathrm{c}$ and triglycerides. Again, we could not make any inferences on the prediction accuracy of person- and contextrelated characteristics, as these are not routinely measured in practice. 


\section{Validation of relevant patient characteristics}

The glycaemic control trajectories and the prediction model with the three patient characteristics were validated using EHR data from another Dutch diabetes care network, i.e. the regional care group ZIO. In this cohort, we identified three glycaemic control trajectories, similar in shape and population distribution to the trajectories identified in the development cohort. The trajectories of both cohorts can be seen in Figure 1. The prediction model, trained in the development cohort and tested in the validation cohort, showed excellent external validity.

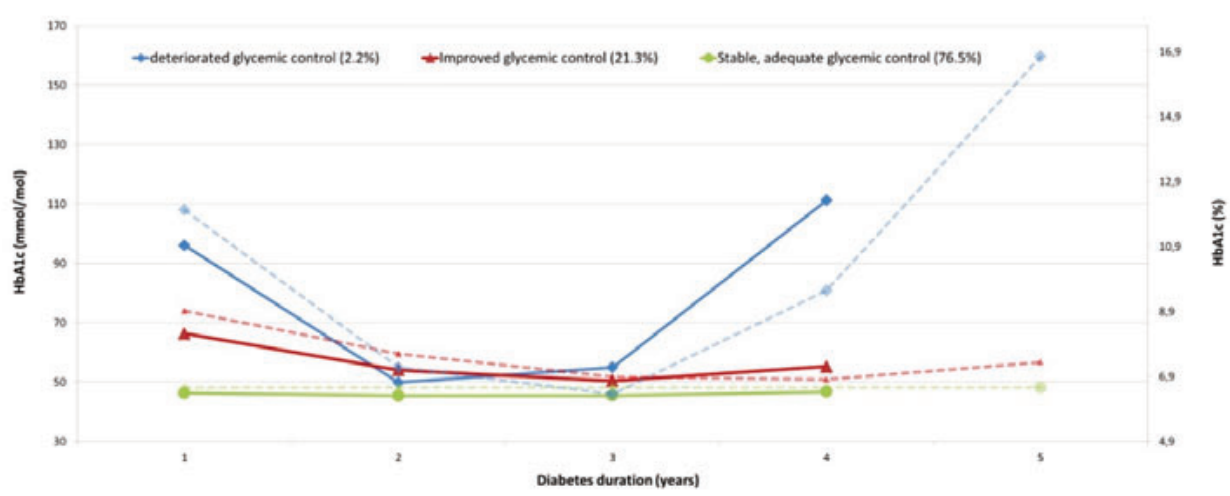

Figure 1. Latent class growth trajectories of the best-fitting models of the development and validation cohorts identified by latent growth mixture modeling. Solid lines = development cohort; dashed lines = validation cohort.

Besides the statistical validation of relevant patient characteristics for patient profiling, we also determined which patient characteristics were most relevant for estimating health care needs according to healthcare providers (HCP) and patients. Both HCPs and patients found health-related characteristics relevant for estimating patients' healthcare needs. However, HCPs preferred to estimate healthcare needs using person- and context-related characteristics. They ranked self-efficacy as the most relevant estimator. In contrast, patients were more in favor of health-related characteristics and ranked HbA1c as the most relevant estimator.

\section{Preferences towards type 2 diabetes care}

With regard to the preferences of patients towards type 2 diabetes care, we found that patients preferred to receive usual care: they had a preference towards planning their daily diabetes care together with a HCP, receiving individual lifestyle education, medication and emotional support as well as having three-monthly consultation visits, and spending less time on self-management. Patients strongly did not prefer to receive emotional support from a psychologist. Heterogeneity in preferences could be explained in part by differences in sex, education level and glucose-lowering drug use. We did not find significant preference differences between the three glycaemic control trajectories. 


\section{Theoretical considerations}

This section reflects on the results of this dissertation. First, a reflection on the patient profiling approach for type 2 diabetes is provided. Second, the quality of diabetes care will be addressed. Finally, patient satisfaction is discussed.

\section{Patient profiling approach for type 2 diabetes}

The patient profiling approach, described in more detail in Chapters 2 and 8 , is a tailored care approach based on the assessment of health-, person-, and/or context-related patient characteristics and the subsequent stratification of patients into subgroups with similar care needs, preferences and abilities. For each subgroup different configurations of care and support are available. Figure 2 shows the framework of the patient profiling approach.

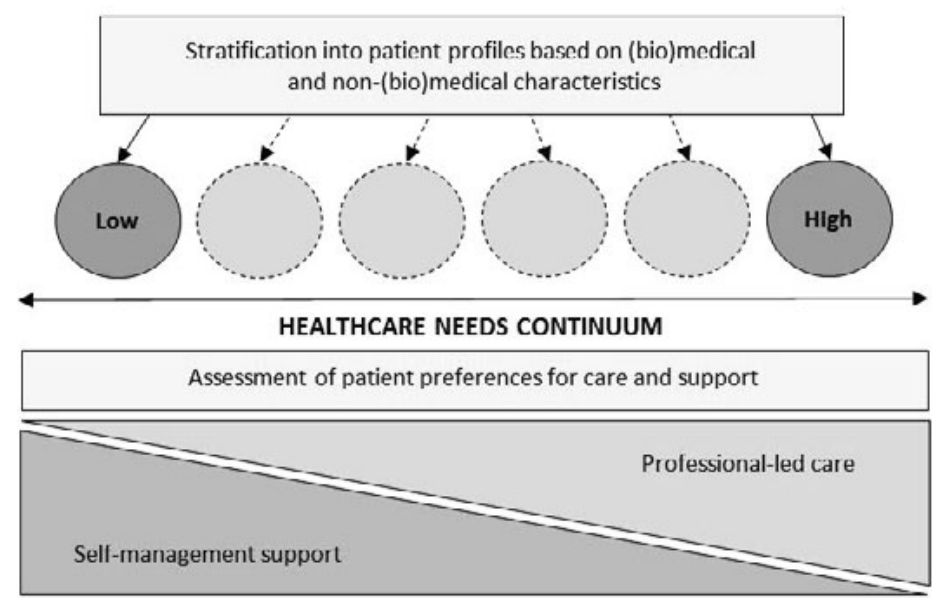

Figure 2. Framework for tailored chronic care management based on patient profiles

In this dissertation, we described the development of patient profiles for the treatment of type 2 diabetes. The first part of our profiles contains the stratification of patients into a glycaemic control trajectory based on $\mathrm{BMI}, \mathrm{HbA1c}$, and triglycerides (Chapter 5). The second part is not completely developed yet, but it will contain a consultation model to promote a dialogue between HCPs and patients on relevant biopsychosocial patient characteristics. The exact characteristics that should be discussed and how care should be tailored is yet to be determined. When complete, the patient profiles can serve as a tool to establish more personalization of care.

We started to develop the patient profiles as a response to the current state of type 2 diabetes care in the Netherlands. Although the quality of the care seems to be quite good (described in the section below), it is not a perfect fit for the $21^{\text {st }}$ century. Current type 2 diabetes care is based on a disease management approach, introduced to change care from reactive and episodic to proactive, continuous, and multidisciplinary care [3]. This has led to a 
better coordination of care and the introduction of evidence-based protocols $[1,2,4]$. However, disease management is a disease-oriented approach, which tends to neglect, for example, patients' co-morbidities [5, 6]. Therefore, the Chronic Care Model (CMM) was developed to respond to the growing need of the healthcare system to change how it addresses the needs of patients with chronic diseases [5]. The CCM is a framework consisting of various strategies important to present-day healthcare systems, such as self-management support (e.g. patient education) and information systems (e.g. EHRs). These strategies can be tailored to the patients' conditions. However, the CCM is patient rather than person-centered. It tends to neglect the person behind the patient, which is problematic, because in the past decade or so, the landscape of chronic care has further changed, increasing the need for a more person-centered approach [7-9]. Previous studies, including our own cross-sectional study with data from The Maastricht Study, have for example found individuals with low socioeconomic status (SES) (often measured by using several indicators such as income and education) are more likely to develop type 2 diabetes and have a worse disease progression compared to individuals with higher SES [10-14]. Therefore, it is important to discuss contextrelated patient characteristics in the treatment of type 2 diabetes. The recently introduced framework on integrated, people-centered health services by the World Health Organization (WHO), emphasizes the need for such person-oriented approach [15]. The vision of this framework is to ensure that health services are tailored to patients' needs and preferences and are provided in partnership with them. An important part of our patient profiling approach is the dialogue between HCPs and patients on relevant biopsychosocial patient characteristics. Therefore, the patient profiles we are developing, correspond with this vision of the WHO framework.

It also corresponds with the vision of George Engel, and American physician, who, already forty years ago, stated that there was hardly any room for the social, psychosocial, and behavioral dimensions of illness in health care [16]. He agreed that HCPs should not only know their patients on a biological level, but also on a social and psychosocial level. Indeed, our Delphi panel, described in Chapter 6, revealed that HCPs who treat patients with type 2 diabetes seem to agree on such a broad, whole person approach. Furthermore, the results from our cross-sectional analysis with the data from The Maastricht Study, described in Chapter 4, showed that person- and context-related characteristics might be relevant as well for patient profiling. The success of patients' self-management behavior increases when cultural differences and personal, family, and community resources become part of the treatment [17]. In previous research, patients have reported that they would like their healthcare provider to show more interest in their life and provide more explanation and involvement in diabetes care $[18,19]$. Indeed, a recent study showed that when HCPs not only discuss health-related patient characteristics, but also person- and context related characteristics, such as quality of life, self-management skills, and social support, patients seem to appreciate it and their involvement increases [20]. 


\section{Quality of diabetes care}

In the studies described in Chapters 4 and 5 of this dissertation, we found that 65 to $75 \%$ of patients with type 2 diabetes had sufficient glycaemic control. Most of the patients included in these studies received care according to a Dutch primary care-based disease management program for type 2 diabetes, which ensures the delivery of multidisciplinary care under a bundled payment system [21]. In other countries where such an approach is implemented, similar percentages of sufficient glycaemic control were observed [22-24]. Based on these results, one could argue that the quality of diabetes-specific management programs is good. For the Netherlands, this is not only shown by the high number of patients with sufficient glycaemic control, but also by its second ranking in the Euro Diabetes Index [4]. At the same time, the care for patients with type 2 diabetes is expensive [25]. In 2016, the direct healthcare costs for type 2 diabetes in the Netherlands were $€ 1.3$ billion. A total of $€ 1.1$ billion was spend on diabetes-related complications.

Taking into account the good quality and high costs of current type 2 diabetes care, and the need to keep the care sustainable on the long term, it is prudent to focus on improving the efficiency of care. For example, by offering less frequent consultation visits. A previous Dutch study found that patients with sufficient glycaemic control who either preferred or were undecided about receiving six-monthly consultations, maintained their glycaemic control level with six-monthly consultations instead of the usual three-monthly consultations [26]. However, taking away part of their care might be difficult for patients with type 2 diabetes. A described in the section above, Individuals with low SES, are more likely to suffer from or develop type 2 diabetes. Low SES has also been associated with low self-management [27]. In addition, our DCE, described in Chapter 7 of this dissertation, showed that, regardless of glycaemic control status, patients with type 2 diabetes did not prefer less frequent consultation visits. This means that we need to find a common ground in redistributing healthcare resources. Patients with sufficient glycaemic control could, for example, receive less professional-led care and more effective (digital) self-management education- and support. Patients with insufficient control on the other hand, might not only need to receive effective self-management education- and support, but also a higher intensity of professionalled care.

\section{Patient satisfaction}

In current diabetes care, patient consultations seem to focus on clinically oriented issues, such as optimal blood glucose levels [19]. Furthermore, past qualitative research has shown that patients are unable to describe the role of the practice nurse beyond clinical checks and were also not sure what they can expect from their practice nurse [18]. Therefore, it is not a surprise that the results of our Delphi panel showed that patients with type 2 diabetes considered health-related patient characteristics to be the most relevant characteristics for estimating healthcare needs (Chapter 6). The results from our DCE (Chapter 7) also showed that patients had a preference for the traditional care model for type 2 diabetes in the Netherlands, including three-monthly consultations and individual group education. From these findings, 
we could conclude that patients have a preference for maintaining the current care approach for type 2 diabetes in primary care. However, healthcare is the fastest growing service in the world, which currently faces increasing demands and diminishing resources [28]. Therefore, changes are needed in order to keep health care sustainable, as already briefly discussed in the section above. Several factors necessary for a sustainable healthcare have been mentioned in the literature [29]. One of these factors is the acceptability and support or the public (alias patients) towards health care changes. Although the evidence remains weak, personalization of care seems to increase patient satisfaction [30]. When implementing approaches to personalize care, such as patient profiling, it is important to adequately guide patients when changes in diabetes care organization are implemented to keep healthcare sustainable.

\section{Methodological considerations}

This section discusses the methodological strengths and limitations of the studies in this dissertation. The study designs and data sources, group-based methodology, patient involvement, and generalizability of the results are discussed.

\section{Study designs and data sources}

The main objective of this dissertation was to develop and validate patient profiles as a way to establish tailored care for patients with type 2 diabetes. To do this, we used several study designs: a systematic literature review (Chapter 3), a cross-sectional study (Chapter 4), retrospective cohort studies (Chapter 5), a Delphi study (Chapter 6), and a DCE (Chapter 7). Using these different study designs to develop patient profiles is unique. Together they provided us with more in-depth information and knowledge, and each of the studies helped us to shed light on the topic from different angles, creating a more complete picture.

The systematic review shed light on the fact that person- and context-related patient characteristics in relation to glycaemic control are rarely taken into account in evaluation studies of integrated diabetes care programs. The cross-sectional study with data from The Maastricht Study enabled us to explore this relationship further. The main advantage of this study is its comprehensive phenotyping approach [31]. In contrast to the retrospective cohort studies, which included real-world data, the Maastricht Study has strict inclusion and exclusion criteria. For example, only participants age 40 to 75 years old were included. Furthermore, part of the participants in The Maastricht Study were diagnosed with type 2 diabetes at the study sight and had not yet received diabetes care. Their HbA1c might have therefore been higher compared to patients who already received type 2 diabetes care. These limitations might have reduced the external validity of the findings [32].

We chose to build the first part of the patient profiles (step 2 and 3 in Figure 3) based on the results of the retrospective cohort studies. In comparison to the Maastricht Study, this design allowed us to follow quite a large number of patients over a longer period and to build and validate a stratification model based on latent growth mixture modeling (LGMM) analysis 
and machine learning techniques. Moreover, cohort studies with real-world data have the advantage of recording the actual care that patients receive. This may paint a more realistic picture, as the data was registered without the presence of a researcher or study protocol to influence the data [33]. Furthermore, the generalizability of real-world data studies are generally higher then, for example randomized controlled trials, as they often include data from large patient groups who did not have strict in- or exclusion criteria [34].

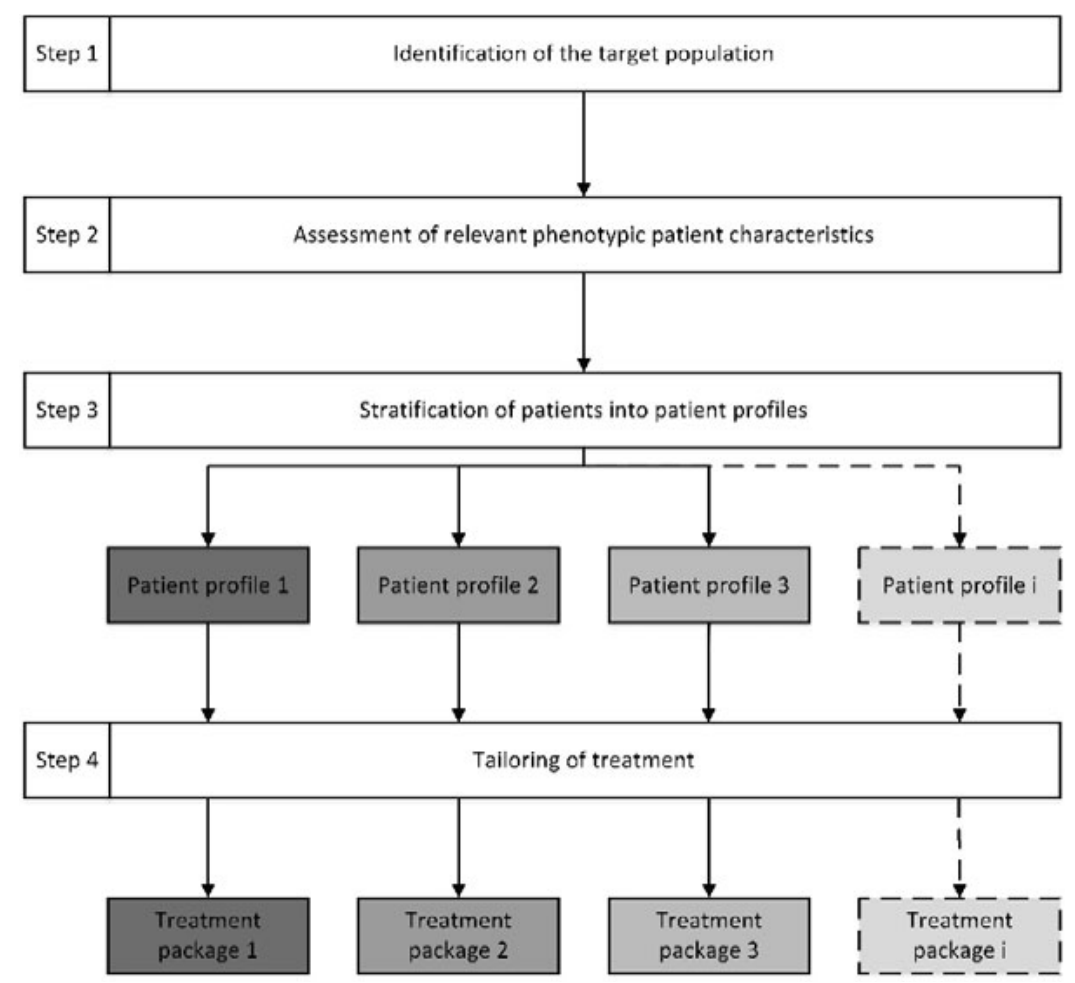

Figure 3. The patient profiling approach. Treatment packages may differ in frequency of consultations, education material, etc.

However, a retrospective study design, especially one with real-world data, also has its limitations. First, there is a lack of quality control surrounding data collection. HCPs from the participating primary care practices collected and recorded the data in the EHRs from the start of diabetes diagnosis, without an accurate check on consistency and appropriateness. This could have led to missing and less rigorous data. Fortunately, HCPs use the information in the EHRs for the treatment and follow-up of their patients and as proof that they provided the care as agreed upon with health insurers for declaration purposes, which might have improved the accuracy of data registration. Furthermore, to guarantee the quality of the data, we conducted range checks, excluded outliers and used full information maximum likelihood (FIML) as a missing data estimation approach [35]. 
Second, retrospective methods are limited to the data available in the database and cannot be influenced by the researchers. This has three consequences. First, the data becomes less comparable to other data. The variable heart failure for example was collected in the development cohort, but not in the validation cohort. As a result, we could not check whether this variable was a relevant characteristic for predicting glycaemic control trajectories. Second, the diabetes care that patients received may have influenced the patterns of the identified glycaemic control trajectories. For example, the HbA1c levels in the stable, adequate and improved glycaemic control trajectories remained stable or improved, possibly because of an increase in glucose-lowering drug prescriptions.

Third, important patient information in relation to the research question might be unavailable. In both our retrospective cohorts, context-related characteristics were not included in the database, because they are not routinely measured in practice. Earlier studies have shown that these characteristics have an impact on people's health, which suggests that they might be important for patient profiling. To overcome this problem, the original idea was to match the retrospective data from the ZIO cohort with the cross-sectional data from The Maastricht Study [11, 36, 37], creating a longitudinal dataset, containing not only health and person-related patient characteristics, but also context-related patient characteristics. Matching was to take place using patient identification numbers, which are given to all patients who receive diabetes disease management through the bundled payment system in the Netherlands. However, part of the participants in The Maastricht Study were diagnosed with type 2 diabetes at the study sight, did not yet have such a number, and could therefore not be matched. This resulted in a dataset one-fourth the size of the ZIO cohort. We therefore chose not to combine the two datasets, but analyze them separately instead.

To achieve true translational research it is important to include the voices of HCPs and patients as well. Therefore, we conducted a Delphi study (Chapter 6) and DCE (Chapter 7). The studies provided us with useful views on the opinions of patients regarding relevant patient characteristics for estimating healthcare needs and their preferences towards type 2 diabetes care. In both studies, patients had to complete questionnaires and although instructions were provided, this might have been difficult for some patients. Especially since the patient population in both studies included older (the average age was 69 years in the Delphi study and 67 years in the DCE) and mostly lower educated patients. In a DCE, respondents are assumed to use complex decision strategies by considering all attributes and making their choice based on trade-offs [38]. This becomes more difficult for patients who are older, lower educated and less literate and could result in invalid conclusions regarding the attribute level estimates [38]. The lack of context in the Delphi study might have resulted in patients seeing things from the HCPs' perspective. In these respects, a more qualitative approach method, such as face to face interviews, to gain insights into the opinions and preferences of patients towards type 2 diabetes care might have been better. It would have given the researchers a chance to define and explain the characteristics and attributes more thoroughly. However, face to face interviews give patients less time to think and could result in potential interviewer bias [39]. 


\section{Group-based methodologies}

The application of latent class and growth mixture modeling in clinical research has rapidly increased in the past decade [40]. These approaches simplify heterogeneous populations into a number of homogeneous classes based on individual response patterns [41]. As the main theme of this dissertation is about personalizing care, these person-centered approaches seemed appropriate. Instead of variable-centered approaches, such as regression, which focus on describing the relationship among variables, person-centered approaches focus on the relationship among individuals [41]. This is relevant, because the goal of the patient profiling approach is to stratify patients into distinct classes based on individual response patterns, in our case individual glycaemic control patterns, so that patients within a class are more similar than patients between classes and most likely also need and prefer other configurations of care.

In Chapters 4 and 5 of this dissertation, we applied latent class analysis (LCA) and LGMM to identify classes of patients based on quality of life measures (Chapter 4 ) and glycaemic control over time (Chapter 5), respectively. Instead of LCA and LGMM, we could have chosen other clustering methods, such as $k$-means clustering, mentioned in Chapter 8 of this dissertation or hierarchical clustering [42]. In all three methods, patients with similar characteristics can be stratified into classes. The most important difference between LCA and LGMM and $k$-meansand hierarchical clustering is the procedure of choosing the number of classes. LCA and LGMM use a "model-based" method [42]. This means that a statistical model allows the comparison between different numbers of classes to be statistically tested. In k-means- and hierarchical clustering the decision on the number of classes is arbitrary or subjective and thus less robust. We therefore chose to identify classes of patients using LCA and LGMM. This does not mean that the number of classes in a LCA and LGMM should be solely determined by the statistical model. The research question, clinical relevance, and the individual variability within a group should also be taken into account $[41,43]$. To obtain further evidence that the classes are real, the results should be replicated in another dataset [44]. As described in Chapter 5, we replicated our LGMM findings from the ZODIAC cohort in the ZIO cohort.

For the LGMM analysis we used $\mathrm{HbA1c}$ as the dependent variable, because it is considered an important intermediate outcome in the treatment of type 2 diabetes. In the current Dutch care protocols for type 2 diabetes, HCPs are instructed to monitor HbA1c levels of patients to reduce the risk of diabetic complications. However, trials have failed to show a negative relationship between tight glycaemic targets and macrovascular complications $[45,46]$. It has been stated that the optimal glycaemic control target should depend on patients' risk for complications [46]. Therefore, efforts should be taken to adequately report diabetic complications in patients' EHRs, which could then be used as outcomes in type 2 diabetes research.

\section{Patient involvement}

Research generally continues to be carried out on patients, but not with patients [47]. However, it is difficult to appropriately inform patient-centered decision making without 
patient involvement [48]. For example, researchers might be interested in knowing the decrease in $\mathrm{HbA} 1 \mathrm{c}$ in patients with type 2 diabetes after intake of a certain hypoglycaemic drug. Some patients, however, may be more interested in the effect of the drug on their body weight. Without asking, researchers cannot know which questions and outcomes are important to patients. Since patients are gaining a more active role in health care and care is becoming more personalized, the collaboration with patients in health care research in the past decades has increased $[47,49]$. Authors who would like to publish in the BMJ, one of the oldest general medicine journals, are now required to report on their partnership with patients during the research project [50]. Although much of the evidence base concerning the impact of patient involvement in research remains weak, it is thought to lead to greater quality and relevance of the research [49].

At the start of the PROFILe project we therefore established a patient panel consisting of six patients with type 2 diabetes. The patient panel met once to twice a year with the researchers of the PROFILe project. During the first meeting, patients were informed on the aims and activities of the PROFILe project. Their roles and expectations and those of the researchers were discussed. During consecutive meetings, patients were informed on the results of the project and asked for advice on the user friendliness and clarity of recruitment materials, patient information and questionnaires. The inclusion of a patient panel helped to assess the appropriateness, wording and timing of the research instruments, and to adapt the information in patient information letters to better suit patients with type 2 diabetes. Therefore, it is likely that the face validity, which refers to the relevance of a test as it appears to the test participants, of the DCE and Delphi panel questionnaires improved. These beneficial impacts of patient involvement in research have also been observed in previous studies [49].

The 'participation ladder' model shows that we could have given the patient panel more decision-making power [51, 52]. This model consist of five levels of patient participation in research, ranging from only informing patients to giving patients complete control in decision making. The patient panel of our research project acted on the second level, called the consultation level, in which patients are asked for advice, but the research team holds decision making power. It has been stated that patient involvement has the most positive impact when patients are involved as partners in a research team (level 4) [49]. We chose a less prominent role for the patient panel, because at the start of our project we were unsure about the contribution patients could bring to the research. We felt that the topics discussed during our research meetings (e.g. data analysis) might be too difficult for patients to understand. We were also unsure about how confidential information provided in meetings would be treated. These and other problems related to the involvement of patients in research have been reported before and are often reason for researchers not to involve patients [49]. However, these problems or challenges may be diminished by providing enough time and money to the researchers to establish a good working relationship with the patients and to appropriately educate and train them. If so, patient involvement in research can be a valuable contribution 
providing insights from different perspectives, improving the quality of the research process, and leading to the identification of gaps in research that future studies need to address.

\section{Generalizability}

When developing a prediction model, like the one we built to predict the glycaemic control trajectories of newly diagnosed patients with type 2 diabetes, it is not sufficient to show that it successfully predicts the outcome of interest in the initial development cohort [53]. Unfortunately, it is common for studies to perform an internal validation only [54] . In this approach, the dataset is split into two or more parts. The model is developed on the first portion of the dataset, also known as the training set, and its predictive accuracy is tested on the other portion(s) of the dataset. This does not give evidence on how well the model performs in other groups of patients. It tends to give optimistic results, because the datasets are very similar. Indeed, in our study described in Chapter 5, the 5-fold cross-validation of the prediction model in the development cohort performed very well. However, an accurate prediction model is of no benefit if it is not generalizable.

To test the true generalizability of a prediction model, an external validation is necessary on data elsewhere. One of the major strengths of our prediction model is therefore that we added a validation cohort to our study. This enabled us to train the prediction model in the development cohort and test it in the validation cohort. The patients in the validation cohort received care according to the same protocols as the patients in the development cohort, but they lived in another Dutch province. The prediction model performed very well in the validation cohort, which made us to conclude that the model is generalizable to other populations.

However, all patients in the studies included in this dissertation were from the south of Limburg, one of the twelve Dutch provinces, and/or in the north of the Netherlands. In these Dutch regions, there is hardly any ethnic diversity, as the majority of inhabitants is Caucasian. Our results are therefore generalizable to these parts of the Netherlands, but might be less generalizable to the central-western part of the Netherlands, consisting of the four largest Dutch cities. In this region, there is more ethnic diversity. The prevalence of type 2 diabetes is higher in the Dutch non-western immigrant population compared to the Dutch non-immigrant population. They also tend to have higher HbA1c values, less physical activity and a higher use of healthcare services [55]. The inclusion of patients with a non-western immigrant background in our studies might have therefore resulted in glycaemic control trajectories that differed in size and shape and in different patient opinions and preferences towards type 2 diabetes care. Indeed, a previously developed risk score for type 2 diabetes developed for the Caucasian population, turned out to be less efficient among South Asians and Africans [56].

Another issue with the generalizability lies in the fact that only a small percentage (2-4\%) of the population with newly diagnosed type 2 diabetes was stratified into the deteriorated glycaemic control trajectory. For the DCE, this meant that we were only able to include six patients into this trajectory. Due to this low number of patients, inferences about their preferences towards type 2 diabetes care are difficult to make. Since the glycaemic control of 
the patients belonging to this trajectory is far from sufficient, learning about their preferences in especially important for tailoring their care. Therefore, another recruitment strategy for this population might have been in place. For example, instead of recruiting this patient population via postal mail, having their GPs personally ask them might have maximized participation.

\section{Future directions}

\section{Practice}

Our patient profiling approach consists of several steps (Figure 3). In step 3, patients are stratified into glycaemic control trajectories, based on three easily obtainable patient characteristics (BMI, HbA1c, and triglycerides). Subsequently, between step 3 and step 4, a dialogue takes place between HCPs and patients on relevant biopsychosocial patient characteristics. This step is not yet portrayed in Figure 3. We decided later on to add this step to the patient profiling approach, based on the results of the cross-sectional study with data from The Maastricht Study (Chapter 4) and our Delphi panel (Chapter 6), which showed us that it might be relevant to also tailor treatment based on psychosocial characteristics.

The patient profiling approach has several implications for clinical practice. First, the prediction tool, predicting patients' glycaemic control trajectories, forms a good starting point for HCPs and patients to discuss further diabetes management. It may also reassure those patients stratified into the adequate glycaemic control trajectory and raise awareness about the importance of good self-management for patients stratified in the deteriorated glycaemic control group. Second, the dialogue that follows after the stratification of patients into the glycaemic control trajectories allows the HCPs to listen to the stories of patients while gaining insights into the needs, preferences, and abilities, but also into their attitudes, and barriers to change, which undoubtedly influence self-management. Third, both steps allow for the active involvement of patients in the decision-making process. Previous studies have found that the majority of patients prefer to be actively involved in decision-making [57]. Shared-decision making (SDM) also seems to improve patient's knowledge of and attitude towards a disease, satisfaction towards the care, and trust in the $\operatorname{HCP}[20,58]$. Over time this may lead to greater treatment adherence, cost-effectiveness of care and ultimately improved health. However, these relationships remain largely untested in the empirical research [58].

Depending on the outcomes of the prediction tool and the dialogue between HCPs and patients, care can be tailored to match the patients' needs, preferences and abilities. Thus far, we are unsure about the content and the strategy for offering the different treatment packages to patients. Two main approaches to tailored care have been mentioned in the literature: 1) The assistive decision approach, where recommended treatment packages are not provided; and 2) the directive decision approach, which recommends or even prescribes a specific treatment package depending on the glycaemic control trajectory and the outcome of the dialogue between HCPs and patients [59]. Both approaches have their (dis)advantages. The assistive approach leaves more room for intuition of HCPs and patients and is therefore more respectful of the judgement of HCPs and patients. The directive approach on the other 
hand may have greater clinical impact. Another possibility might be to offer something in between these two approaches. In that case, each treatment package would consist of different treatment options, varying, for example, from group-based education, and sixmonthly consultation visits, to a self-management app. It is up to the HCPs and patients to decide which of the options inside a treatment package to pick.

\section{Policy}

In April 2018, a task force, led by the Dutch ministry of Health, Welfare and Sport and consisting of HCPs and healthcare administrators, published a report called 'The right care in the right place' (in Dutch: De juiste zorg op de juiste plek) to contribute to the needed transformation towards a more sustainable healthcare system [60]. The meaning behind 'the right care in the right place' is to prevent (expensive) care, transfer care (closer to home), and replace care (by for example e-health). Patient profiles can form an instrument to achieve part of these goals by tailoring care depending on patients' needs, preferences and abilities. For example, some of the consultation visits for patients with sufficient glycaemic control may be replaced with self-management, supported by e-health applications, thereby transferring and preventing unnecessary care.

However, before the implementation of the profiles in practice, it is important that health insurers play a role in the patient profiling approach. Currently, in the Netherlands, care groups receive a single fee from health insurers for the full 'bundle' of diabetes care. The services that the bundle should contain are codified in the Dutch Diabetes Federation Health Care Standard for type 2 diabetes [2] and are in accordance with diabetes guidelines from the Dutch college of General Practitioners on type 2 diabetes [1]. HCPs in the Netherlands who treat patients with type 2 diabetes strictly adhere to these guidelines [4]. Furthermore, health insurers oblige care groups to reveal their results on performance indicators, such as the number of patients having their HbA1c measured [61]. In the long term, the patient profiling approach could form the basis for a more tailored funding approach for type 2 diabetes care, by establishing a 'bundle' of diabetes care services matching each patient profile. Such a responsible and flexible approach to healthcare funding has been shown to lead to better alignment of resources and more effective cost management [62]. This also entails that adjustments need to be made in the diabetes care protocols. In the current Dutch Diabetes Federation Health Care standard for type 2 diabetes, it is mentioned that HCPs should tailor care by providing personal care plans [2]. However, currently there is no tool available to guide them in providing these care plans. The patient profiling approach could be a solution to this problem.

Whether the patient profiles are implemented in practice or not will depend, for a large part, on the cost-effectiveness of the approach. In a recent study on the implementation of a structured diabetes consultation model with a focus on personal and context-related patient characteristics, incremental diabetes care costs were low [20]. Moreover, the authors assumed that the effectiveness of diabetes care is enhanced if patients' preferences are 
structurally taken into account. It is likely that this would also be the case for the patient profiles that we are developing.

As described in Chapter 8 of this dissertation, the patient profiling approach is not restricted to the management of type 2 diabetes. The approach could be applied to the management of many, if not all, diseases, but with varying types of patient characteristics for the stratification of patients into subgroups. Due to the rise in number of people with multiple medical conditions, there is a growing need for approaches that take into account this multi-morbidity instead of focusing on a single-disease $[63,64]$. The patient profiling approach might also be suitable for this. Of course, stratifying patients with disease-specific characteristics, such as we did, is not appropriate, but psychosocial characteristics, such as SES and social support, affect the progress of many diseases and could therefore be used for the stratification of patients with multi-morbidity into subgroups.

\section{Research}

First, because not all the steps in our patient profiling approach have been completely finished, qualitative approaches should be used to gain a better understanding on relevant person- and context-related characteristics from both the HCP and patient perspective and the preferences of patients from each of the glycaemic control trajectories towards type 2 diabetes care. The insights gained will be used to inform the dialogue between HCPs and patients, as well as the content and approach for offering the treatment packages.

Part of the development of our patient profiling approach consisted of multivariable prediction research. In the literature, three phases in prediction research are distinguished: 1) development of the prediction model; 2) external validation of the model; and 3) studying the impact of the prediction model in clinical practice (e.g. HCPs and patient experience, health outcomes, and cost-effectiveness of care) [65]. While there are plenty of publications on the development of a prediction model, publications on the validation and even more so on the impact of prediction models are scarce $[59,65]$. In this dissertation, we described the development and the validation of our prediction model. After completion of the patient profiles, the next step should therefore be the execution of an impact study to determine whether the patient profiling approach leads to achieving the Triple Aim (e.g. improved patient experience, health outcomes, and cost-effectiveness of care) [66]. The ideal design of an impact study is a cluster-randomized controlled study, where primary care practices are the cluster units of randomization [65]. When randomization takes place on the patient level, the same HCP would have to treat half his/her patients using usual care and the other half using the patient profiling approach. This could lead to a learning effect, reducing the contrast between usual care and the patient profiling approach [65]. Randomizing on the HCP level could also lead to contamination, when HCPs exchange experiences and information with each other. Therefore, randomization on the primary care practice level is preferable.

Research on EHRs and data driven research are increasing in popularity [67]. They can provide major opportunities for improving health systems, including facilitating more stratified care by using patient characteristics. However, most data collected in healthcare 
organizations only contain health-related patient characteristics. To achieve more effective stratified care it is important to create databases that also include person- and context-related characteristics. Sharing of data from different sources is therefore essential. In the Netherlands for example, EHR data could be matched with government population level epidemiological data, such as those stored and managed by Statistics Netherlands (in Dutch: Centraal Bureau voor de Statistiek), creating a rich dataset with a broad range of patient characteristics. However, data sharing is not as easy as it sounds, because it is related to issues of trust, data privacy, confidentiality and control of data about individuals once it is shared [67]. Right now, healthcare data is scattered in different healthcare systems, which prevents data sharing and puts the privacy of patients at risk [68]. It would help if healthcare data are owned and controlled by patients themselves. A solution for this are so-called blockchain storage platforms [68]. Blockchain decentralizes data, which is therefore not impacted by the behavior of any one organization and ideal for ensuring data integrity. For example, when an EHR is generated and signed it can be written to a blockchain, providing absolute proof that the EHR cannot be changed. Right now, blockchain use is slow and difficult. However, there is hope, as blockchain services are emerging. 


\section{References}

1. Nederlands huisartsen genootschap. NHG-standaard Diabetes mellitus type 2 (vierde (partitiële) herziening). 2018.

2. Netherlands Diabetes Federation. NDF Care Standard. Transparancy and quality of diabetes care for people with diabetes type 2 [NDF Zorgstandaard. Transparantie en kwaliteit van diabeteszorg voor mensen met type 2 diabetes] Amersfoort: Netherlands Diabetes Federation 2015.

3. Kesteloot K. Disease management. A new technology in need of critical assessment. Int J Technol Assess Health Care 1999; 15:506-519.

4. Cebolla Garrofé B, Björnberg A, Yung Phang A. Euro Diabetes Index 2014. Health Consumer Powerhouse Ltd. 2014.

5. Boehmer KR, Abu Dabrh AM, Gionfriddo MR, Erwin P, Montori VM. Does the chronic care model meet the emerging needs of people living with multimorbidity? A systematic review and thematic synthesis. PLoS One 2018; 13:e0190852.

6. Gress S, Baan CA, Calnan M, Dedeu T, Groenewegen P, Howson H, et al. Co-ordination and management of chronic conditions in Europe: the role of primary care--position paper of the European Forum for Primary Care. Qual Prim Care 2009; 17:75-86.

7. Frosch DL, Kaplan RM. Shared decision making in clinical medicine: past research and future directions. Am J Prev Med 1999; 17:285-294.

8. Tattersall RL. The expert patient: a new approach to chronic disease management for the twenty-first century. Clin Med (Lond) 2002; 2:227-229.

9. Truog RD. Patients and doctors--evolution of a relationship. N Engl J Med 2012; 366:581585.

10. Derks IP, Koster A, Schram MT, Stehouwer CD, Dagnelie PC, Groffen DA, et al. The association of early life socioeconomic conditions with prediabetes and type 2 diabetes: results from the Maastricht study. Int J Equity Health 2017; 16:61.

11. Houle J, Lauzier-Jobin F, Beaulieu MD, Meunier S, Coulombe S, Cote J, et al. Socioeconomic status and glycemic control in adult patients with type 2 diabetes: a mediation analysis. BMJ Open Diabetes Res Care 2016; 4:e000184.

12. Ross NA, Gilmour H, Dasgupta K. 14-year diabetes incidence: the role of socio-economic status. Health Rep 2010; 21:19-28.

13. Sacerdote C, Ricceri F, Rolandsson O, Baldi I, Chirlaque MD, Feskens E, et al. Lower educational level is a predictor of incident type 2 diabetes in European countries: the EPIC-InterAct study. Int J Epidemiol 2012; 41:1162-1173.

14. Elissen AMJ, Hertroijs DFL, Schaper NC, Bosma H, Dagnelie PC, Henry RM, et al. Differences in biopsychosocial profiles of diabetes patients by level of glycaemic control and health-related quality of life: The Maastricht Study. PLoS One 2017; 12:e0182053.

15. World Health Organization Framework on integrated, people-centered health services: Report by the Secretariat. 2016.

16. Engel GL. The need for a new medical model: a challenge for biomedicine. Science 1977; 196:129-136.

17. Kahn R, Anderson JE. Improving diabetes care: the model for health care reform. Diabetes Care 2009; 32:1115-1118. 
18. Boyle E, Saunders R, Drury V. A qualitative study of patient experiences of type 2 diabetes care delivered comparatively by general practice nurses and medical practitioners. Journal of Clinical Nursing 2015; 25:1977-1986.

19. Brundisini F, Vanstone M, Hulan D, DeJean D, Giacomini M. Type 2 diabetes patients' and providers' differing perspectives on medication nonadherence: a qualitative metasynthesis. BMC Health Serv Res 2015; 15:516.

20. Rutten G, van Vugt HA, de Weerdt I, de Koning E. Implementation of a Structured Diabetes Consultation Model to Facilitate a Person-Centered Approach: Results From a Nationwide Dutch Study. Diabetes Care 2018; 41:688-695.

21. Nolte E, Knai C, Saltman RB. Assessing chronic disease management in European health systems: Concepts and approaches. Copenhagen, Denmark: World Health Organiation of behalf of the European Observatory on Health Systems and Policies; 2014.

22. Elissen AM, Duimel-Peeters IG, Spreeuwenberg C, Spreeuwenberg M, Vrijhoef HJ. Toward tailored disease management for type 2 diabetes. Am J Manag Care 2012; 18:619-630.

23. Pimouguet C, Le Goff M, Thiebaut R, Dartigues JF, Helmer C. Effectiveness of diseasemanagement programs for improving diabetes care: a meta-analysis. CMAJ 2011; 183:E115-127.

24. Rothe U, Muller G, Schwarz PE, Seifert M, Kunath H, Koch R, et al. Evaluation of a diabetes management system based on practice guidelines, integrated care, and continuous quality management in a Federal State of Germany: a population-based approach to health care research. Diabetes Care 2008; 31:863-868.

25. Peters ML, Huisman EL, Schoonen M, Wolffenbuttel BHR. The current total economic burden of diabetes mellitus in the Netherlands. Neth J Med 2017; 75:281-297.

26. Wermeling PR, Gorter KJ, Stellato RK, de Wit GA, Beulens JW, Rutten GE. Effectiveness and cost-effectiveness of 3-monthly versus 6 -monthly monitoring of well-controlled type 2 diabetes patients: a pragmatic randomised controlled patient-preference equivalence trial in primary care (EFFIMODI study). Diabetes Obes Metab 2014; 16:841-849.

27. Levine DA, Allison JJ, Cherrington A, Richman J, Scarinci IC, Houston TK. Disparities in selfmonitoring of blood glucose among low-income ethnic minority populations with diabetes, United States. Ethn Dis 2009; 19:97-103.

28. Dey PK, Hariharan S, Brookes N. Managing healthcare quality using logical framework analysis. Managing Service Quality 2006; 16:203-222.

29. Crisp N. What would a sustainable health and care system look like? BMJ 2017; 358:j3895.

30. Wolf DM, Lehman L, Quinlin R, Zullo T, Hoffman L. Effect of patient-centered care on patient satisfaction and quality of care. J Nurs Care Qual 2008; 23:316-321.

31. Schram MT, Sep SJ, van der Kallen CJ, Dagnelie PC, Koster A, Schaper N, et al. The Maastricht Study: an extensive phenotyping study on determinants of type 2 diabetes, its complications and its comorbidities. Eur J Epidemiol 2014; 29:439-451.

32. Sedgwick P. External and internal validity in clinical trials. BMJ 2012; 344.

33. Mahajan R. Real world data: Additional source for making clinical decisions. International journal of applied \& basic medical research 2015; 5:82-82.

34. Elissen A, Nolte E, Hinrichs-Krapels S, Conklin A, Adams J, Cadier B, et al. Evaluating chronic disease management in real-world settings in six European countries: Lessons from the collaborative DISMEVAL project; 2014. 
35. Muthén B. On structural equation modeling with data that are not missing completely at random. Psychometrika 1987; 52:431-462.

36. Bosma H. Social epidemiology: Shuttling between upstream and downstream: A personal and narrative review. OA Epidemiology 2014; 2:5.

37. Klabbers G, Bosma H, Kempen GI, Benzeval M, Van den Akker M, van Eijk JT. Do psychosocial profiles predict self-rated health, morbidity and mortality in late middleaged and older people? J Behav Med 2014; 37:357-368.

38. Veldwijk J, Determann D, Lambooij MS, van Til JA, Korfage IJ, de Bekker-Grob EW, et al. Exploring how individuals complete the choice tasks in a discrete choice experiment: an interview study. BMC Med Res Methodol 2016; 16:45.

39. Snowball JD, Wilis KG. Interview versus self-completion questionnaires in discrete choice experiments. Applied Economics Letters 2011; 18:1521-1525.

40. Nagin DS, Odgers CL. Group-based trajectory modeling in clinical research. Annual review of clinical psychology 2010; 6:109-138.

41. Jung $T$, Wickrama KAS. An introduction to latent class growth analysis and growth mixture modeling. Social and Personality Psychology Compass 2008; 2:302-317.

42. Schreiber JB, Pekarik AJ. Technical Note: Using Latent Class Analysis versus K-means or Hierarchical Clustering to Understand Museum Visitors. The Museum Journal 2014; 57:45-59.

43. van de Schoot R, Sijbrandij M, Winter SD, Depaoli S, Vermunt JK. The GRoLTS-checklist: guidelines for reporting on latent trajectory studies. Structural Equation Modeling 2016; 24:451-467.

44. Ram N, Grimm KJ. Growth Mixture Modeling: A Method for Identifying Differences in Longitudinal Change Among Unobserved Groups. Int J Behav Dev 2009; 33:565-576.

45. Rodriguez-Gutierrez R, Montori VM. Glycemic Control for Patients With Type 2 Diabetes Mellitus: Our Evolving Faith in the Face of Evidence. Circ Cardiovasc Qual Outcomes 2016; 9:504-512.

46. Lipska KJ, Krumholz HM. Is Hemoglobin A1c the Right Outcome for Studies of Diabetes? JAMA 2017; 317:1017-1018.

47. Sacristan JA, Aguaron A, Avendano-Sola C, Garrido P, Carrion J, Gutierrez A, et al. Patient involvement in clinical research: why, when, and how. Patient Prefer Adherence 2016; 10:631-640.

48. Tinetti $\mathrm{ME}$, Basch $\mathrm{E}$. Patients' responsibility to participate in decision making and research. JAMA 2013; 309:2331-2332.

49. Brett J, Staniszewska S, Mockford C, Herron-Marx S, Hughes J, Tysall C, et al. Mapping the impact of patient and public involvement on health and social care research: a systematic review. Health Expect 2014; 17:637-650.

50. Richards T, Schroter S, Price A, Godlee F. Better together: patient partnership in medical journals. BMJ 2018; 362.

51. Abma TA, Broerse JEW. Patient participation as dialogue: setting research agendas. Health Expectations 2010; 13:160-173.

52. Arnstein SR. A Ladder Of Citizen Participation. Journal of the American Institute of Planners 1969; 35:216-224.

53. Altman DG, Vergouwe $Y$, Royston $P$, Moons KG. Prognosis and prognostic research: validating a prognostic model. BMJ 2009; 338:b605.

54. Reilly BM, Evans AT. Translating clinical research into clinical practice: impact of using prediction rules to make decisions. Ann Intern Med 2006; 144:201-209. 
55. Reijneveld SA. Reported health, lifestyles, and use of health care of first generation immigrants in The Netherlands: do socioeconomic factors explain their adverse position? J Epidemiol Community Health 1998; 52:298-304.

56. Spijkerman AM, Yuyun MF, Griffin SJ, Dekker JM, Nijpels G, Wareham NJ. The performance of a risk score as a screening test for undiagnosed hyperglycemia in ethnic minority groups: data from the 1999 health survey for England. Diabetes Care 2004; 27:116-122.

57. Chewning B, Bylund CL, Shah B, Arora NK, Gueguen JA, Makoul G. Patient preferences for shared decisions: a systematic review. Patient Educ Couns 2012; 86:9-18.

58. Shay LA, Lafata JE. Where is the evidence? A systematic review of shared decision making and patient outcomes. Med Decis Making 2015; 35:114-131.

59. Moons KG, Kengne AP, Grobbee DE, Royston P, Vergouwe Y, Altman DG, et al. Risk prediction models: II. External validation, model updating, and impact assessment. Heart 2012; 98:691-698.

60. Ministerie van Volksgezondheid WeS. De juiste zorg op de juist plek. Wie durft? . 2018.

61. Campmans-Kuijpers MJE, Baan CA, Lemmens LC, Klomp MLH, Romeijnders ACM, Rutten GEHM. Association between quality management and performance indicators in Dutch diabetes care groups: a cross-sectional study. BMJ Open 2015; 5.

62. Parsons M, Rouse P, Sajtos L, Harrison J, Parsons J, Gestro L. Developing and utilising a new funding model for home-care services in New Zealand. Health Soc Care Community 2018; 26:345-355.

63. Farmer C, Fenu E, O'Flynn N, Guthrie B. Clinical assessment and management of multimorbidity: summary of NICE guidance. BMJ 2016; 354:i4843.

64. Kingston A, Robinson L, Booth $H$, Knapp M, Jagger $C$, for the Mp. Projections of multimorbidity in the older population in England to 2035: estimates from the Population Ageing and Care Simulation (PACSim) model. Age and Ageing 2018; 47:374-380.

65. Toll DB, Janssen KJ, Vergouwe Y, Moons KG. Validation, updating and impact of clinical prediction rules: a review. J Clin Epidemiol 2008; 61:1085-1094.

66. Berwick DM, Nolan TW, Whittington J. The triple aim: care, health, and cost. Health affairs 2008; 27:759-769.

67. Kostkova P, Brewer H, de Lusignan S, Fottrell E, Goldacre B, Hart G, et al. Who Owns the Data? Open Data for Healthcare. Front Public Health 2016; 4:7.

68. Yue $X$, Wang H, Jin D, Li M, Jiang W. Healthcare Data Gateways: Found Healthcare Intelligence on Blockchain with Novel Privacy Risk Control. J Med Syst 2016; 40:218. 
SUMMARY 
In the Netherlands, evidence-based care standards exist to optimize the management of type 2 diabetes. These care standards are highly standardized. Not all patients seem to benefit from this 'one-size-fits-all' approach. Therefore, the Dutch PROFILe project, which stands for PROFiling people's healthcare needs to support Integrated, person-centered models for Longterm disease management, started in 2014. The aim of this project was to develop and validate so-called 'patient profiles' as an instrument for tailoring chronic care management to the needs, preferences and abilities of patients. This dissertation describes the development and validation of patient profiles for type 2 diabetes care.

Chapter 1 contains a general introduction to this dissertation. The symptoms, epidemiology, consequences, and quality of care for type 2 diabetes are discussed, as well as the importance of personalizing care. Furthermore, the aims and outlines of this dissertation are specified.

The design of the PROFILe project is presented in Chapter 2. The research aims and questions are described, as well as the different phases of the project, its settings, and the methods used for data collection and analysis. A conceptual framework for the patient profiling approach is also provided.

Chapter 3 describes a systematic literature review that was performed to identify which patient-related effect modifiers influence the outcomes of integrated care programs for type 2 diabetes in primary care. A total of 27 studies were included. We found that baseline age, glucose-lowering drugs, diabetes duration and $\mathrm{HbA} 1 \mathrm{c}$ were associated with glycaemic control, at either baseline or follow-up. Information on person- and context-related patient characteristics in the included studies was limited.

A cross-sectional epidemiological study using data from The Maastricht Study (Chapter 4) was performed to assess the biopsychosocial profile (including person-, context-, and healthrelated characteristics) of patients with type 2 diabetes. We observed that patients with insufficient glycaemic control had a worse biopsychosocial profile (e.g. more diabetes-related distress and complications, higher body mass index, and lower self-efficacy) than patients with sufficient glycaemic control. Zooming in on the group of patients with insufficient glycaemic control, we identified two health-related quality of life (HRQoL) classes: one with a low probability of HRQoL problems and one with a higher probability in several HRQoL domains. Patients in the former class had a better biopsychosocial profile than those in the latter class. We concluded that insufficient glycaemic control, particularly in combination with low HRQoL, is associated with a generally worse biopsychosocial profile. Further research is needed into the complex and multidimensional causal pathways explored in this study, so as to increase our understanding of the heterogeneous care needs and preferences of persons with type 2 diabetes, and translate this knowledge into tailored care.

Chapter $\mathbf{5}$ shows the results of a retrospective cohort study using real-world data from a large diabetes care network, the Zwolle Outpatient Diabetes project Integrating Available Care (ZODIAC). In total, 10,528 patients with newly diagnosed type 2 diabetes were included in the analysis. Within this population, three distinct glycaemic control trajectories were identified using a clustering method called 'latent growth mixture modeling' (LGMM): 1) stable, 
adequate glycaemic control; 2) improved glycaemic control; and 3) deteriorated glycaemic control. Trajectory memberships could accurately be predicted with three easily obtainable patient characteristics: baseline body mass index, $\mathrm{HbA1c}$, and triglycerides. The trajectories and prediction tool were validated using data from 3,777 patients with type 2 diabetes treated in a different Dutch diabetes care network (i.e. the regional care group ZIO). Again, three glycaemic control trajectories were identified, similar in shape and population distribution to the trajectories identified in the development cohort. The external validity of the prediction model with the three patient characteristics, trained in the development cohort and tested in the validation cohort, was high. The receiver-operating characteristic (ROC) area under the curve was 0.96, indicating excellent accuracy. It can therefore be used in clinical practice as a quick and easy tool to provide tailored diabetes care.

Chapter 6 presents the findings from an online Delphi study among healthcare providers (HCPs) and patients with type 2 diabetes. Aim of this study was to gain insight into the opinions of HCPs and patients regarding relevant patient characteristics for estimating the healthcare needs of people with type 2 diabetes. Both HCPs and patients reported health-related characteristics as relevant for estimating patients' healthcare needs. However, there was also discrepancy in opinions between HCPs and patients. HCPs found context-related and personrelated characteristics more relevant to estimate healthcare needs than patients did. They ranked self-efficacy as the most relevant estimator. In contrast, patients found health-related characteristics more relevant and ranked $\mathrm{HbA} 1 \mathrm{c}$ as the most relevant estimator. To achieve more tailored, patient-centered diabetes care, it is important that both groups agree on the topics that are important to discuss during patient consultations.

To elicit patients' preferences towards type 2 diabetes care, a discrete choice experiment was conducted among 288 patients (Chapter 7). We found that patients had a preference towards planning their daily diabetes care together with a HCP, receiving individual lifestyle education, medication- and emotional support from a HCP, three-monthly consultation visits, and spending less time on self-management. Patients strongly preferred to not receive emotional support from a psychologist. Heterogeneity in preferences could be explained by differences in sex, education level and glucose-lowering drug use. We did not find preference differences between the three glycaemic control trajectories. This discrete choice experiment revealed that people with type 2 diabetes prefer to receive the care they currently receive. Therefore, it is important to adequately guide people when changes in diabetes care are implemented to keep healthcare sustainable.

In Chapter 8, the PROFILe project of the Maastricht University and The Tailored Healthcare project of the Technical University Delft (TU Delft) were compared. The aim of both projects was the development of patient profiles. At Maastricht University, the profiles were developed for the management of type 2 diabetes and at the TU Delft for the management of patients undergoing low limb joint replacement surgery. Both projects are similar in terms of the steps taken in the patient profiling approach, but differ with respect to the methods used for identification of the profiles. Both approaches have their advantages and disadvantages. For example, the mixed-methods approach used by the TU Delft requires less patients to be 
enrolled in the study, whereas our approach with a large sample size might lead to a more accurate stratification of patients into the patient profiles. Researchers or clinicians who want to extend the patient profiling approach to other patient populations should carefully evaluate the advantages and disadvantages of each approach in relation to their project's focus and available resources.

Chapter 9 summarizes and discusses the main findings. In addition, the theoretical- and methodological considerations of the studies are presented, as well as implications for future practice, policy and research. 
SAMENVATTING 
In Nederland wordt gebruik gemaakt van evidence-based zorgstandaarden om de zorg voor patiënten met diabetes mellitus type 2 (hierna diabetes type 2 genoemd) te optimaliseren. Deze zorgstandaarden, zoals het woord al suggereert, zijn erg gestandaardiseerd. Niet alle patiënten ondervinden voordeel van deze 'one-size-fits-all' aanpak. In 2014 is daarom het Nederlandse PROFILe project van start gegaan, wat staat voor PROFiling people's healthcare needs to support Integrated, person-centered models for Long-term disease management. Het doel van dit project was om zogenaamde 'patiëntprofielen' te ontwikkelen en valideren, als instrument om de chronische zorg af te stemmen op de behoeften, preferenties en mogelijkheden van patiënten. Dit proefschrift beschrijft de ontwikkeling en validatie van de patiëntprofielen voor diabetes type 2 zorg.

Hoofdstuk 1 bevat een algemene introductie van dit proefschrift. De symptomen, epidemiologie, consequenties en de kwaliteit van zorg voor diabetes type 2 worden bediscussieerd, alsmede het belang van het personaliseren van zorg. De doelen en de inhoud van dit proefschrift worden ook benoemd.

Het design van het PROFILe project is gepresenteerd in Hoofdstuk 2. De onderzoeksdoelen en vragen zijn uitgelegd, alsmede de verschillende fases van het project, de setting en de methoden van dataverzameling- en analyses. Een conceptueel raamwerk voor de patiëntprofielen is ook verschaft.

Hoofdstuk 3 beschrijft een systematische literatuur review die is uitgevoerd om te achterhalen welke patiënt-gerelateerde effectmodificatoren invloed hebben op de uitkomsten van geïntegreerde zorgprogramma's voor diabetes type 2 in de eerste lijn. In totaal werden 27 studies geïncludeerd. We vonden dat leeftijd, bloedsuikerverlagende medicatie, diabetesduur en $\mathrm{HbA} 1 \mathrm{c}$ op baseline geassocieerd waren met glykemische controle. Informatie over persoons- en context-gerelateerde patiëntkarakteristieken in de geïncludeerde studies was bijna niet beschikbaar.

Een cross-sectionele epidemiologische studie werd uitgevoerd met gebruik van data van De Maastricht Studie (Hoofdstuk 4) om het biopsychosociale profiel (bestaande uit persoons, context- en gezondheids-gerelateerde karakteristieken) van patiënten met diabetes type 2 vast te stellen. We observeerden dat patiënten met ontoereikende glykemische controle een slechter biopsychosociaal profiel hadden (bijvoorbeeld meer diabetes-gerelateerde stress en complicaties, hogere body mass index en een lagere zelfredzaamheid) dan patiënten met een toereikende glykemisch controle. Door verder in te zoomen op de groep patiënten met ontoereikende glykemische controle identificeerden we twee klassen qua gezondheidsgerelateerde kwaliteit van leven ( $\mathrm{K} v \mathrm{~L})$ : één met een lage kans op beperkingen in $\mathrm{KvL}$ en één met een hogere kans op beperkingen in KvL. Patiënten in die laatste klasse hadden een minder gunstig biopsychosociaal profiel dan patiënten in de eerste klasse. We concludeerden dat ontoereikende glykemische controle, vooral in combinatie met een lage kwaliteit van leven, geassocieerd is met een minder gunstig biopyschosociaal profiel. Meer onderzoek is nodig naar de complexe en multidimensionale oorzaak-gevolg relaties die in deze studie zijn 
verkend, om de heterogene zorgbehoeften en preferenties van patiënten met diabetes type 2 beter te kunnen begrijpen en om deze kennis te kunnen vertalen in zorg op maat.

Hoofdstuk 5 laat de resultaten zien van een retrospectieve cohortstudie waarin gebruik is gemaakt van data afkomstig uit een groot diabetes zorgnetwerk, de Zwolle Outpatient Diabetes project Integrating Available Care (ZODIAC). In totaal werden er 10,528 patiënten met nieuwe gediagnosticeerde diabetes type 2 geïncludeerd in de analyses. In deze populatie werden, doormiddel van een clustermethode genaamd 'latent growth mixture modeling' (LGMM), drie klassen van glykemische controle over de tijd geïdentificeerd: 1) stabiele, toereikende glykemische controle; 2) verbeterde glykemische controle; en 3) verergerde glykemische controle. Klasse lidmaatschap kon accuraat voorspeld worden met drie simpel te verkrijgen patiëntkarakteristieken: baseline body mass index, $\mathrm{HbA} 1 \mathrm{c}$ en plasma triglyceriden. De klassen en het predictiemodel werden gevalideerd met data van 3,777 patiënten met diabetes type 2 die behandeld werden in een ander diabeteszorgnetwerk (de regionale zorggroep ZIO). Ook in deze populatie werden drie klassen geïdentificeerd op basis van glykemische controle over de tijd, vergelijkbaar in beloop en populatiedistributie met de klassen geïdentificeerd in het ontwikkelcohort. De externe validiteit van het predictiemodel met de drie patiëntkarakteristieken, getraind in het ontwikkelcohort en getest in het validatie cohort, was hoog. De receiver-operating characteristic (ROC) area onder de curve was 0.96, wat een excellente accuraatheid weergeeft. Het model kan dus gebruikt worden in de klinische praktijk als een snelle en makkelijke tool om zorg op maat te leveren.

Hoofdstuk 6 presenteert de uitkomsten van een online Delphi studie onder zorgverleners en patiënten met diabetes type 2 . Het doel van deze studie was om inzicht te verkrijgen in de mening van zowel zorgverleners als patiënten met betrekking tot relevante patiëntkarakteristieken om de zorgzwaarte van mensen met diabetes type 2 te kunnen bepalen. Zowel zorgverleners als patiënten rapporteerden gezondheids-gerelateerde karakteristieken als relevant om de zorgzwaarte van patiënten te bepalen. Echter waren er ook discrepanties tussen de mening zorgverleners en patiënten. Zorgverleners vonden context- en persoons-gerelateerde karakteristieken meer relevant voor het bepalen van de zorgzwaarte dan patiënten. De zorgverleners beoordeelden zelfredzaamheid als de meest relevante karakteristiek. Patiënten daarentegen vonden gezondheids-gerelateerde karakteristieken relevanter en scoorde $\mathrm{HbA} 1 \mathrm{c}$ als de meest relevante karakteristiek. Om meer zorg op maat te bewerkstelligen, is het van belang dat beide groepen het eens zijn over de onderwerpen die belangrijk zijn om te bespreken tijdens een patiëntconsult.

Om de patiëntvoorkeuren van patiënten met diabetes type 2 met betrekking tot de eerstelijnszorg mee te nemen, werd een zogenaamd discrete choice experiment uitgevoerd onder 288 patiënten (Hoofdstuk 7). We vonden dat patiënten een voorkeur hadden voor het plannen van hun dagelijkse diabeteszorg samen met een zorgverlener, het ontvangen van individuele leefstijleducatie, het ontvangen van medicatie- en emotionele steun van een huisarts, één consultatie met een praktijkondersteuner per drie maanden en het besteden van minder tijd aan zelfmanagement. Ze hadden ook een sterke voorkeur om emotionele steun niet van een psycholoog te ontvangen. Heterogeniteit in de voorkeuren van patiënten 
kon verklaard worden door verschillen in geslacht, educatieniveau en type glucose verlagende medicatie. We vonden geen verschillen in voorkeur tussen de drie glykemische controle groepen, zoals beschreven in Hoofdstuk 5. Dit discrete choice experiment heeft laten zien dat patiënten met diabetes type 2 de voorkeur geven aan de huidige zorg. Het is daarom belangrijk om patiënten goed te begeleiden als veranderingen in de zorg geïmplementeerd worden om de zorg te verduurzamen.

In Hoofdstuk 8 werden het PROFILe project van de Universiteit Maastricht en het Tailored Healthcare project van de Technische Universiteit Delft (TU Delft) met elkaar vergeleken. Het doel van beide projecten was het ontwikkelen van patiëntprofielen. De patiëntprofielen van de Maastricht University zijn ontwikkeld voor patiënten met diabetes type 2 en de patiëntprofielen van de TU Delft voor de behandeling van patiënten die een gewricht vervangende operatie van de onderste extremiteiten ondergaan. Beide projecten zijn vergelijkbaar qua stappen die gevolgd zijn in de patiëntprofielenaanpak, maar verschillen op het gebied van de methoden die gebruikt zijn om de profielen te identificeren. Beide aanpakken hebben hun voor- en nadelen. De mixed-methods aanpak die is gebruikt door de TU Delft bijvoorbeeld, vereist de inclusie van minder patiënten, terwijl onze aanpak met een grotere patiëntenpopulatie wellicht tot een accuratere stratificatie van patiënten in profielen leidt. Onderzoekers en zorgverleners die de patiëntprofielenaanpak uit willen breiden naar andere patiëntpopulaties moeten de voor- en nadelen van de twee projecten zorgvuldig evalueren in relatie tot de focus van hun eigen project en de beschikbare middelen.

Hoofdstuk 9 geeft een samenvatting en bediscussieerd de belangrijkste resultaten. Daarnaast zijn de theoretische- en methodologische consideraties van de studies gepresenteerd, alsmede de implicaties voor de praktijk, onderzoek en beleid. 


\section{VALORISATIE}


Diabetes mellitus type 2, ook wel suikerziekte genoemd, is een ziekte waarbij het lichaam niet meer goed reageert op insuline, een hormoon verantwoordelijk voor de bloedsuikerspiegel. In Nederland hebben ongeveer één miljoen mensen diabetes mellitus type 2 (hierna diabetes type 2 genoemd), vaak veroorzaakt door een ongezonde leefstijl. Wanneer de bloedsuikerspiegel van mensen met diabetes type 2 niet voldoende daalt, kunnen er complicaties en andere ziekten optreden, zoals amputaties, hart -en vaatziekten en nierfalen. Dit betekent dat diabetes type 2 niet alleen een grote impact heeft op de patiënt, maar ook op de zorgkosten. In 2016 heeft de ziekte in Nederland ongeveer 2,9 miljard euro gekost. De verwachting is dat het aantal patiënten met diabetes type 2 en de daarmee gepaarde kosten de komende jaren alleen maar toe zullen nemen. Om de gezondheid en de ervaren kwaliteit van de zorg te waarborgen en de zorgkosten niet verder te laten stijgen, moeten er daarom veranderingen plaatsvinden in de zorg. Op dit moment ontvangen de meeste patiënten met diabetes type 2 eerstelijnszorg bij een praktijkondersteuner en/of huisarts. Deze zorg is gebaseerd op de standaarden van het Nederlands Huisartsen Genootschap (NHG) en de Nederlandse Diabetes Federatie (NDF). In deze standaarden worden adviezen gegeven aan zorgverleners over bijvoorbeeld medicatie, het ondersteunen van een gezonde leefstijl en het aantal consulten per jaar. De adviezen gaan uit van de gemiddelde patiënt met diabetes type 2. Dit betekent dat, enkele uitzonderingen daargelaten, iedere patiënt met diabetes type 2 dezelfde zorg aangeboden krijgt. Deze zorg werkt niet voor alle patiënten even goed. Ongeveer één derde van de patiënten met diabetes 2 heeft bijvoorbeeld een bloedsuikerspiegel die onvoldoende onder controle is. In plaats van gestandaardiseerde zorg aan te bieden, wordt daarom steeds meer geopperd om de zorg persoonsgerichter te maken. Een eerste stap om dit te verwezenlijken is het doen van wetenschappelijk onderzoek. Een tweede belangrijke stap is het kenbaar maken van de onderzoeksresultaten aan belanghebbenden. Onder deze zogenaamde 'valorisatie' verstaat de Universiteit van Maastricht "het proces van waarde creatie uit kennis, door kennis geschikt en/of beschikbaar te maken voor maatschappelijk (en/of economische) benutting en geschikt te maken voor vertaling in concurrerende producten, diensten, processen en nieuwe bedrijvigheid". In dit hoofdstuk wordt daarom een overzicht gegeven van de relevantie van dit proefschrift voor belanghebbenden.

\section{Relevantie voor patiënten en zorgverleners}

We kunnen helaas niet voor iedere patiënt de zorg zo aanpassen dat deze perfect aansluit op zijn of haar wensen, behoeften en mogelijkheden. Wel kunnen we proberen om de zorg daar beter op aan te laten sluiten dan nu het geval is. Daarom hebben we in ons onderzoek zogenaamde 'patiëntprofielen' ontwikkeld. Het doel van deze profielen is om patiënten op basis van een aantal kenmerken in te delen in subgroepen met vergelijkbare wensen, behoeften en mogelijkheden. Uit ons onderzoek kwam naar voren dat we met een drietal biomedische patiëntkenmerken de toekomstige bloedsuikerspiegel van patiënten kunnen voorspellen en ze zo in kunnen delen in één van drie klinisch relevante subgroepen: 1) een groep met een adequate bloedsuikerspiegel; 2) een groep met een verbeterende bloedsuikerspiegel en 3) een groep met een verslechterende bloedsuikerspiegel. Het voorspellen van de bloedsuikerspiegel kan een goede aanleiding zijn voor patiënten en zorgverleners om de diabetesmedicatie en leefstijl van patiënten te bespreken. Het kan 
daarnaast patiënten geruststellen die in de groep met een adequate bloedsuikerspiegel zijn ingedeeld en patiënten in de verslechterende groep het belang doen inzien van een gezonde leefstijl. Het gesprek dat volgt na het indelen van patiënten in subgroepen geeft tevens de mogelijkheid aan zorgverleners om te luisteren naar de verhalen van patiënten en daarmee inzicht te verkrijgen in hun behoeften, voorkeuren en mogelijkheden. Het geeft patiënten de mogelijkheid om actief betrokken te zijn bij het zorgproces. Uit eerder onderzoek is gebleken dat patiënten hier behoefte aan hebben. Een actieve patiëntparticipatie kan na verloop van tijd leiden tot betere medicatietrouw, gezondere patiënten en lagere zorgkosten.

Aan de hand van de indeling van patiënten in één van de drie subgroepen en het gesprek dat daar op volgt, kan de zorg voor patiënten worden aangepast om beter te voldoen aan hun behoeften, voorkeuren en mogelijkheden. Op dit moment wordt nog onderzocht hoe deze zorg er precies uit moet komen te zien.

\section{Relevantie voor beleidsmakers en zorgverzekeraars}

Voordat de patiëntprofielen geïmplementeerd kunnen worden is het voor beleidsmakers en zorgverzekeraars van belang om te weten of de patiëntprofielen kosteneffectief zijn. Omdat de ontwikkeling van de patiëntprofielen nog niet volledig is afgerond, kunnen we daar op dit moment nog niks over zeggen. De verwachting is dat de patiëntprofielen de zorg persoonsgerichter maken aan de hand van de behoeften, voorkeuren en mogelijkheden van patiënten. Een aantal consulten voor patiënten in de groep met een adequate bloedsuikerspiegel zouden bijvoorbeeld vervangen kunnen worden door zelfmanagementondersteuning in de vorm van een e-health programma. De zorg wordt daardoor vervangen en onnodige zorg wordt voorkomen. Dit is de essentie van het in 2018 opgestelde rapport 'de juist zorg op de juiste plek'. Dit rapport, opgesteld door o.a. zorgverleners, wetenschappers en beleidsmakers onder leiding van het Ministerie van Volksgezondheid, Welzijn en Sport, heeft als doel een bijdrage te leveren aan het stapsgewijs verbeteren van het Nederlandse zorgstelsel.

Mocht de patiëntprofielenaanpak kosteneffectief blijken, dan dient het integrale bekostigingssysteem van de diabeteszorg aangepast te worden. Op dit moment wordt de diabeteszorg bekostigd op basis van keten-DBC contracten tussen zorgverzekeraars en zorggroepen. Een zorggroep bestaat uit een groep zorgverleners, bijvoorbeeld huisartsen, praktijkondersteuners en diëtisten, die samen de zorg voor diabetes op zich nemen. Voor iedere patiënt met diabetes type 2 krijgt een zorggroep per jaar een bepaald budget van de zorgverzekeraars om de complete diabetesbehandeling in de eerste lijn te bekostigen. Die behandeling is gebaseerd op wat er in de richtlijnen staat. De patiëntprofielenaanpak kan in de toekomst de basis vormen voor een flexibeler bekostigingssysteem, waarbij het budget en de behandeling passen bij het profiel van de patiënt. Zo'n flexibele aanpak kan leiden tot een betere besteding van middelen, afgestemd op de zorgbehoefte van patiënten.

\section{Relevantie voor onderzoekers}

De studies die beschreven zijn in dit proefschrift zijn relevant voor onderzoekers, die onderzoek doen naar persoonsgerichte zorg. De aanpak voor het ontwikkelen van patiëntprofielen zoals wij die hebben voorgesteld bestaat uit vier stappen: 1) identificatie van de patiëntpopulatie; 2 ) beoordelen van relevante patiëntkarakteristieken; 3) stratificatie van 
patiënten in patiëntprofielen en 4) aanpassen van de zorg. Deze aanpak is niet exclusief bedoeld voor het persoonsgerichter maken van de diabeteszorg, maar kan ook gebruikt worden door onderzoekers voor de ontwikkeling van persoonsgerichtere behandeling van andere ziekten en multimorbiditeit.

Bij de ontwikkeling van patiëntprofielen is het belangrijk om de voorkeuren van patiënten mee te nemen. Zoals beschreven in Hoofdstuk 7 van dit proefschrift hebben wij de voorkeuren van patiënten met betrekking tot de diabeteszorg achterhaald doormiddel van een discrete choice experiment (DCE). Deze methode wordt steeds vaker gebruikt in de gezondheidszorg. Hoewel een DCE een goede manier is om voorkeuren te achterhalen, zijn er ook nadelen. Eén van de belangrijkste nadelen is dat een DCE niet voor iedereen even makkelijk te begrijpen is. Dit kan tot selectieve non-respons leiden. Onderzoekers doen er daarom goed aan om na te denken over het inzetten van andere methoden om patiëntvoorkeuren te achterhalen. Voor sommige patiëntgroepen zijn kwalitatieve methoden wellicht betrouwbaarder.

Uit dit proefschrift blijkt dat niet alleen gezondheids-gerelateerde kenmerken belangrijk zijn voor het persoonsgerichter maken van de zorg, maar ook persoons- en contextgerelateerde kenmerken. De meeste databanken bevatten voornamelijk gezondheidsgerelateerde kenmerken van patiënten. Het is daarom belangrijk om databanken te creëren die ook de persoons- en context-gerelateerde kenmerken van patiënten bevatten en de mogelijkheden van koppeling op persoonsniveau te verkennen.

\section{Verspreiding van de resultaten}

Vanaf de start van ons onderzoek in 2014, hebben verschillende activiteiten plaatsgevonden om de resultaten te verspreiden. Allereerst heeft tijdens de uitvoering van de onderzoeken overleg plaatsgevonden met patiënten, zorgverleners, wetenschappers, beleidsmakers en zorgverzekeraars om de resultaten te bespreken. Daarnaast zijn in totaal zes van de zeven hoofdstukken uit dit proefschrift gepubliceerd in wetenschappelijke tijdschriften. Deze publicaties zijn vrij beschikbaar voor iedereen die daar interesse in heeft. Naast deze publicaties zijn de resultaten uit dit proefschrift gepresenteerd op verschillende congressen in binnen- en buitenland. De komende periode zal aandacht besteed worden aan het afronden van de ontwikkeling van de patiëntprofielen en het implementeren van de profielen in de praktijk. 
DANKWOORD 
In de zomer van 2014 verhuisde ik van New York, Manhattan naar Maastricht voor een vierjarig promotietraject. Chocolate chip cookies van Levain Bakery ruilde ik in voor Limburgse vlaai, de metro voor de fiets en een klein kamertje voor een appartement met terras. Ik liet veel goede vrienden achter en ging in het stille, kleine en voor mij onbekende Maastricht een nieuw leven opbouwen. Ik had er een hard hoofd in, maar dankzij een hele fijne werkplek, een nieuwe vriendenkring, mijn familie, improvisatietheater, vastelaovend, de zaote hermenie en de wekelijkse vlaai, voelde ik mij in no time helemaal thuis. Aan het onderzoek en de totstandkoming van dit proefschrift hebben velen bijgedragen. Een aantal mensen die ik de afgelopen jaren heb ontmoet wil ik op deze plek graag hiervoor bedanken.

Te beginnen met mijn promotieteam, Arianne, Martijn, Nicolaas en Dirk. Als er een prijs zou bestaan voor beste promotieteam zou deze naar jullie gaan! Ik heb veel gehad aan onze besprekingen, zelfs in het uitzonderlijke geval wanneer er geen pizza, sushi of taart voorhanden was. Jullie vullen elkaar goed aan en hebben ervoor gezorgd, door het stellen van kritische vragen, goede ideeën, constructieve feedback en vertrouwen in mij, dat ik altijd met veel plezier aan dit proefschrift heb gewerkt. Arianne, duizendmaal dank dat je er in de afgelopen vier jaar altijd voor me bent geweest. Ik vond ons overleg altijd zeer waardevol en had na afloop het gevoel weer op het goede spoor te zitten. Je wist precies de vinger op de zere plek te leggen. Martijn, hoewel je vond dat ik wel erg vaak op vakantie was, heb ik veel aan je gehad. Jouw medische kennis en ervaring in het veld brachten mij tot nieuwe inzichten. Je was altijd positief en complimenteus en kwam met goede suggesties om mijn geschreven stukken te verbeteren. Nicolaas, officieel ben je geen lid van mijn promotieteam, des te bewonderingswaardiger is het dat je altijd bij de besprekingen aanwezig was en al mijn stukken van feedback hebt voorzien. Net als Martijn, voorzag jij mij van waardevolle nieuwe inzichten. Geniet van je 'pensioen'. Dirk, last maar zeker niet least. Wat ben jij een goede promotor! Hoe druk je het ook hebt, altijd kon ik bij je binnenlopen en keek je snel, kritisch en als een pietje precies naar mijn stukken. Je hebt van mij niet alleen een betere onderzoeker gemaakt, maar ook een betere danseres. Van de Schotse tot de Spaanse, ik dans ze nu allemaal.

Naast de leden van mijn promotieteam, zijn er nog meer mensen die mij waardevolle feedback op het onderzoek hebben gegeven. De leden van de patiënten klankbordgroep en de wetenschappelijke- en stakeholderadviesraad, hartelijk dank daarvoor.

Prof. dr. J.F.M. Metsemakers, Dr. J.F.B.M. Fiolet, prof. dr. M Minkman, Dr. P.M. Rijken en prof. dr. S.P.J. Kremers, leden van de promotiecommissie. Hartelijk dank voor het beoordelen van mijn proefschrift.

Bedankt Sanne Groenemeijer, Jonathan Briers en Arnout van Diermen van Novo Nordisk voor de financiering van mijn onderzoek. 
Bij het opstellen van dit proefschrift heb ik veel gebruik gemaakt van reeds bestaande data. Prof. dr. Henk Bilo, dr. Anne Huizing van ZIO en het Management Team van De Maastricht Studie, bedankt voor het beschikbaar stellen van deze data.

Mijn werkzaamheden vonden voor het grootste gedeelte plaats in een groot, zwart gebouw met geblindeerde ramen. Klinkt best eng, maar dat was het niet. Er werken hele prettige mensen. Op de eerste plaats is daar Tessa, een collega met wie ik mijn werkkamer deel. Tessa is een sfeermaker. Denk aan onze permanente kerstboom, een vier jaar oude wijnfles, de plantjes die jij zo goed in leven houdt, maar vooral door je goede humeur. Binnenkort ga je ons verlaten. Ik ga onze gesprekken, wandelingen en jouw taaladviezen missen. Sinds kort is er een nieuwe kamergenoot aangeschoven. Irma, ik hoop dat je nog vele jaren de kamer met mij zult delen. Brigitte, onze secretaresse, ondanks je drukke baan, valt het op hoe relaxed en vrolijk je bent. Vaak tijd voor een praatje en het lukt je altijd om besprekingen te plannen die eigenlijk niet te plannen zijn. Het komt vast doordat Tessa en ik je zo'n mooie kamer hebben gegeven. Alle andere collega's van de vakgroep Health Services Research, bedankt voor jullie collegialiteit en de fijne samenwerking de afgelopen jaren.

Ik woonde nog geen week in Maastricht of ik werd door Eveline, collega en niet veel later goede vriendin, meegenomen naar 'PhD Improv', een wekelijkse activiteit met als doel het uitvoeren van improvisatietheater. Mijn donderdagavonden waren vanaf dat moment gevuld. Dank aan allen, met name Adam, Bas, Diogo, Dixon, Fred, Frederik, Fred C, Jo-Anne, Jessie, Mahdi, Mehrdad, Nienke, Paola, Sanne, Sanne R en Toby, die ik daar de afgelopen jaren heb leren kennen, voor de vriendschappen die zijn ontstaan, voor jullie aanstekelijke enthousiasme en voor de vele, vaak lachwekkende, scènes die de afgelopen jaren de revue zijn gepasseerd.

Een proefschrift schrijven houdt je bezig. Soms iets teveel. Het is goed om af en toe je spullen te pakken en ergens naartoe te gaan waar je met hele andere dingen bezig kunt zijn. Dankzij mijn fantastische reismaatjes was dat geen probleem. Jessie, Sanne, Mehrdad en Adam, we hebben in vier jaar tijd bijna een wereldreis gemaakt. Van Noorwegen naar Nieuw-Zeeland en, omdat het nog niet avontuurlijk genoeg was, naar Kirgizië. Het is bijzonder hoe goed we elkaar aanvulden en hoeveel lol we hadden. Ik kijk uit naar onze toekomstige reizen!

Mijn lieve paranimfen Jessie en Sanne, jullie verdienen een derde vermelding. Sanne, jij was één van de eersten die ik in Maastricht leerde kennen. Je nodigde me vaak uit en stimuleerde me om aan verschillende activiteiten deel te nemen. Op mijn verjaardag gaf je me een trommel met stokken. Ik kon er niet meer onderuit, ik moest en zou lid worden van jouw, en inmiddels ook mijn, zaote hermenie, de Sevraoje. Nu nog samen Limburgs leren en onze inburgering is compleet. Jessie, zonder jou was dit proefschrift er ook geweest, maar wel veel later. Heel veel dank dat ik af en toe bij je mocht bivakkeren, dat je me aan het werk hebt gezet, voor heerlijke hapjes hebt gezorgd en mijn klaagzangen hebt aangehoord. Een goede 
vriendin is goud waard en dat blijkt! Fred, mijn derde, onofficiële paranimf. Schoonmaken is niet echt jouw ding, maar toch ben ik heel blij met jou als huisgenoot! Dankjewel dat je af en toe een eitje voor me bakt, mij soms van mijn werk vandaan trekt om een serie te kijken en een luisterend oor biedt.

Aan mijn Haagse dispuutvriendinnen, Elise, Helena, Marie, Marieke, Marisa en Sabine, bedankt voor jullie gezellige bezoekjes aan Maastricht de afgelopen jaren. Ondanks dat we niet bij elkaar in de buurt wonen, hoop ik dat onze vriendschap nog lang blijft bestaan.

In New York, I lived in International House. A place with over a 150 different nationalities. I sometimes refer to it as the 'magical place', because living there was truly magical. I am very happy to have lived there alongside some very nice, special and crazy people who soon became my friends. Anisha, Antoine, Jean, Kim, Mel, Rasmus, Sofia, Genevieve, Bhavna, Claire, Divya, Jasmine, Miguel, and Tenzin, thank you for all the good times we have had, for keeping in touch and for meeting up whenever and wherever possible. Special thanks to Anisha, for correcting the shitty English (her words) of my articles.

De Dronten Diva's, Merel, Meeke en Barbara. We kennen elkaar al ons hele leven. Vroeger zagen we elkaar elke dag, nu ééns in de zoveel maanden. Ik vind het heel sjiek (zoals ze dat in het Limburgs zeggen) dat onze vriendschap is blijven bestaan. Het is fijn om te weten dat jullie er altijd zijn. Op naar de volgende 33 jaar!

Brenda and Leeda, almost 16 years ago, during my highschool year in Louisville, Kentucky, you gave me a home away from home and made my American dream come true. You feel like family and that makes me so happy. During my PhD, I visited you a few times. You always made me feel very welcome, prepared the most amazing food and just did about everything to give a me a good time. Thank you for everything! You are not the only great persons in your family though. Gramps and Grandma Barb, besides my own grandparents, you are the best grandparents a kid could ever wish for. Visiting you in Ohio is something I always look forward to, because your house is so full with love!

Naast al deze vrienden en mijn American family, zijn er nog een aantal mensen die mij heel dierbaar zijn. Allereerst mijn nichten. Eline, Ilse en Elke, we zien (en vooral appen!) elkaar eigenlijk pas vaker sinds de start van mijn PhD. Dat kwam goed uit, want onze weekendjes weg waren voor mij een welkome afleiding. Wat kan ik lachen met en om jullie en wat is het fijn om alles te kunnen delen!

Jim, mijn broertje, het leven is nooit saai met jou. Je doet altijd wel een beetje stoer, maar je bent eigenlijk heel lief en als het erop aankomt sta je altijd voor mij klaar. Ik ben jou en Celeste heel dankbaar voor het helpen met de lay-out van dit proefschrift. 
Lieve pap en mam, voor Nederlandse begrippen wonen we nog steeds ver van elkaar vandaan, maar wat is het fijn dat de afstand een stuk kleiner is geworden. Het is heerlijk om zo nu en dan een weekendje terug te gaan naar het warme nest waarin ik ben opgegroeid. Wat ben ik blij met jullie (en ook met jouw kookkunsten, mam)! We hebben er weleens grappen overgemaakt, maar het is echt zo, zonder jullie liefde, steun en de kansen die jullie mij gegeven hebben, was dit proefschrift er niet geweest. Dit proefschrift draag ik daarom aan jullie op. 


Dorijn Hertroijs was born on the $8^{\text {th }}$ of October 1985 in Kampen, the Netherlands. After finishing secondary education at Almere College in Dronten and Seneca High School in Louisville, Kentucky, she studied Nutrition and Dietetics at The Hague University of Applied Sciences, obtaining her bachelor's degree in 2008. She continued her studies

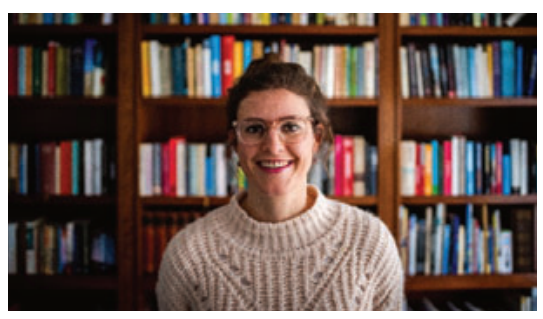
at the VU University in Amsterdam, where she obtained her research master's degree in Lifestyle and Chronic Disorders with the distinction cum laude. As part of the master program she conducted research at the Dutch Malnutrition Steering Group at the VU University Medical Center in Amsterdam and at the Obesity Research Clinic at Columbia University in New York City. After employment as a project coordinator at the Youth Alcohol Clinic at the Reinier de Graaf Hospital in Delft, she returned to New York City where she worked as a teaching assistant and obtained a master's degree in Nutrition at New York University. She returned to the Netherlands to start a PhD at the department of Health Services Research at Maastricht University. She finished this PhD in 2019 and is currently working as a post-doctoral researcher at the same department. 
PUBLICATIONS 


\section{Journals}

D.F.L. Hertroijs, A.M.J. Elissen, M.C.G.J. Brouwers, M. Hiligsmann, N.C. Schaper, D. Ruwaard. Preferences of people with type 2 diabetes for diabetes care: a discrete choice experiment. Diabetic Medicine. Accepted.

A.N. van Smoorenburg, D.F.L. Hertroijs, T. Dekkers, A.M.J. Elissen, M. Melles. Patients'perspective on self-management: Type 2 diabetes in daily life. Under review.

D.F.L. Hertroijs, M.C.G.J. Brouwers, A.M.J. Elissen, N.C. Schaper \& D. Ruwaard. Relevant patient characteristics for estimating healthcare needs according to healthcare providers and people with type 2 diabetes: A Delphi survey. Under review.

T. Dekkers \& D.F.L. Hertroijs. Tailored Healthcare: Two perspectives on development and use of patient profiles. Advances in Therapy. 2018;35(9):1453-1459.

D.F.L. Hertroijs, A.M.J. Elissen, M.C.G.J. Brouwers, N.C. Schaper, D. Ruwaard. Relevant patient characteristics for guiding tailored integrated diabetes primary care: a systematic review. Primary Health Care Research and Development. 2018;19(5):424-447.

D.F.L. Hertroijs, A.M.J. Elissen, M.C.G.J. Brouwers, N.C. Schaper. S. Köhler, M.C. Popa, S. Asteriadis, S.H. Hendriks, H.J. Bilo, D. Ruwaard. A risk score including body mass index, glycated haemoglobin and triglycerides predicts future glycaemic control in people with type 2 diabetes. Diabetes, Obesity and Metabolism. 2017;20(3):681-688.

A.M.J. Elissen, D.F.L. Hertroijs, N.C. Schaper, H. Bosma, P.C. Dagnelia, R.M. Henry, C.J. van der Kallen, A. Koster, M.T. Schram, C.D.A. Stehouwer, J.S.A.G. Schouten, T.T.J.M. Berendschot, D. Ruwaard. Differences in biopsychosocial profiles of diabetes patients by level of glycaemic control and health-related quality of life: The Maastricht Study. PloS One. 2017;12(7):1-17.

A.M.J. Elissen, D.F.L. Hertroijs, N.C. Schaper, H.J.M. Vrijhoef, D. Ruwaard. Profiling patients'healthcare needs to support integrated, person-centered models for long-term disease management (Profile): Research design. International Journal of Integrated Care. 2016;16(2):1-11.

M.E. Platek, D.F.L Hertroijs, J.M. Nicholson, N. Parekh. Sensitivity and specificity of malnutrition screening tools used in the adult hospitalized patient setting: A systematic review. Topics in Clinical Nutrition. 2015; 30(4):289-301.

R.D. Tenardi, M.C. Früwald, D. Hertroijs, H. Jürgens, J. Bauer. Nutritional status of children and young adults with ewing sarcoma or osteosarcoma at diagnosis and undergoing multimodality therapies. Pediatric Blood and Cancer. 2012; 59(4):621-626. 
D. Hertroijs, C. Wijnen, E. Leistra, M. Visser, E. van der Heijden, H. Kruizenga. Rehabilitation patients: undernourished and obese? Journal of Rehabilitation Medicine. 2012; 44(8):696701.

\section{Conference contributions}

D.F.L. Hertroijs \& A.M.J. Elissen. Patiëntprofielen voor persoonsgerichte diabeteszorg. NDF Symposium van onderzoek naar praktijk: aan de slag met het diabetesjaargesprek, 2 april 2019, Ede, the Netherlands (oral presentation).

D.F.L. Hertroijs, A.M.J. Elissen, M.C.G.J. Brouwers, M. Hiligsmann, N.C. Schaper, D. Ruwaard. Patient's preferences for diabetes care: a discrete choice experiment. $18^{\text {th }}$ International Conference on Integrated Care, 23-25 May 2018, Utrecht, the Netherlands (oral poster presentation).

D.F.L. Hertroijs. Differences in biopsychosocial profiles of patients with type 2 diabetes by level of glycemic control and quality of life. Wetenschapssymposium De Maastricht Studie, 29 maart 2018, Maastricht, the Netherlands (oral presentation).

D.F.L. Hertroijs, A.M.J. Elissen, M.C.G.J. Brouwers, N.C. Schaper. S. Köhler, M.C. Popa, S. Asteriadis, S.H. Hendriks, H.J. Bilo, D. Ruwaard. Identification and prediction of HbA1C trajectories among patients with newly diagnosed type 2 diabetes: a latent class and machine learning approach. Annual Research Meeting Academy Health, $25-27$ June 2017, New Orleans, USA (pitch and poster presentation).

D.F.L. Hertroijs, M.C.G.J. Brouwers, A.M.J. Elissen, N.C. Schaper \& D. Ruwaard. How do Patients with Type 2 Diabetes Value their Care? A Systematic Review and Focus Group Study. ISOQOL 23 ${ }^{\text {rd }}$ Annual Conference, 19-22 October 2016, Copenhagen, Denmark (poster presentation).

D.F.L. Hertroijs, A.M.J. Elissen, M.C.G.J. Brouwers, N.C. Schaper, D. Ruwaard. Which patient characteristics are relevant in guiding tailored diabetes care? A systematic review. $16^{\text {th }}$ International Conference on Integrated Care, 23-25 May 2016, Barcelona, Spain (oral poster presentation)

D.F.L. Hertroijs, A.M.J. Elissen, N.C. Schaper, H.J.M. Vrijhoef, D. Ruwaard Profiling patients' healthcare needs to support integrated, person-centered models for long-term disease management (PROFILe): Study design and rationale. $15^{\text {th }}$ International Conference on Integrated Care, 25-28 March 2015, Edinburgh, UK (oral presentation)

D.F.L Hertroijs, M.E. Platek, J.M. Nicholson, N. Parekh. Diagnostic accuracy and cost effectiveness of malnutrition screening tools and subsequent nutrition intervention among adult hospitalized patients. Clinical Nutrition Week, Savannah, GA, USA, 18-21 January 2014, Georgia, USA (oral presentation). 
D.F.L Hertroijs \& M.E. Platek. Weight loss and other adverse outcomes for head and neck cancer patients undergoing treatment. Experimental Biology, Boston, USA, 20-24 April 2013, Boston, USA (poster presentation). 
